Universidad de Lima

) DFXOMtde Ingeniería!, QCXVWDO

\&DUHDde Ingeniería Industrial

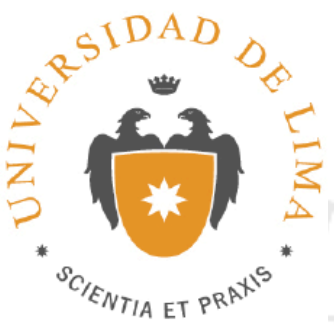

\title{
ESTUDIO DE PREFACTIBILIDAD PARA LA INSTALACIÓN DE UN CENTRO ECOEFICIENTE DE FISIOTERAPIA DIRIGIDO AL ADULTO MAYOR EN LA CIUDAD DE LIMA
}

Trabajo de investigación para optar el título profesional GHIngenierR Industrial

\author{
Juan Carlos Cris Castillo Salazar \\ Código 20052540 \\ Jimmy Paúl Silva Bazán
}

Código 19962654

Asesor

Luis Enrique Chávez Gurmendi

Lima - Perú

Julio de 2015 


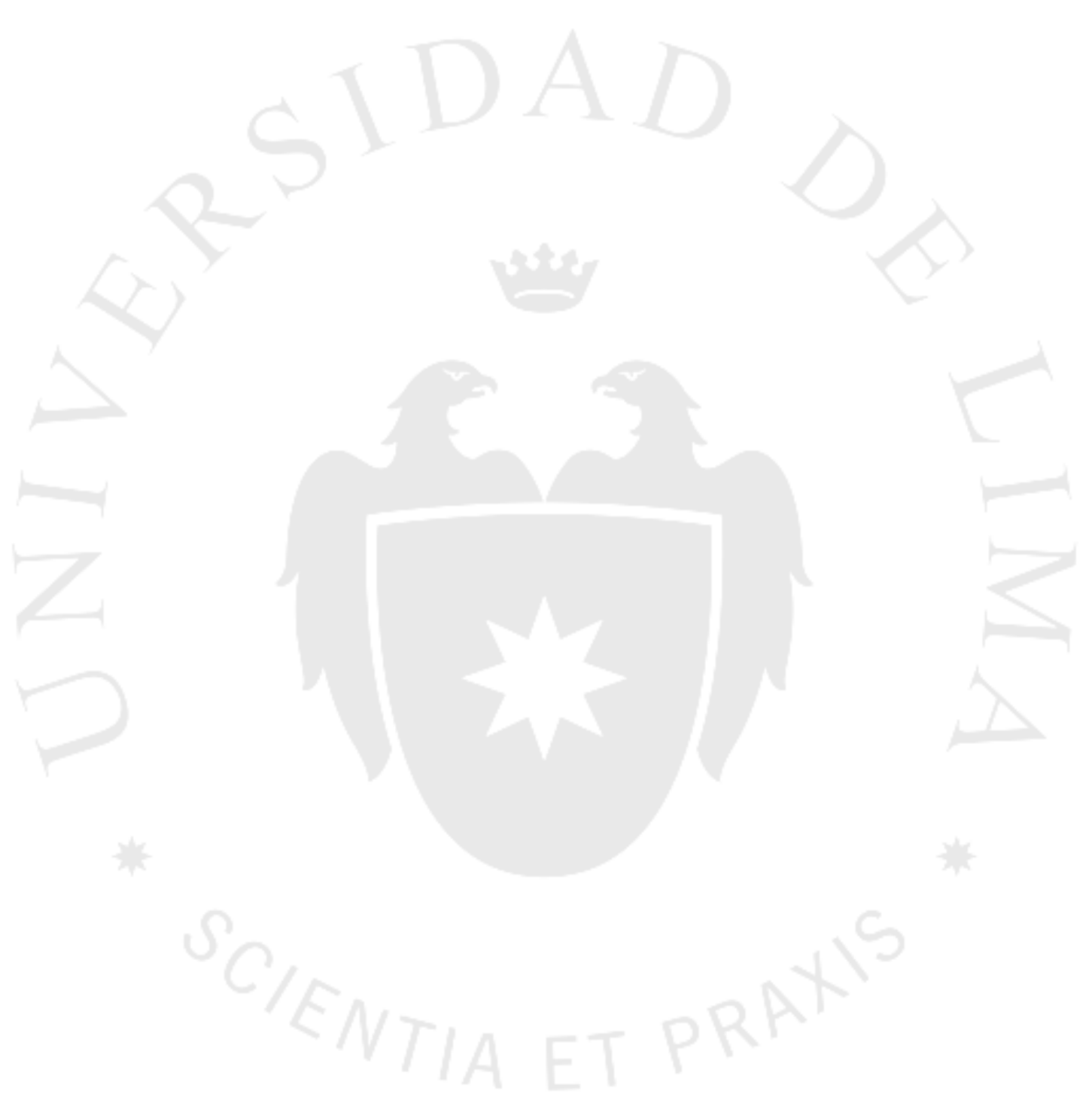


ESTUDIO DE PREFACTIBILIDAD PARA LA INSTALACIÓN DE UN CENTRO ECOEFICIENTE DE FISIOTERAPIA DIRIGIDO AL ADULTO MAYOR EN LA CIUDAD DE LIMA 


\section{TABLA DE CONTENIDO}

CAPÍTULO I: ASPECTOS GENERALES …................................................... 1

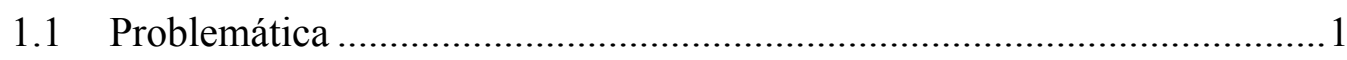

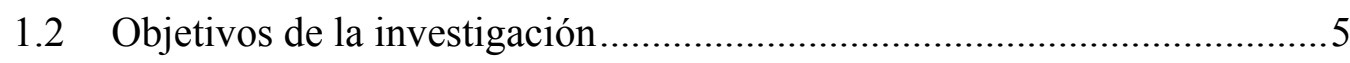

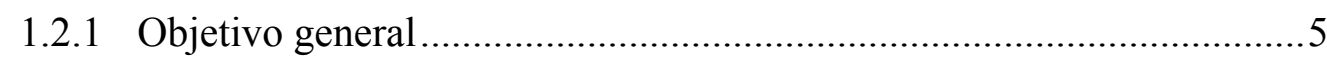

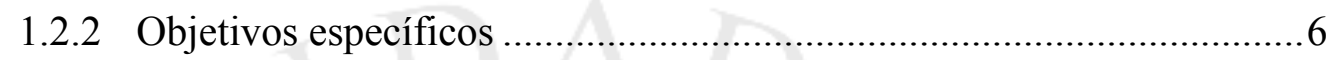

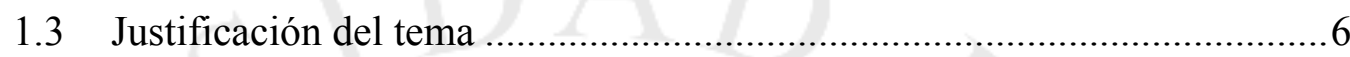

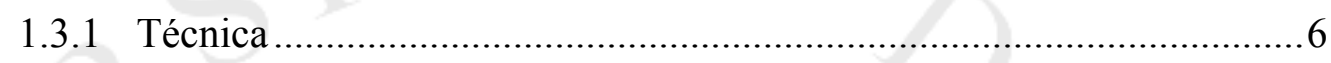

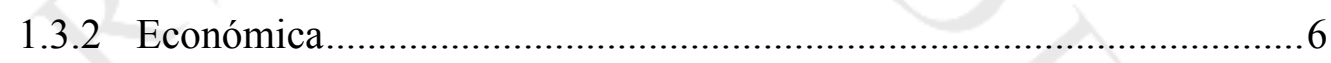

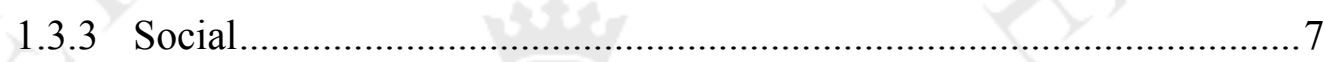

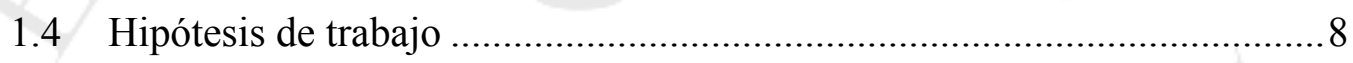

1.5 Marco referencial de la investigación ..................................................... 8

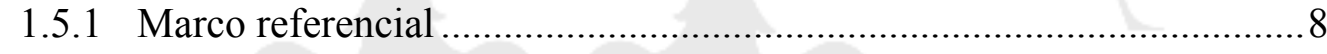

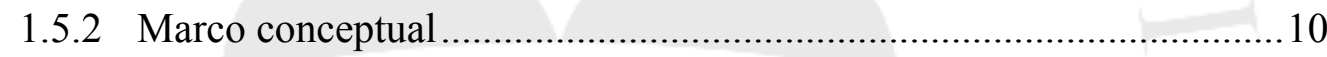

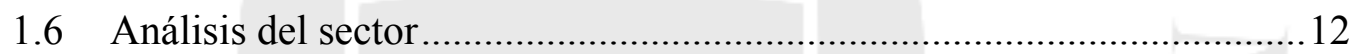

1.6.1 Análisis de las cinco fuerzas del sector............................................ 13

1.6.1.1 Poder de negociación de los compradores o clienes ......................13

1.6.1.2 Poder de negociación de proveedores o vendedores .....................13

1.6.1.3 Amenaza de nuevos entrantes ................................................... 14

1.6.1.4 Amenaza de productos sustitutos ............................................. 14

1.6.1.5 Rivalidad entre competidores ................................................. 14

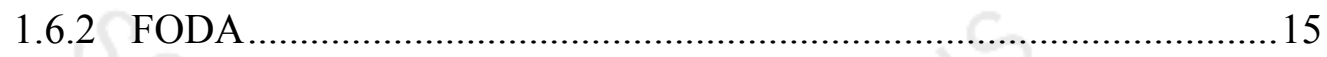

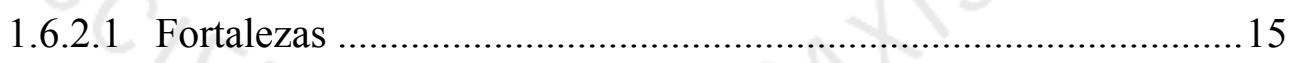

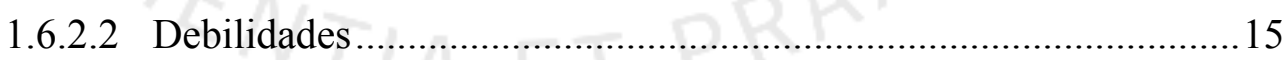

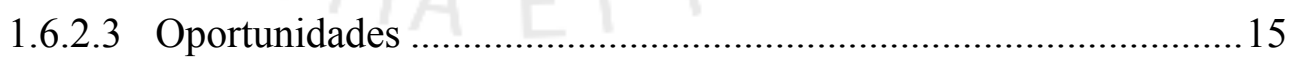

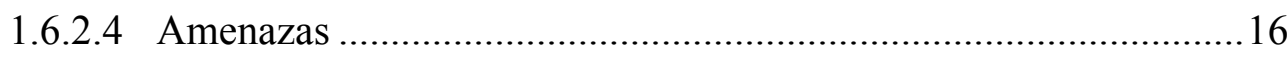

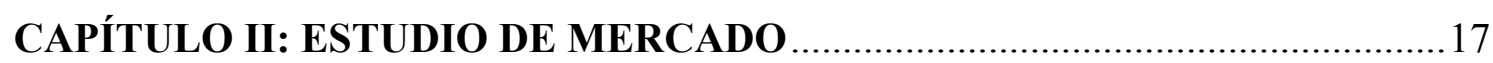

2.1 Aspectos generales del estudio de mercado.............................................17

2.1.1 Definición del servicio .............................................................. 17

2.1.2 Principales características del servicio............................................. 18

2.1.2.1 Posición arancelaria NANDINA, CIUU ...................................... 18

2.1.2.2 Usos y características del servicio.............................................. 18 
2.1.2.3 Servicios sustitutos y complementarios

2.1.3 Definición del área de influencia del servicio...................................22

2.1.4 Determinación de la metodología que se empleará en el estudio de mercado .23

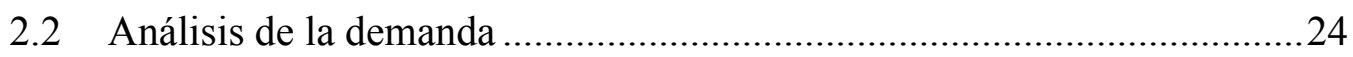

2.2.1 Cuantificación de los posibles mercados objetivo .............................24

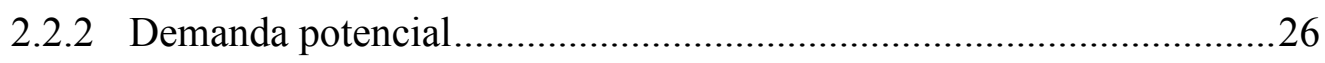

2.2.2.1 Patrones de consumo del servicio ...............................................26

2.2.2.2 Aplicación de estudios cualitativos y cuantitativos........................30

2.2.2.3 Determinación de la demanda potencial ......................................39

2.2.3 Proyección de la demanda potencial y metodología del análisis .........43

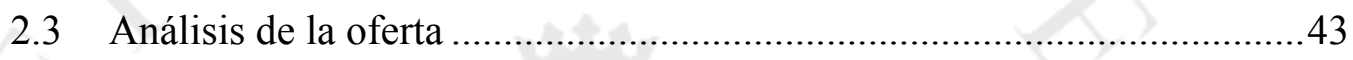

2.3.1 Análisis de la competencia. Número de operadores y ubicaciones .....43

2.3.2 Descripción de las características del servicio ofertado por los

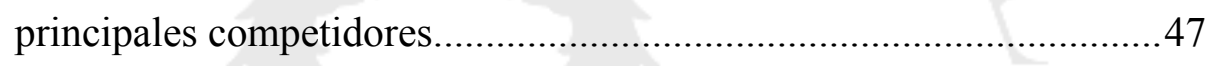

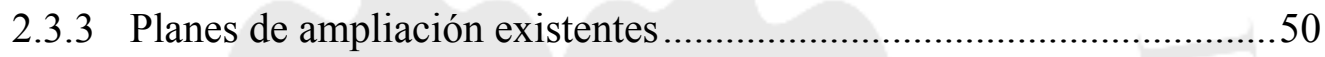

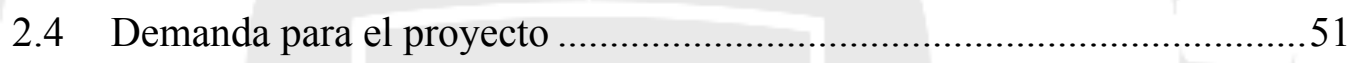

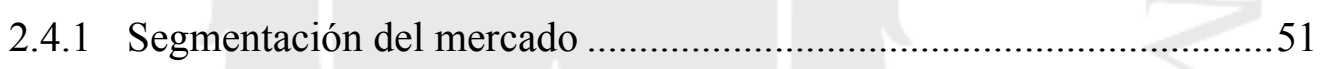

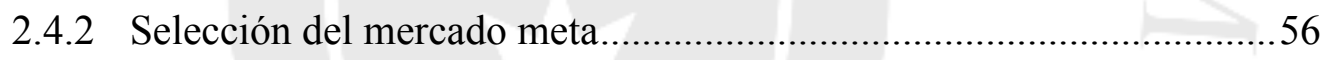

2.4.3 Determinación de la demanda para el proyecto ................................57

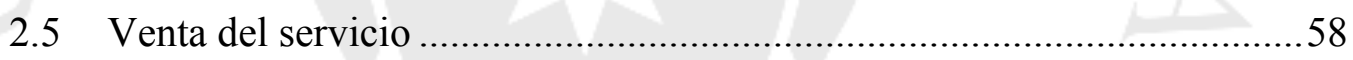

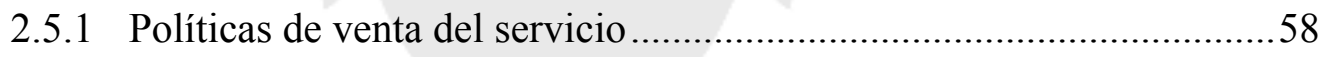

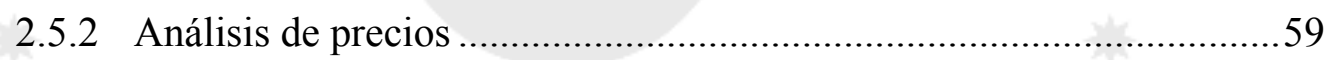

2.5.2.1 Tendencia histórica de los precios..............................................59

2.5.2.2 Precios actuales y niveles del servicio ........................................60

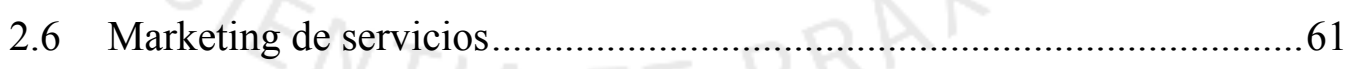

2.6.1 Características principales del servicio ..........................................62

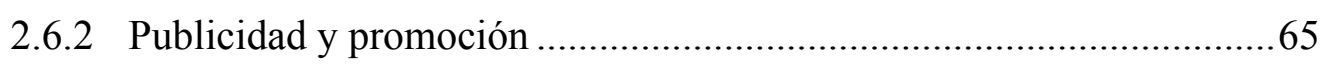

CAPÍTULO III: LOCALIZACIÓN DEL SERVICIO ......................................... 70

3.1 Análisis de los factores de localización ..................................................71

3.2 Posibles ubicaciones de acuerdo a factores predominantes.....................79

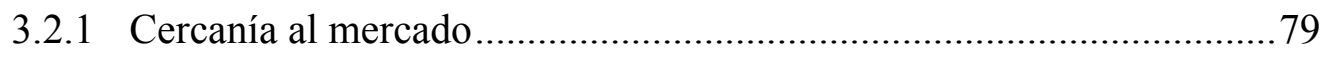

3.2.2 Requerimientos de infraestructura y condiciones socio-económicas ..80

3.3 Evaluación y selección de la localización del servicio .............................82 
3.3.1 Evaluación y selección de la microlocalización del servicio 85

CAPÍTULO IV: DIMENSIONAMIENTO DEL SERVICIO 88

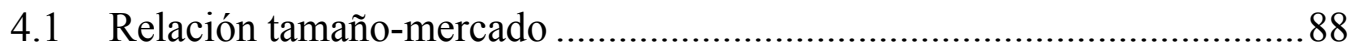

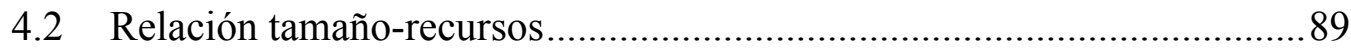

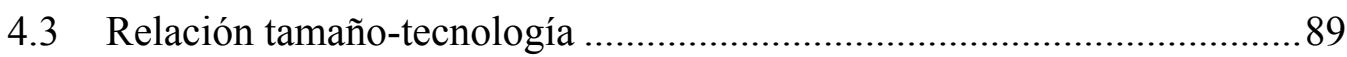

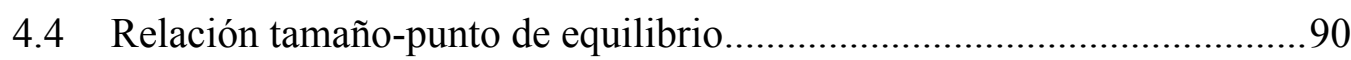

4.5 Selección de la dimensión del servicio ................................................91

CAPÍTULO V: INGENIERÍA DEL PROYECTO …............................................ 92

5.1 Definición del servicio basada en sus características de operación..........92

5.1.1 Especificaciones técnicas del servicio .............................................92

5.2 Tecnología existente y proceso de realización del servicio......................98

5.2.1 Naturaleza de la tecnología requerida ............................................98

5.2.1.1 Descripción de la tecnología existente .........................................98

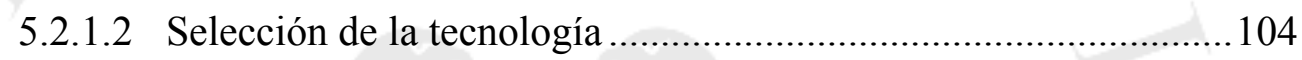

5.2.2 Proceso de realización del servicio ............................................... 107

5.2.2.1 Descripción del proceso del servicio..........................................107

5.2.2.2 Diagrama de flujo del servicio ................................................ 108

5.3 Características de las instalaciones y equipo ....................................... 110

5.3.1 Selección de las instalaciones y equipo .......................................... 110

5.3.2 Especificaciones de las instalaciones y equipo ..............................112

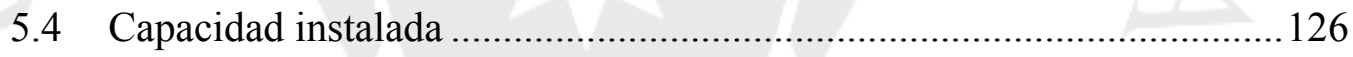

5.4.1 Cálculo de la capacidad instalada del servicio .................................126

5.4.2 Cálculo detallado del número de recursos para el servicio................130

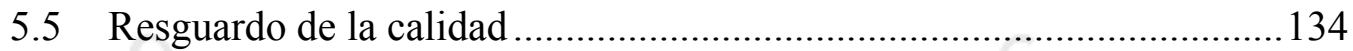

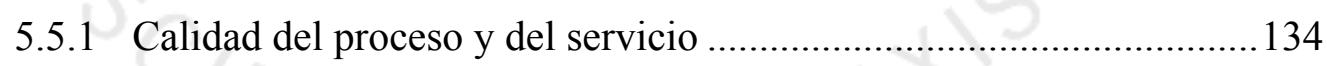

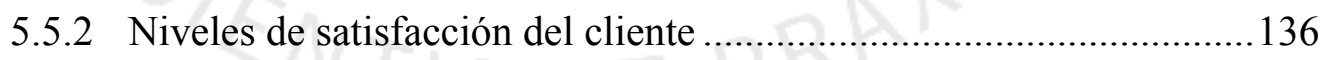

5.5.3 Medidas de resguardo de la calidad ..............................................137

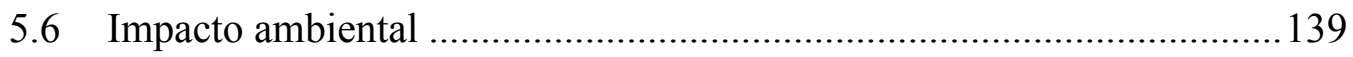

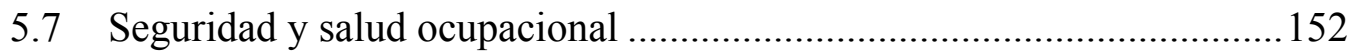

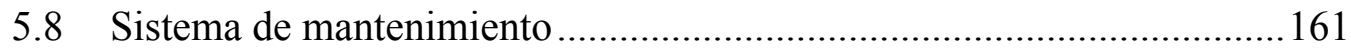

5.9 Programa de operaciones del servicio ................................................. 165

5.9.1 Consideraciones sobre la vida útil del proyecto............................... 165

5.9.2 Programa de las operaciones del servicio durante la vida útil del

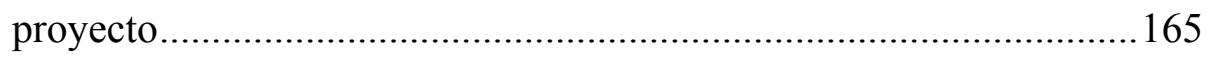


5.10 Requerimiento de materiales, personal y servicios.............................. 166

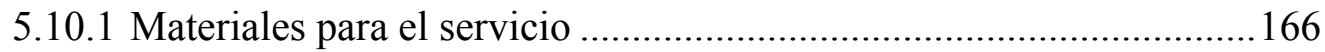

5.10.2 Determinación del requerimiento de personal de atención al cliente 168

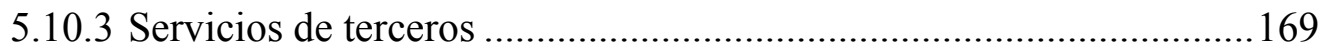

5.10.4 Otros: energía eléctrica, agua, transportes, etc............................... 171

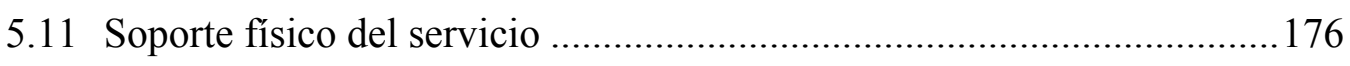

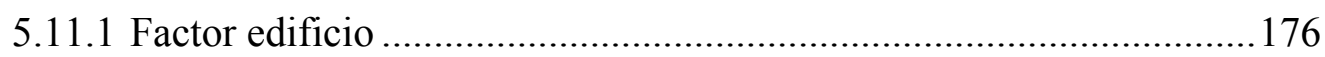

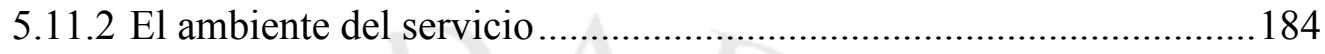

5.12 Disposición de la instalación del servicio............................................190

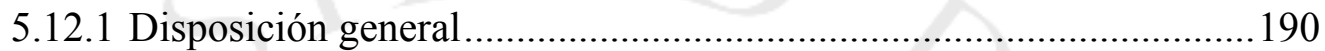

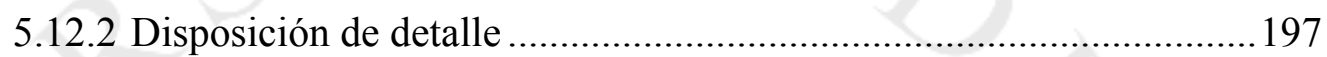

5.13 Cronograma de implementación del proyecto ......................................199

CAPÍTULO VI: ORGANIZACIÓN ADMINISTRATIVA ................................20

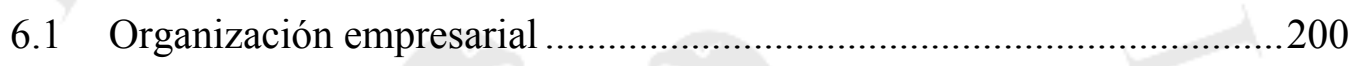

6.2 Requerimientos de personal directivo, administrativo y de soporte interno

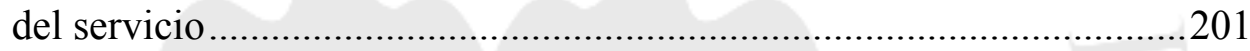

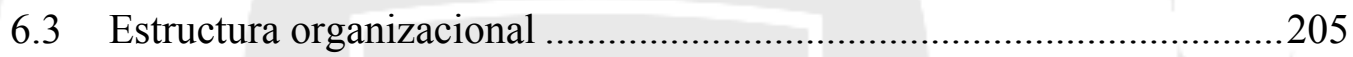

CAPÍTULO VII: ASPECTOS ECONÓMICOS …..............................................206

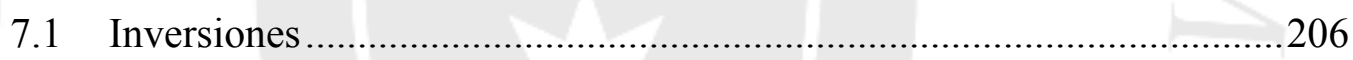

7.1.1 Inversión en la infraestructura para el servicio ...............................206

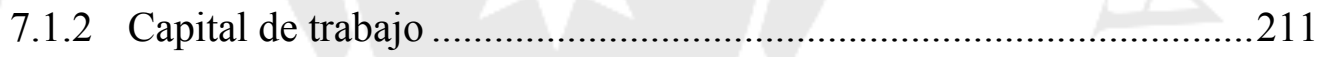

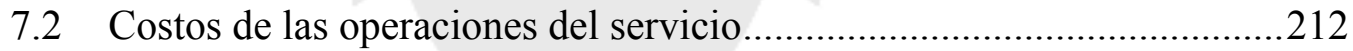

7.2.1 Costos de materiales del servicio ....................................................212

7.2.2 Costo de los servicios (energía eléctrica, agua, transporte, etc.) .......213

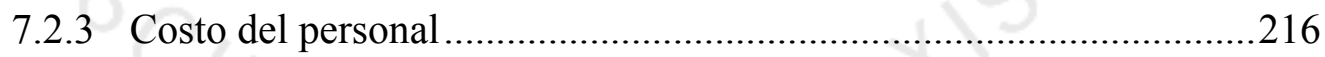

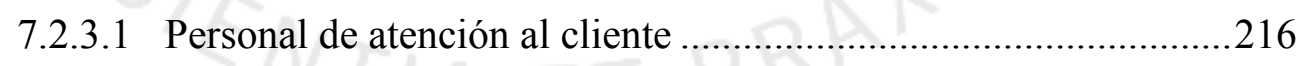

7.2.3.2 Personal de soporte interno del servicio....................................217

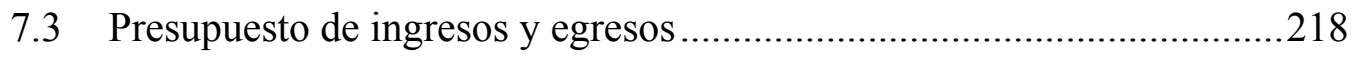

7.3.1 Presupuesto de ingreso por ventas ................................................218

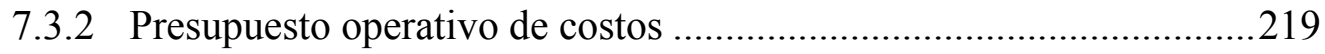

7.3.3 Presupuesto operativo de gastos administrativos............................221

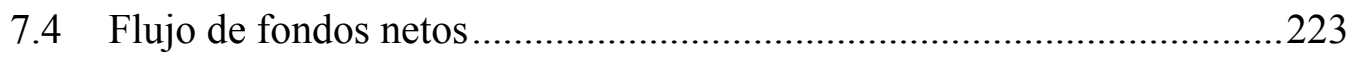

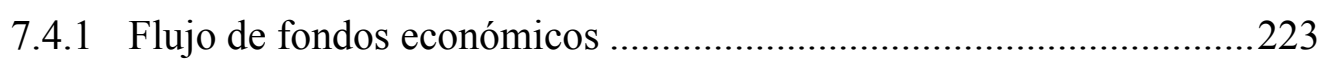

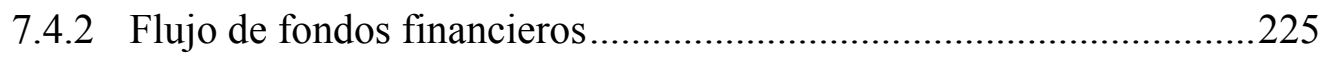




\section{CAPÍTULO VIII: EVALUACIÓN ECONÓMICA Y FINANCIERA DEL}

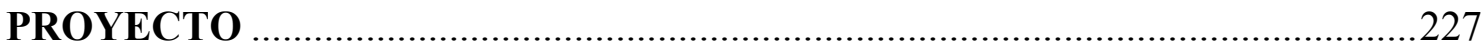

8.1 Evaluación económica: VAN, TIR, B/C, PR …..................................222

8.2 Evaluación financiera: VAN, TIR, B/C, PR ........................................228

8.3 Análisis de los resultados económicos y financieros del proyecto........229

8.4 Análisis de sensibilidad del proyecto ...............................................230

CAPÍTULO IX: EVALUACIÓN SOCIAL DEL PROYECTO.............................2234

9.1 Identificación de las zonas y comunidades de influencia del proyecto ..234

9.2 Impacto en la zona de influencia ..........................................................223

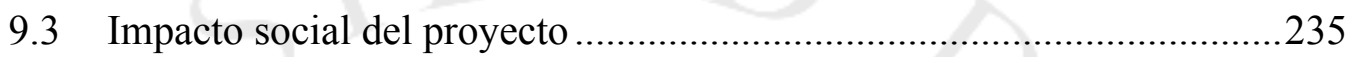

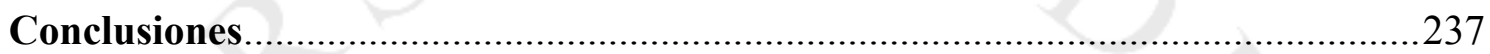

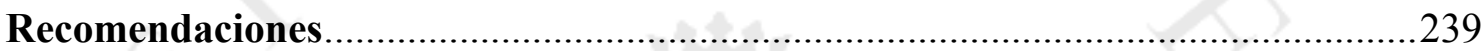

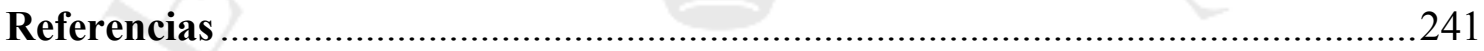

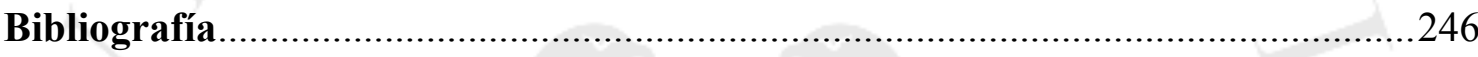

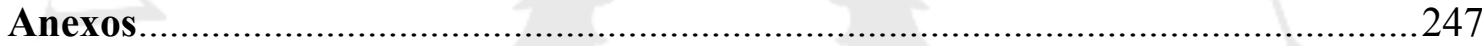




\section{ÍNDICE DE TABLAS}

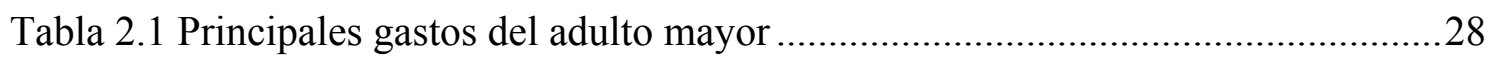

Tabla 2.2 Importancia de los atributos en los centros de rehabilitación física.................35

Tabla 2.3 Tasa anual de crecimiento poblacional - INEI ............................................42

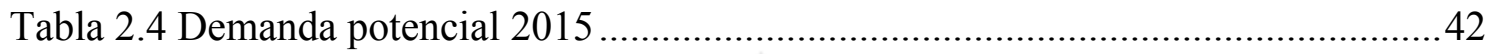

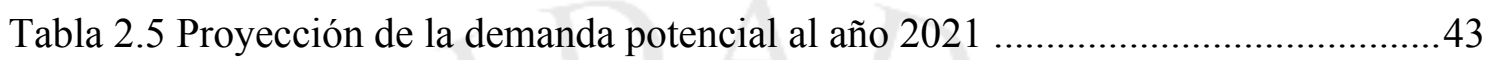

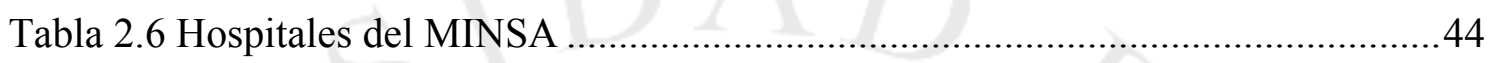

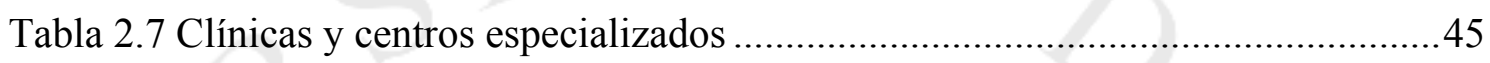

Tabla 2.8 Clínicas y centros especializados (continuación) .........................................46

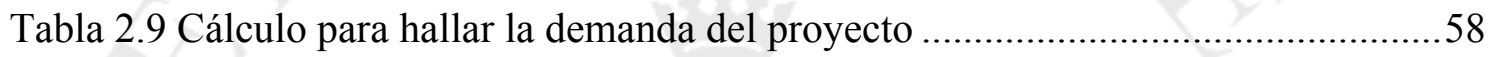

Tabla 2.10 Proyección de la demanda para el proyecto ................................................58

Tabla 2.11 Precio promedio de los servicios de fisioterapia .........................................61

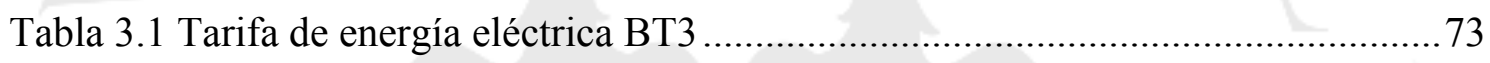

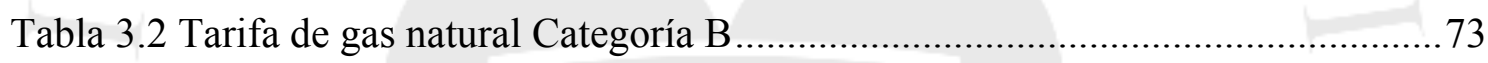

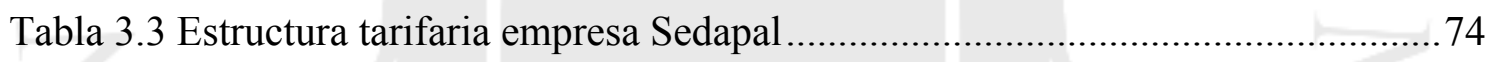

Tabla 3.4 Precios de terrenos en Lima Metropolitana.................................................. 75

Tabla 3.5 Matriz de enfrentamiento de los factores de localización ..............................83

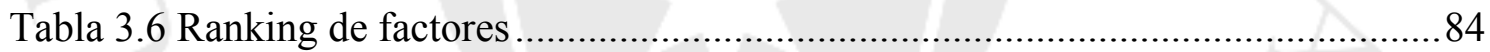

Tabla 3.7 Índice de usos para la ubicación de actividades urbanas en el distrito de San

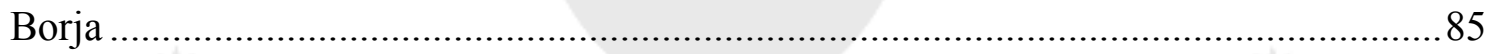

Tabla 3.8 Matriz de enfrentamiento de los factores de microlocalización.......................86

Tabla 3.9 Número de terrenos disponibles para construcción en San Borja ....................86

Tabla 3.10 Ranking de factores de la microlocalización.............................................. 87

Tabla 4.1 Proyección de la demanda para el proyecto .................................................. 88

Tabla 4.2 Ratios del dimensionamiento del servicio................................................... 91

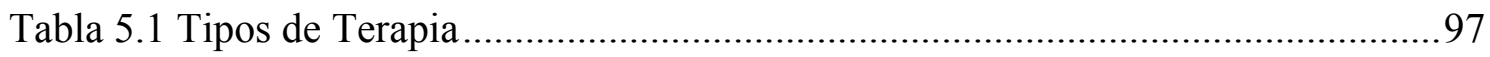

Tabla 5.2 Selección de la tecnología para la implementación del centro de rehabilitación

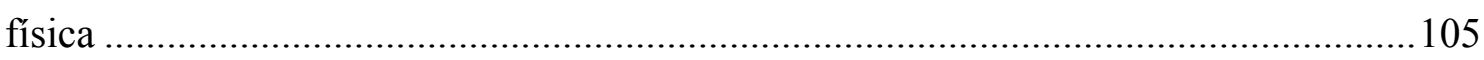

Tabla 5.3 Selección de la tecnología ecoeficiente para las instalaciones del centro.....107

Tabla 5.4 Equipos seleccionados en el proceso de programación de citas y registro de historias clínicas 
Tabla 5.5 Equipos seleccionados en el proceso de rehabilitación física

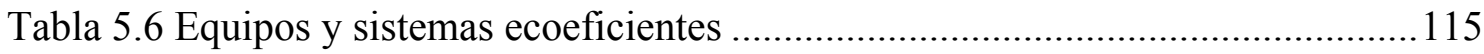

Tabla 5.7 Equipos y duración de la terapia de alivio del dolor .................................... 127

Tabla 5.8 Equipos y duración de la terapia de restauración de la movilidad .................127

Tabla 5.9 Capacidad instalada de la terapia de alivio del dolor ....................................129

Tabla 5.10 Capacidad instalada de la terapia de restauración de la movilidad .............129

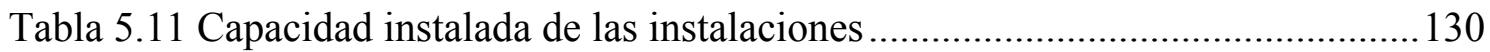

Tabla 5.12 Cálculo del número de máquinas de la terapia de alivio del dolor..............131

Tabla 5.13 Cálculo del número de máquinas de la terapia de restauración de la

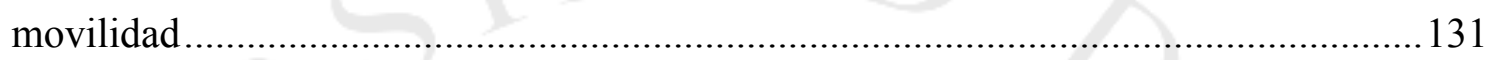

Tabla 5.14 Cálculo del número de instalaciones del centro ........................................131

Tabla 5.15 Cálculo del número de recursos humanos del centro ................................ 133

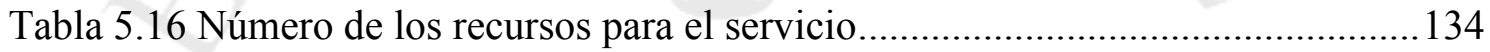

Tabla 5.17 Periodicidad de limpieza en equipos y personal ....................................... 138

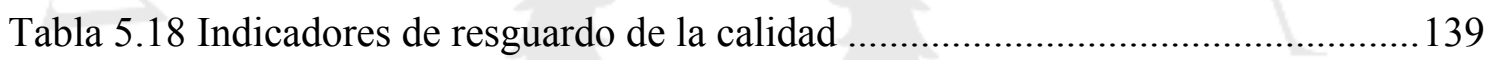

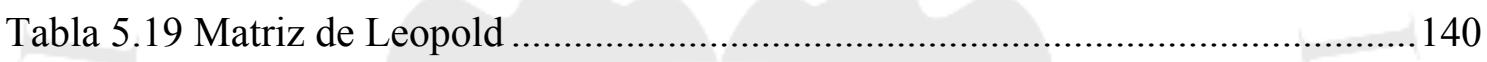

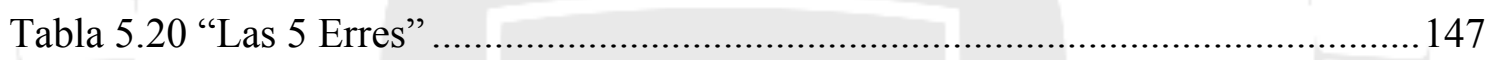

Tabla 5.21 Código de colores para la segregación de residuos solidos .......................148

Tabla 5.22 Recomendaciones para minimizar el impacto ambiental en la construcción

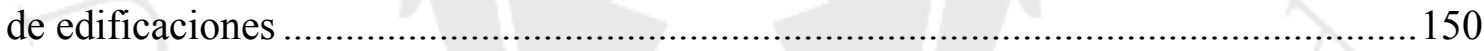

Tabla 5.23 Indicadores ecoeficientes de desempeño.............................................. 152

Tabla 5.24 Parámetros para la evaluación del riesgo (1)............................................. 156

Tabla 5.25 Parámetros para la evaluación del riesgo (2)............................................157

Tabla 5.26 Matriz de identificación de peligros y evaluación de riesgos IPER.............158

Tabla 5.27 Matriz de identificación de peligros y evaluación de riesgos IPER

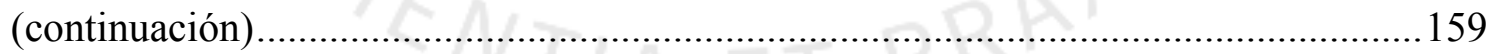

Tabla 5.28 Resistencias máximas del sistema de pozos de puesta a tierra.....................163

Tabla 5.29 Mantenimiento preventivo de los equipos críticos..................................... 164

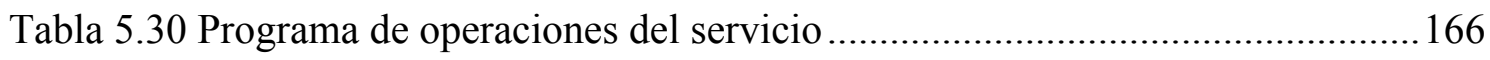

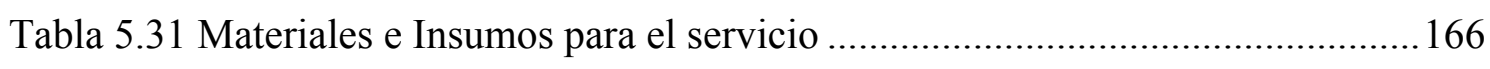

Tabla 5.32 Cantidad anual de materiales e insumos para el servicio ............................ 167

Tabla 5.33 Personal del servicio de rehabilitación física ............................................ 169

Tabla 5.34 Requerimiento de agua del servicio de rehabilitación física.......................171

Tabla 5.35 Requerimiento de agua de oficinas .................................................... 171 
Tabla 5.36 Requerimiento de agua anual

Tabla 5.37 Requerimiento de energía eléctrica del servicio de rehabilitación física.... 173

Tabla 5.38 Requerimiento de energía eléctrica de oficinas......................................... 173

Tabla 5.39 Requerimiento de energía eléctrica anual .............................................. 174

Tabla 5.40 Requerimiento de gas natural del calentador de piscina ............................ 174

Tabla 5.41 Requerimiento de gas natural para agua caliente .....................................175

Tabla 5.42 Requerimiento de gas natural anual ..................................................... 175

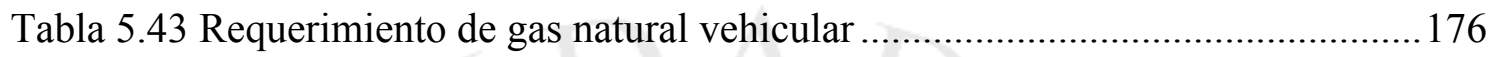

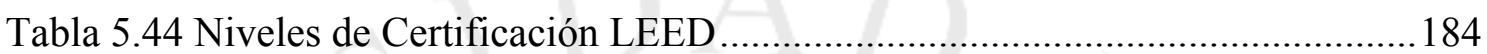

Tabla 5.45 Cálculo de dimensiones de elementos móviles de cubículo de terapia de

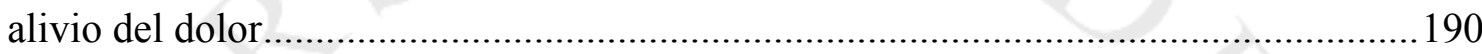

Tabla 5.46 Cálculo de superficie de cubículo para terapia de alivio del dolor ............. 191

Tabla 5.47 Cálculo de dimensiones de elementos móviles de cubículo de terapia de

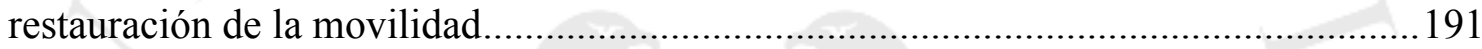

Tabla 5.48 Cálculo de superficie de cubículo para terapia de restauración de la movilidad

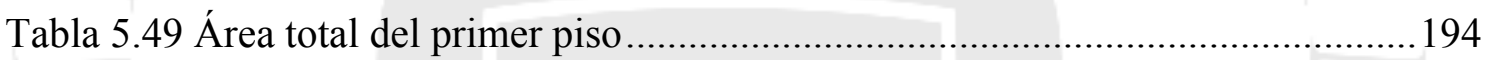

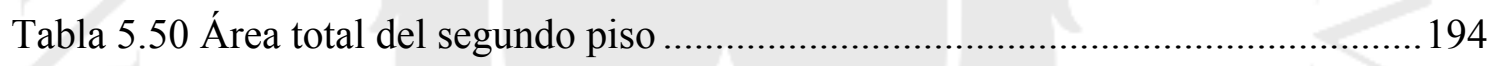

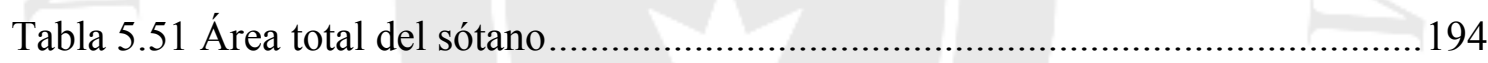

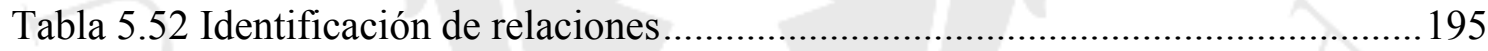

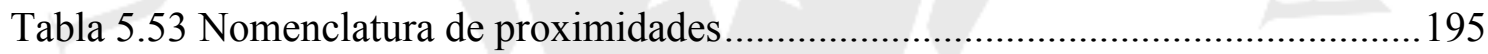

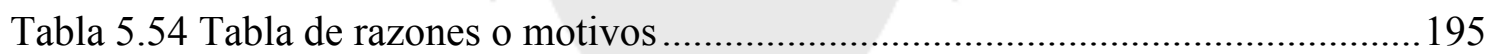

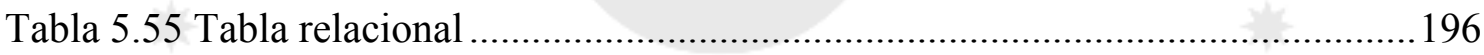

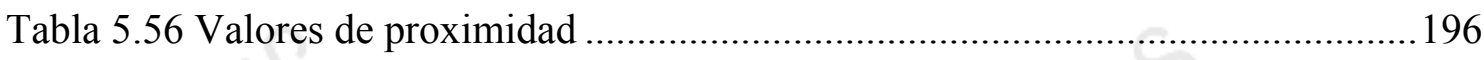

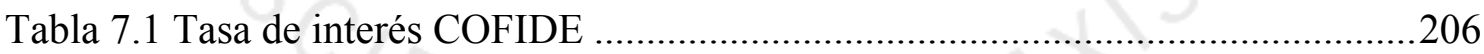

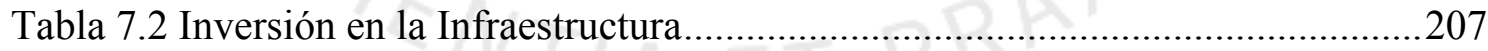

Tabla 7.3 Inversión en los equipos del servicio ..........................................................208

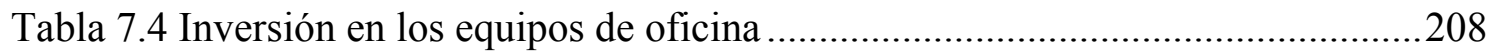

Tabla 7.5 Inversión en el mobiliario y enseres del servicio .......................................209

Tabla 7.6 Inversión en el mobiliario y enseres de oficinas ........................................209

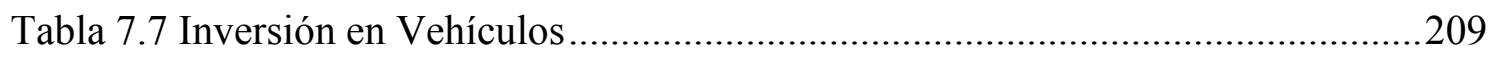

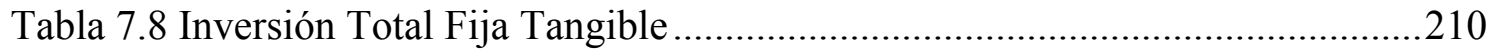

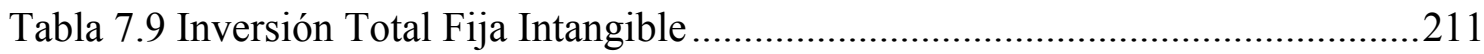

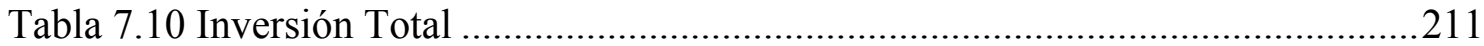


Tabla 7.11 Capital de Trabajo

Tabla 7.12 Costo de materiales e insumos .......................................................................213

Tabla 7.13 Costo anual de energía eléctrica ...............................................................2. 213

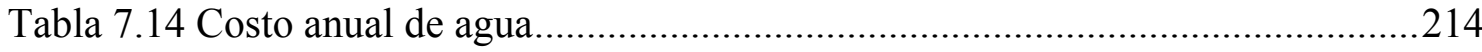

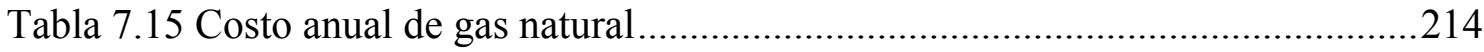

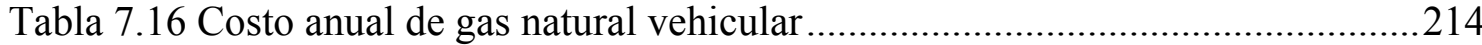

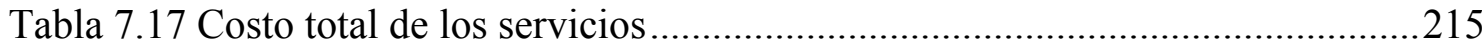

Tabla 7.18 Costo de los servicios de terceros ..............................................................216

Tabla 7.19 Costo anual de los servicios de terceros ....................................................216

Tabla 7.20 Costo anual de Mano de Obra Directa (MOD) .........................................2217

Tabla 7.21 Costo anual de Mano de Obra Indirecta (MOI) .......................................217

Tabla 7.22 Costo anual del personal administrativo .................................................218

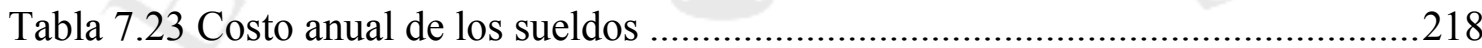

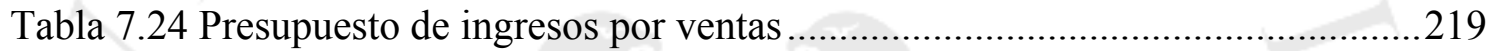

Tabla 7.25 Depreciación anual de activos fijos tangibles .........................................220

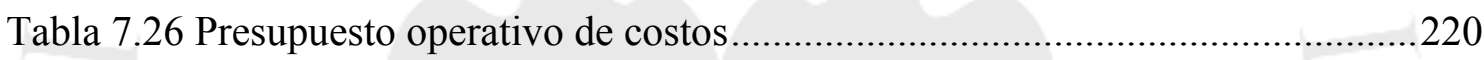

Tabla 7.27 Amortización anual de activos fijos intangibles .....................................222

Tabla 7.28 Presupuesto operativo de gastos administrativos .....................................222

Tabla 7.29 Estado de Resultados y Flujo de Fondos Económicos ................................224

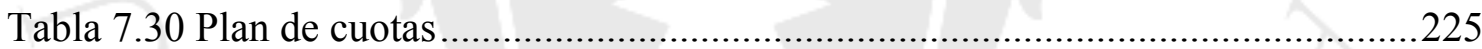

Tabla 7.31 Estado de Resultados y Flujo de Fondos Financieros ................................226

Tabla 8.1 Costo de Oportunidad del Inversionista (COK) ........................................228

Tabla 8.2 Valores de la Evaluación Económica...........................................................228

Tabla 8.3 Costo Promedio Ponderado de Capital (CPPC) ...........................................229

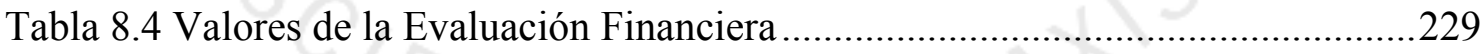

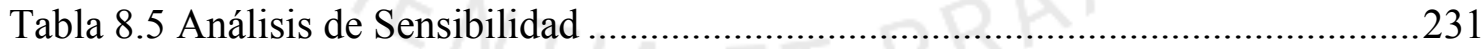

Tabla 9.1 Indicadores de Evaluación Social ...............................................................236 


\section{ÍNDICE DE FIGURAS}

Figura 1.1 Incremento y proyección de la población adulto mayor en Lima

Metropolitana

Figura 1.2 Principal origen de las personas con discapacidad 2

Figura 1.3 Porcentaje de adultos mayores con enfermedades crónicas.............................3

Figura 1.4 Diferencia entre el tiempo de solicitud y atención de una cita .......................4

Figura 1.5 Tiempo promedio de espera de atención de citas ........................................4

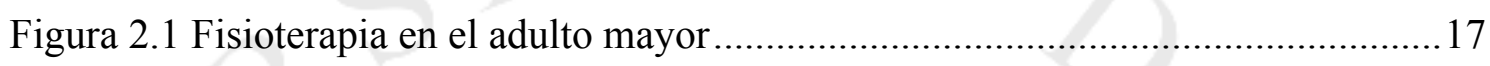

Figura 2.2 Departamentos del Perú con la más alta población adulto mayor .................22

Figura 2.3 Población de Lima Metropolitana según grupo de edades ..........................25

Figura 2.4 Porcentaje de la población de Lima Metropolitana según grupo de edades..25

Figura 2.5 Penetración de mercado de los servicios de salud en el Perú ........................26

Figura 2.6 Penetración de mercado de los servicios de salud en Lima Metropolitana ...27

Figura 2.7 Asistencia del adulto mayor a centros de salud en Lima Metropolitana .......28

Figura 2.8 Frecuencia de asistencia del adulto mayor a centros de salud en Lima

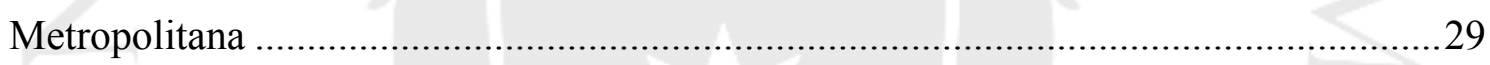

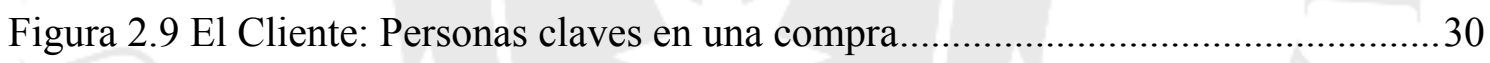

Figura 2.10 Porcentaje de encuestados adultos mayores o con algún familiar mayor a 60 años

Figura 2.11 Porcentaje de encuestados con problemas musculares que requieran rehabilitación física

Figura 2.12 Porcentaje de encuestados que han tomado en algún momento los servicios

de rehabilitación física. .32

Figura 2.13 Lugares donde acuden por los servicios de rehabilitación física.................33

Figura 2.14 Frecuencia de uso de los servicios de rehabilitación física..........................33

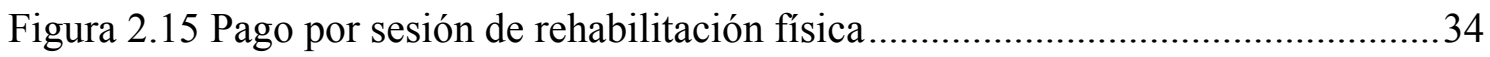

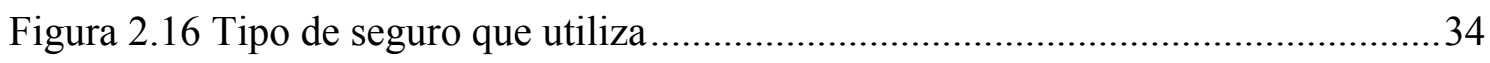

Figura 2.17 Como considera los servicios de rehabilitación física donde se atiende .....35

Figura 2.18 Porcentaje de encuestados que acudirían a un centro de rehabilitación física

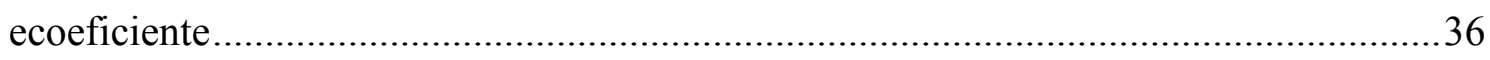

Figura 2.19 Porcentaje de adultos mayores con enfermedades crónicas según género ..40 
Figura 2.20 Porcentaje de adultos mayores con enfermedades crónicas en tratamiento.40

Figura 2.21 Tipo de discapacidad que reportan los adultos mayores............................. 41

Figura 2.22 Perfiles zonales de Lima Metropolitana ....................................................52

Figura 2.23 Población adulto mayor según perfiles zonales de Lima Metropolitana .....53

Figura 2.24 Población de Lima Metropolitana según grupo de edades ...........................53

Figura 2.25 Principal fuente de ingresos del adulto mayor en Lima Metropolitana .......54

Figura 2.26 Población de adultos mayores de Lima Metropolitana por NSE .................55

Figura 2.27 Tendencia histórica de precios de los servicios de salud. 60

Figura 3.1 Número de clínicas y centros que brindan los servicios de rehabilitación física

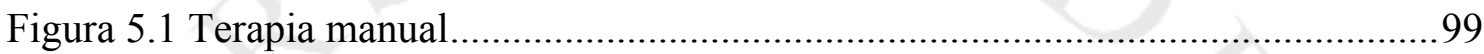

Figura 5.2 Terapia manual asistida con equipos mecánicos .......................................99

Figura 5.3 Terapia manual asistida con equipos eléctricos ..................................... 100

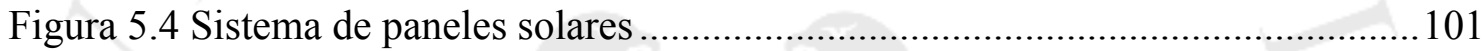

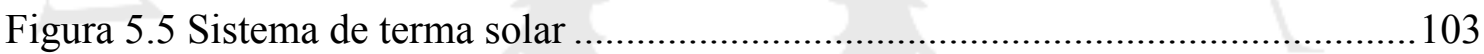

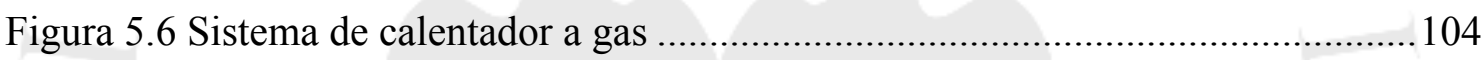

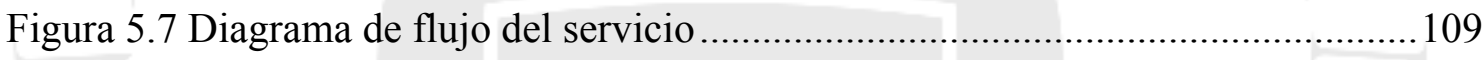

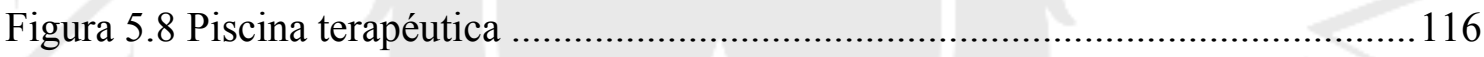

Figura 5.9 Sistema y equipos de la piscina fisioterapéutica ......................................118

Figura 5.10 Equipos para el proceso de programación de citas y registro de historias clínicas

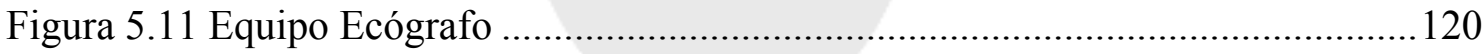

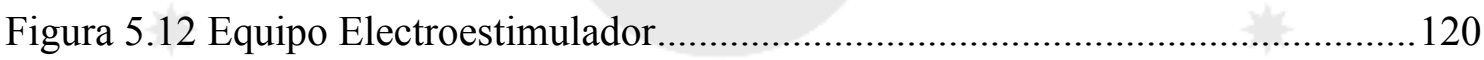

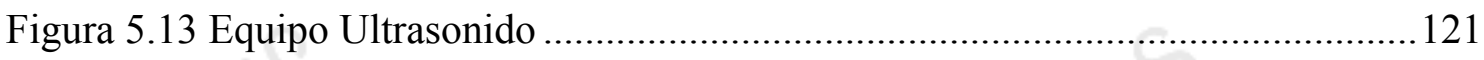

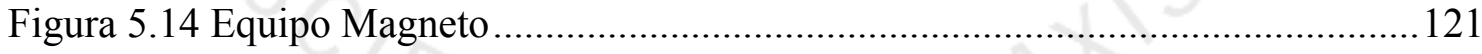

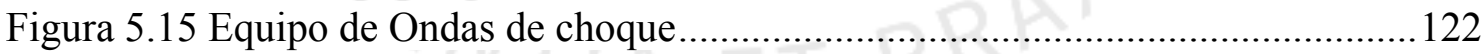

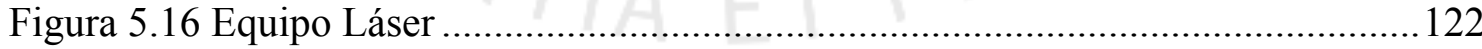

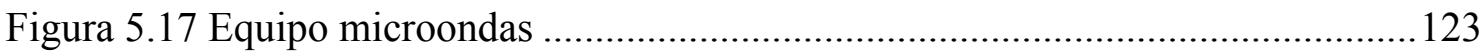

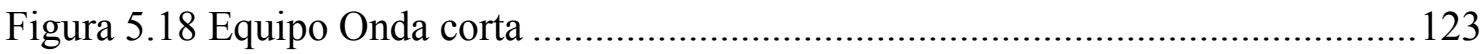

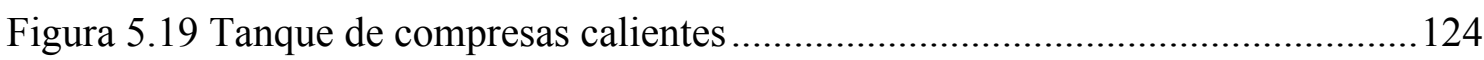

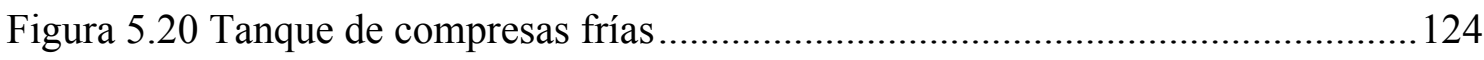

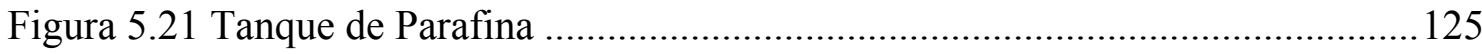

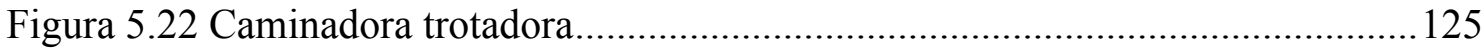

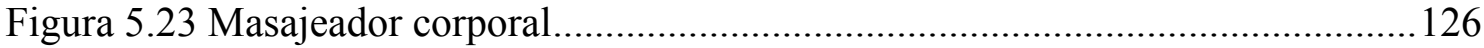




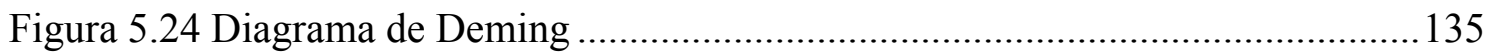

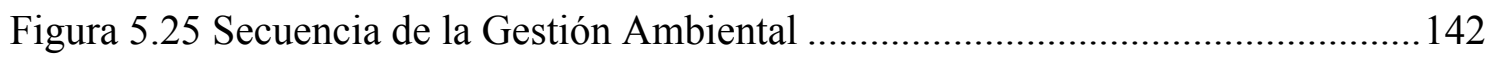

Figura 5.26 Etiqueta de equipo sobre su consumo de energía .................................... 145

Figura 5.27 Tachos de recolección de residuos sólidos .............................................. 148

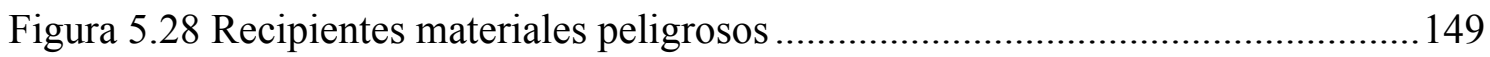

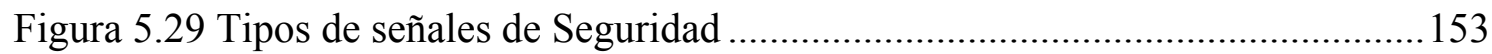

Figura 5.30 Extintor PQS para clase de fuego ABC …............................................. 154

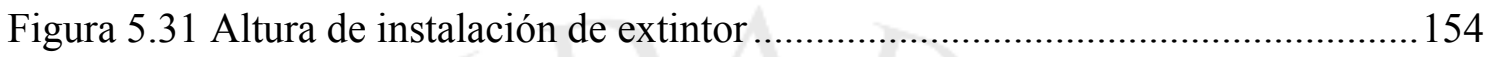

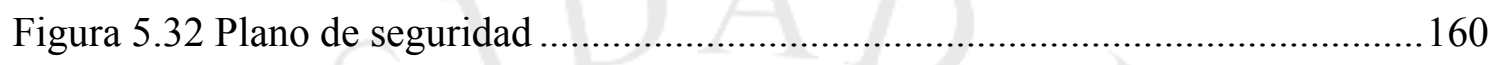

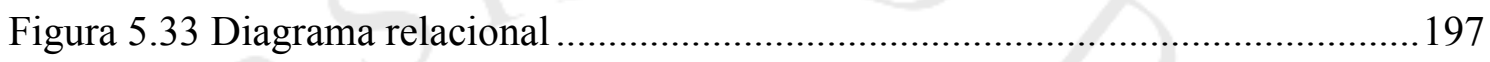

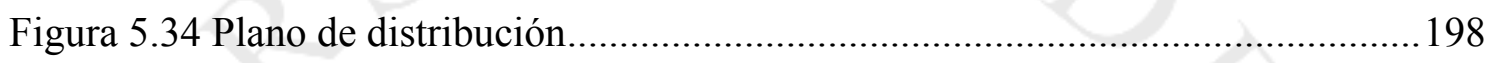

Figura 5.35 Cronograma de implementación del proyecto ........................................ 199

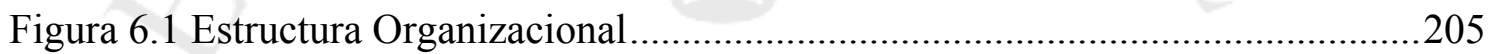

Figura 8.1 Variación del Valor actual Neto (VAN) en los distintos escenarios ...........231

Figura 8.2 Variación de la Tasa Interna de Retorno Económica (TIRE) ......................232

Figura 8.3 Variación de la Tasa Interna de Retorno Financiera (TIRF) .......................232

Figura 9.1 Zona de influencia: Distrito de San Borja.................................................234 


\section{ÍNDICE DE ANEXOS}

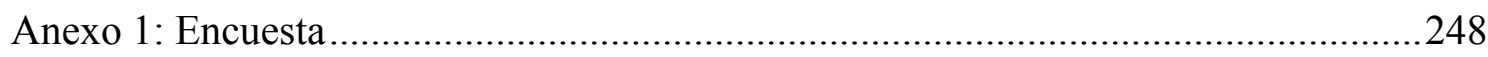

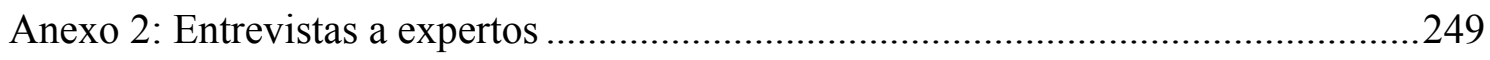

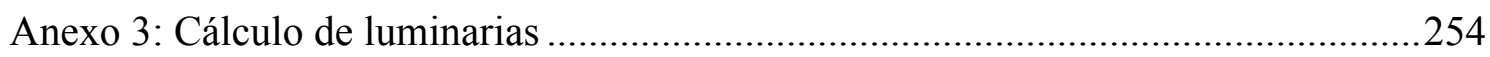

Anexo 4: Cálculo del número de equipos de aire acondicionado ................................255

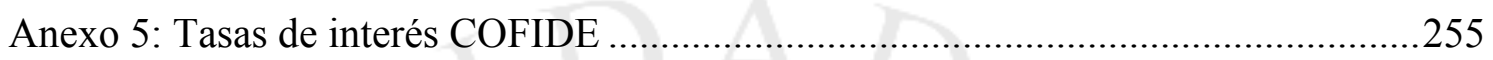

Anexo 6: Tasa de libre riesgo y riesgo de mercado ......................................................2. 256

Anexo 7: Ficha de inscripción virtual de establecimientos de salud............................257 


\section{RESUMEN EJECUTIVO}

El presente proyecto de investigación tiene como objetivo principal demostrar la viabilidad técnica, económica y de mercado de implementar un establecimiento que brinde servicios de fisioterapia a los adultos mayores de la ciudad de Lima Metropolitana enfocado en mejorar la calidad de vida de sus pacientes, en el aumento del nivel de servicio de sus terapias y en la optimización de la eficiencia de sus instalaciones a través de la implementación de un sistema de gestión ambiental basado en la ecoeficiencia lo que contribuirá en el desarrollo sostenible y mitigación del impacto ambiental en el área de influencia del proyecto.

El mercado al cual va dirigido el servicio está conformado por hombres y mujeres de nivel socioeconómico "A" de la ciudad de Lima Metropolitana con edades a partir de los 60 años denominados adultos mayores, que sufren de enfermedades músculo-esqueléticas o de alguna discapacidad física. A partir de dicha población, se determinó una demanda para el proyecto en 4.690 adultos mayores para el año 2015 y de 4.991 adultos mayores para el año 2021 equivalentes a 119.781 sesiones para dicho año. Asimismo, se determinó la oferta de mercado identificando a las principales clínicas y centros especializados considerados como la competencia del proyecto, identificando a su vez los precios y niveles de servicio que actualmente ofrecen, lo cual permitió definir los precios de los servicios que se cobrarán y los niveles de servicio que se ofrecerá a los pacientes del centro.

Para decidir la zona donde se implementará el centro, se propusieron tres distritos de la ciudad de Lima Metropolitana en base a los factores de localización aplicando el método semi-cuantitativo de Ranking de Factores, obteniendo como resultado que la localización del centro para la implementación del proyecto sería el distrito de San Borja.

Respecto al dimensionamiento del servicio se compararon los resultados de la relación tamaño mercado, tamaño tecnología y tamaño punto de equilibrio y se llegó a 
la conclusión que la dimensión del servicio estará determinado por el ratio tamañomercado en el último año del proyecto puesto que conduce a obtener los resultados más favorables en términos económicos.

Se describieron las características técnicas del servicio definiendo los tipos de fisioterapia que se brindarán y la descripción y selección de la tecnología a utilizar, además de la elección tanto de los equipos médicos de rehabilitación física como de los equipos ecoeficientes para el ahorro de los recursos utilizados en el centro. Asimismo, se determinó la capacidad instalada tanto de los procesos de cada terapia como de las instalaciones, así como el número de los recursos necesarios para la prestación del servicio.

Se desarrolló un sistema de gestión ambiental basado en la ecoeficiencia, el cual implica un uso eficiente de los recursos reduciendo los costos de operación y la minimización de los impactos ambientales contribuyendo así a la sostenibilidad del área de influencia del proyecto. Este sistema se establece bajo las buenas prácticas para el uso eficiente de los recursos.

Se definieron todos los requerimientos necesarios a nivel de materiales e insumos, personal de atención al cliente y servicios para la implementación del centro. Asimismo, se determinó el área específica donde se realizarán las terapias físicas mediante el cálculo de las superficies de distribución utilizando el método de Guerchet para la evaluación del espacio físico, dando como resultado un área total de $896 \mathrm{~m}^{2}$.

Dentro de los aspectos económicos se determinó que la estructura de financiamiento considerará que el accionista aporte el 35\% del monto requerido y el $65 \%$ será financiado por COFIDE con una tasa efectiva anual de $11,27 \%$ a 5 años. Además, se definió la inversión total conformada por la infraestructura del proyecto, los equipos y el capital de trabajo la cual asciende a S/. 13.703.839. A su vez se definieron los presupuestos de ventas, costos de operación y gastos administrativos y los flujos tanto económicos como financieros. 
La evaluación económica del proyecto determinó financiarlo al obtener indicadores financieros favorables para su implementación tales como un Valor Actual Neto (VAN) de S/. 5.737.486 con una tasa de descuento CPPC de 12,94\%, una tasa interna de retorno (TIR) de 38,39\%, un indicador Beneficio Costo de 2,20 y un periodo de recupero de 4 años y 2 meses menor a los 5 años de evaluación del proyecto.

Se realizó el análisis de sensibilidad donde se simularon 3 escenarios en los cuales la demanda de mercado se incrementó (escenario optimista), no se modificó (escenario esperado) y disminuyó (escenario pesimista), dando como resultado la no viabilidad del proyecto en su evaluación económica al disminuir la demanda en 20\%; todas las demás evaluaciones en los distintos escenarios resultaron favorables para la viabilidad del proyecto.

Finalmente se realizó la evaluación social del proyecto donde se identificaron impactos positivos como la generación de empleos y la contribución a la sostenibilidad del medio ambiente en la zona de influencia del centro de fisioterapia. 


\section{EXECUTIVE SUMMARY}

The main aim of the present research project is to demonstrate the technical, economic and market feasibility of implementing an establishment that provides physiotherapy services for seniors of the city of Metropolitan Lima focused on improving the quality of life for patients, increasing the level of service of its therapies and optimizing the efficiency of its facilities through the implementation of an environmental management system based on the eco-efficiency which will contribute to sustainable development and mitigation of the environmental impact in the project's area of influence.

The target market of this service is conformed by men and women according to the socioeconomic level "A" of the city of Metropolitan Lima aged from 60 years, the so-called seniors that suffer from musculo-skeletal diseases or some physical disability. From this population it was determined for the Project a demand of 4.690 seniors by year 2015 and of 4.991 seniors by year 2021 equivalent to 119.781 sessions for said year. Therefore, the market offering was established by identifying the main clinics and specialized centers considered as the competition of the Project, identifying at the same time the prices and level of services currently offered, which allow fixing prices to be charged and the level of services to be offered to the center's patients.

In order to determine the zone where the center will be implemented, three districts of the city of Lima were proposed in basis of location factors by applying the semi-quantitative method of Ranking of Factors, obtaining as a result that the location of the center for the implementation of the project would be the District of San Borja.

In relation to the dimensioning of the service, the results of the relation sizemarket, size-technology and size-balance point were compared and it is concluded that the dimension of the service will be determined by the size-market ratio in the last year of the Project due to it leads to the most favourable results in economic terms. 
The technical characteristics of the service were described by defining the types of physiotherapy that will be provided as well as the description and selection of the technology to be used, also the selection of both medical equipment for physical rehabilitation and eco-efficient equipment for saving the resources used by the center. Therefore, the capability of both process of each therapy and installations were determined, as well as the number of resources necessary for the provision of services.

An environmental management system was developed based on the ecoefficiency, which implies an efficient use of the resources by reducing operating costs and the minimization of environmental impacts, thus contributing to the sustainability of the project's area of influence. This system is established under the good practices for the efficient use of the resources.

All the necessary requirements such as materials and supplies, customer service personnel and services for the implementation of the center were defined. Therefore, it was determined the specific area where the physical therapies will be done through the calculation of the distribution surfaces using the Guerchet Method in order to evaluate the physical space, resulting in a total area of $896 \mathrm{~m}^{2}$.

Within the economical aspects, it was established that the financing structure will consider that the shareholder would contribute $35 \%$ of the required amount and $65 \%$ shall be financed by the Development Finance Corporation of Peru (COFIDE) with an effective annual rate of $11,27 \%$ to 5 years. In addition, it was defined the total investment made up of the Project's infrastructure, the equipment and the working capital which amounts to $\mathrm{S} / \mathrm{13} .703 .839$. In turn, the sales budgets, operating costs and administrative expenses were established as well as both economic and financial flows.

The economic evaluation of the Project established to finance it by obtaining favourable financial indicators to its implementation such as a Net Present Value (NPV) of S/. 5.737.486 with a WACC discount rate of $12,94 \%$, an internal rate of return (IRR) 
of $38,39 \%$, a benefit/cost indicator of 2,20 and a recovery period of 4 years and 2 months less to the 5 years of the evaluation of the project.

A sensitivity analysis were done by simulating three scenarios in which the market demand has increased (optimistic scenario), it was not modified (expected scenario) and decreased (optimistic scenario), giving as a result the non-viability of the Project in its economic evaluation by reducing the demand in $20 \%$; all the rest of evaluations in the different scenarios were favourable for the viability of the project.

Finally, the social evaluation of the Project was done where positive impacts were identified such as employment generation and the contribution to the environmental sustainability in the area of influence of the Physiotherapy Center. 


\section{CAPÍTULO I: ASPECTOS GENERALES}

\subsection{Problemática}

El presente proyecto de investigación "Estudio de prefactibilidad para la instalación de un centro ecoeficiente de fisioterapia dirigido al adulto mayor en la ciudad de Lima", se basa en la instalación e implementación de un establecimiento que brinda servicios de fisioterapia para adultos mayores enfocado en la mejora del nivel del servicio y en la optimización de la eficiencia de sus instalaciones a través de la implementación de un plan de manejo ambiental basado en la ecoeficiencia.

Su importancia como proyecto de investigación en la Ingeniería Industrial radica en los beneficios económicos que se generarían por su implementación, en la mejora de la calidad de vida de su público objetivo, en su contribución al desarrollo sostenible y en la mitigación del impacto ambiental en su área de influencia.

En los últimos años la población de adultos mayores de la ciudad de Lima (sin incluir la provincia constitucional del Callao) viene presentando un incremento significativo según información obtenida del Instituto Nacional de Estadística e Informática (INEI); y con proyección a seguir creciendo. 
Figura 1.1

Incremento y proyección de la población del adulto mayor en Lima Metropolitana

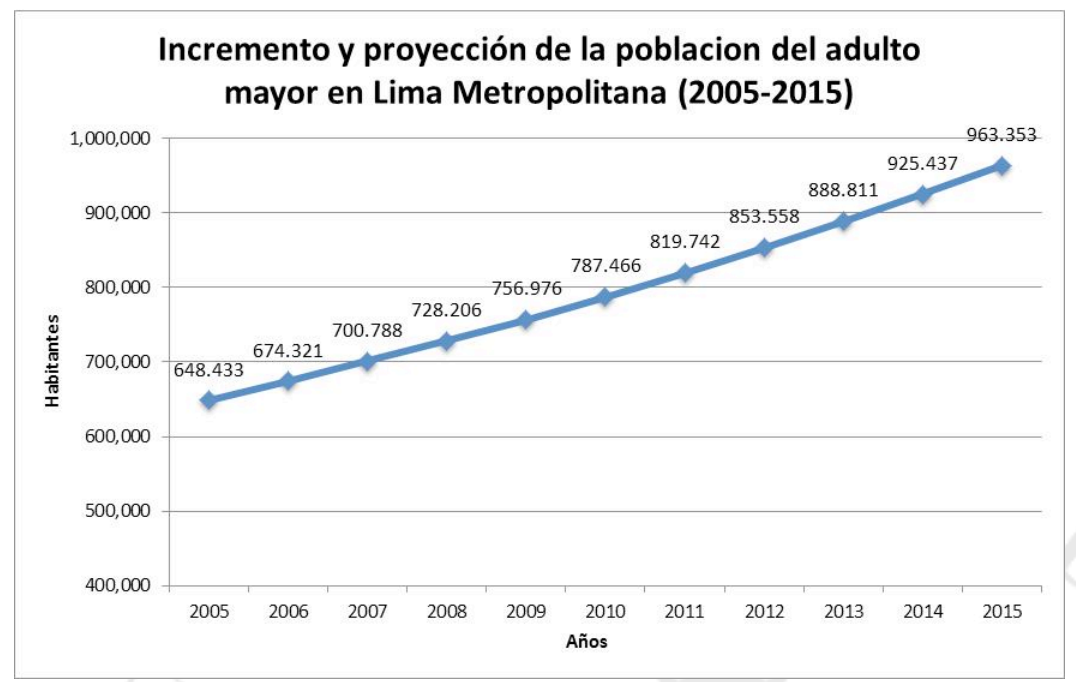

Fuente: INEI

Elaboración Sropia

Asimismo, según una reciente encuesta sobre discapacidad a nivel nacional de esa misma organización, se muestra que el principal origen de limitación de las personas con alguna discapacidad es la edad avanzada (32,5\%).

Figura 1.2

Principal origen de las personas con discapacidad

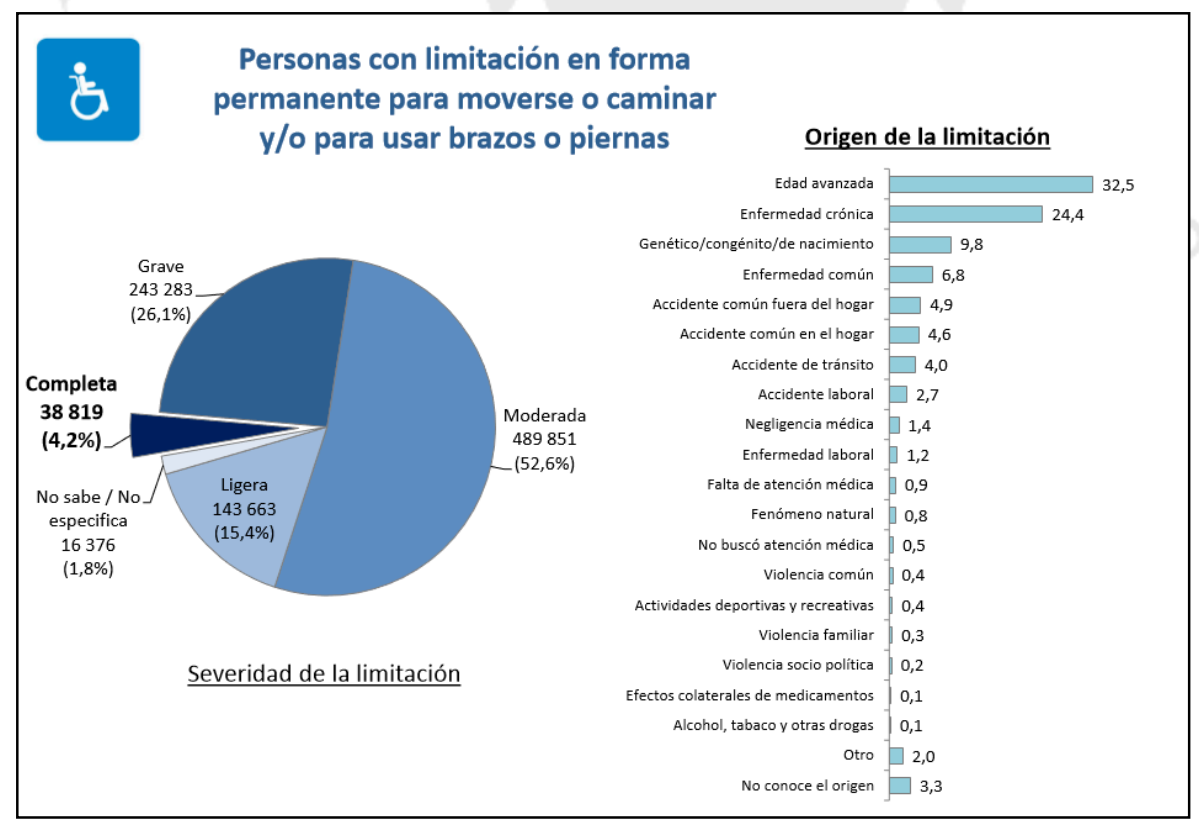

Fuente: INEI 
Existe también un gran número de adultos mayores que sufren enfermedades de tipo reumáticas que requieren los servicios de rehabilitación física; según la Tecnóloga Médica Lic. Diana Mundaca Chávez CTMP 8808, las enfermedades de este tipo se dan en esta población en particular: "El gran problema de los adultos mayores son las enfermedades reumáticas, como son la artrosis, la artritis y estas no tienen cura, son enfermedades progresivas, empiezan y van complicándose con el tiempo."1

Aquí se encuentra una gran población que demandará los servicios médicos de rehabilitación física y a la vez requerirán dichos servicios por un tiempo prolongado y recurrente; la frecuencia de estos servicios es alta puesto que los adultos mayores los necesitan de por vida y varias veces al año para atenuar los síntomas de su enfermedad.

Según los resultados de la "Encuesta de Salud y Bienestar del Adulto Mayor 2012” del Ministerio de Desarrollo e Inclusión Social (MIDIS) las enfermedades crónicas más recurrentes en los adultos mayores son la artrosis/reumatismo (39\%), hipertensión (30\%) y la osteoporosis (18\%), entre otras enfermedades.

Figura 1.3

Porcentaje de adultos mayores con enfermedades crónicas

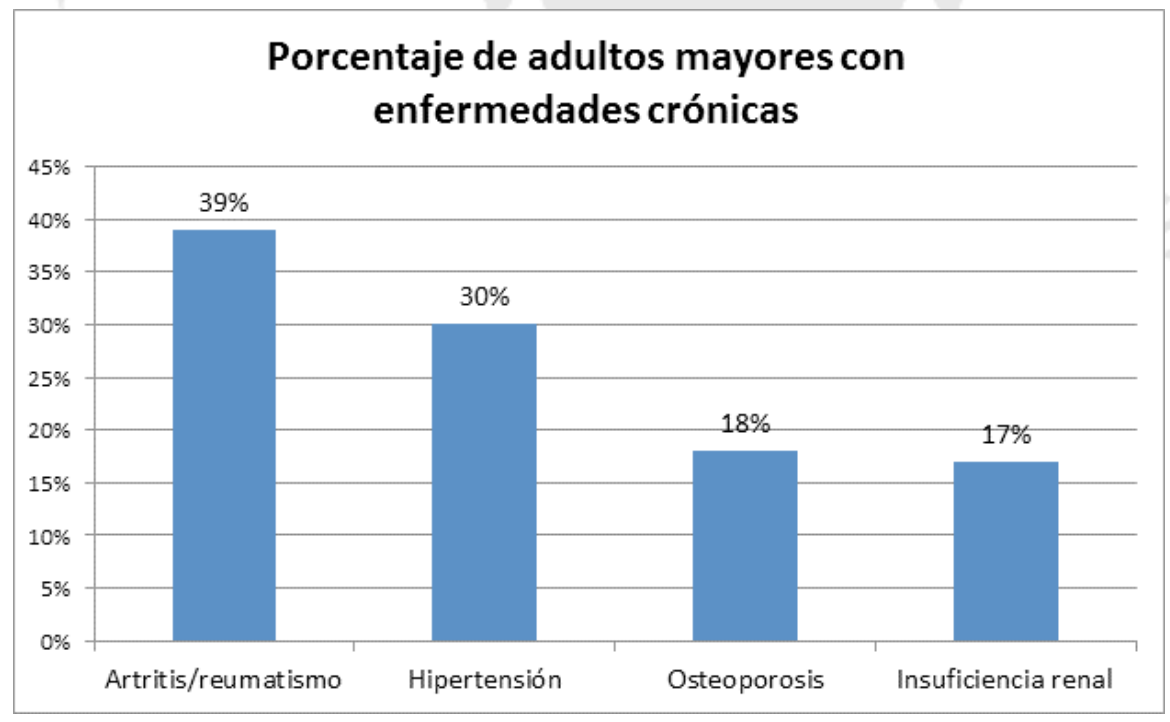

Fuente: Ministerio de Desarrollo e Inclusión Social Elaboración Sropia

${ }^{1}$ Mundaca Chávez, Diana. Tecnólogo Medico CTMP 8808. [Fecha de la entrevista: 28 de febrero de 2015] 
A su vez se conoce, a través de la "Encuesta de Satisfacción de los Usuarios del Aseguramiento Universal en Salud" (AUS) elaborado por la Superintendencia Nacional de Aseguramiento en Salud (SUNASA), que existen diferencias significativas entre el tiempo de solicitud de la cita y la atención de la misma en los diferentes establecimientos de salud.

Figura 1.4

Diferencias entre el tiempo de solicitud y atención de una cita

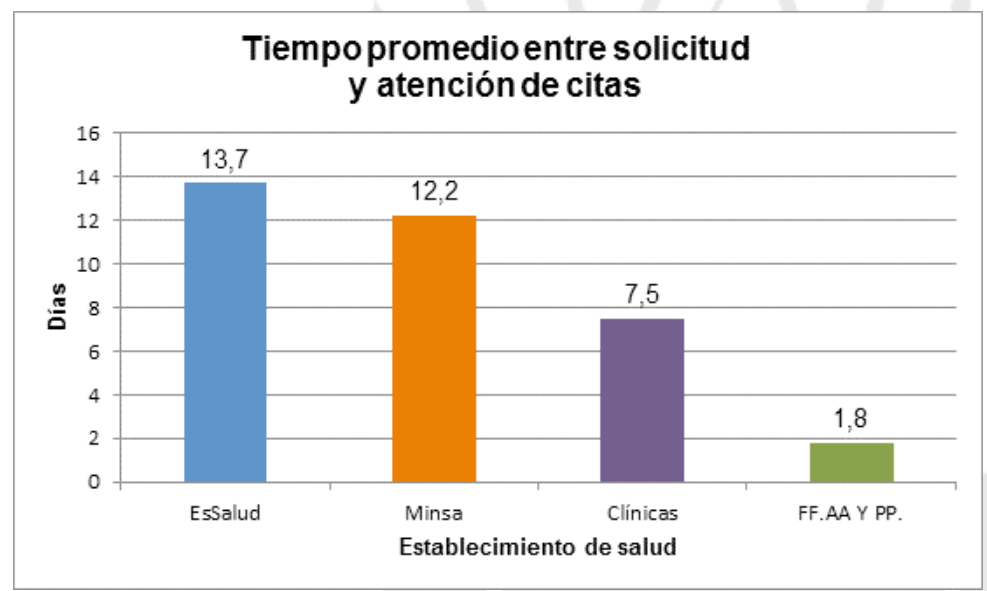

Fuente: SUNASA

Elaboración Sropia

Estas diferencias también se observan en los tiempos de espera en la atención de citas entre los diferentes establecimientos de salud.

Figura 1.5

Tiempo promedio de espera de atención de citas

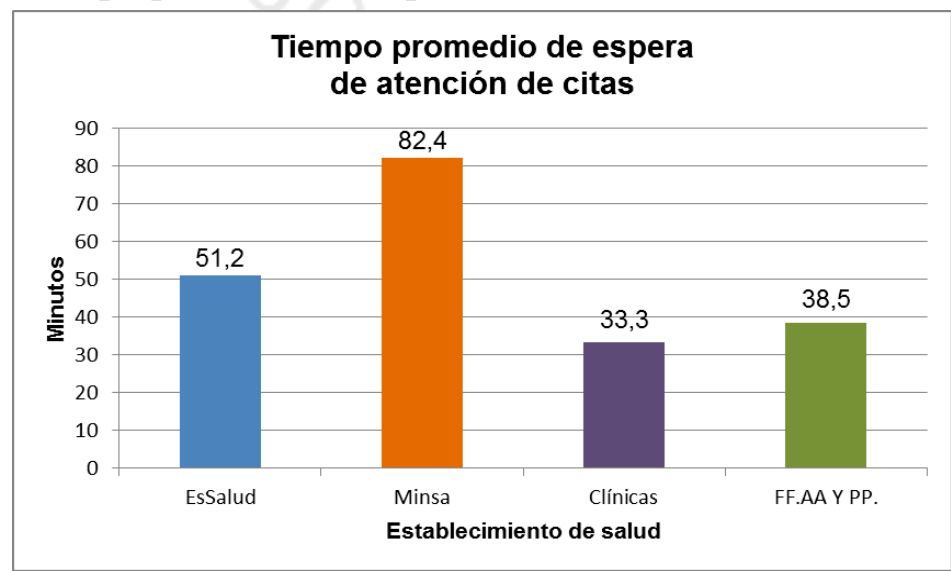

Fuente: SUNASA

Elaboración Sropia 
Por otro lado, en la actualidad la legislación sobre los temas ambientales se desarrollan cada vez más a consecuencia de la preocupación mundial por la ecología y el medio ambiente, existiendo una mayor conciencia ambiental que genera que las empresas adopten compromisos medio ambientales que contribuyan a mejorar el lugar donde se vive evitando su degradación.

Producto de esto, según un artículo periodístico publicado en el diario El Comercio, la empresa Arellano Marketing afirma que "El consumidor peruano está dispuesto a gastar entre un $20 \%$ a $30 \%$ más en empresas que demuestran respetar y cuidar el medio ambiente". 2

Toda la información antes mencionada conlleva a concluir que la población de adultos mayores que requiere de servicios de fisioterapia está en aumento y hay un buen porcentaje de ella que se encuentra insatisfecha con los actuales niveles de servicio que ofrece el mercado, además de existir una arraigada y creciente preocupación por el medio ambiente.

Esto genera una gran oportunidad de negocio en la que se buscará satisfacer las necesidades del público objetivo (adultos mayores) y maximizar la rentabilidad como empresa, al implementar un sistema de gestión ambiental basado en la ecoeficiencia que permitirá ahorrar en recursos y contribuir con la sostenibilidad del medio ambiente.

\subsection{Objetivos de la investigación}

\subsubsection{Objetivo general}

Demostrar la viabilidad técnica, económica y de mercado para la instalación de un centro ecoeficiente de fisioterapia dirigido al adulto mayor en la ciudad de Lima, que

\footnotetext{
${ }^{2}$ Arellano, Rolando. "Sección Negocios" El Comercio. Lima, 29 de setiembre de 2010
} 
contribuya a mejorar la calidad de vida de dichas personas y a la vez favorezca a la sostenibilidad del medio ambiente.

\subsubsection{Objetivos específicos}

- Realizar un estudio de mercado para definir la demanda potencial del proyecto, estableciendo si es viable su puesta en marcha.

- Implementar un plan de ecoeficiencia de gestión ambiental que asegure el cuidado del medio ambiente en nuestros procesos y servicios.

- Evaluar y definir la localización para la instalación del centro.

- Establecer la mejor disposición de planta para la implementación del centro.

- Determinar la cantidad de personal necesario para los servicios de fisioterapia.

- Determinar la inversión y los costos para la instalación del centro.

\subsection{Justificación del tema}

\subsubsection{Técnica}

Existe la tecnología y el personal calificado para implementar un centro de estas características. A la vez se están desarrollando nuevas tecnologías para el tratamiento de lesiones con nuevos equipos de última generación para dichos tratamientos. Por el lado de la ecoeficiencia los avances tecnológicos brindan soluciones eficientes que ayudan a ahorrar recursos haciendo que los procesos sean más eficientes.

\subsubsection{Económica}

Al utilizar planes ecoeficientes en el centro, generará un ahorro de los recursos necesarios para la operación del mismo y por ende un aumento en el margen de 
utilidades de la empresa. Al inicio se incrementarán los costos de implementación de medidas ecoeficientes para los procesos pero a futuro y en el tiempo de vida del negocio se generaría la reducción de dichos recursos haciendo que la empresa sea más rentable.

Stefan Austermühle en su libro "Sostenibilidad y ecoeficiencia en la empresa moderna" brinda un alcance más preciso de cómo alcanzar un nivel de ecoeficiencia aceptable, la cual produzca una mejora económica para la empresa: "Llegar a una mayor ecoeficiencia requiere inversión en renovación tecnológica y en el desarrollo del capital humano de la empresa, lo que generalmente es compensada con los ahorros en su aplicación. Las empresas obtienen estos ahorros directos al disminuir consumos de materias primas y energía, así como ahorros indirectos al disminuir, entre otras cosas, el costo de tratamientos de residuos y emisiones al ser generados en menor cantidad."3

\subsubsection{Social}

La justificación social del presente estudio de investigación radica en la mitigación del impacto ambiental que producirá el uso eficiente de la energía eléctrica y agua alcanzando un desarrollo sostenible en beneficio de las generaciones futuras. "El cambio gerencial hacia una empresa ecoeficiente y más sostenible no es solo un proceso para mejorar el éxito empresarial, sino también una herramienta para un cambio de la sociedad en si misma hacia un futuro más sano con una mayor calidad de vida". 4

Asimismo, se contribuirá a mejorar la calidad de vida de los pacientes (adultos mayores) a través del restablecimiento de las condiciones y capacidades físicas de estas personas inclusive llegando a ser reinsertados nuevamente en la sociedad. Por otro lado se garantiza la generación de nuevos puestos de trabajo en beneficio del área donde se ubicará el proyecto.

${ }^{3}$ Austermühle, Stefan. Sostenibilidad y ecoeficiencia en la empresa moderna. 1 era ed. Lima, Universidad Peruana de Ciencias Aplicadas (UPC), junio de 2012. Pág. 245

${ }^{4}$ Ibídem, pág. $244-245$ 


\subsection{Hipótesis de trabajo}

El presente proyecto es factible debido a que en la ciudad de Lima existe un mercado que va a aceptar los servicios de fisioterapia propuestos pues la población del adulto mayor está creciendo gradualmente y requiere mejorar su calidad de vida mediante una adecuada atención de su salud física, además de existir un mayor interés y disposición en la población a contratar servicios relacionados al cuidado del medio ambiente.

\subsection{Marco referencial de la investigación}

\subsubsection{Marco referencial.}

El tema tratado en el presente trabajo de investigación ha sido desarrollado en trabajos anteriores de seminario de investigación y distintas tesis realizados por alumnos de la Universidad de Lima; sin embargo estos han tenido enfoques diferentes. Dichos trabajos de investigación son los siguientes:

- Calderón Cano, Claudia; Ota Elliott, Ernesto Tsuyoshi. "Estudio preliminar para instalación de un centro de rehabilitación física y entretenimiento para el adulto mayor". Lima 2012

Este estudio se centra en los distintos tipos y métodos de rehabilitación que existen incluyendo un programa de actividades de entretenimiento para el adulto mayor; sin embargo no aborda el tema medio ambiental que en el presente estudio se propone.

- Larrea Cardozo, Arturo Ernesto; Quevedo Chávez, Mariella Alejandra. "Estudio preliminar para la implementación de un centro geriátrico de cuidado de pacientes con demencia senil". Lima 2012 
El concepto de este estudio difiere del propuesto en que se enfoca en la implementación de una instalación residencial de cuidados especializados para el adulto mayor que sufre de demencia senil donde el paciente permanecerá bajo los cuidados de personal capacitado para tratar dicha enfermedad.

- Ramos Quispe, Rosa Angélica; Sáenz Molina, Diego Alfredo. "Estudio preliminar para la implementación de un centro de residencia y atención para adultos mayores de 70 años". Lima 2010

El propósito de este proyecto fue implementar un centro de atención para adultos mayores pero permanente donde las personas son inquilinas del centro hasta que lo deseen. A diferencia de nuestro estudio que se enfoca en la rehabilitación física del adulto mayor.

- Costa López, Leonardo Martín. "Estudio de prefactibilidad para la puesta en marcha de un centro de gimnasia y terapia geriátrica”. Lima 2008

En este trabajo se ha tomado en cuenta un enfoque diferente al presente estudio, puesto que se centra en actividades de recreación para el adulto mayor como Thai chi o canto y dirigidas mayormente a personas sanas.

- Martínez de Pinillos Figueroa, Viviana Marlen; Patiño La Noire, Karina Lisbeth. "Estudio preliminar para la instalación de un ecolodge mediante la utilización de servicios ecoeficientes". Lima 2011

La similitud que presenta este estudio con el que proponemos radica en la utilización de la ecoeficiencia como método para el ahorro de los recursos y el cuidado del medio ambiente generando el desarrollo sostenible en el área de influencia del estudio. 


\subsubsection{Marco conceptual}

Durante el proceso de envejecimiento se producen cambios fisiológicos tanto en el aspecto orgánico como en el mental. Dichos cambios, que son normales, con el paso de los años predisponen a una serie de eventos que conllevan al adulto mayor a presentar variadas enfermedades. "Entre los 30 y los 80 años se pierde un 30\% a 40\% de la masa muscular. Dicha pérdida no es lineal y se acelera con la edad. La fuerza muscular disminuye asimismo con los años, ya que las fibras tipo II (permiten hacer el movimiento rápidos) disminuyen más que las fibras tipo I (mantienen el tono muscular, la postura, musculo del cuello, pelvis, etc.) y las unidades motoras reducen su densidad". 5

Esta información obtenida fue contrastada con la entrevista realizada al Tecnólogo Médico Lic. Rubén Silva Bazán CTMP 8586, en la cual nos recalcaba la condición del adulto mayor respecto a su salud física; concluyendo que en esta edad, los adultos mayores están más propensos a sufrir lesiones y enfermedades que requieran rehabilitación. "Con el aumento de la edad se pierde la masa ósea lo que conlleva a que la persona; en su etapa de adultez, sufra enfermedades ligadas al sistema musculo esquelético. La relación de las enfermedades óseas; como la osteoporosis, con las lesiones musculares radica en que al debilitarse los huesos por la disminución de calcio en el tejido óseo, se produce una inestabilidad en la inserción muscular aumentando la probabilidad de dichas lesiones musculares". 6

Tomando en cuenta esto, la ciencia que mejor se adecúa a aliviar y mejorar los problemas físicos surgidos en la tercera edad es la Fisioterapia. Según el "Segundo Informe del comité de expertos de la OMS en Rehabilitación Médica" reunidos en Ginebra en 1969 define la fisioterapia como: "Arte y ciencia del tratamiento físico por medio de la gimnasia reeducativa, el calor, el frío, la luz, el masaje y la electricidad; entre los objetivos del tratamiento figuran el alivio del dolor, el aumento de la

${ }^{5}$ Escuela de Medicina Pontificia Universidad Católica de Chile. "Algunos Cambios Asociados al envejecimiento". Boletín Vol. 29, Nro. 1-2. Dpto. de Medicina Interna.

$<$ http://escuela.med.puc.cl/publ/boletin/geriatria/algunoscambios.html $>$

${ }^{6}$ Silva Bazán, Rubén. Tecnólogo Medico CTMP 8586. [Fecha de la entrevista: 7 de abril de 2014] 
circulación, la prevención y corrección de incapacidades y la recuperación máxima de la fuerza, la movilidad y la coordinación"”7

Los efectos positivos de la fisioterapia en ancianos incluyen tanto beneficios físicos como psicológicos. Muchas veces las personas de la tercera edad encuentran en ella una actividad diferente, que las ayuda a salir de su rutina e interactúan fuera de su círculo habitual. Esto establece una motivación importante, lo que aumenta su autoestima y les otorga la vitalidad que muchas veces necesitan.

Respecto a la ecoeficiencia esta se define como: "Una filosofía administrativa que impulsa a las empresas a buscar mejoras ambientales, paralelamente con los beneficios económicos. Se enfoca en la oportunidades de negocios, y permite a las empresas ser más responsables ambientalmente y más rentables" 8

La Comisión Mundial sobre Medio Ambiente y Desarrollo (World Business Council for Sustainable Development) atribuye la importancia de la ecoeficiencia en: "Proporcionar bienes y servicios a un precio competitivo que satisfaga las necesidades humanas y la calidad de vida, al tiempo que reduzca progresivamente el impacto ambiental y la intensidad de la utilización de los recursos a lo largo del ciclo de vida, hasta un nivel compatible con la capacidad de carga estimada del planeta"

Surge aquí el concepto de desarrollo sostenible el cual sustenta la tesis de un desarrollo de tal manera que no se agoten los recursos que requieren las generaciones futuras para vivir con la misma calidad de vida que se tiene actualmente.

Para esto muchas empresas adoptan la ecoeficiencia como nuevo enfoque logrando generar ahorro en sus procesos, así como otros beneficios; Lorena Muro,

\footnotetext{
${ }^{7}$ Segundo Informe del comité de expertos de la OMS en Rehabilitación Medica. Ginebra 1969. $<$ http://whqlibdoc.who.int/trs/who_trs_419_spa.pdf $>$

${ }^{8}$ Austermühle, Stefan. Sostenibilidad y ecoeficiencia en la empresa moderna. $1 \mathrm{era}$ ed. Lima, Universidad Peruana de Ciencias Aplicadas (UPC), junio de 2012. Pág. 243

9 Gutiérrez Divizia Víctor. "La ecoeficiencia y su impacto en el medio ambiente". Revista PAIDEIA XXI. Vol. 2, N³. Diciembre 2012.
} 
directora de operaciones del Council on Green para América Latina en su artículo "Empresas ecoeficientes son el nuevo enfoque de productividad" comenta: "Las empresas con operaciones ecoeficientes obtienen grandes beneficios como generar más ingresos, crear nichos de mercado, reducir costos de operación y proyectar una mejor imagen entre otros."

\subsection{Análisis del sector}

Los servicios de fisioterapia y rehabilitación física están adscritos al sector salud que a su vez se divide en el sector público y privado. Dentro del sector privado se encuentran las Entidades Prestadoras de Servicios (EPS), las aseguradoras privadas, las clínicas privadas especializadas y no especializadas, los centros médicos y consultorios médicos.

En los últimos años este sector viene creciendo a ritmo constante y con proyección a seguir haciéndolo, según un artículo denominado "A todo pulmón, el crecimiento del sector salud y del aseguramiento" del diario Gestión; ellos afirman que: "Estamos de acuerdo en que el sector salud ha aumentado, se mantiene en una dinámica de cambio y de mayor competitividad. El mercado de salud en el Perú en el 2013 fue de US\$ 10,000 millones y desde el año 2010, viene creciendo a un ritmo de 18\%. El sector privado es el principal motor y está propulsado por el incremento de la capacidad adquisitiva de la población y la mayor penetración de seguros"11

Dentro de todo este panorama se observa un crecimiento en el sector salud y sobretodo en los servicios para el adulto mayor: "Cada vez crece más la demanda por servicios de cuidado para el adulto mayor, dentro y fuera de casa. Cada vez más gente vive más y llega a una avanzada edad en mejor estado. Hay, además, toda una

\footnotetext{
${ }^{10}$ Empresas ecoeficientes son el nuevo enfoque de productividad. "Empresas y Negocios". Año 12, N 564. Feb 2013. Pág. 23

11 "A todo pulmón, el crecimiento del sector salud y del aseguramiento" Diario Gestión. Lima, 24 de agosto del 2014
} 
oportunidad de consolidación del mercado hospitalario y de cadenas de consultorios especializados en cirugía plástica, odontología, etc." ${ }^{\prime 2}$

En conclusión se observa un gran dinamismo en el sector salud (incluyendo los servicios de rehabilitación física) con proyección a seguir creciendo, haciendo énfasis en aquellos servicios dirigidos al adulto mayor.

\subsubsection{Análisis de las cinco fuerzas del sector}

\subsubsection{Poder de negociación de los compradores o clientes}

Los servicios de fisioterapia tienen una amplia gama de especialidades, por lo que existe poca probabilidad de que los compradores puedan ejercer un gran poder de negociación sobre este sector. Sin embargo, al tratarse servicios con frecuencia de prestación, sí son sensibles en cuanto a la calidad, puesto que si los clientes no ven resultados en mediano plazo cambian de centro de atención.

Dicho esto, se puede afirmar que los clientes exigen servicios de calidad en lo que respecta a servicios de fisioterapia sobre todo en el segmento al que se busca atender, el adulto mayor. Asimismo, existe cierta fidelidad a un centro de atención, sobre todo si se trata de un centro amigable con el medio ambiente, pero esto no quiere decir que no haya sensibilidad al cambio por parte de los clientes. Se concluye entonces que esta fuerza es media.

\subsubsection{Poder de negociación de proveedores o vendedores}

Existe una alta oferta en el mercado local de los equipos y suministros requeridos para la instalación del centro y la prestación de los servicios de fisioterapia;

\footnotetext{
${ }^{12}$ Westreicher H. Guillermo. "Banca y salud son los sectores más atractivos para la inversión de las grandes empresas”. Diario Gestión. Lima, 19 de enero del 2015.
} 
sin embargo, al ser un centro que recién se instalará la demanda de equipos y suministros será baja y los precios que se logren negociar con los proveedores no necesariamente serán los mejores. Se concluye entonces que el poder de negociación de proveedores es alto.

\subsubsection{Amenaza de nuevos entrantes}

El sector de servicios de fisioterapia presenta una amplia gama de especialidades y público objetivo, lo que conlleva a que no existan grandes barreras de ingreso de nuevos competidores con propuestas de servicios innovadores y tecnología moderna. Por tal motivo, se puede afirmar que la amenaza de nuevos entrantes en el sector de servicios de fisioterapia para adultos mayores es alta.

\subsubsection{Amenaza de productos sustitutos}

Los servicios de fisioterapia para adultos mayores pueden ser sustituidos por otros servicios como la acupuntura, moxibustión, reflexología, quiropráctica, entre otros, que son considerados como técnicas de medicina alternativa que alivian temporalmente las dolencias de los pacientes. Asimismo, existen productos farmacéuticos como parches para el dolor, pomadas, pastillas, entre otros que los pacientes se podrían automedicar, pero al igual que el caso anterior solo alivian los malestares o dolencias temporalmente. Por lo tanto, se puede afirmar que la amenaza de productos sustitutos es media.

\subsubsection{Rivalidad entre competidores}

El sector de servicios de fisioterapia presenta un gran número de competidores, quiénes no presentan mayor diferenciación en los servicios ofrecidos pues la tecnología utilizada generalmente es la misma. Sin embargo, esto no quiere decir que algún competidor pueda implementar nueva tecnología o técnicas de tratamiento, pero la 
probabilidad de que esto ocurra es baja. Dicho esto, se puede afirmar que la rivalidad entre competidores es alta.

\subsubsection{FODA}

\subsubsection{Fortalezas}

- Centro especializado en la rehabilitación física del adulto mayor.

- Médicos terapeutas con experiencia y altamente capacitados.

- Tecnología médica en terapia física de última generación.

- Reducción de costos de operación al contar con un sistema de gestión ambiental basado en la ecoeficiencia.

- Proyección de una buena imagen empresarial proporcionada por nuestra cultura medio ambiental.

\subsubsection{Debilidades}

- Alta inversión en la implementación y puesta en marcha del proyecto.

- Dependencia de proveedores extranjeros para la adquisición de máquinas y equipos modernos.

- Alta inversión en estrategias de marketing y publicidad.

- Alta rotación del personal fisioterapeuta.

\subsubsection{Oportunidades}

- Aumento de la población adulto mayor en la ciudad de Lima con proyección al crecimiento. 
- Innovación en el sector salud en cuanto a la tecnología utilizada para la mejora del sistema músculo-esquelético de los pacientes.

- Tiempos de espera prolongados para la consulta y atención en los establecimientos de salud.

- Aumento de la preocupación por el ecosistema y el despertar de la conciencia medio ambiental.

- Facilidad de obtención de créditos bancarios.

- Política gubernamental inclusiva interesada en la atención a personas con discapacidades físicas.

\subsubsection{Amenazas}

- Ingreso de nuevos centros de rehabilitación física orientados a una cultura ecoeficiente.

- Servicios sustitutos con buena acogida en el mercado nacional.

- Estancamiento de la economía peruana.

- Crisis económica internacional. 


\section{CAPÍTULO II: ESTUDIO DE MERCADO}

\subsection{Aspectos generales del estudio de mercado}

\subsubsection{Definición del servicio}

El servicio que la presente investigación propone consiste en la prestación de servicios de fisioterapia en un centro ecoeficiente, cuyo objetivo principal es mejorar la calidad de vida del adulto mayor de la ciudad de Lima a través de un equipo de fisioterapeutas especializados en las diferentes áreas de la rehabilitación física y manejo del dolor, que garantizarán una atención de calidad y un alto nivel de servicio. Todo esto estará respaldado mediante el uso de avanzada tecnología y modernas instalaciones ecoeficientes.

Figura 2.1

Fisioterapia en el adulto mayor

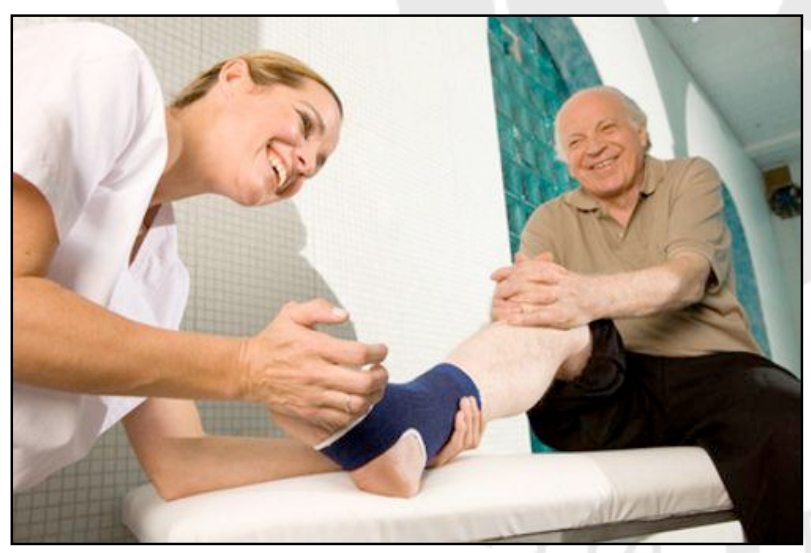

Fuente: Body Healing Fisioterapia

La optimización de la eficiencia de las instalaciones del proyecto se realizará a través de la implementación de un plan de manejo ambiental basado en la ecoeficiencia, lo cual contribuirá a que la empresa sea más rentable y al desarrollo sostenible y mitigación del impacto ambiental en el área de influencia del proyecto, a la vez que se genera conciencia ambiental entre los pacientes, sus familiares y público en general. 


\subsubsection{Principales características del servicio}

\subsubsection{Posición arancelaria NANDINA, CIIU}

El servicio objeto de estudio de la presente investigación no posee posición arancelaria debido a que dicha codificación solo aplica para mercancías (bienes materiales) que son importadas desde otros países hacia el Perú.

Por otro lado, la Clasificación Industrial Internacional Uniforme (CIIU), según la cuarta revisión de la Clasificación Industrial Internacional Uniforme de todas las actividades económicas (CIIU Revisión 4), establece que el servicio de la presente investigación corresponde a:

Sección Q: Actividades de atención de la salud humana y de asistencia social

División 86: Actividades de atención de la salud humana

Grupo 869: Otras actividades de atención de la salud humana

Clase 8690: Esta clase comprende las actividades de atención de la salud humana que no se realizan en hospitales ni entrañan la participación de médicos ni de odontólogos: actividades de enfermeros, parteras, fisioterapeutas y otro personal paramédico especializado en optometría, hidroterapia, masaje terapéutico, ergoterapia, logoterapia, podología, homeopatía, quiropráctica, acupuntura, etcétera. ${ }^{13}$

\subsubsection{Usos y características del servicio}

Los servicios de fisioterapia son prestados para restablecer la función física y la movilidad de los pacientes, atenuar al máximo dolores musculares, mejorar su estado

\footnotetext{
${ }^{13}$ Dirección Nacional de Cuentas Nacionales - INEI. “Clasificación Industrial Internacional Uniforme de todas las actividades económicas" (Revisión 4)"
} 
psicológico y aumentar su fuerza y resistencia. Todo esto con el fin de reincorporarlos lo más pronto y en las mejores condiciones a sus actividades de la vida diaria.

Dado que el público objetivo del proyecto es el adulto mayor de la ciudad de Lima el uso de los servicios de fisioterapia se puede considerar como frecuente.

El servicio se iniciará con una evaluación global del paciente para después establecer planes de tratamiento individualizados, comprometiéndolo a participar activamente en su recuperación, tanto a él como a sus familias.

El servicio contemplará programas de rehabilitación física cuyo objetivo será tratar los trastornos y lesiones que afectan al sistema músculo-esquelético de los adultos mayores como la artrosis, artritis, osteoporosis. Además de enfermedades como hemiplejias, parálisis de nervios, distrofias musculares, neuralgias y trastornos del movimiento como parkinson y esclerosis múltiple.

Por otro lado las terapias que se ejecutarán consistirán en la utilización de masajes, corriente eléctrica controlada, vibraciones sonoras de alta frecuencia, calor como medio terapéutico, trabajos dentro del agua, entre otros.

Las instalaciones donde se llevarán a cabo los servicios de rehabilitación física, serán ecoeficientes y ello implica el uso de materiales de construcción de bajo impacto ambiental, utilización de equipos de bajo consumo energético, implementación de planes de manejo de residuos sólidos y de reutilización de agua así como la instalación de áreas verdes.

Se ofrecerá un mejor nivel de servicio para las atenciones mediante una óptima programación de citas que ayudará a reducir los tiempos de espera de atención de citas llevado a cabo por el área de servicio al cliente, el cual desarrollará canales de atención telefónicos, chat on line, entre otros. 
Adicionalmente se ofrecerá el servicio de transporte para pacientes que requieran ser trasladados al centro debido a su grave condición física.

\subsubsection{Servicios sustitutos y complementarios}

Los servicios de fisioterapia para adultos mayores pueden ser sustituidos por otros servicios como la moxibustión, reflexología, acupuntura, quiropráctica, entre otros, los cuales alivian temporalmente las dolencias de los pacientes. Asimismo, existen productos farmacéuticos como parches para el dolor, pomadas, pastillas, entre otros que los pacientes se podrían automedicar.

A continuación una breve descripción de los servicios sustitutos antes mencionados:

\section{Huesero}

Es una práctica antigua conocida como un oficio que se enfoca en la atención a fracturas, luxaciones, esguinces y dolores musculares. Dichas personas adquieren el conocimiento de forma empírica lo que no garantiza el tratamiento adecuado para las personas que sufren lesiones musculares.

\section{Quiropractica o Quiropraxia}

Es un tipo de medicina alternativa la cual se ocupa del diagnóstico, tratamiento y prevención de las alteraciones del sistema músculo-esquelético donde se utilizan manipulaciones manuales especialmente en la columna vertebral logrando el mejoramiento del cuerpo y la movilidad necesaria para una vida normal. 


\section{Acupuntura}

La acupuntura es una técnica de medicina tradicional china que consiste en la estimulación de determinados puntos del cuerpo y el sistema nervioso mediante la inserción de agujas, con el fin de aliviar el dolor, equilibrar la energía vital y regularizar el sistema nervioso.

\section{Moxibustión}

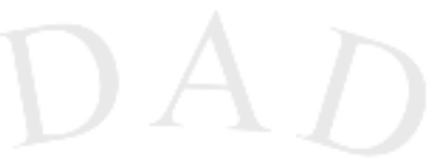

La moxibustión es una técnica de la medicina tradicional china complementaria a la acupuntura que utiliza el calor de la planta "artemisa" para sanar; dicha técnica utiliza las hojas de la artemisa que, una vez secas, se muelen y su polvo en incandescencia alcanza los 500 y 600 grados centígrados aplicándose sobre los puntos de acupuntura. La artemisa tiene la propiedad de ser analgésica y antiinflamatoria aliviando los dolores articulares como la artrosis o la artritis y las dolencias originadas por el frío, como la rigidez lumbar.

\section{Reflexología}

La reflexología es un tipo de terapia manual basada en ejercer presión mediante "digitopuntura" en determinados puntos del cuerpo llamados zonas reflejo, que están energéticamente enlazados con los órganos internos, buscando un efecto benéfico sobre otras partes del cuerpo, y de mejora en la salud general.

Respecto a los servicios complementarios las ecografías son muy empleadas en este sector con la finalidad de realizar tanto una evaluación inicial como final del estado del paciente, buscando un diagnóstico que permita desarrollar el tratamiento de rehabilitación óptimo en beneficio de su recuperación. La ecografía es un procedimiento de diagnóstico que se realiza a los tejidos blandos como los músculos, tendones y ligamentos. Las tomografías también son utilizadas pero no muy 
frecuentemente; si bien es cierto que utilizan rayos " $X$ " para obtener imágenes radiográficas del interior del organismo en caso de traumatismos o fracturas mayormente se utilizan para diagnosticar lesiones de los órganos internos, tumores, infecciones, entre otras patologías.

\subsubsection{Definición del área de influencia del servicio}

El proyecto se desarrollará en el área geográfica de Lima Metropolitana, en donde se estima una población de 9.740 .410 habitantes al 2014. Dicha cifra incluye la zona urbana de los 43 distritos de la provincia de Lima (8.743.955 habitantes) y los 6 distritos de la Provincia Constitucional del Callao (996.455 habitantes). ${ }^{14}$

Se seleccionó dicha área geográfica por ser la de mayor población del adulto mayor en el Perú y por su gran dinamismo económico.

Figura 2.2

Departamentos del Perú con la más alta población adulto mayor

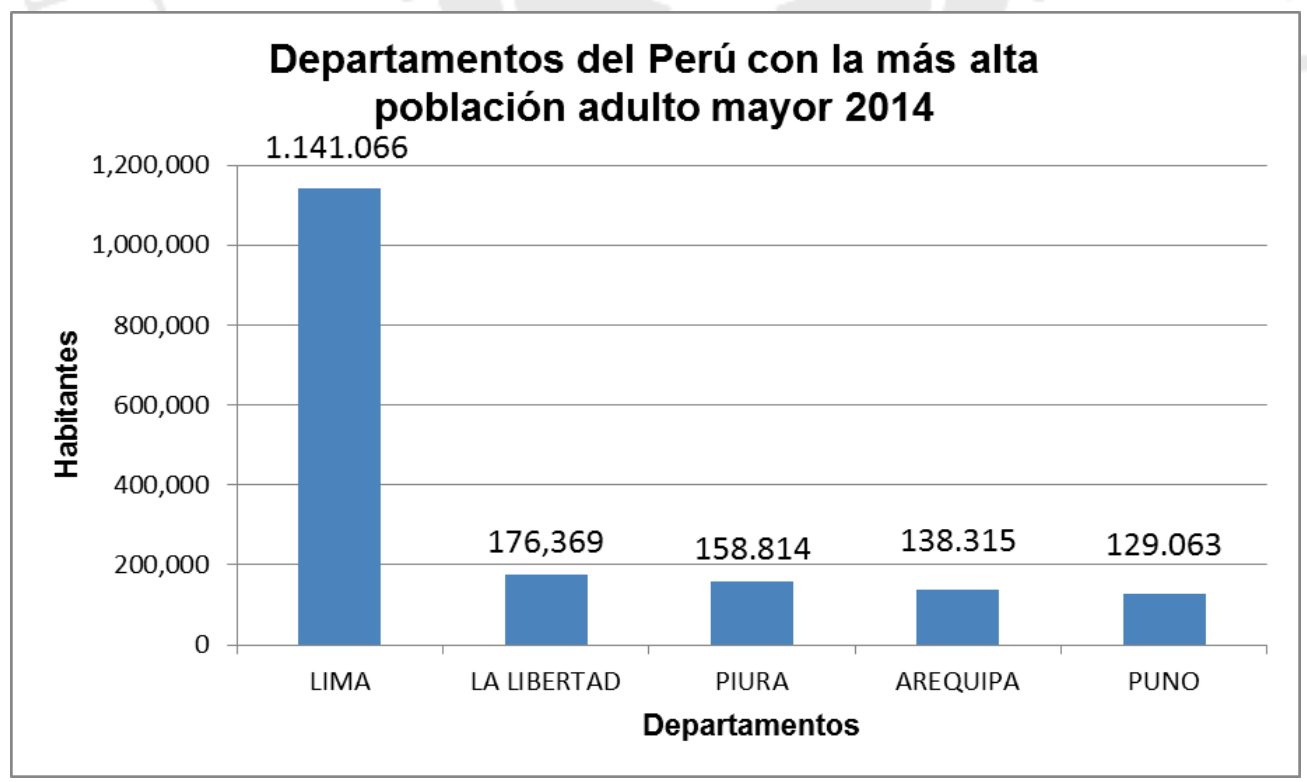

Fuente: INEI

Elaboración Sropia

\footnotetext{
${ }^{14}$ Ipsos Perú. Estadística Poblacional 2014
} 


\subsubsection{Determinación de la metodología que se empleará en el estudio de mercado}

La metodología a utilizar será la aplicación de una encuesta exploratoria con la finalidad de determinar el grado de aceptación de un centro especializado de rehabilitación física ecoeficiente que satisfaga a los adultos mayores que posean alguna dolencia muscular.

Asimismo se requiere evaluar también el grado de satisfacción de los adultos mayores y sus familiares respecto a los actuales centros de rehabilitación a los cuales acuden para realizar su tratamiento. La frecuencia de atención y los costos por los que están dispuestos a pagar también son parte de este estudio. Se realizará también dos entrevistas a expertos fisioterapeutas colegiados por el Colegio de Tecnólogos Médicos del Perú con la finalidad de obtener de primera mano el funcionamiento de un centro de rehabilitación física, las principales características del servicio, las principales técnicas utilizadas y toda la experiencia vivencial entre los pacientes y el fisioterapeuta.

Además se revisarán las siguientes fuentes primarias como secundarias: "Perfil del Adulto Mayor 2014" de Ipsos Marketing, estadísticas del Instituto Nacional de Rehabilitación (INR), datos de estadística poblacional del INEI, "Encuesta de satisfacción de usuarios de la Superintendencia Nacional de Aseguramiento en Salud" (SUNASA), entre otras.

Con la finalidad de realizar la encuesta es necesario determinar la muestra a utilizar. Se tomará la siguiente formula estadística de población infinita puesto que la población a evaluar será mayor a 100.000 elementos:

Fórmula de Muestreo para población infinita

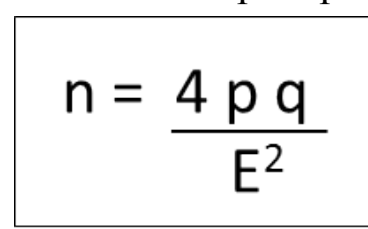

Dónde:

n: Tamaño de la muestra

p: Probabilidad de ocurrencia

q: Probabilidad de no ocurrencia

E: Error muestral 
Para realizar el muestreo es necesario hacer una prueba piloto con la finalidad de hallar la probabilidad de ocurrencia (p y q) por lo que se realizó una sola pregunta de carácter dicotómico a 40 personas, la pregunta que se realizó fue la siguiente: “¿Estaría dispuesto a atenderse o llevar a sus familiares a un centro de rehabilitación física especializado en la atención al adulto mayor con políticas y planes de manejo ambiental?"

Los resultados se muestran a continuación:

\begin{tabular}{|c|c|}
\hline SI: 37 & NO: 3 \\
\hline Porcentaje: $90 \%$ & Porcentaje: $10 \%$ \\
\hline
\end{tabular}

Siendo:

Con los datos obtenidos se halla la muestra:

$$
\begin{aligned}
& \text { p: } 0.9 \\
& \text { q: } 0.1 \\
& \text { E: } 0.05
\end{aligned}
$$

$$
n=\frac{4(0.9)(0.1)}{(0.05)^{2}}=111 \text { encuestas }
$$

Finalmente se obtiene que el tamaño de la muestra es de 111 encuestas a realizar.

\subsection{Análisis de la demanda}

\subsubsection{Cuantificación de los posibles mercados objetivo}

Para los servicios de fisioterapia se tiene como posibles mercados objetivos a la población de Lima Metropolitana según sus grupos de edades. 
Figura 2.3

Población de Lima Metropolitana según grupo de edades

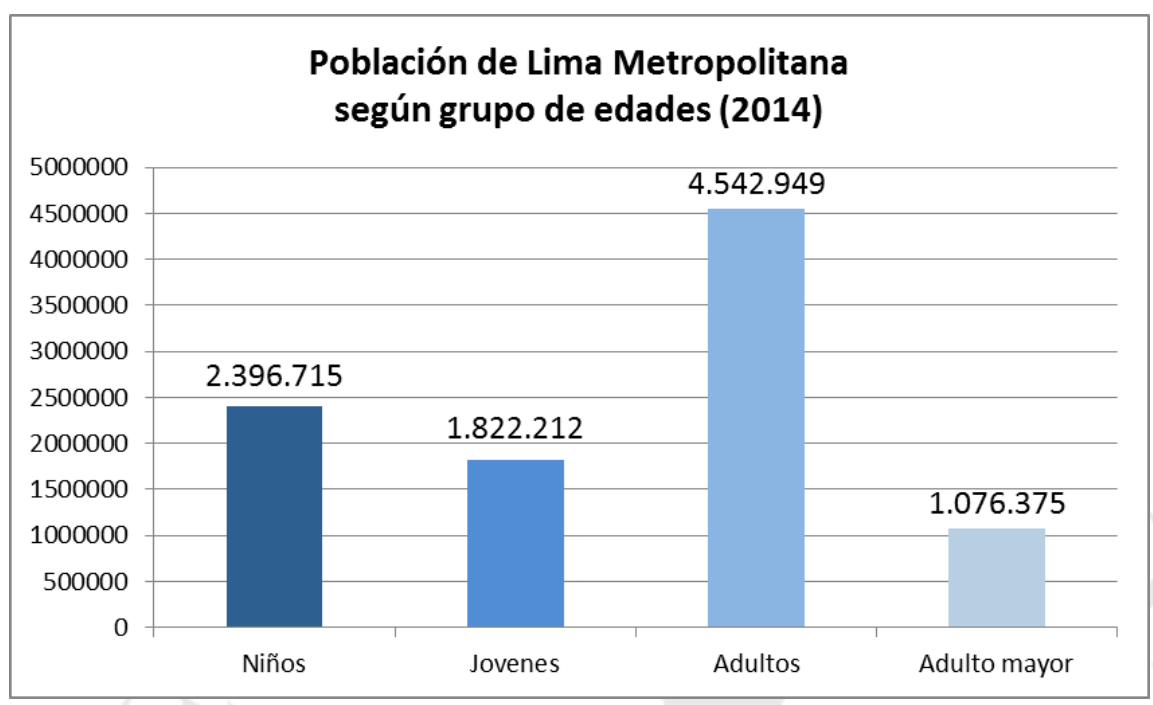

Fuente: INEI

Elaboración Sropia

Figura 2.4

Porcentaje de la población de Lima Metropolitana según grupo de edades

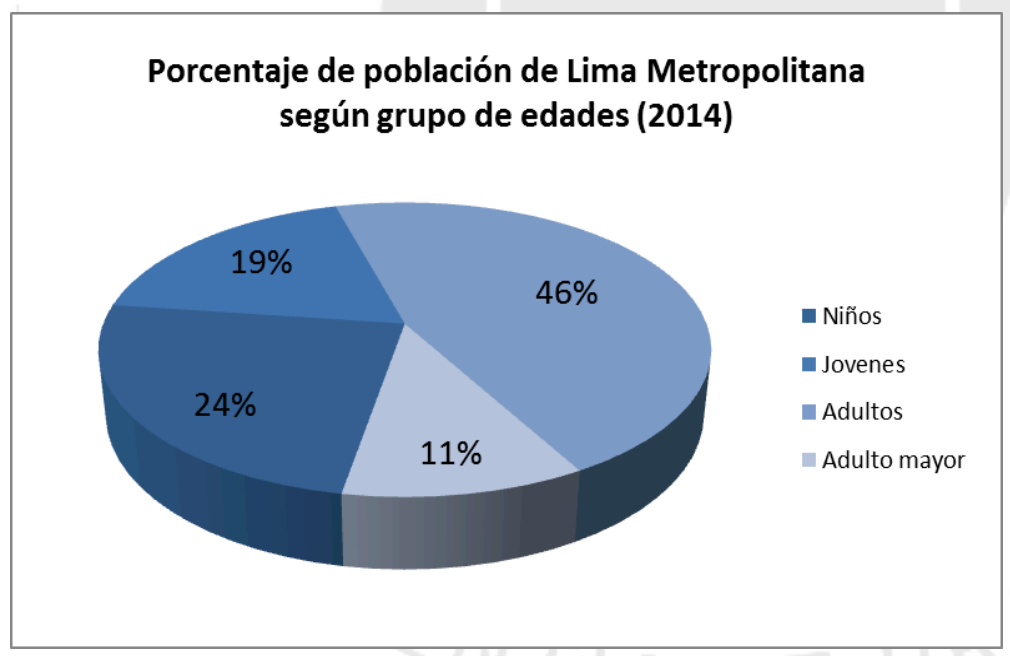

Fuente: INEI

Elaboración Sropia

El presente proyecto estará dirigido a personas con edades a partir de los 60 años denominados adultos mayores los que representan el 11\% de la población de Lima Metropolitana. Los principales motivos de dicha elección se deben a que ésta población se encuentra en pleno crecimiento (ver figura 1.1), representan un mercado más fiel y constante por la recurrencia de las enfermedades musculo-esqueléticas y son más propensos a sufrir lesiones físicas por su misma edad. 


\subsubsection{Demanda potencial}

\subsubsection{Patrones de consumo del servicio}

Los patrones de consumo a tomar en cuenta para conocer mejor el perfil del adulto mayor que hace uso de los servicios de rehabilitación física son: penetración de mercado, principales gastos, lugares más frecuentes de compra, frecuencia de compra y lealtad de marca.

\section{Penetración de mercado}

Se tomará como referencia el estudio acerca del "Análisis de la demanda y el acceso a los servicios de salud" (2011) del Ministerio de Salud, donde se muestra que la población de adultos mayores que busca atención de salud en el Perú es de 57,5\%. Por este motivo se considera que la penetración de mercado del servicio se aproxima a este porcentaje.

Figura 2.5

Penetración de mercado de los servicios de salud en el Perú

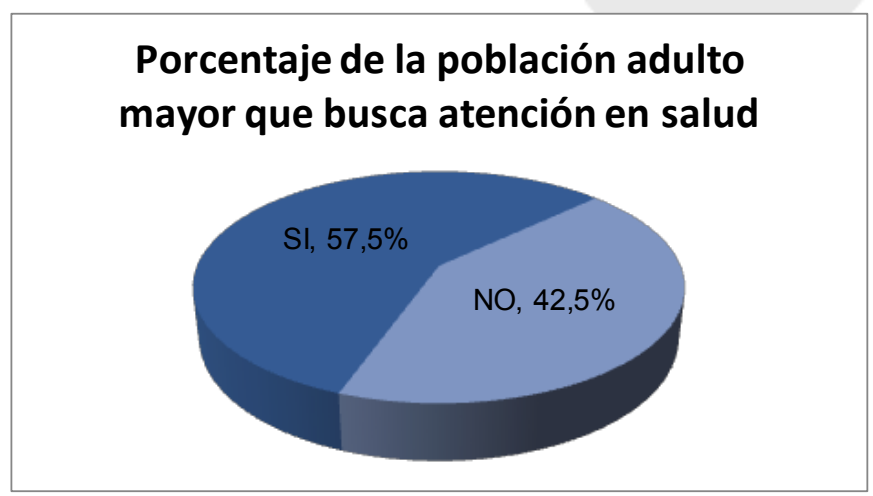

Fuente: MINSA

Elaboración Sropia.

A un nivel más regional, según el "Perfil del adulto mayor" de Ipsos Marketing 2014, se afirma que el 39\% de los adultos mayores de Lima Metropolitana sufre alguna 
dolencia que requiere de los diversos servicios de salud que existen. Por este motivo se puede considerar que la penetración de mercado del servicio en Lima Metropolitana se aproxima a este porcentaje.

Figura 2.6

Penetración de mercado de los servicios de salud en Lima Metropolitana

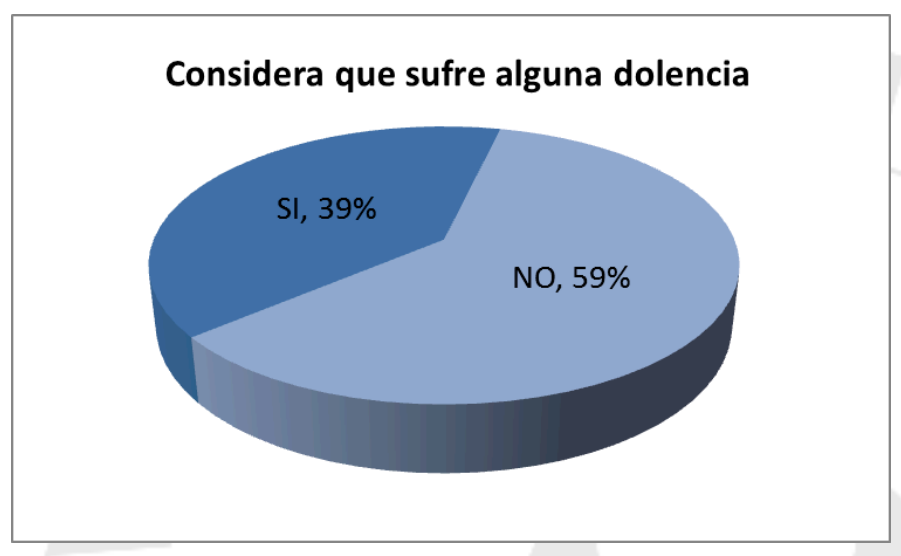

Fuente: Ipsos Marketing. Elaboración Sropia.

\section{Principales gastos}

Los principales gastos en los que incurren los adultos mayores son los concernientes a aquellos que se refieren al hogar y a su cuidado personal, tales como alimentación, gastos de la casa referidas a pagos de luz, agua, teléfono, entre otros; cuidado y aseo personal, medicinas y transporte.

A continuación se presenta la información referida a la utilización del dinero que realizan los adultos mayores según el "Perfil del adulto mayor 2014" en Lima Metropolitana: 
Tabla 2.1

Principales gastos del adulto mayor

\begin{tabular}{|l|c|}
\hline Comida en el hogar & $84 \%$ \\
\hline Gastos de la casa (luz, agua, telef.) & $57 \%$ \\
\hline Cuidado y aseo personal & $51 \%$ \\
\hline Medicinas & $45 \%$ \\
\hline Transporte & $38 \%$ \\
\hline Ropa y calzado & $38 \%$ \\
\hline
\end{tabular}

Fuente: Ipsos Marketing. Elaboración Sropia.

\section{Lugares de compra más frecuente}

Los problemas de salud de los adultos mayores son atendidos mayormente en los establecimientos de ESSALUD con un 43\% y el Ministerio de Salud (MINSA) que ascienden a un $36 \%$, un porcentaje menor acude a las clínicas privadas y consultorios particulares (17\%) como se muestra a continuación.

Figura 2.7

Asistencia del adulto mayor a centros de salud en Lima Metropolitana

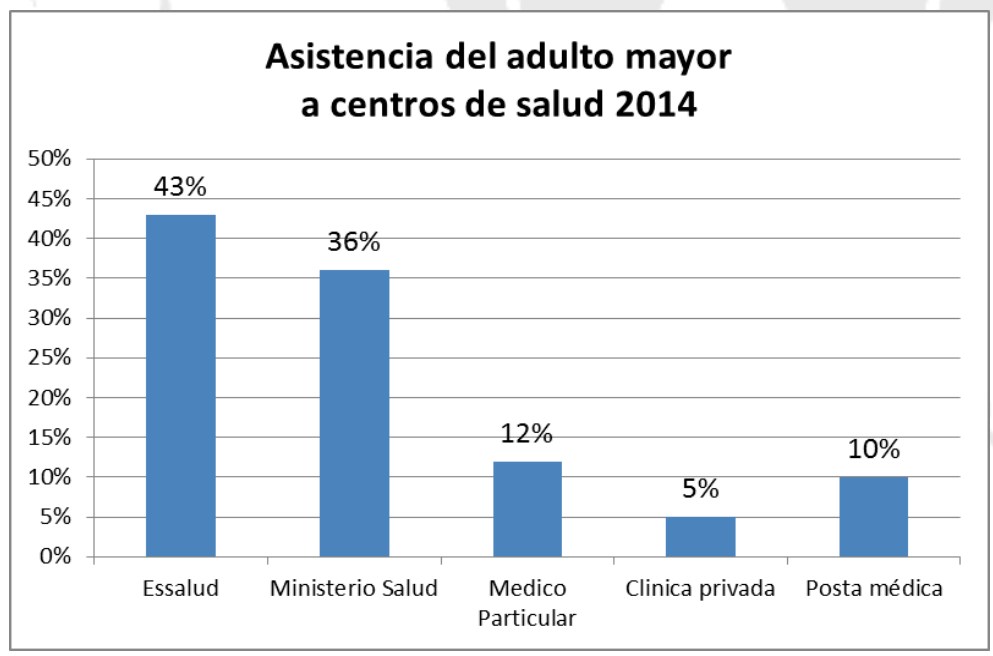

Fuente: Ipsos Marketing.

Elaboración Sropia. 


\section{Frecuencia de compra}

Según el "Perfil del adulto mayor" de Lima Metropolitana, las personas mayores de 60 años acuden en su mayoría ocasionalmente a chequeos médicos o por enfermedades a los diferentes centros de salud que se encuentran en la capital. El 26\% asiste una vez al mes a los servicios de salud ofertados; un 34\% visita dichos centros ocasionalmente y el 19\% acude una o dos veces al año.

Figura 2.8

Frecuencia de asistencia del adulto mayor a centros de salud en Lima Metropolitana

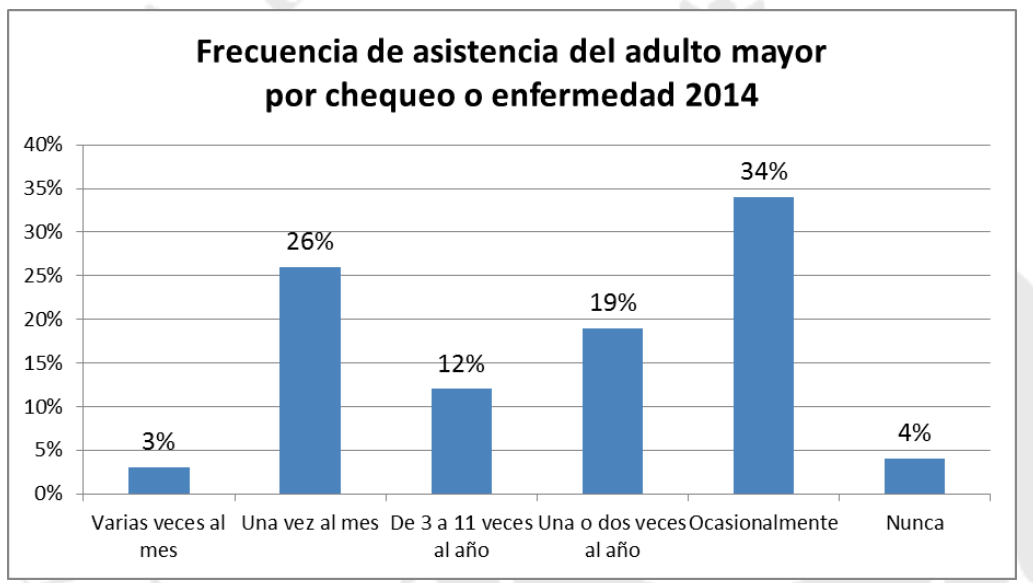

Fuente: Ipsos Marketing. Elaboración Sropia.

\section{Lealtad de marca}

Como se mencionó anteriormente, al tratarse de servicios con frecuencia de prestación, estos son sensibles en cuanto a la calidad, puesto que si los clientes no ven resultados en mediano plazo cambian de centro de atención. Sin embargo, el adulto mayor es una persona de alta resistencia al cambio y al tratarse algún problema físico y quedar satisfecho por la calidad y resultados del mismo tiende a permanecer en el mismo lugar. 
Según Arellano Marketing, se debe identificar quiénes son las personas que participan en las decisiones de compra de sus productos. Una vez detectado esto, se deberán elaborar propuestas que sean beneficiosas para todos ellos.

Figura 2.9

El Cliente: Personas claves en una compra

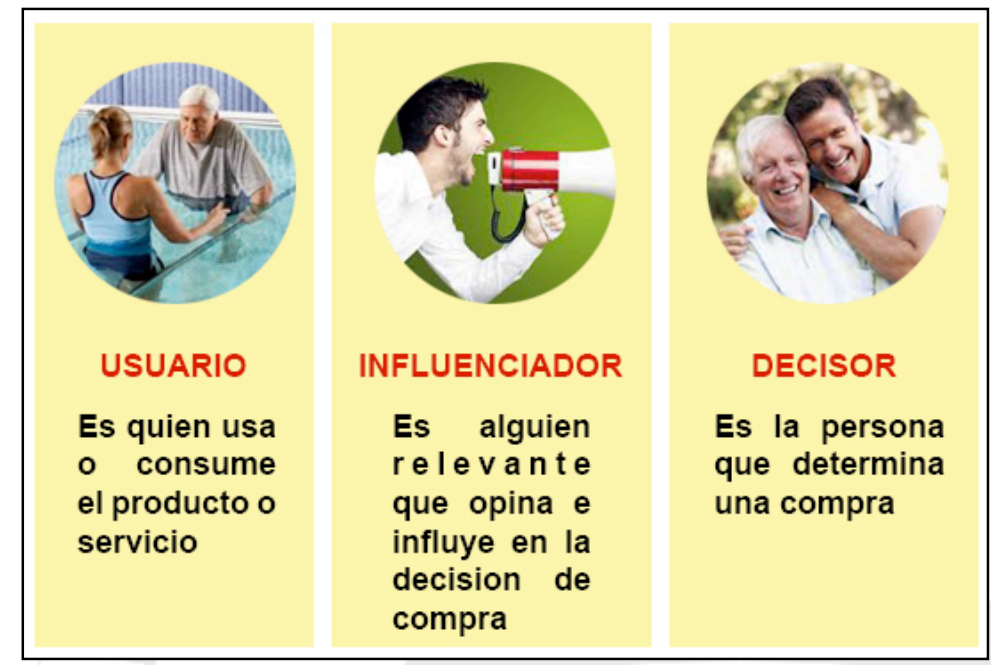

Fuente: Diario Peru21

Elaboración Sropia

En el presente proyecto, los usuarios del servicio son los adultos mayores pero los decisores de compra en algunos casos son los adultos mayores y en otros los familiares de los cuales dependen. Por tal motivo todos los esfuerzos de marketing estarán dirigidos tanto a los adultos mayores como a sus hijos y familiares más cercanos que influyan y decidan en la adquisición del servicio.

\subsubsection{Aplicación de estudios cualitativos y cuantitativos}

Se realizaron dos estudios, uno cuantitativo el cual consistió en una encuesta (ver anexo 1) realizada a los adultos mayores y personas que posean familiares mayores de 60 años con la finalidad de determinar el grado de aceptación de un centro especializado de rehabilitación física ecoeficiente que satisfaga a los adultos mayores que posean alguna dolencia muscular y el grado de satisfacción de los actuales centros, entre otros aspectos. 
El otro estudio fue cualitativo donde se realizaron dos entrevistas a expertos fisioterapeutas colegiados a fin de obtener las principales características del servicio haciendo énfasis en los tratamientos al adulto mayor, las principales técnicas utilizadas y toda la experiencia vivencial entre los pacientes y el fisioterapeuta.

A continuación se presentan los resultados de la encuesta:

- El 92\% de los encuestados afirmó tener más de 60 años o algún familiar adulto mayor.

Figura 2.10

Porcentaje de encuestados adultos mayores o con algún familiar mayor a 60 años

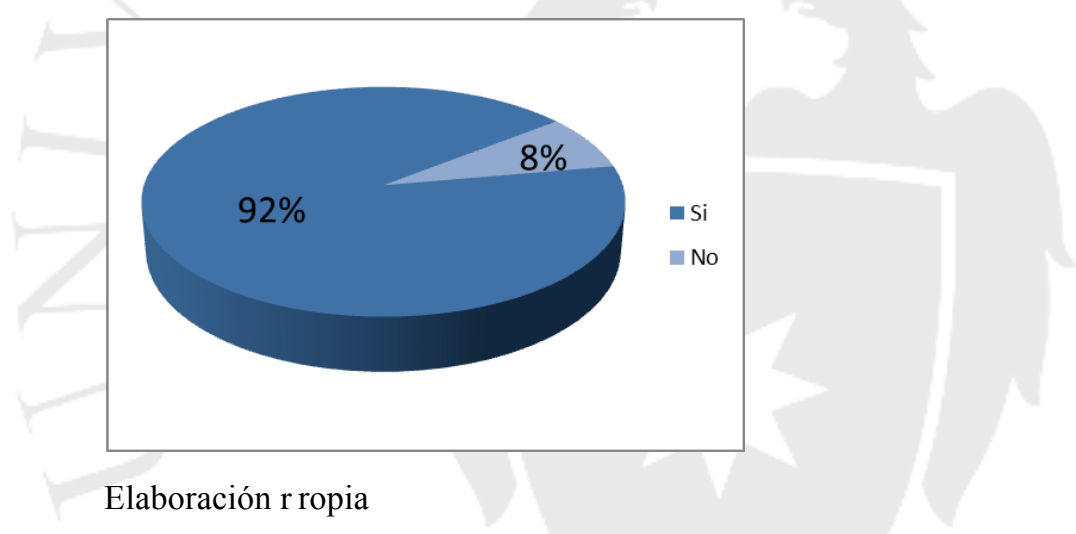

- El $62 \%$ de los encuestados refirió tener algún problema muscular o tener algún familiar adulto mayor con algún problema muscular que requiera rehabilitación física. 
Figura 2.11

Porcentaje de encuestados con problemas musculares que requieren rehabilitación física

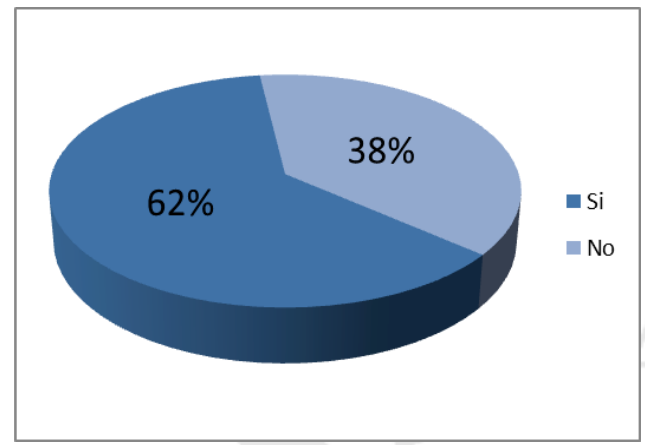

Elaboración Sropia

- El $70 \%$ de los encuestados se encuentra actualmente o ha tomado en algún momento los servicios de rehabilitación física.

\section{Figura 2.12}

Porcentaje de encuestados que han tomado en algún momento los servicios de rehabilitación física

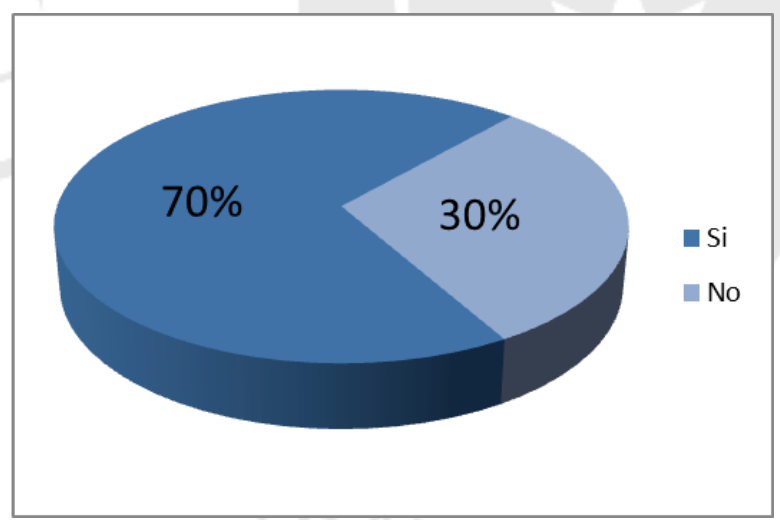

Elaboración Sropia

- La mayoría de los encuestados acude a las clínicas y centros especializados en rehabilitación física para llevar a cabo sus tratamientos de recuperación con un porcentaje que asciende a $55 \%$ en total. El 24\% acude a hospitales y un $20 \%$ utiliza los servicios de fisioterapeutas independientes. 
Figura 2.13

Lugares donde acuden por los servicios de rehabilitación física

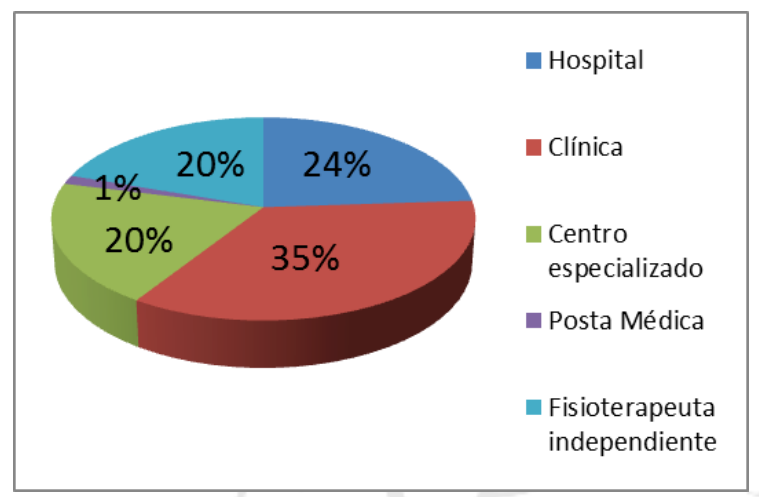

Elaboración Sropia

- La mayoría de los encuestados acude a los centros de rehabilitación física con una frecuencia de "3 veces por semana" lo cual asciende a un 44\%. El 14\% lo hace semanalmente y el $13 \%$ realiza sus terapias " 2 veces por semana". Solo el $10 \%$ acude a sus rehabilitaciones "quincenalmente". Realizando el cálculo del promedio ponderado; éste da como resultado que los encuestados acuden a los centros de rehabilitación física 2 veces por semana.

Figura 2.14

Frecuencia de uso de los servicios de rehabilitación física

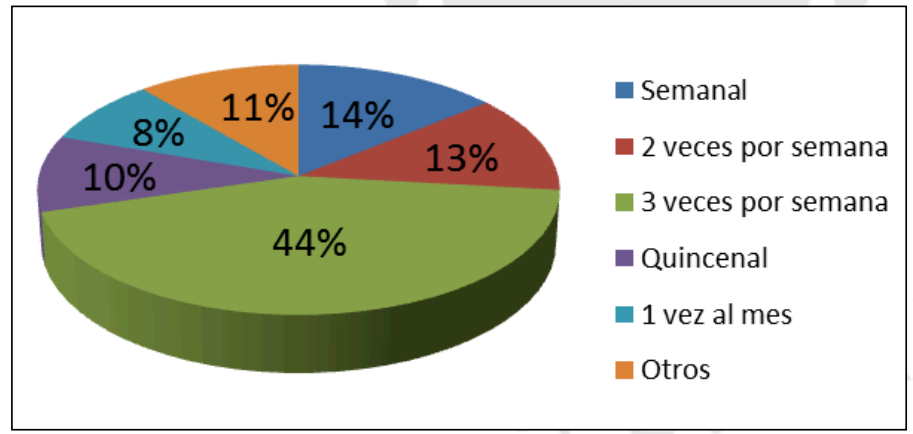

Elaboración Sropia

- El pago que realizan los encuestados por una sesión de rehabilitación física en su mayoría está en el rango de "menos de $\mathrm{S} / .30$ " con un $37 \%$ empero existe un 55\% que paga por una sesión de rehabilitación "entre S/. 40 y S/. 60"; es decir paga más por dicha sesión. Solo el 11\% de los encuestados paga más de S/.60. 
Figura 2.15

Pago por sesión de rehabilitación física

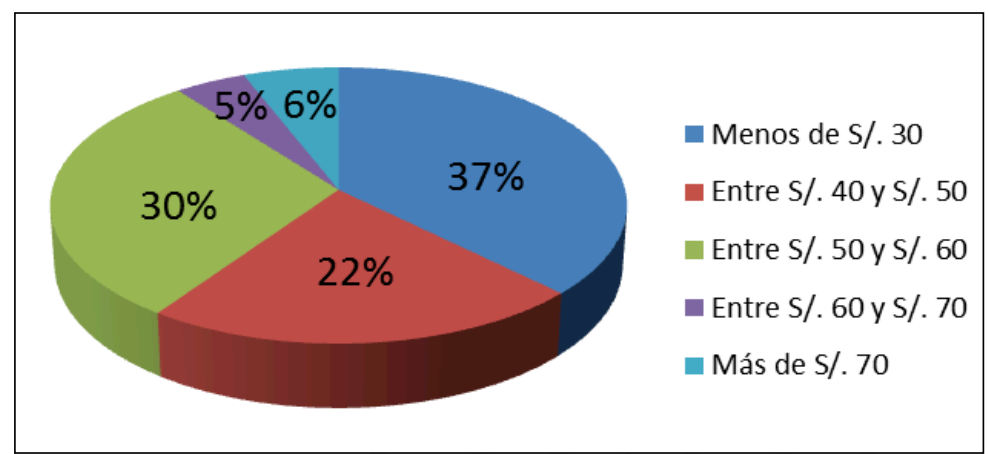

Elaboración Sropia

- Se observa que la mayoría de encuestados $(70 \%)$ utiliza algún seguro para tomar los servicios de rehabilitación física, el $26 \%$ utiliza el seguro social de salud y el $25 \%$ hace uso de su seguro particular, solo el 19\% utiliza las empresas prestadoras de salud EPS. El 30\% de los encuestados que asiste a sus terapias de rehabilitación no utiliza seguro.

Figura 2.16

Tipo de seguro que utiliza

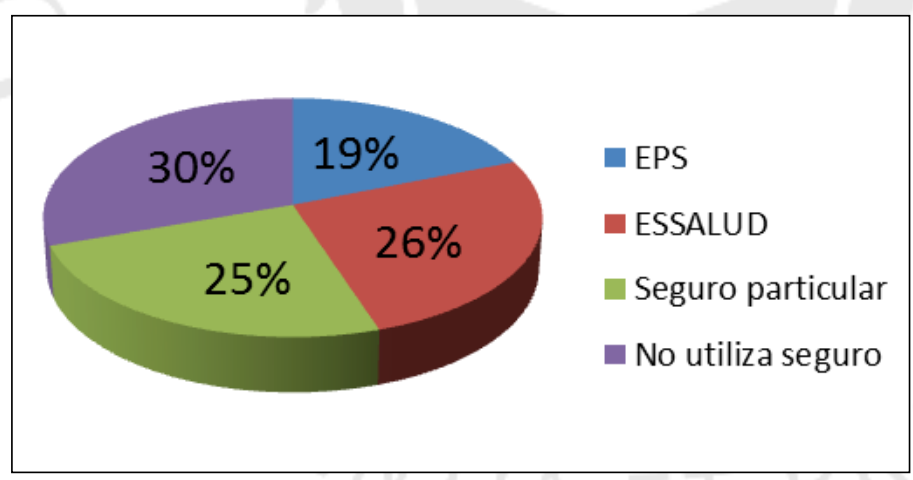

Elaboración Sropia

- La gran mayoría de los encuestados; el $82 \%$, considera a los centros de rehabilitación física donde reciben sus terapias como "buenos" o "muy buenos", solo el $16 \%$ considera que el centro al cual acude es "regular", ningún encuestado lo consideró "malo" pero si el $2 \%$ lo considera "muy malo". 
Figura 2.17

Como considera los servicios de rehabilitación física donde se atiende

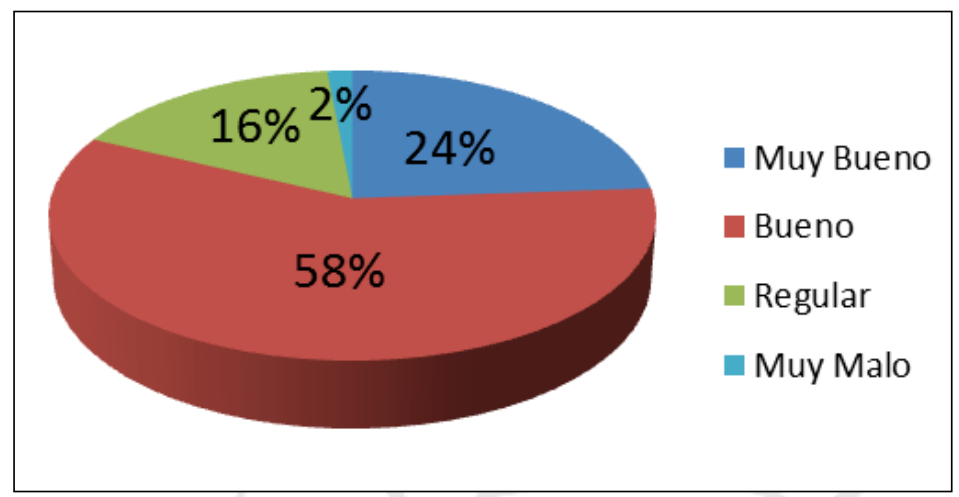

Elaboración Sropia

- El atributo que es considerado como el más importante al adquirir los servicios de rehabilitación física según la encuesta realizada es el "Prestigio del fisioterapeuta" lo que conlleva a recibir un servicio de calidad en la atención de los pacientes. El atributo de la "Tecnología" ocupa el segundo lugar en cuanto a importancia; la "Disponibilidad de atención" en tercer lugar y la "Comodidad de las instalaciones" le sigue en este orden; finalmente la "Ubicación" está considerada en el quinto lugar de importancia y el atributo "Precio" no es considerado como importante quedando ubicado en el último lugar.

\section{Tabla 2.2}

Importancia de los atributos en los centros de rehabilitación física

\begin{tabular}{|l|r|r|r|r|r|r|}
\hline ATRIBUTOS & $\mathbf{1}$ & $\mathbf{2}$ & $\mathbf{3}$ & $\mathbf{4}$ & $\mathbf{5}$ & \multicolumn{1}{c|}{$\mathbf{6}$} \\
\hline Prestigio del fisioterapeuta & $40,0 \%$ & $20,0 \%$ & $4,6 \%$ & $9,2 \%$ & $10,8 \%$ & $15,4 \%$ \\
\hline Disponibilidad de atención & $12,3 \%$ & $15,4 \%$ & $32,3 \%$ & $24,6 \%$ & $6,2 \%$ & $9,2 \%$ \\
\hline Ubicación & $15,4 \%$ & $15,4 \%$ & $15,4 \%$ & $10,8 \%$ & $24,6 \%$ & $18,5 \%$ \\
\hline Comodidad de instalaciones & $6,2 \%$ & $15,4 \%$ & $18,5 \%$ & $26,2 \%$ & $26,2 \%$ & $7,7 \%$ \\
\hline Tecnología & $15,4 \%$ & $26,2 \%$ & $20,0 \%$ & $15,4 \%$ & $12,3 \%$ & $10,8 \%$ \\
\hline Precio & $10,8 \%$ & $7,7 \%$ & $9,2 \%$ & $13,9 \%$ & $20,0 \%$ & $38,5 \%$ \\
\hline
\end{tabular}

Elaboración Sropia

- Sobre la cantidad de encuestados que estarían dispuestos a atenderse o llevar a sus familiares a un centro de rehabilitación física especializado en la atención al adulto mayor con políticas y planes de manejo medio ambiental; la investigación 
señala que el $97 \%$ acudiría a dicho centro lo que consideramos como casi la totalidad de los encuestados.

Figura 2.18

Porcentaje de encuestados que acudirían a un centro de rehabilitación física ecoeficiente

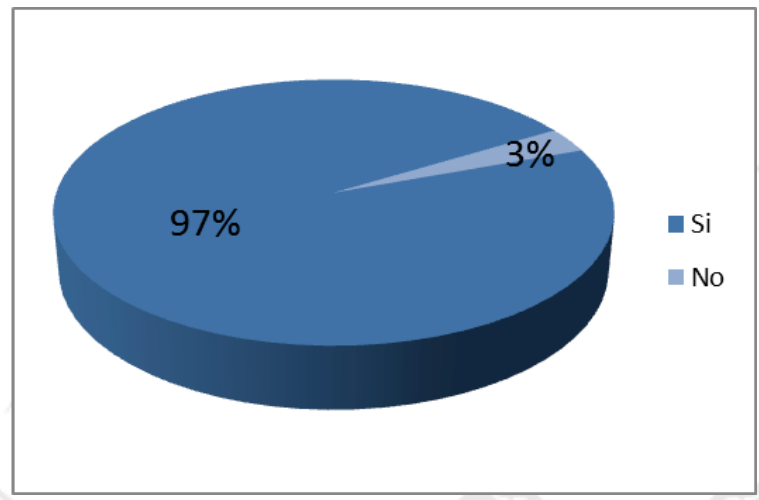

Elaboración Sropia

- Finalmente el promedio de escala de intensidad de la intención de compra después del análisis es 70\%.

En conclusión según la encuesta se observa que existe un gran número de personas adultas mayores o con familiares mayores de 60 años que requieren los servicios de rehabilitación física (62\%), esta información contrastada con la de la "Encuesta de salud y bienestar del adulto mayor 2012" del MIDIS donde los adultos mayores que sufren de enfermedades musculares asciende al 57\%, se observa que tienen una gran aproximación en los resultados.

El $82 \%$ de los encuestados considera que los centros de rehabilitación física donde se atienden son "buenos" o "muy buenos" con lo que se concluye que la mayoría está satisfecha con los servicios que se les brinda.

La mayoría de los encuestados acude a las clínicas y centros especializados en rehabilitación física para llevar a cabo sus tratamientos de recuperación con un 
porcentaje que asciende a 55\%, asisten 2 veces por semana en promedio, el $70 \%$ utiliza algún tipo de seguro y gastan en promedio S/. 50 .

Es importante destacar que al ofrecer los servicios de rehabilitación física se tenga en cuenta los atributos más importantes; según la encuesta realizada el "Prestigio del fisioterapeuta" y la "Tecnología", son los aspectos más importantes a tener en cuenta para la implementación del centro. Por otro lado el lugar donde se instale el centro y el precio por el cual se pague no juegan un papel preponderante ya que se trata de la salud de los adultos mayores, la mayoría padres de familia.

La intención de compra o en nuestro caso la intención de atenderse o llevar a sus familiares a un centro de rehabilitación física especializado en la atención al adulto mayor con políticas y planes de manejo medio ambiental es de $97 \%$ y el promedio de escala de intensidad de la intención de compra es $70 \%$. Corrigiendo la intención de compra con este dato, el resultado de la demanda susceptible a ser captada por el proyecto será de $68 \%$.

En cuanto a los principales hallazgos recogidos por la entrevista realizada a dos expertos fisioterapeutas, presentamos lo siguiente:

1. Los adultos mayores están más propensos a sufrir lesiones musculares por un problema de tipo articular, las articulaciones se van desgastando y deformando, lo que conlleva a que el paciente tenga problemas de dolor o debilidad muscular.

2. El gran problema de los adultos mayores son las enfermedades reumáticas, como son la artrosis, la artritis y estas no tienen cura, son enfermedades progresivas, empiezan y van complicándose con el tiempo. Otro problema que deriva del mismo desgaste óseo es la osteoporosis y por ende son propensos a las fracturas que necesitaran definitivamente de terapia física. 
3. Los tiempos de recuperación en los adultos mayores comparados con el de otros grupos es relativo y depende mucho de su organismo, las lesiones que tengan y de su estilo de vida.

4. No existen diferencias en los tratamientos tanto para los adultos como para los adultos mayores. La diferencia radica mucho más en los antecedentes de las enfermedades del paciente que en la edad.

5. Existe una relación estrecha entre el fisioterapeuta y los familiares del adulto mayor básicamente en la de informar cuales son los pasos de su recuperación y cómo evoluciona su enfermedad a lo largo del tratamiento, a la vez de proporcionar el apoyo necesario tanto en las terapias realizadas en el centro como en el domicilio.

6. En todos los centro de rehabilitación física se procede en primer lugar a realizar una evaluación terapéutica con un médico especialista ya sea un médico fisiatra o un tecnólogo médico para después proceder con la terapia.

7. En promedio se recomienda de 7 a 10 sesiones para recuperar una lesión de tipo músculo-esquelética con una frecuencia de 3 veces por semana.

8. Los métodos utilizados para el tratamiento de los adultos mayores con lesiones físicas son los mismos utilizados para las terapias en general, estas son: la laserterapia que se emplea para regenerar el tejido y en otros casos desinflamar; la magnetoterapia, la cual mejora la calidad ósea y la recuperación del tejido óseo en una fractura; la masoterapia que consiste en masajes terapéuticos que ayudan a liberar el tejido muscular; la kinesioterapia emplea ejercicios para movilizar músculos y ganar rango articular; la electroterapia, es aplicar corriente controlada como analgésico para aliviar el dolor; la ultrasonoterapia la cual genera sonido en intensidad tan alta que va a producir un masaje interno dentro del músculo removiendo las adherencias que se forman entre tejido y tejido; y la termoterapia donde se emplean las compresas frías y calientes para disminuir contracturas musculares. En cuanto a las nuevas tecnologías se presenta un nuevo método llamado ondas de choque que acelera el proceso de recuperación del paciente. 
9. La idea de la instalación de un centro de fisioterapia ecoeficiente especializado para el adulto mayor es considerada por el entrevistado como un "plus" para la empresa en cuanto a su economía, y a la vez aportaría al cuidado del medio ambiente.

10. La gran mayoría de los pacientes llega a un centro médico especializados por las recomendaciones que haya recibido, referidas al trato y la atención.

\subsubsection{Determinación de la demanda potencial}

El presente proyecto está dirigido a la población adulto mayor de Lima Metropolitana del nivel socioeconómico "A" que asciende al 7,2\% y que requiere de los servicios de rehabilitación física. Este requerimiento parte de las diferentes enfermedades de tipo musculo-esqueléticas que presentan los adultos mayores y los distintos niveles de discapacidad que poseen.

Se sabe que los adultos mayores presentan enfermedades crónicas en huesos y músculos producidos por el desgaste de los mismos a consecuencia de su misma edad y por ende necesitan de los servicios de rehabilitación física.

Según los resultados de la "Encuesta de Salud y Bienestar del Adulto Mayor 2012" del Ministerio de Desarrollo e Inclusión Social (MIDIS) las enfermedades crónicas más recurrentes en los adultos mayores son la artrosis/reumatismo, hipertensión y la osteoporosis, las cuales afectan al 39\%, 30\% y 18\% de adultos mayores respectivamente, entre otras enfermedades. 
Figura 2.19

Porcentaje de adultos mayores con enfermedades crónicas según género

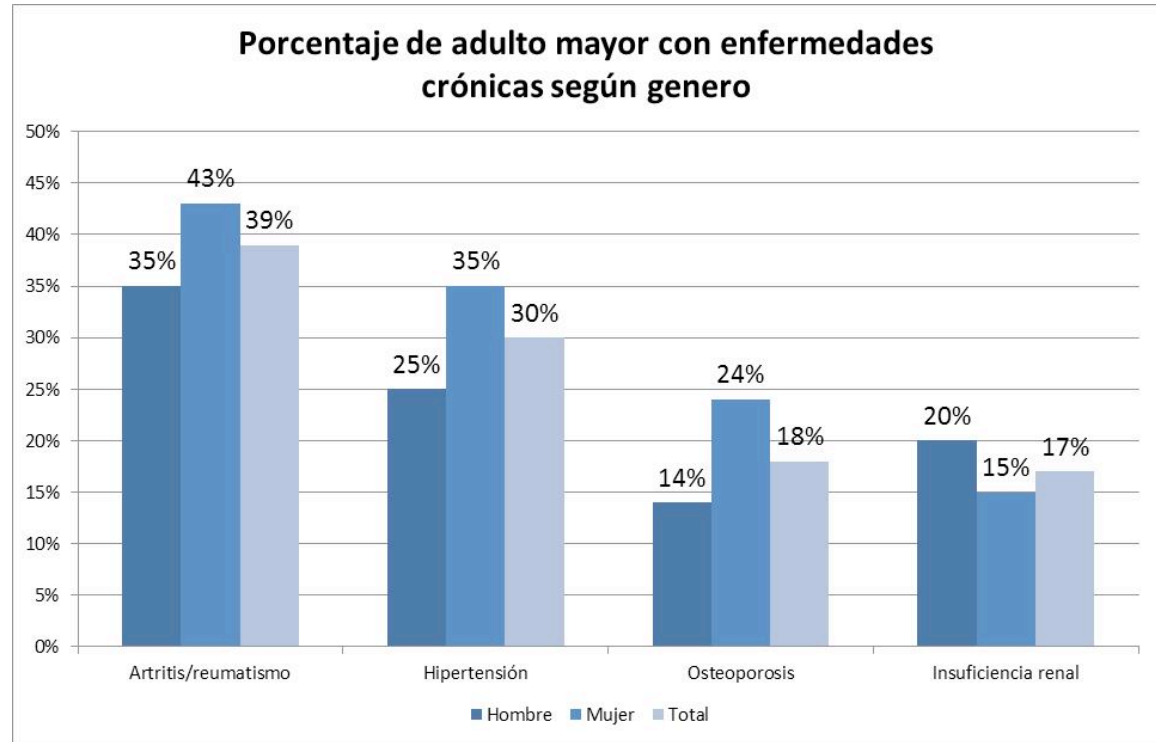

Fuente: Ministerio de Desarrollo e Inclusión Social Elaboración Sropia

Por otro lado, se indagó sobre el nivel y acceso al tratamiento médico que los adultos mayores tienen, teniéndose en promedio que sólo un $50 \%$ de adultos mayores recibe tratamiento a la enfermedad que padece.

Figura 2.20

Porcentaje de adultos mayores con enfermedades crónicas en tratamiento

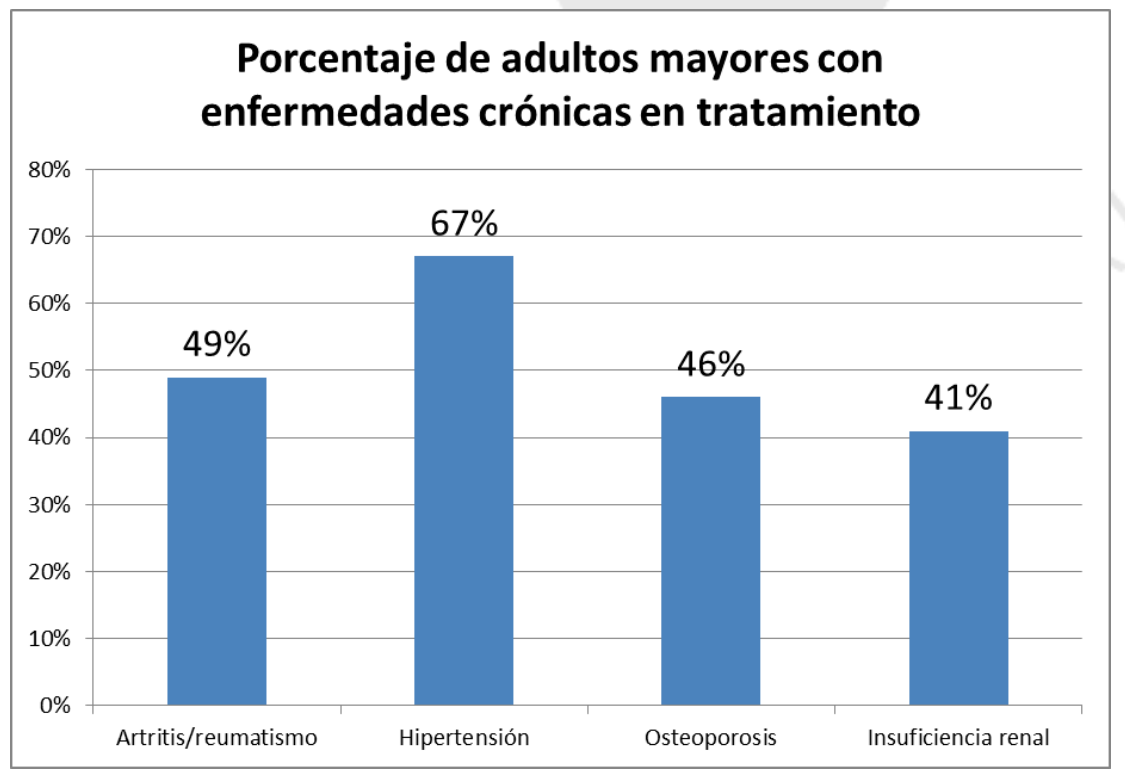

Fuente: Ministerio de Desarrollo e Inclusión Social Elaboración Sropia 
Respecto al tipo de discapacidad que reportan los adultos mayores observamos que el $8 \%$ posee discapacidad en el uso de brazos y piernas.

Figura 2.21

Tipo de discapacidad que reportan los adultos mayores

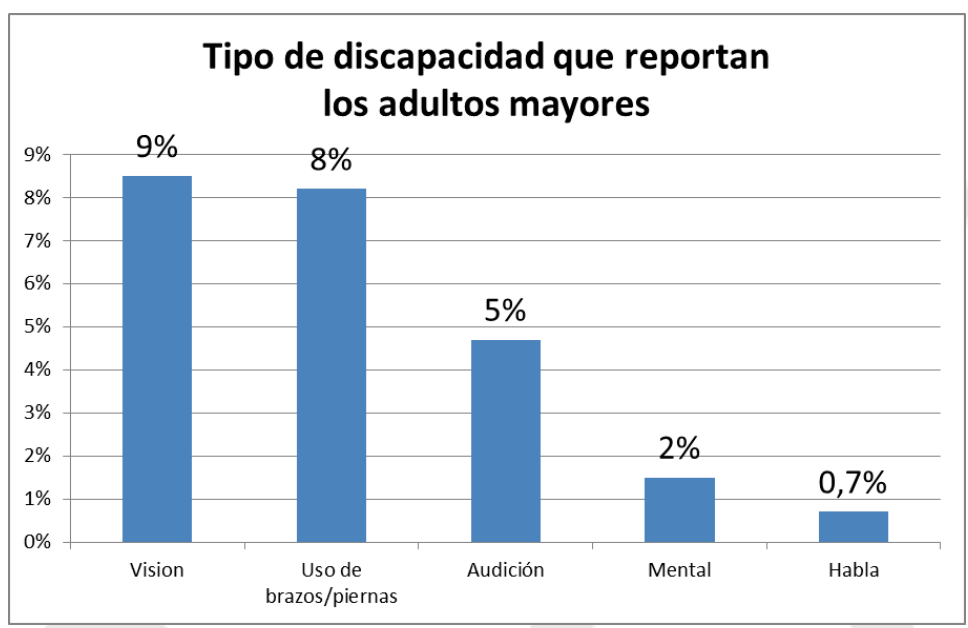

Fuente: Ministerio de Desarrollo e Inclusión Social Elaboración Sropia

Para hallar la demanda potencial se tomará la población total de adultos mayores de Lima metropolitana para luego obtener la demanda con los parámetros descritos anteriormente; así tenemos:

La población total de adultos mayores en Lima metropolitana en el 2012 asciende a 1.052.924 habitantes; el 7,2\% de dicha población, es decir 75.811 adultos mayores pertenecen al nivel socioeconómico “A”. Se sabe que el 57\% de la población adulto mayor sufre de artritis/reumatismo y osteoporosis lo que nos da como resultado 43.212 adultos mayores que sufren de estas enfermedades. De estos, solo el 47,5\% de adultos mayores recibe tratamiento lo que asciende a 20.526 habitantes.

Por otro lado solo el $8 \%$ de los adultos mayores del nivel socioeconómico "A" posee discapacidad en el uso de brazos y piernas (6.065 hab.) y en promedio el $50 \%{ }^{15}$ recurre a tratamiento por lo que resulta 3.032 adultos mayores.

${ }^{15}$ Encuesta de Salud y Bienestar del Adulto Mayor 2012 - Ministerio de Desarrollo e Inclusión Social 
Finalmente la demanda potencial para el año 2012 es de 23.558 adultos mayores y utilizando la tasa de crecimiento poblacional se hallará la demanda potencial para el año 2015

Tabla 2.3

Tasa anual de crecimiento poblacional - INEI

\begin{tabular}{|c|c|}
\hline \multicolumn{2}{|c|}{$\begin{array}{c}\text { Tasa anual de } \\
\text { crecimiento poblacional }\end{array}$} \\
\hline 2012 & $1,13 \%$ \\
\hline 2013 & $1,13 \%$ \\
\hline 2014 & $1,11 \%$ \\
\hline 2015 & $1,10 \%$ \\
\hline
\end{tabular}

Fuente: INEI

Elaboración Sropia

Para hallar la demanda potencial para el año 2015 se toma la población de adultos mayores del 2012 resultante del análisis anterior y se multiplica por la tasa anual de crecimiento poblacional para cada año lo que da finalmente una demanda potencial para el 2015 de 24.354 adultos mayores.

En cuanto a las sesiones de rehabilitación física que toman los adultos mayores; estas ascienden en promedio a 8 sesiones por vez, 3 veces al año para estas enfermedades. Realizando los cálculos correspondientes se obtiene la demanda potencial en sesiones de fisioterapia para el año 2015 que asciende a 584.490 .

Tabla 2.4

Demanda potencial 2015

\begin{tabular}{|c|c|c|c|}
\hline Año & $\begin{array}{c}\text { Tasa de } \\
\text { crecimiento }\end{array}$ & $\begin{array}{c}\text { Demanda } \\
\text { Potencial } \\
\text { (en hab.) }\end{array}$ & $\begin{array}{c}\text { Demanda } \\
\text { Potencial } \\
\text { (en sesiones) }\end{array}$ \\
\hline 2012 & $1,13 \%$ & 23.558 & 565.395 \\
\hline 2013 & $1,13 \%$ & 23.824 & 571.784 \\
\hline 2014 & $1,11 \%$ & 24.089 & 578.131 \\
\hline 2015 & $1,10 \%$ & 24.354 & 584.490 \\
\hline
\end{tabular}

Fuente: INEI

Elaboración Sropia 


\subsubsection{Proyección de la demanda potencial y metodología del análisis}

Para proyectar la demanda potencial, se utilizará la tasa de crecimiento anual poblacional elaborada por el INEI. Como se mencionó anteriormente el número promedio de sesiones a las que asisten los adultos mayores es de 8 sesiones por vez, 3 veces al año y se utilizarán también estos datos para la proyección de la demanda hasta el año 2021.

Tabla 2.5

Proyección de la demanda potencial al año 2021

\begin{tabular}{|c|c|c|c|}
\hline Año & $\begin{array}{c}\text { Tasa de } \\
\text { crecimiento }\end{array}$ & $\begin{array}{c}\text { Demanda } \\
\text { Potencial } \\
\text { (en hab.) }\end{array}$ & $\begin{array}{c}\text { Demanda } \\
\text { Potencial } \\
\text { (en sesiones) }\end{array}$ \\
\hline 2015 & $1,10 \%$ & 24.354 & 584.490 \\
\hline 2016 & $1,08 \%$ & 24.617 & 590.803 \\
\hline 2017 & $1,07 \%$ & 24.880 & 597.124 \\
\hline 2018 & $1,06 \%$ & 25.144 & 603.454 \\
\hline 2019 & $1,04 \%$ & 25.405 & 609.730 \\
\hline 2020 & $1,01 \%$ & 25.662 & 615.888 \\
\hline 2021 & $0,99 \%$ & 25.916 & 621.985 \\
\hline
\end{tabular}

Fuente: INEI

Elaboración Sropia

\subsection{Análisis de la oferta}

\subsubsection{Análisis de la competencia. Número de operadores y ubicaciones}

Dentro de toda la gama de instituciones que brindan los servicios de rehabilitación física existen diversas ofertas dependiendo del lugar donde se brinda el servicio y del precio. Es así que podemos clasificar los lugares donde las personas asisten a sus terapias en:

- Hospitales

- Clínicas 
- Centros especializados en rehabilitación física

- Fisioterapeutas independientes

- OMAPED (Oficina municipal de atención a la persona con discapacidad)

A continuación se presentan los hospitales que brindan los servicios de rehabilitación física divididos según a la red a la cual pertenecen:

\section{Hospitales del MINSA}

Se presentan los hospitales que son gestionados po la dirección del Ministerio de Salud:

Tabla 2.6

Hospitales del MINSA

\begin{tabular}{|l|c|}
\hline \multicolumn{1}{|c|}{ Hospital } & Ubicación \\
\hline Hospital Nacional Arzobispo Loayza & Lima \\
\hline Hospital Nacional Dos de Mayo & Lima \\
\hline Hospital Nacional Cayetano Heredia & San Martín de Porres \\
\hline Hospital Nacional Daniel Alcides Carrión & Callao \\
\hline Hospital Sergio E. Bernales & Comas \\
\hline Hospital María Auxiliadora & San Juan de Miraflores \\
\hline Hospital Nacional Hipólito Unánue & Pueblo Libre \\
\hline Hospital Santa Rosa & Puente Piedra \\
\hline Hospital Puente Piedra Carlos Lanfranco La Hoz & San Juan de Lurigancho \\
\hline Hospital de San Juan de Lurigancho & \\
\hline
\end{tabular}

Fuente: MINSA

Elaboración Sropia

\section{Hospitales de la Solidaridad}

Los Hospitales de la Solidaridad son instituciones que dependen de la Municipalidad de Lima y brindan, entre otras especialidades, los servicios de rehabilitación física. Estos se encuentran en los principales distritos de Lima como Ate, Carabayllo, Chorrillos, Comas, La Victoria, Magdalena, Puente Piedra, San Juan de Lurigancho, San Juan de Miraflores, San Martín de Porres, Surquillo, Villa El Salvador, Villa María del Triunfo entre otros distritos y brindan dichos servicios a personas de niveles socioeconómicos medio y medio bajo. 


\section{Hospitales ESSALUD}

Dentro de las instituciones administrados por ESSALUD existen tres grandes hospitales los cuales son: Hospital Sabogal del Callao, Hospital Rebagliati en Lince y el Hospital Almenara ubicado en el Cercado de Lima que a su vez se dividen en tres grandes redes asistenciales que son conformadas por hospitales, centros médicos, postas médicas y policlínicos, cabe resaltar que no en todas estos centros se ofrecen los servicios de rehabilitación física.

El presente proyecto se centrará aquellas instituciones que se asemejen a la propuesta tales como las clínicas privadas y los centros especializados en fisioterapia. En tal sentido se presentan a continuación las principales instituciones consideradas como nuestra competencia.

Tabla 2.7

Clínicas y centros especializados

\begin{tabular}{|l|c|}
\hline \multicolumn{1}{|c|}{ Clínicas y Centros Especializados } & Ubicación \\
\hline Clínica Anglo Americana & San Isidro \\
\hline Clínica Anglo Americana & Lima \\
\hline Clínica Bellavista & San Martín de Porres \\
\hline Clínica Cayetano Heredia & Pueblo Libre \\
\hline Clínica Centenario Peruano Japonesa & Surco \\
\hline Clínica Chacarilla Medicina física y rehabilitación & Miraflores \\
\hline Clínica Delgado & Surco \\
\hline Clínica de Día Jockey Salud & San Borja \\
\hline Clínica de Especialidades Médicas & Miraflores \\
\hline Clínica de Reumatismo & San Isidro \\
\hline Clínica El Golf & Lima \\
\hline Clínica González & Miraflores \\
\hline Clínica Good Hope & San Borja \\
\hline Clínica Internacional & Lima \\
\hline Clínica Internacional & Independencia \\
\hline Clínica Jesús del Norte & San Isidro \\
\hline Clínica Limatambo & Miraflores \\
\hline Clínica Los Andes & La Molina \\
\hline Clínica Montefiori & Chorrillos \\
\hline Clínica Maison de Sante & San Miguel \\
\hline Clínica Providencia & Pueblo Libre \\
\hline Clínica San Bernardo & San Isidro \\
\hline Clínica Javier Prado & \\
\hline
\end{tabular}

Fuente: Asociación de clínicas particulares del Perú - Doctoralia Elaboración Sropia 
Tabla 2.8

Clínicas y centros especializados (continuación)

\begin{tabular}{|c|c|}
\hline Clínicas y Centros Especializados & Ubicación \\
\hline Clínica Ricardo Palma & San isidro \\
\hline Clínica San Borja & San Borja \\
\hline Clínica San Camilo & Lima \\
\hline Clínica San Felipe & La Molina \\
\hline Clínica San Felipe & Jesús María \\
\hline Clínica San Gabriel & San Miguel \\
\hline Clínica San Juan Bautista & San Juan de Lurigancho \\
\hline Clínica San Pablo & Surco \\
\hline Clínica San Vicente & San Martín de Porres \\
\hline Clínica Santa María del Sur & San Juan de Miraflores \\
\hline Clínica Stella Maris & Pueblo Libre \\
\hline Clínica Tezza & Surco \\
\hline Clínica Vesalio & San Borja \\
\hline Corpus Et Vita, Medicina Física y Rehabilitación & La Molina \\
\hline Fisiocenter Perú & Magdalena \\
\hline Fisiomagna & San Borja \\
\hline Fisioterapia Salud y Vida & Lima \\
\hline Fisioterapia TMO & Miraflores \\
\hline Fisioterapia TMO & La Molina \\
\hline Fisioterp & San Miguel \\
\hline Hogar Clínica San Juan de Dios & San Luis \\
\hline Instituto Especializado de Rehabilitación & Callao \\
\hline Instituto Peruano de Neurociencias & Lince \\
\hline Irconfe & La Molina \\
\hline Kinefis & Callao \\
\hline Manos que curan & Miraflores \\
\hline MEDIFAS Fisioterapia geriatrica & La Molina \\
\hline Medirehab & Jesús María \\
\hline Neomedica & Miraflores \\
\hline Nopain & Miraflores \\
\hline Nopain & San Borja \\
\hline Oetpac Milagritos León Cossio & San Martín de Porres \\
\hline Physiomed Fisioterapia y Rehabilitación & San Borja \\
\hline Physiomove & La Molina \\
\hline Red Salud & Jesús María \\
\hline Spine Center Perú & San Isidro \\
\hline Teramedic Center & Surco \\
\hline CEM Vital Center & San Borja \\
\hline Bamboo Senior Health Services & Surco \\
\hline Centro Especializado En Ondas de Choque & San Borja \\
\hline Centro médico especializado OSI & Miraflores \\
\hline Centro médico especializado OSI & Surco \\
\hline Centro médico especializado OSI & Los Olivos \\
\hline Centro Médico MEDEX & San Isidro \\
\hline Cerefbrimmer & Pueblo Libre \\
\hline Cerfid & Surco \\
\hline
\end{tabular}

Fuente: Asociación de clínicas particulares del Perú - Doctoralia Elaboración Sropia 
Finalmente el número de operadores de la competencia directa ascienden a 33 centros especializados y 36 clínicas dando como resultado un total de 69 establecimientos donde se brindan los servicios de fisioterapia y rehabilitación física.

\subsubsection{Descripción de las características del servicio ofertado por los principales competidores}

Entre los principales competidores se encuentran las clínicas que brindan los servicios de rehabilitación física y los centros especializados en fisioterapia, empero las clínicas no se enfocan solo en la rehabilitación física de sus pacientes sino que ofrecen una gran cantidad de servicios orientados a la salud total de las personas como son la medicina interna, odontología, oftalmología, por nombrar algunas especialidades dentro de toda la gama en salud.

Por este motivo, este estudio se enfocará en la descripción de las características de los principales centros especializados en rehabilitación física considerados como la competencia directa:

\section{Clínica Chacarilla Medicina Física y Rehabilitación}

Es una clínica especializada en medicina física y rehabilitación que pertenece al complejo hospitalario San Pablo, ubicada en Santiago de Surco, este centro brinda tratamientos avanzados en medicina física, rehabilitación cardiovascular, rehabilitación pulmonar, rehabilitación de suelo pélvico, rehabilitación de pie diabético, terapia de lenguaje, terapia ocupacional, sicología y nutrición.

\section{Centro médico especializado OSI Miraflores, Surco y Los Olivos}

Es una red de especialistas en fisioterapia y rehabilitación con sedes en Miraflores, Surco y Los Olivos. Cuentan con 15 años de experiencia en el Perú y con el 
respaldo de las principales compañías de Seguro y EPS como Pacifico, Rímac, Mapfre y La Positiva para atender a sus principales clientes.

Realizan un moderno tratamiento multidisciplinario que combina las mejores prácticas de la fisioterapia, acupuntura y quiropráctica computarizada. Ofrecen los servicios de fisioterapia traumatológica, neurológica, reumatológica, deportiva y de salud ocupacional.

\section{Cerfid}

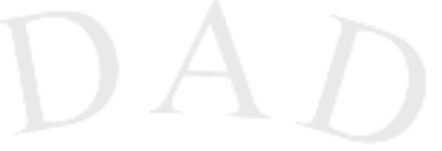

Centro especializado de rehabilitación física y del dolor ubicado en Lince, es una institución privada que brinda los servicios de medicina física y rehabilitación dirigido principalmente al manejo del dolor músculo-esquelético, de la columna vertebral y rehabilitación integral de sus pacientes, ofrecen los servicios de rehabilitación física, neurológica, reumatológica, cardiaca, respiratoria, terapia del lenguaje, ocupacional y atención domiciliaria.

\section{Fisiocenter Perú}

Ubicado en el distrito de Magdalena, es un centro especializado en fisioterapia con el método Pilates que ofrecen tratamientos en rehabilitación física para la recuperación de problemas de columna, hernias lumbares o cervicales, ciática, etc; recuperación funcional post trauma de pacientes que han sufrido accidentes, fracturas y cirugías, lesiones deportivas, restablecimiento de lesiones neurológicas, parálisis facial, así como el alivio del dolor y recuperación de la movilidad.

\section{Fisioterapia TMO}

Es un centro especializado en rehabilitación física con dos sedes situadas en los distritos de Miraflores y La Molina. Dicho centro utiliza técnicas especializadas basadas 
en el estudio de la biomecánica, básicamente hace uso de las manos como su principal herramienta para brindar una recuperación integral y rápida.

A diferencia de los otros centros, Fisioterapia TMO se ocupa principalmente de los problemas de dolor, limitación de movimiento y prevención de lesiones musculares y óseas en el ambiente deportivo; además de brindar servicios especializados en eventos de competencias, visitas a domicilio y a empresas.

\section{Spine Center Perú}

Ubicado en el distrito de San Isidro, este centro posee un enfoque en el manejo adecuado de las diferentes patologías del sistema musculo-esquelético con énfasis en la columna vertebral. Posee especialistas en el manejo del dolor, diagnóstico y tratamiento de lesiones deportivas y manejo de los problemas reumáticos y osteoporóticos en la columna vertebral de los adultos mayores.

Cabe resaltar que el servicio está dirigido a los adultos mayores mediante una atención integral llamada geriatría a domicilio, donde fisioterapeutas capacitados visitan a los adultos mayores en condiciones de dependencia que no puedan aproximarse al centro.

\section{Physiomove}

Brinda los servicios de fisioterapia integral a empresas, a domicilio, para deportistas y niños y fisioterapia en geriatría. Respecto al servicio de fisioterapia en 
geriatría Physiomove aplica métodos y técnicas de fisioterapia en adultos mayores sanos o con alguna disfunción, realizando una evaluación previa para determinar sus capacidades e implementar un plan de rehabilitación física adecuado a las necesidades de cada paciente.

\section{Bamboo Senior Health Services}

Es una clínica especializada en medicina del adulto mayor, ubicada en Surco que busca mejorar su salud, mejorar su independencia y seguridad en el día a día reduciendo la discapacidad y fomentando el autocuidado del adulto mayor.

Este es un servicio integral al adulto mayor puesto que ofrecen consultas médicas en fisiatría y acupuntura que incluyen terapias físicas, ocupacional y de lenguaje pero a la vez brindan también los servicios de geriatría, sicología, nutrición, cardiología, neurología, urología y dermatología.

\subsubsection{Planes de ampliación existentes}

En general los centros médicos privados han realizado diversas inversiones en los últimos años, ampliando su oferta médica, la principal idea de las empresas es llegar cada vez a más sectores, pero estas inversiones que amplían sus operaciones no son específicamente en servicios de rehabilitación física y fisioterapia, sino en ampliaciones de infraestructura y equipos observándose esto mayormente en las clínicas.

Por ejemplo la Clínica Delgado inició a fines del año 2014 sus operaciones en un nuevo local con más de 40 especialidades incluyendo la de medicina física y rehabilitación. La Clínica San Pablo invertirá en mejorar su infraestructura y comprar nuevos equipos de ayuda diagnóstica. La Clínica San Gabriel estará construyendo una torre de 10 pisos para ampliar su servicio ambulatorio y hospitalario además de invertir en su área de emergencia pediátrica a fin de triplicar su capacidad. 
La Clínica Good Hope tiene planes para llevar su oferta médica a los distritos de Chosica y Carabayllo, del mismo modo, la Clínica Limatambo planea contar con 7 sedes para el año 2019.

Finalmente la clínica angloamericana está implementando la ampliación y mejora de todos sus servicios que incluirán un centro quirúrgico ambulatorio, una nueva sala de operaciones, unidades de cuidados intensivos y el diseño de amplios espacios de confort.

\subsection{Demanda para el proyecto}

\subsubsection{Segmentación del mercado}

Existen diferentes variables de segmentación a tener en cuenta para dividir al mercado. Para tal división utilizaremos los criterios geográficos, demográficos, psicográficos y conductual:

- Geográfico: El presente estudio tiene como área de influencia la ciudad de Lima metropolitana la cual se divide en 5 perfiles zonales: Lima Norte, Lima Sur, Lima Centro, Lima Este y El Callao; cada perfil agrupa diferentes distritos según su ubicación geográfica. 
Figura 2.22

Perfiles zonales de Lima Metropolitana

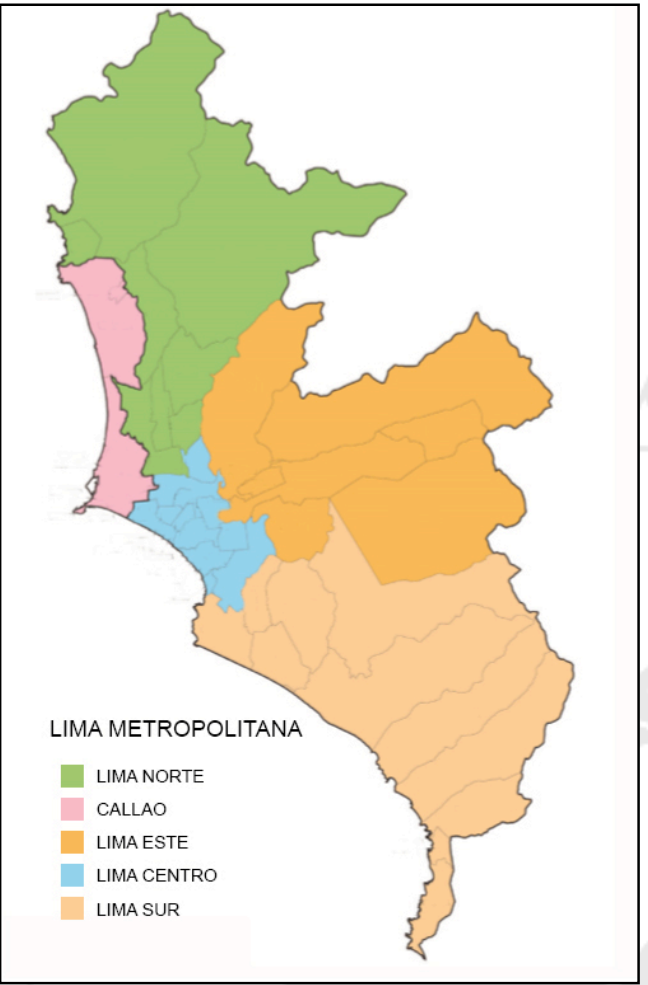

Fuente: INEI

Elaboración Sropia

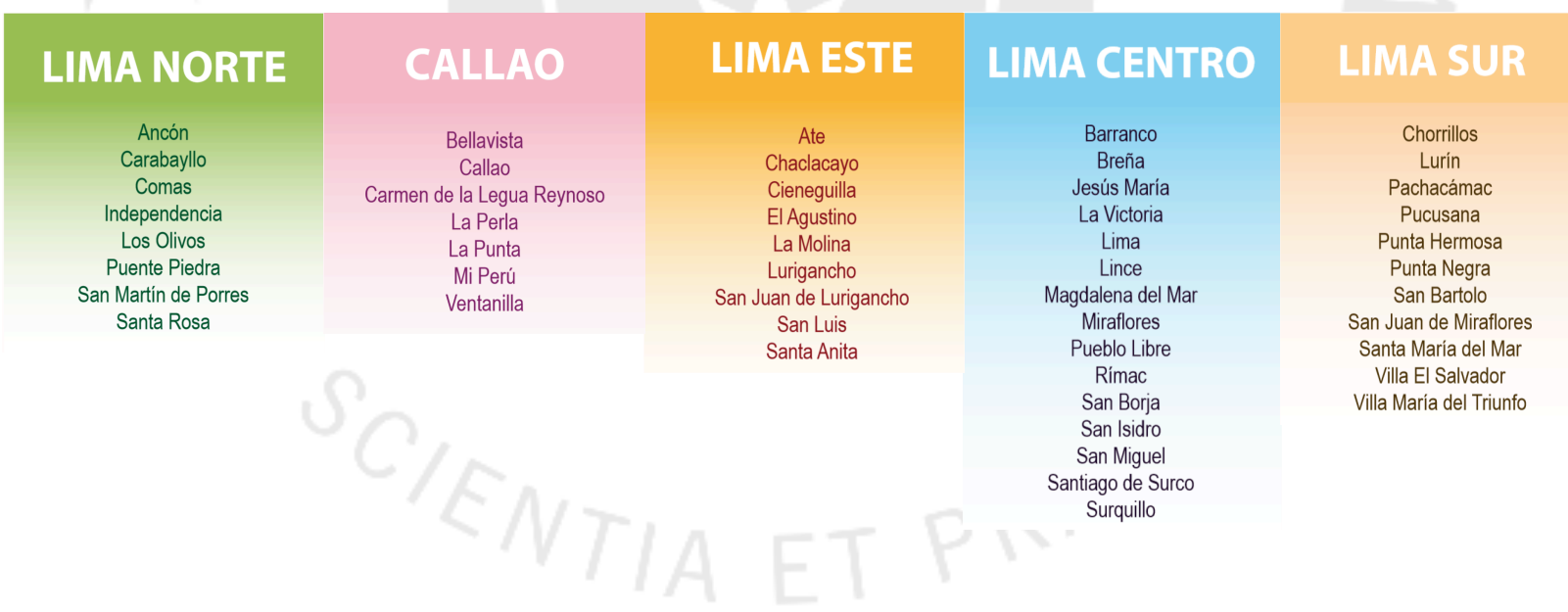

La población adulto mayor dentro de los perfiles zonales de Lima Metropolitana se divide de la siguiente manera: 
Figura 2.23

Población adulto mayor según perfiles zonales de Lima Metropolitana

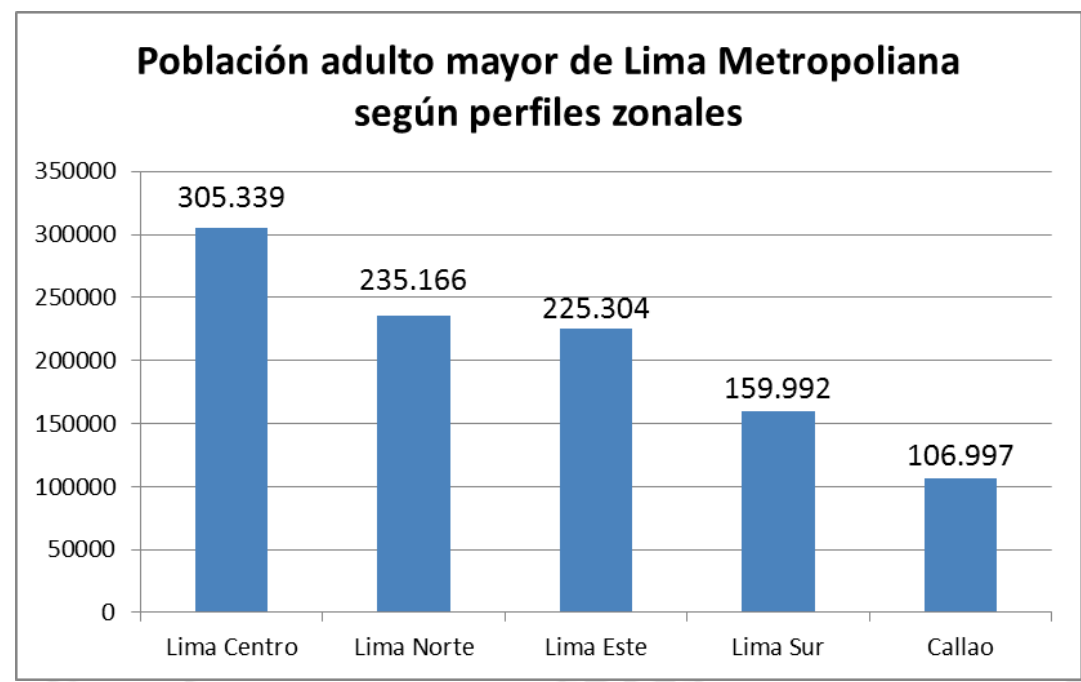

Fuente: INEI

Elaboración Sropia

- Demográfico: El mercado al cual nos dirigimos es el compuesto por los adultos mayores hombres y mujeres de 60 años a más de la ciudad de Lima, esto según las variables de género y edad, los cuales ascienden a 1.076.375 habitantes.

Figura 2.24

Población de Lima Metropolitana según grupo de edades

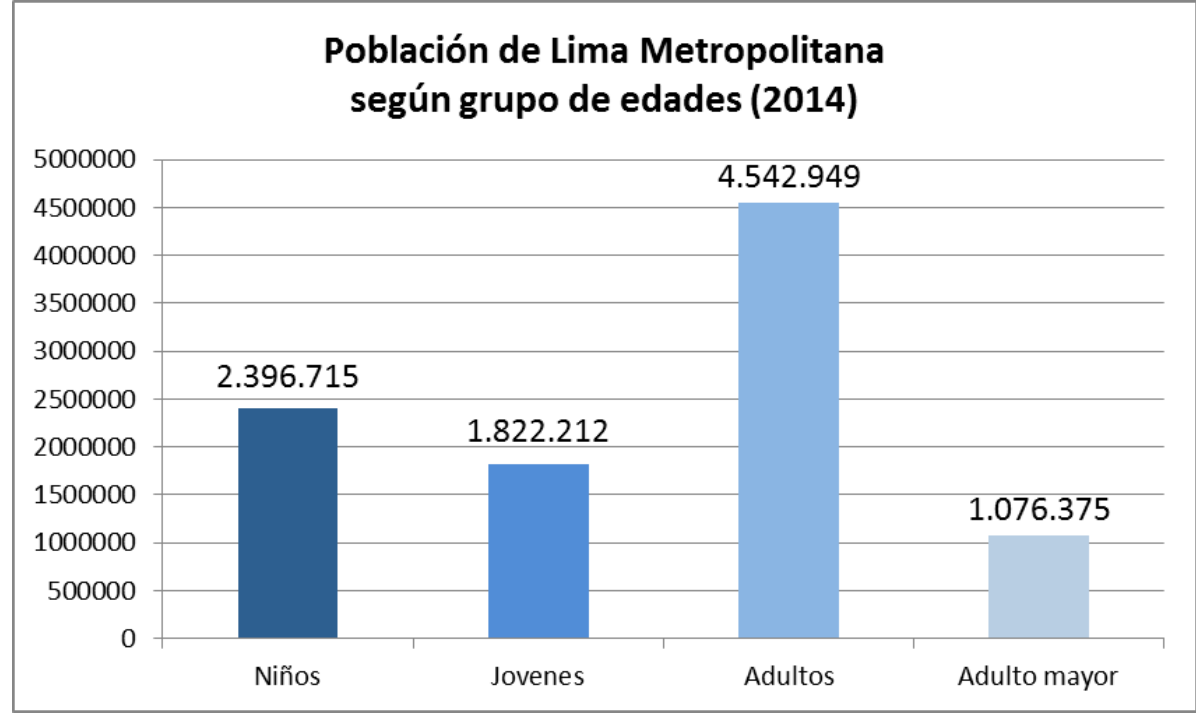

Fuente: INEI

Elaboración Sropia 
En relación a la variable ingresos, la principal fuente de ingreso de los adultos mayores es su jubilación con un $27 \%$, la segunda fuente de ingresos es el dinero proporcionado por hijos que viven dentro del hogar (16\%) y el 11\% posee un sueldo o salario. El 10\% recibe ingresos por "cachuelos" y el mismo porcentaje recibe dinero proporcionado por los hijos que viven fuera del hogar.

Figura 2.25

Principal fuente de ingresos del adulto mayor en Lima Metropolitana

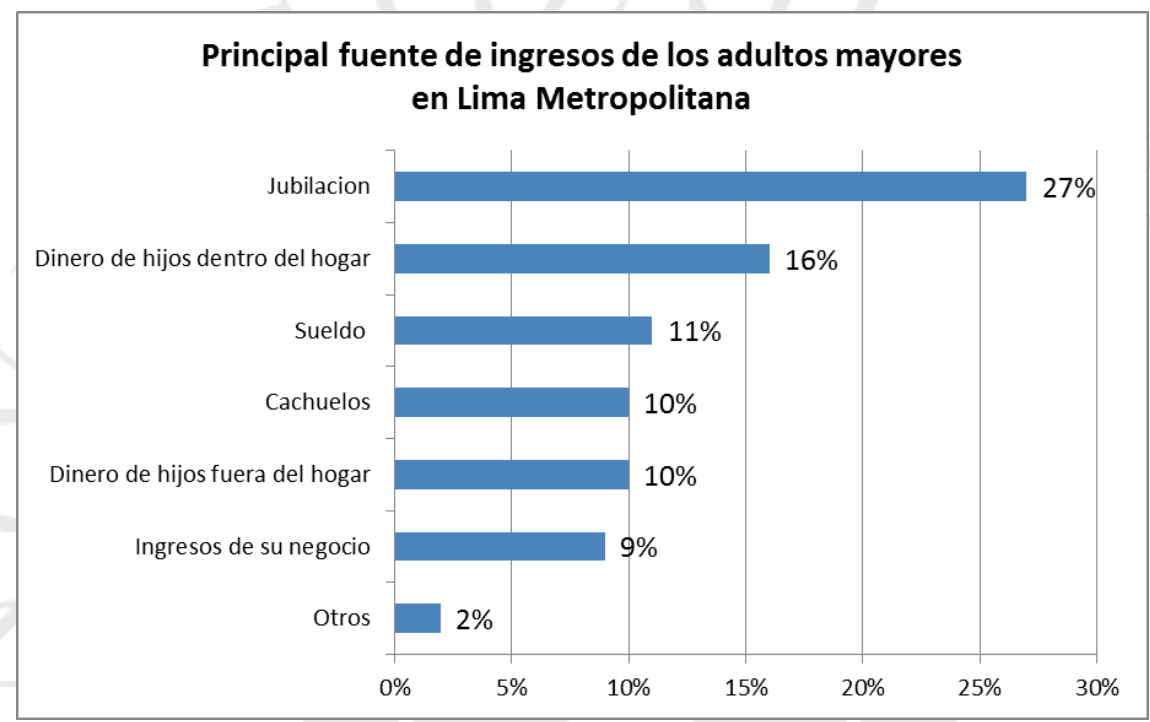

Fuente: Ipsos Marketing.

Elaboración Sropia.

Respecto a los niveles socioeconómicos, la población de adultos mayores de la ciudad de Lima Metropolitana sin incluir a la provincia constitucional del Callao asciende a 927.000 habitantes. En la siguiente figura se muestra su distribución por nivel socioeconómico. 
Figura 2.26

Población de adultos mayores de Lima Metropolitana por NSE

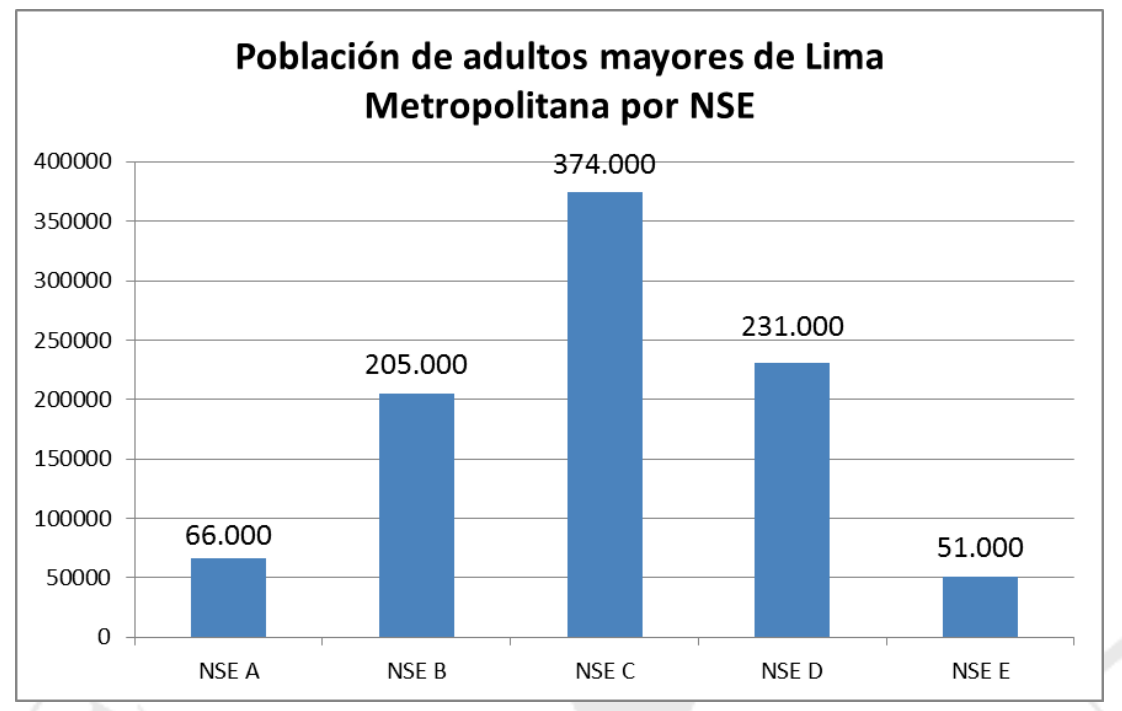

Fuente: Ipsos Marketing.

Elaboración Sropia.

- Psicográfico: Los estilos de vida es una variable utilizada también para la segmentación de mercado. Según Arellano Marketing existen 6 estilos de vida; estos son: Los Sofisticados, los Progresistas, las Modernas, los Adaptados, las Conservadoras y los Austeros. A continuación se presentan las principales características de cada estilo de vida:

Los Sofisticados: Lo conforman el 6\% de la población. Invierten mucho en su cuidado personal, evalúan el ambiente del punto de venta y el servicio, buscan productos de alta calidad y toman el precio como indicador de calidad.

Las Modernas: Compran productos light o saludables, pasean por tiendas por departamento, valoran la experiencia en el punto de venta, usan marcas como referente de calidad y valor social. Ascienden al 23\% de la población.

Los Progresistas: Son extremadamente prácticos y modernos, evalúan el costobeneficio, compran lo necesario, prefieren los puntos de ventas cercanos y son utilitarios en su consumo. Estos suman el 23\%. 
Las Conservadoras: Lo conforman el $20 \%$ de la población y son files a sus caseros de siempre, les gustan las promociones del canal moderno y la abundancia en productos es un referente, prefieren rendimiento y calidad.

Los Adaptados: Ascienden al $16 \%$ y buscan una compra rápida en establecimientos modernos, no se alejan mucho de su rutina, compran producto reconocidos y prefieren los productos tradicionales.

Los Austeros: Frecuentan casi a diario los mercados, comprar es una necesidad, viven el día y piden fiado, compran lo indispensable. Lo conforman el 12\%.

- Conductual: Un aspecto importante dentro de los hábitos del adulto mayor es la costumbre a realizar ejercicios, existe un $57 \%$ (más de la mitad) de adultos mayores en Lima Metropolitana que acostumbra a realizar algún tipo de ejercicio o actividad física. Este punto es importante puesto que depende mucho de su estado físico o que no presente ninguna enfermedad muscular para realizar esta actividad.

Otro punto importante a tener en cuenta es la estadística que manejan los especialistas del Hospital 2 de Mayo respecto a las caídas sufridas por los adultos mayores; ellos afirman que 3 de cada 10 adultos mayores sufren una caída al año ${ }^{16}$ por lo que existe un $30 \%$ de adultos mayores que probablemente necesiten los servicios de rehabilitación física para su recuperación.

\subsubsection{Selección del mercado meta}

El mercado meta está conformado por los hombres y mujeres mayores de 60 años llamados adultos mayores de nivel socioeconómico "A" de los estilos de vida

\footnotetext{
${ }^{16}$ Silva Nole, Luis. "Tres de cada diez adultos mayores sufren una caída al año" El Comercio.
} Lima, 1 de agosto de 2014. 
"sofisticados" y "modernas" con enfermedades reumáticas como artrosis o artritis, osteoporosis y los que sufren alguna discapacidad física que recurren a tratamientos, cuidan de su salud y realizan ejercicio o alguna actividad física principalmente del perfil zonal Lima Centro. También se considera a los adultos mayores que sufren accidentes como caídas que requieran rehabilitación física.

Para hallar el mercado meta en términos cuantitativos se tomará la demanda potencial hallada anteriormente al año 2014 la cual asciende a 24.089 habitantes y el porcentaje de la población de adultos mayores del perfil zonal Lima Centro al mismo año el cual es de $28,37 \%$ lo que da como resultado un mercado meta de 6.833 adultos mayores en el año 2014.

Finalmente para hallar el mercado meta del proyecto para el año 2015 se utilizará el índice de incremento poblacional de dicho año $(1,1 \%)$ lo que da como resultado 6.909 adultos mayores.

\subsubsection{Determinación de la demanda para el proyecto}

La demanda para el proyecto para el año 2015 será determinada con la intención de compra hallada en la encuesta de investigación, el mercado meta y el promedio de escala de intensidad. Como se mencionó anteriormente la intención de atenderse o llevar a sus familiares a un centro de rehabilitación física especializado en la atención al adulto mayor con políticas y planes de manejo medio ambiental es de 97\% y el promedio de escala de intensidad de la intención de compra es $70 \%$, al corregir la intención de compra obtenemos como resultado $67,9 \%$ que es la demanda susceptible a ser captada por el proyecto. Al calcular el mercado meta 2015 (6.909 hab.) con el porcentaje de intención de compra corregido $(67,9 \%)$ da como resultado una demanda para el proyecto de 4.690 adultos mayores. 
Tabla 2.9

Cálculo para hallar la demanda del proyecto

\begin{tabular}{|l|c|}
\hline \multicolumn{2}{|c|}{$\begin{array}{c}\text { Cálculo de la demanda } \\
\text { para el proyecto (en hab.) }\end{array}$} \\
\hline Mercado meta 2015 & 6.909 \\
\hline Intención de compra & $97 \%$ \\
\hline Promedio escala de intensidad & 0,7 \\
\hline Corrección de intención de compra & $67,9 \%$ \\
\hline Demanda para el proyecto 2015 & 4.690 \\
\hline
\end{tabular}

Elaboración Sropia

La demanda para el presente proyecto es 4.690 adultos mayores siendo necesario hallar la demanda del proyecto en número de sesiones al año; en tal sentido se sabe que los adultos mayores realizan en promedio 8 sesiones por vez, 3 veces al año obteniendo la demanda para el proyecto en sesiones de rehabilitación física que asciende a 112.560.

Tabla 2.10

Proyección de la demanda para el proyecto

\begin{tabular}{|c|c|c|c|}
\hline Año & $\begin{array}{c}\text { Tasa de } \\
\text { crecimiento }\end{array}$ & $\begin{array}{c}\text { Demanda } \\
\text { Potencial } \\
\text { (en hab.) }\end{array}$ & $\begin{array}{c}\text { Demanda } \\
\text { Potencial } \\
\text { (en sesiones) }\end{array}$ \\
\hline 2015 & $1,10 \%$ & 4.690 & 112.560 \\
\hline 2016 & $1,08 \%$ & 4.741 & 113.776 \\
\hline 2017 & $1,07 \%$ & 4.791 & 114.993 \\
\hline 2018 & $1,06 \%$ & 4.842 & 116.212 \\
\hline 2019 & $1,04 \%$ & 4.893 & 117.421 \\
\hline 2020 & $1,01 \%$ & 4.942 & 118.607 \\
\hline 2021 & $0,99 \%$ & 4.991 & 119.781 \\
\hline
\end{tabular}

Fuente: INEI

Elaboración Sropia

\subsection{Venta del servicio}

\subsubsection{Políticas de venta del servicio}

Las principales políticas de venta del servicio de rehabilitación física ecoeficiente para adultos mayores se presentan a continuación: 
- Los precios tanto de las consultas como de las rehabilitaciones tendrán incluido el Impuesto General a las Ventas (IGV). Los pacientes podrán recibir a cambio del pago una boleta o factura que acredite el servicio.

- Los pagos se realizarán en efectivo y con tarjetas de débito o crédito. Podrán ser en moneda nacional o extranjera al tipo de cambio interbancario del día.

- Se brindarán paquetes promocionales con descuentos los cuales consistirán en ofrecer pagar un determinado número de sesiones por adelantado y ser acreedor a una sesión de gracia lo que nos beneficiará en fomentar liquidez al negocio y a la vez crear un ahorro para el adulto mayor.

- Se realizarán alianzas estratégicas con clínicas y hospitales que no posean servicios de rehabilitación física o que excedan en su capacidad con la finalidad de atender con mayor prontitud a los adultos mayores y a la vez crear convenios con todas las compañías de seguros para acceder a más clientes.

- Los adultos mayores podrán acceder a una tarjeta de cliente preferente que ofrecerá descuentos en consultas y terapias.

\subsubsection{Análisis de precios}

\subsubsection{Tendencia histórica de los precios}

No existen precios históricos de los servicios de rehabilitación física pero se tomará como referencia el índice de variación de precios en salud para obtener una aproximación basada en datos reales. 
La información obtenida del Instituto Nacional de Estadística e Informática (INEI) en el sistema de índices de precios al consumidor del sector salud en su acápite servicios para pacientes, se observa el indicador servicios médicos; el cual desde el año 2012 (tomado como base) hasta el año 2014 se ha visto incrementado en 14,87\% con una tendencia al alza de los precios de servicios de salud y por ende, los precios concernientes a los servicios de rehabilitación física.

Figura 2.27

Tendencia histórica de precios de los servicios de salud

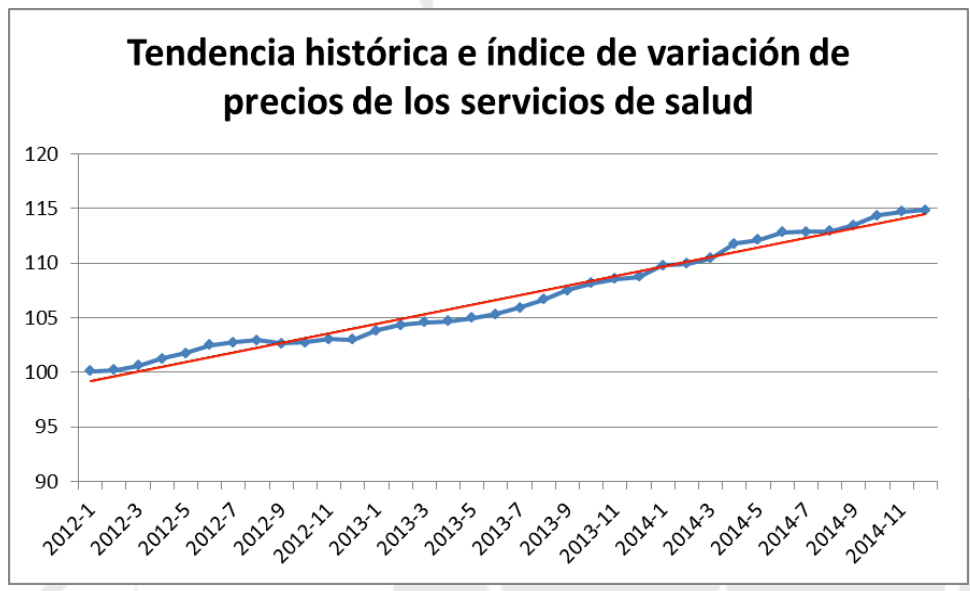

Fuente: INEI

Elaboración Sropia

\subsubsection{Precios actuales y niveles del servicio}

Existe una diferencia en los precios actuales de los servicios de rehabilitación física dependiendo de los establecimientos donde se ofrecen. Cabe señalar también que existe una diferencia entre el precio de una sesión de rehabilitación y el de una evaluación terapéutica o consulta. Es necesario señalar que para que un paciente proceda con sus sesiones de rehabilitación es necesario en primer lugar pasar por dicha evaluación o consulta.

Actualmente los precios de los servicios de rehabilitación física de las clínicas y los centros especializados considerados como competencia se encuentran alrededor de 
$\mathrm{S} / .85$ en promedio, esto en relación a las consultas médicas y en cuanto a las terapias el costo es de S/. 70 en promedio, tal como se observa en el siguiente cuadro:

Tabla 2.11

Precio promedio de los servicios de fisioterapia

\begin{tabular}{|l|c|c|}
\hline Clínica - Centro Médico & Consulta & Terapia \\
\hline Fisiocenter Perú & $\mathrm{S} / .40$ & $\mathrm{~S} / .60$ \\
\hline Fisioterapia TMO & $\mathrm{S} / .50$ & $\mathrm{~S} / .70$ \\
\hline Physiomove & $\mathrm{S} / .50$ & $\mathrm{~S} / .40$ \\
\hline Centro médico especializado OSI & $\mathrm{S} / .120$ & $\mathrm{~S} / .70$ \\
\hline Clínica de rehabilitación física Chacarilla & $\mathrm{S} / .160$ & $\mathrm{~S} / .100$ \\
\hline Clínica El Golf cita 100 & $\mathrm{S} / .100$ & $\mathrm{~S} / .80$ \\
\hline Clínica Jockey Salud & $\mathrm{S} / .80$ & $\mathrm{~S} / .65$ \\
\hline Promedio & $\mathrm{S} / . \mathbf{8 5 , 7 1}$ & $\mathrm{S} / . \mathbf{6 9 , 2 9}$ \\
\hline
\end{tabular}

Elaboración Sropia

Un aspecto importante a tener en cuenta referente al pago de los servicios de rehabilitación física, es la utilización de los seguros médicos por lo que el costo tanto en las consultas como en las sesiones de fisioterapia se reduce considerablemente llegando el paciente a pagar hasta la mitad del costo promedio.

En cuanto al nivel de servicio que es la probabilidad de cumplir con las sesiones solicitadas, según la Norma Técnica de Salud de la Unidad Productora de Servicios de Medicina de Rehabilitación (NTS N079 - MINSA/DGSP - INR. V.01.) el estándar del nivel de servicio para establecimientos del sector salud del Nivel II y Categoría II-1 respecto a los pacientes rehabilitados de una determinada discapacidad o enfermedad física en un determinado periodo de tiempo es del $80 \%$.

\subsection{Marketing de servicios}

A nivel empresarial es necesario definir una ventaja competitiva que diferencie a este proyecto del resto de empresas que brindan servicios de rehabilitación física. Por tal motivo se debe elegir dicha ventaja dependiendo de los servicios que se ofrezcan al público objetivo; según Michael Porter existen dos tipos de ventajas competitivas que 
se pueden observar en el mercado; estas son El Liderazgo en Costos que es la capacidad de realizar un producto o servicio a un precio inferior al de los competidores y La Diferenciación del Producto o servicio, es decir la capacidad de ofrecer un producto distinto y más atractivo para los consumidores.

Para lograr estas ventajas competitivas existen tres estrategias competitivas genéricas que se pueden aplicar. Estas son: El Liderazgo en Costos, La Diferenciación y El Enfoque; en el presente caso se utilizará la estrategia de El Enfoque para lograr una ventaja competitiva de Diferenciación de nuestro servicio. Esta estrategia llamada también Marketing Concentrado o Segmentación basada en la diferenciación consiste en lograr una fuerte posición de mercado especializándose en un segmento; en este caso el de los adultos mayores de la ciudad de Lima, ofreciendo el mejor servicio puesto que se tiene conocimiento de las necesidades específicas de este segmento que son las de aliviar el dolor y de que los adultos mayores puedan realizar sus actividades diarias independientemente de los problemas físicos que posean brindándoles una mejor calidad de vida.

\subsubsection{Características principales del servicio}

Hablando estrictamente de los servicios; estos poseen características especiales que hacen que el marketing de servicios sea diferente a las estrategias que se llevan a cabo con los productos tangibles.

Los servicios poseen cuatro características inherentes que se presentan a continuación:

- Intangibilidad: Los servicios no se adquieren, se experimentan.

- Inseparabilidad: Los servicios se venden, se producen y se consumen al mismo tiempo.

- Heterogeneidad: Todos los servicios no son iguales, cada experiencia es única. 
- Naturaleza Perecedera: Los servicios se consumen y terminan, no se pueden inventariar.

Por tal motivo los esfuerzos de marketing que se realizarán son distintos a aquellos que ejecutan las empresas que comercializan productos; estas basan su estrategia en las 4 P's (producto, precio, plaza, promoción); en el caso de las empresas de servicios, se manejan las $3 \mathrm{P}^{\prime} \mathrm{s}$ (personal de servicio, pruebas físicas y procesos). En base a esto se definirán las principales características del servicio.

\section{Personal de Servicio}

Se contará con personal fisioterapeuta altamente calificado tanto en las habilidades propias necesarias para la rehabilitación física de los pacientes como en la atención al cliente. Se contratarán médicos fisiatras de primer nivel y tecnólogos médicos experimentados en enfermedades músculo-esqueléticas que padecen los adultos mayores.

El personal de primer contacto del servicio como son la recepcionista y los operadores telefónicos generarán una buena interacción a fin de ofrecer una óptima atención al cliente. Para esto se realizarán capacitaciones que motiven al personal a ofrecer una excelente calidad de servicio.

\section{Pruebas Físicas}

Se construirá una infraestructura moderna con cómodas instalaciones que brinden un ambiente confortable en cuanto a la temperatura y la acústica del centro para crear una atmosfera idónea para brindar los servicios de rehabilitación física. Se contará también con mobiliario ergonómico y modernos equipos de última generación todo esto comprendido dentro de una cultura de cuidado medioambiental. 
Por tal motivo las instalaciones donde se llevarán a cabo los servicios de rehabilitación física, serán ecoeficientes lo que implica el uso de materiales de construcción de bajo impacto ambiental, utilización de equipos médicos de bajo consumo energético, implementación de planes de manejo de residuos sólidos y de reutilización de agua así como la instalación de áreas verdes.

\section{Procesos del Servicio}

Para dar inicio al servicio, el cliente tendrá tres formas de contratarlo ya sea vía internet por medio de la web, contacto telefónico o contacto directo en el centro. Por cualquiera de los tres medios se les explicará a los clientes los beneficios de los servicios de rehabilitación física, los médicos especialistas y los días en que podrán separar sus citas.

Luego, los clientes tendrán que pasar por una evaluación con el médico fisiatra para después establecer planes de tratamiento individualizados con los diferentes fisioterapeutas a su disposición, para dicho tratamiento se brindarán los diferentes métodos utilizados para la rehabilitación del paciente, estos son:

- Laserterapia: Rayos láser para regenerar el tejido.

- Magnetoterapia: Ondas magnéticas para recuperar el tejido óseo.

- Masoterapia: Masajes terapéuticos.

- Kinesioterapia: Ejercicios para movilizar músculos.

- Electroterapia: Corriente controlada como analgésico.

- Ultrasonoterapia: Sonido en alta intensidad para producir un masaje interno.

- Termoterapia: Compresas frías y calientes para disminuir contracturas.

- Hidroterapia: Baños de agua para la relajación muscular.

- Ondas de Choque: Ondas que acelera el proceso de cicatrización y calcificación del paciente. 
Se completarán los servicios de rehabilitación con ecografías en los músculos y tejidos para determinar la necesidad de extender el tratamiento o en caso contrario, dar de alta al paciente.

Se brindarán paquetes promocionales con descuentos los cuales consisten en ofrecer pagar un determinado número de sesiones por adelantado y ser acreedor a una sesión de gracia; a la vez se podrá acceder a una tarjeta de cliente preferente que ofrecerá descuentos en consultas y terapias. Adicionalmente se ofrecerá el servicio de transporte para pacientes que requieran ser trasladados al centro debido a su deficiente condición física.

En conclusión, se hará hincapié en proporcionar un servicio de alta calidad que satisfaga las necesidades de los adultos mayores a tal punto que puedan volver cuando sufran cualquier molestia muscular y recomienden el centro especializado a otras personas.

\subsubsection{Publicidad y promoción}

En primer lugar se creará la imagen de la empresa definida como un servicio especializado de rehabilitación física dirigido al adulto mayor basado en la ecoeficiencia de sus instalaciones, dando a conocer los beneficios de la especialización en las lesiones de los adultos mayores, proporcionando el mejor tratamiento y brindando una excelente calidad de servicio sin descuidar el medio ambiente.

Estos beneficios radican en el conocimiento a fondo y la experiencia en el tratamiento de las enfermedades físicas de los adultos mayores lo que conlleva a que el paciente después de su tratamiento sienta bienestar, salud y que no sienta dolor con la finalidad de que regrese a sus actividades de la vida diaria, mejorando su calidad de vida. Todo esto en un centro con políticas y planes medio ambientales dónde los pacientes sientan que están colaborando de alguna manera la preservación del medio ambiente. 
El público objetivo son los adultos mayores de 60 años y sus familiares directos de los cuales depende. El presupuesto asignado para la publicidad y promoción del centro asciende a S/.50.000 para el primer año por ser el periodo de introducción del servicio y S/.30.000 para cada uno de los cuatro años restantes donde se realizarán actividades para mantener la imagen de marca en la mente de los clientes. Para promocionar el centro especializado en rehabilitación física se utilizarán los siguientes medios:

\section{Internet}

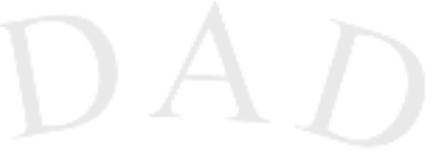

Se construirá una página web atractiva siguiendo las directrices técnicas y de calidad que permiten un mejor rastreo por parte de los buscadores con la finalidad de captar clientes y mejorar la imagen del centro. Se incluirá la información acerca de los especialistas, los distintos tipos de terapia, la tecnología que se utiliza, ubicación, personal de contacto, instalaciones, videos y noticias sobre rehabilitación física y cuidado del medio ambiente. En el sitio web se podrán realizar citas online, dar opiniones y sugerencias y recibir todo tipo de feedback para mejorar el servicio.

Con la página web elaborada, ésta se inscribirá en los registros electrónicos como Doctoralia: página de internet que agrupa a la mayoría de clínicas y centros especializados en distintas áreas del sector salud.

A la vez, se tendrá más presencia en la web con una fanpage en Facebook y un canal en Youtube con videos de la empresa resaltando la importancia del cuidado de la salud de los adultos mayores y el cuidado del medio ambiente y algunos testimonios de personas que han sido atendidas en el centro.

\section{Periódicos}

Se colocarán avisos en los diarios de mayor lectoría de nuestro público objetivo como son "El Comercio" y "Gestión" y en el suplemento dominical "VIU" de "El 
Comercio". A la vez también se gestionará la presencia en los especiales de salud que periódicamente publican los principales periódicos de la capital como el diario "El Comercio" dentro del suplemento semanal "Día 1".

\section{Revistas especializadas}

Se crearán avisos en revistas especializadas como la revista "Fisio Perú" en su formato impreso y web; y en revistas de alta lectoría como son la revista "Somos", revista "Hola" y el suplemento "Ellos y Ellas" de la revista "Caretas".

\section{Publicidad impresa}

Se elaborará un folleto atractivo en diferentes formatos (dípticos o trípticos) con toda la información acerca del servicio; la distribución de los folletos se llevará a cabo en los Centros Integrales de Atención a la Persona Adulta Mayor (CIAM), clubes sociales de la ciudad y en las distintas farmacias que existen en la zona aledaña al centro.

Todo lo relacionado al merchandising como son polos, lapiceros, papelería, tasas, llaveros, gorros con el logo del centro impreso serán elaborados con materiales reciclados y serán distribuidos en "activaciones" que se realizarán en los mismos lugares mencionados.

\section{Relaciones Públicas o Publicity}

Se pondrá más énfasis en este punto puesto que las estrategias en relaciones públicas hacen que tengamos presencia directa en nuestro público objetivo. Se realizarán acciones para tener presencia en radio y televisión sin tener que pagar por los 
espacios puesto que resultan excesivamente caros. A continuación presentamos las acciones concretas que se llevarán a cabo:

- Realizar un evento de inauguración contando como maestro de ceremonias a Gianfranco Brero, actor y conductor referente mayor de 60 años invitando a reconocidos médicos traumatólogos, fisiatras y fisioterapeutas; instituciones como municipalidades, destacados adultos mayores y a la prensa para luego lanzar un publirreportaje sobre el evento en la sección "Empresas y protagonistas" de la revista "Somos".

- Gestionar la asistencia a distintos programas de televisión por cable como el programa de salud "La Buena Vida" de Plus TV, noticieros que visiten el centro y programas relacionados a iniciativas empresariales como "Mundo Empresarial" en el canal de cable Canal N.

- En lo que respecta al medio radial, también se gestionará la presencia del centro en los programas "Más allá de las canas" programa especial para adultos mayores y "Cuidando tu salud" que son transmitidos por RPP, la radio más sintonizada en Lima.

- Participar en los concursos dedicados a la ecoeficiencia empresarial para mejorar la imagen de la empresa y celebrar los diversos días en el calendario medio ambiental como el Día Mundial de la Tierra (22 abril), Día del Medio Ambiente (5 de junio), Día Mundial del Agua (22 marzo), Día Nacional del Ahorro de Energía (21 octubre), entre otros con la finalidad de concientizar y sensibilizar a los clientes de la importancia de su participación en la solución de los problemas medioambientales.

- Crear convenios con la municipalidad donde se instalará el servicio para ofrecer descuentos a los vecinos que posean la tarjeta preferente de dicho municipio.

- Colocar stands volantes en los Centros Integrales de Atención a la Persona Adulta Mayor (CIAM) de los distritos de la zona de influencia del centro, en los 
diferentes clubes sociales y clubes deportivos como golf o tenis con la finalidad de dar a conocer los beneficios del centro de rehabilitación y despejar dudas acerca de las enfermedades físicas que afectan a los adultos mayores.

- Tener presencia en actividades deportivas como maratones, caminatas, entre otras organizadas por las distintas marcas e instituciones.

- Participar en las distintas campañas de salud organizadas por el Ministerio de Salud y las distintas municipalidades aledañas a la zona del centro.

- Celebrar en el centro los días importantes relacionados a nuestro sector como son el Día Mundial de la Salud (7 abril) y también el Día Internacional del Adulto Mayor (1 octubre) y el Día Nacional del Adulto Mayor (26 agosto) en invitar a la prensa para tener presencia en medios.

\section{Guías de anunciantes}

El centro especializado se registrará como anunciante en páginas web relacionadas con la medicina física y rehabilitación; así mismo se registrarse en las guías de anunciantes como las páginas amarillas tanto en su formato digital como el impreso.

\section{Recomendación de otros clientes}

El "boca a boca" se considera un factor clave y uno de los métodos más efectivos para atraer nuevos clientes al centro. Se realizarán todos los esfuerzos para que el paciente salga conforme y satisfecho con el servicio y sobretodo el trato recibido; la idea es que no solo retorne; sino que recomiende el centro a su entorno más cercano. 


\section{CAPÍTULO III: LOCALIZACIÓN DEL SERVICIO}

En este punto se realizará un estudio de localización con la finalidad de encontrar una ubicación apropiada para el desarrollo del proyecto, proponiendo lugares tentativos que sean los más adecuados para la instalación y equipamiento del centro.

Para este análisis se debe tener en cuenta varios factores que son importantes a la hora de tomar la decisión más asertiva para su localización.

Debido a que el Lima es la región con mayor población adulta mayor de todo el Perú, la que posee la mejor infraestructura en cuanto a servicios básicos y por su gran dinamismo económico se decidió realizar el estudio de localización en dicha región.

Para decidir la zona donde se implementará el centro se proponen tres distritos de la ciudad de Lima en base a tres factores: El perfil zonal geográfico Lima Centro definido por la segmentación realizada anteriormente, la mayor población de adulto mayor en cada distrito y principalmente los distritos que poseen la mayor oferta de clínicas y centros especializados en rehabilitación física.

Figura 3.1

Número de clínicas y centros que brindan los servicios de rehabilitación física

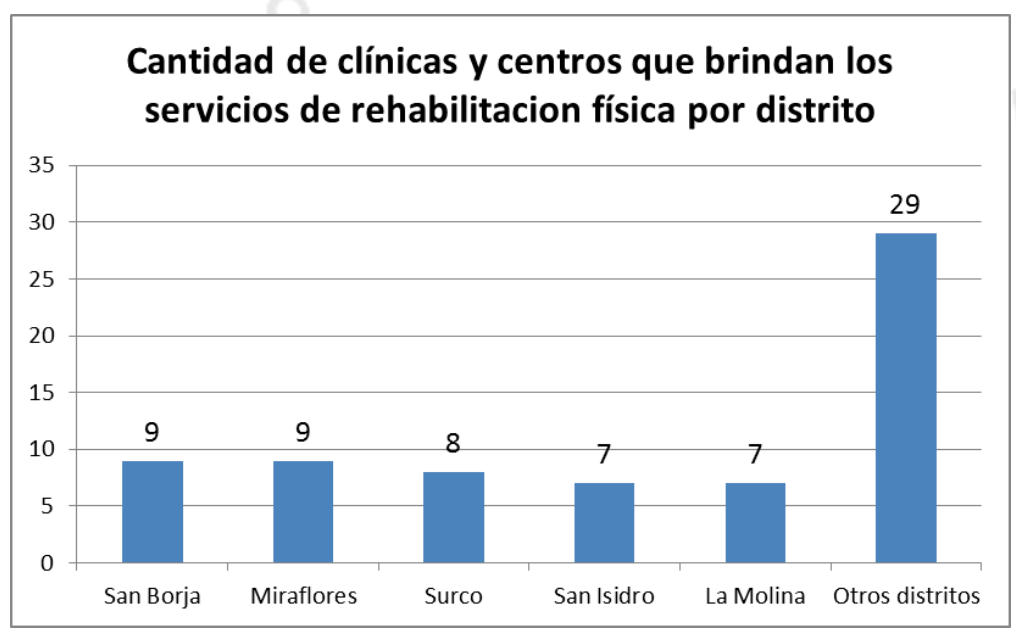

Elaboración Sropia 
Tomando en cuenta estos factores, se proponen los distritos de San Borja, Miraflores y Surco para la ubicación de este proyecto.

\subsection{Análisis de los factores de localización}

Dentro de los principales factores de localización relacionados a la instalación del servicio se tiene:

\section{Proximidad a las materias primas o insumos}

Se encuentran diversas empresas importadoras que ponen a disposición una gran variedad de insumos necesarios para la operación del centro tales como geles, vendajes, guantes de látex y cremas utilizadas para el uso adecuado de los equipos en los pacientes; también existe una gran cantidad de compañías distribuidoras de artículos de oficina necesarios para la administración del centro.

\section{Cercanía al mercado}

El mercado objetivo es el conformado por los adultos mayores que sufren enfermedades musculo-esqueléticas como son la artrosis, artritis y osteoporosis; y que sufren alguna discapacidad física en la ciudad de Lima; específicamente el perfil zonal Lima Centro por lo que la implementación del centro de fisioterapia será instalado en un distrito perteneciente a dicha zona.

Se sabe que el $57 \%$ de adultos mayores sufren estas enfermedades y requieren los servicios de rehabilitación física y la mayor cantidad de población adulto mayor se concentra en la ciudad de Lima Metropolitana con 1.076.375 habitantes; de estos, 24.354 adultos mayores sufren dichas enfermedades físicas. 


\section{Disponibilidad de mano de obra}

Se necesitarán tecnólogos médicos altamente calificados con título profesional y la ciudad de Lima posee universidades de gran renombre que ofrecen la carrera de tecnología médica como son la Universidad Mayor de San Marcos y la Universidad Cayetano Heredia; otras universidades donde se estudia la carrera son la Universidad Federico Villareal y Alas Peruanas.

En relación al mercado laboral en el sector salud según "Perú Económico" hay una gran demanda de profesionales de la salud entre ellos los fisioterapeutas o tecnólogos médicos. Los sueldos de los tecnólogos médicos calificados varían entre $\mathrm{S} / .1 .700$ y S/.2.000 y un médico fisiatra gana alrededor de S/. 6.500 mensuales.

\section{Abastecimiento de energía}

Este factor es fundamental para el funcionamiento del centro puesto que todos los equipos necesarios para los tratamientos fisioterapéuticos funcionan con energía eléctrica. Los distritos donde se planea instalar el centro tienen como empresas distribuidora de energía eléctrica a la compañía Luz del Sur.

Existen diferentes tarifas para cada actividad que se realiza. La tarifa más adecuada para nuestro proyecto, es la tarifa de baja tensión BT3 que generalmente son utilizadas por usuarios industriales y comerciales. 
Tabla 3.1

Tarifa de energía eléctrica BT3

\begin{tabular}{|c|c|c|c|}
\hline \multicolumn{4}{|c|}{$\begin{array}{c}\text { TARIFA CON DOBLE MEDICIÓN DE ENERGÍA ACTIVA Y CONTRATACIÓN O MEDICIÓN } \\
\text { DE UNA POTENCIA 2E1P }\end{array}$} \\
\hline \multirow{11}{*}{$\begin{array}{c}\text { TARIFA } \\
\text { BT3 }\end{array}$} & Descripción & Und. & Tarifa \\
\hline & Cargo Fijo Mensual & $\mathrm{S} / . / \mathrm{mes}$ & 3,03 \\
\hline & Cargo por Energía Activa en Punta & $\mathrm{S} / . / \mathrm{kW} . \mathrm{h}$ & 0,2105 \\
\hline & Cargo por Energía Activa Fuera de Punta & $\mathrm{S} / . / \mathrm{kW} . \mathrm{h}$ & 0,1751 \\
\hline & \multicolumn{3}{|l|}{ Cargo por Potencia Activa de generación para Usuarios: } \\
\hline & Presentes en Punta & $\mathrm{S} / . / \mathrm{kW}-\mathrm{mes}$ & 35,04 \\
\hline & Presentes Fuera de Punta & $\mathrm{S} / . / \mathrm{kW}-\mathrm{mes}$ & 24 \\
\hline & \multicolumn{3}{|l|}{$\begin{array}{l}\text { Cargo por Potencia Activa de redes de distribución para } \\
\text { Usuarios: }\end{array}$} \\
\hline & Presentes en Punta & $\mathrm{S} / . / \mathrm{kW}-\mathrm{mes}$ & 44,31 \\
\hline & Presentes Fuera de Punta & $\mathrm{S} / . / \mathrm{kW}-\mathrm{mes}$ & 40,55 \\
\hline & $\begin{array}{l}\text { Cargo por Energía Reactiva que exceda el 30\% del total de la Energía } \\
\text { Activa }\end{array}$ & $\mathrm{S} / . / \mathrm{kVar} . \mathrm{h}$ & 0,0392 \\
\hline
\end{tabular}

Fuente: Luz del Sur

Elaboración Sropia

Por otro lado también se utilizará gas natural con la finalidad de obtener agua caliente para los distintos procesos y servicios necesarios. La empresa Calidda la cual es la distribuidora de gas natural para la ciudad de Lima será la que proveerá de dicho servicio.

El rango de consumo de metros cúbicos estándar $\left(\mathrm{sm}^{3}\right)$ del centro se encuentra entre los 301 a $17.500 \mathrm{sm}^{3}$ por mes por lo que las tarifas que se manejaran para el servicio son las que se reflejan en la Categoría B.

Tabla 3.2

Tarifa de gas natural Categoría B

\begin{tabular}{|c|c|c|c|}
\hline \multicolumn{4}{|c|}{ PLIEGO TARIFARIO DEL SERVICIO DE DISTRIBUCIÓN DE GAS NATURAL } \\
\hline \multirow{8}{*}{$\begin{array}{c}\text { CATEGORIA B } \\
\text { Rango de consumo: } \\
\text { 301-17.500 } \mathrm{sm}^{3} \text { por } \\
\text { mes }\end{array}$} & Tarifas únicas de distribución & Und. & Tarifa \\
\hline & Margen fijo de comercialización (MFC) & $\mathrm{S} /$. Clientes mes & 78,8685 \\
\hline & Margen variable de distribución (MVD) & $\mathrm{S} / . / 1.000 \mathrm{sm}^{3}$ & 203,675 \\
\hline & \multicolumn{3}{|l|}{ Gas y transporte } \\
\hline & Precio del gas en boca de pozo & $\mathrm{S} / . / \mathrm{GJ}$ & 9,9106 \\
\hline & Tarifa de transporte de gas natural vía red principal & $\mathrm{S} / . / 1.000 \mathrm{sm} 3$ & 118,0402 \\
\hline & Factor de corrección de volumen & - & 1,0000 \\
\hline & Poder calorífico superior promedio del gas natural & $\mathrm{GJ} / \mathrm{sm} 3$ & 0,039973 \\
\hline
\end{tabular}

Fuente: Calidda

ElaboracióQSడpia 


\section{Abastecimiento de agua}

La compañía que abastecerá del servicio de agua y alcantarillado al centro será la empresa SEDAPAL en la categoría Comercial de la clase No Residencial.

El cobro de los servicios de agua se realiza por rangos de consumos, en nuestro caso si el consumo de agua es mayor a $1.000 \mathrm{~m}^{3}$ se cobrara la tarifa de $\mathrm{S} / .4,490$ por los primeros $1.000 \mathrm{~m}^{3}$ y S/. 4,817 por la diferencia.

Tabla 3.3

Estructura Tarifaria Empresa Sedapal

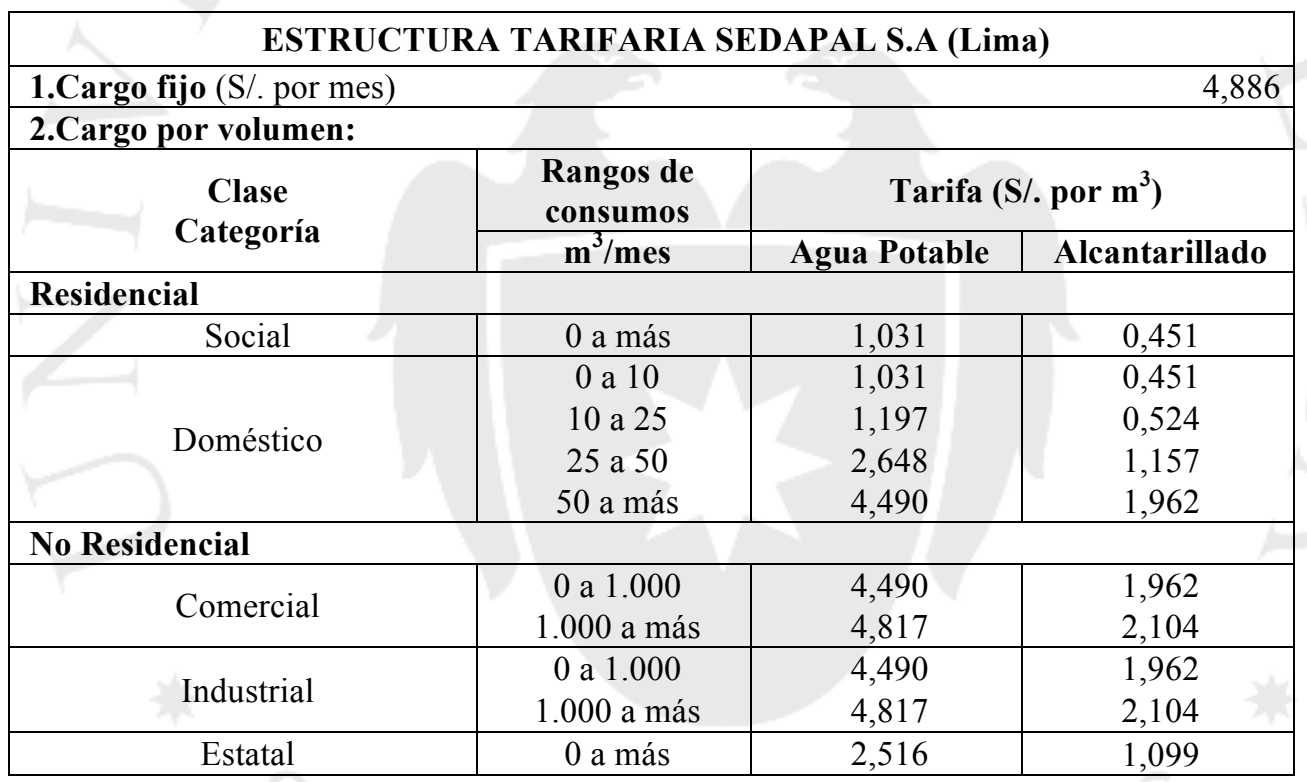

Fuente: SEDAPAL

Elaboración Sropia

\section{Terrenos}

Es importante tener presencia donde se conglomera toda la oferta de los servicios de salud, principalmente los distritos en los cuales se ubican la mayoría de los centros de rehabilitación física. Estos distritos son Miraflores, San Isidro, La Molina, Santiago de Surco y San Borja que son considerados los distritos top por la consultora URBECORP en cuanto al mercado inmobiliario de Lima. 
Si bien es cierto que son pocos los terrenos en la zona urbana, existen casas antiguas que se venden a valor de terreno. El costo de los terrenos por metro cuadrado en los distritos mencionados anteriormente se presenta a continuación:

Tabla 3.4

Precios de terrenos en Lima Metropolitana

\begin{tabular}{|c|c|c|c|c|c|}
\hline \multicolumn{6}{|c|}{ Precios de terrenos en Lima Metropolitana } \\
\hline Lima Top (valor en US\$/m $\mathbf{m}^{2}$ ) & 2010 & 2011 & 2012 & 2013 & 2014 \\
\hline Miraflores & 1.688 & 1.930 & 2.803 & 3.378 & 3.477 \\
\hline San Isidro & 1.394 & 2.044 & 2.081 & 2.845 & 3.026 \\
\hline La Molina & 500 & 553 & 914 & 1.058 & 1.232 \\
\hline Santiago de Surco & 895 & 1.385 & 1.258 & 1.778 & 1.721 \\
\hline San Borja & 1.430 & 1.518 & 1.528 & 2.154 & 2.309 \\
\hline
\end{tabular}

Fuente: URBECORP

Elaboración Sropia

\section{Servicios de transporte}

Las vías de acceso a los diferentes distritos donde se implementaría el centro están interconectadas entre sí por lo que se hace fácil llegar a cualquiera de estas zonas; existen líneas de buses, el tren eléctrico y una gran cantidad de taxis que hacen que el acceso sea posible; lo que sí se considera como un gran problema del transporte en Lima es el tráfico en horas punta y la falta de estacionamientos en los distritos donde se pretende instalar el centro.

\section{Seguridad}

La seguridad ciudadana en los últimos meses viene siendo mermada por la ola de robos, asaltos y asesinatos en los distintos distritos de la capital. La percepción de inseguridad ha aumentado en los últimos años; según una encuesta de la ONG "Lima Como Vamos" en el 2014, la precepción de la inseguridad en Lima ha aumentado a $82 \%$ a comparación del 2012 cuando esta cifra llegaba al 74\%. Este incremento se debe a la ola de asaltos, robos, y casos de sicariato registrados en la capital. 
Surco se encuentra dentro de los 8 distritos más inseguros de la ciudad de Lima según el Instituto de Defensa Legal; en tanto San Borja y Miraflores ocupan el puesto 20 y 22 respectivamente. Cabe señalar que los distritos donde se piensa implementar el centro cuentan con programas de seguridad ciudadana teniendo como primera línea de protección contra la delincuencia los servicios de serenazgo.

\section{Clima}

El clima de la ciudad de Lima es de un lugar de tipo árido, con deficiencia de lluvias durante todo el año; solo se presentan lloviznas ligeras entre abril y diciembre, con un ambiente atmosférico húmedo. La temperatura media anual de Lima es de $18^{\circ} \mathrm{C}$; la temperatura máxima en los meses veraniegos puede llegar a $\operatorname{los} 31^{\circ} \mathrm{C}$ y la mínima a $\operatorname{los} 12^{\circ} \mathrm{C}$ en época invernal. En los últimos años las temperaturas máximas han ido aumentando y las mínimas continúan disminuyendo esto a consecuencia del calentamiento global.

\section{Eliminación de desechos}

La Ley Orgánica de Municipalidades en su artículo $66^{\circ}$, establece las responsabilidades de las municipalidades para normar las actividades relacionadas con el saneamiento ambiental, ejecutar el servicio de limpieza pública y ubicar las áreas para la acumulación de basura; por lo que todo municipio por ley tiene la obligación del recojo y transporte de los desechos producidos por el centro.

Por otro lado existen aproximadamente 203 empresas prestadoras de servicio de residuos sólidos (EPS-RS) en la ciudad de Lima registradas por la Dirección General de Salud Ambiental (DIGESA) las cuales acopian, transportan y disponen de los residuos sólidos hospitalarios en los rellenos sanitarios autorizados. Por tal motivo, el centro al estar sujeto a la normatividad respecto al área de salud, deberá disponer de los residuos hospitalarios como guantes, vendas, yesos, gasas entre otros mediante estas empresas. 
Además se tiene previsto la construcción de una planta oficial de tratamiento de residuos hospitalarios por medio de una asociación público privada que impulsa el Ministerio de Salud (MINSA) que busca ordenar la manipulación, tratamiento y disposición final de estos desechos de todos los establecimientos de salud, públicos y privados de Lima.

\section{Reglamentaciones fiscales y legales}

En lo que respecta a la reglamentación y normas legales establecidas por el Estado existen diversas leyes y reglamentos que se deben cumplir para la construcción e implementación de un centro de rehabilitación física en la ciudad de Lima.

Entre ellas tenemos el Reglamento Nacional de Edificaciones (RNE) en su Título III referente a Edificaciones, en el acápite 1: Arquitectura, nos presenta la Norma A.050 referida a las edificaciones destinadas a ofrecer servicios de salud; en ella se establecen los requisitos y criterios mínimos para el diseño y ejecución de las edificaciones con la finalidad de garantizar la seguridad de las personas, su habitabilidad y la protección al medio ambiente.

Luego de la construcción del centro se debe seguir toda la normativa que implica los trámites de apertura y licencia de funcionamiento en la municipalidad donde se implementará el centro y los lineamientos de seguridad que impone el Sistema Nacional de Defensa Civil.

El sector salud posee dos reglamentos que establecen los requisitos $y$ condiciones para la operación y funcionamiento de los establecimientos de salud y servicios médicos de apoyo, orientados a garantizar la calidad de sus prestaciones. A su vez estos establecimientos deben coordinar sus planes y programas con el Ministerio de Salud. Estos son: 
- Reglamento de Establecimientos de Salud y Servicios Médicos de Apoyo D.S. No 013-2006-SA

- Reglamento General de Establecimientos de Salud del Sub-Sector No Público D.S. No $023-87-S A$

Por otro lado Ley General del Ambiente Ley $\mathrm{N}^{\circ}$ 28611D.S. N $015-2006-\mathrm{EM}$ que establece el marco normativo legal para la gestión ambiental en el Perú, determina los principios y normas básicas que aseguren: "El efectivo ejercicio del derecho constitucional al ambiente saludable, equilibrado y adecuado para el pleno desarrollo de la vida"17. Puesto que las instalaciones del centro serán ecoeficientes se debe cumplir con toda la normatividad vigente.

Además de la Ley General del Ambiente existe la Ley General de Residuos Sólidos Ley $\mathrm{N}^{\circ} 27314$ D.S. $\mathrm{N}^{\circ}$ 057-2004-PCM que establece todos los derechos y obligaciones de nuestra sociedad para asegurar una gestión sanitaria y ambiental en el manejo de los residuos sólidos con la finalidad de prevenir y minimizar los riesgos ambientales y proteger la salud de las personas.

La Ley General de Salud Ley N 26842 D.S. No 001-2009-SA también nos proporciona normativas relacionadas al cuidado del medio ambiente que debemos tener en cuenta al implementar nuestro centro de rehabilitación física; estas normas se refieren al manejo, transporte y disposición de residuos peligrosos para la salud en su capítulo VI "De las sustancias y productos peligrosos para la salud” y a la protección del medio ambiente con acciones concretas que eviten atentar la salud de los ciudadanos en el capítulo VIII "De la protección del ambiente para la salud”.

\section{Condiciones de vida}

La política de nuestra empresa dicta un fuerte interés en el cuidado de la salud de nuestros trabajadores y el medio ambiente; así como también la búsqueda de una

\footnotetext{
${ }^{17}$ Ley General del Ambiente Ley N²8611
} 
buena calidad de vida para ellos por tal motivo, la zona urbana donde se instalará el centro está considerada entre las mejores dentro de la ciudad de Lima con servicios que destacan sobre las demás.

Los distritos de Miraflores, Surco y San Borja realizan grandes esfuerzos en materia ecológica pero el distrito de San Borja destaca sobre los otros puesto que posee políticas ecológicas establecidas que se materializan en acciones concretas como el programa "San Borja en Bici" que busca reducir las emisiones de $\mathrm{CO}_{2}$, el sistema de contenedores subterráneos para el manejo de residuos y el programa "San Borja + Verde", con cerca de 50 mil árboles plantados, entre otras acciones que han generado considerar a San Borja como ejemplo de distrito ecológico en Lima.

\subsection{Posibles ubicaciones de acuerdo a factores predominantes}

\subsubsection{Cercanía al mercado}

El mercado al cual se dirige este proyecto como se mencionó anteriormente, es el segmento de adultos mayores (mayores de 60 años) con enfermedades musculoesqueléticas de la ciudad de Lima; región donde se concentra la mayoría de esta población. Existe un gran número de personas con este tipo de problema, alrededor de 24.354 habitantes; lo que implica que se realicen todo los esfuerzos de captación de clientes en este segmento.

Los distritos elegidos para decidir la instalación del centro son San Borja, Surco y Miraflores considerados entre otras cosas como aquellos con la más alta cantidad de población adulto mayor del nivel socioeconómico "A"; siendo este el mercado objetivo. Dado que el mercado se compone de la oferta y la demanda; se eligieron estos distritos también porque poseen la mayor oferta de clínicas privadas y centros especializados en rehabilitación física. 


\subsubsection{Requerimientos de infraestructura y condiciones socio- económicas}

Todas las construcciones en el Perú deben seguir los lineamientos del Reglamento Nacional de Edificaciones (RNE) donde se establecen los requisitos y criterios mínimos para el diseño y ejecución de las edificaciones con la finalidad de garantizar la seguridad de las personas, su habitabilidad y la protección al medio ambiente. Dicho reglamento posee normas de infraestructura especiales acerca de los centros de salud en su Título III referente a Edificaciones, en el acápite 1: Arquitectura, Norma A.050 referida a las edificaciones destinadas a ofrecer servicios de salud.

Según este reglamento los requerimientos en cuanto a la ubicación del centro; éste se deberá construir en terrenos planos evitando zonas arenosas, pantanosas, con fallas geológicas o con aguas subterráneas. En cuanto a la disponibilidad de servicios básicos deberán contar con abastecimiento de agua adecuado, desagüe, energía eléctrica, comunicaciones y red telefónica, plan de manejo de residuos y sistemas de protección contra incendios. En cuanto a su accesibilidad los terrenos deben ser accesible tanto peatonal como vehicularmente y evitar su proximidad a áreas de influencia industrial.

Finalmente en cuanto a su orientación y factores climáticos las construcciones deben tener protección de vientos dominantes y temperaturas extremas, resistencia a precipitaciones pluviales y capacidad para lograr iluminación y ventilación natural.

Los principales ambientes requeridos para brindar los servicios de salud incluyendo los de rehabilitación física y que son exigidos por el reglamento son:

- Áreas de servicios ambulatorios o diagnóstico.

- Áreas de tratamiento a pacientes.

- Oficinas administrativas.

- Salas de espera.

- Servicios auxiliares. 
- Depósitos y almacenes.

Este reglamento también nos brinda todos los requerimientos necesarios a tener en cuenta para la construcción de las edificaciones destinadas a brindar servicios de salud especificando condiciones especiales para personas con discapacidad como por ejemplo la señalización adecuada, rampas y vías de acceso para sillas de ruedas y la instalación de ascensores y escaleras integradas a dichas vías.

En lo que respecta a las condiciones socioeconómicas; según la Asociación Peruana de Empresas de Investigación de Mercados (APEIM) los distritos donde se concentra mayoritariamente las personas con nivel socioeconómico "A" (nivel al cual nos dirigimos) son Miraflores, San Isidro, San Borja, Surco y La Molina con un 58,1\% y a su vez, son los distritos a evaluar parar el proyecto.

Las principales características de este perfil son que en promedio, en cada vivienda habita un solo hogar y conviven 4 personas. El jefe de familia cuenta con educación universitaria completa; la mayoría son independientes o empresarios. El ingreso familiar mensual promedio es de S/. 11.395 y el gasto aproximadamente de S/. 7.901. Estos ingresos le permiten un elevado grado de comodidad; prácticamente todos cuentan con servicio doméstico y con automóvil. Las viviendas no sólo son cómodas sino espaciosas y lujosas, todos tienen acceso a internet.

En cuanto al tratamiento de la salud, la mayoría cuenta con un seguro médico privado y se atiende en clínicas particulares, tanto para atenciones ambulatorias como hospitalizaciones. En relación al sistema financiero, el nivel de tarjetas tanto bancarias como de casas comerciales alcanza un alto porcentaje. Otra característica es la asistencia a clubes privados y a agrupaciones profesionales y la compra de alimentos se da mayoritariamente en supermercados y las de ropa en tiendas por departamento o tiendas exclusivas. 


\subsection{Evaluación y selección de la localización del servicio}

La evaluación de la localización del centro se definirá mediante el método semicuantitativo llamado ranking de factores puesto que utiliza un sistema de evaluación tomando en consideración los factores de localización analizados anteriormente.

El primer paso es realizar una ponderación de los factores de localización utilizando una matriz de enfrentamiento donde se le asigna un valor de uno (1) al factor más importante o de importancia equivalente y un valor de cero (0) si el factor es menos importante que el factor con el cual es comparado.

Estas ponderaciones determinan la importancia de cada factor de localización para luego teniendo decidido las posibles localizaciones, en nuestro caso tres; calificar cada factor con una puntuación que se presenta a continuación:

- Excelente 10

- Muy Bueno 8

- Bueno 6

- Regular 4

- Deficiente 2

Una vez realizada la calificación se obtendrá un puntaje multiplicando la ponderación por la calificación. Este puntaje determina la elección de la zona adecuada para la localización del centro; todo este análisis se desarrolla en una tabla de ranking de factores que presentamos a continuación: 
Tabla 3.5

Matriz de enfrentamiento de los factores de localización

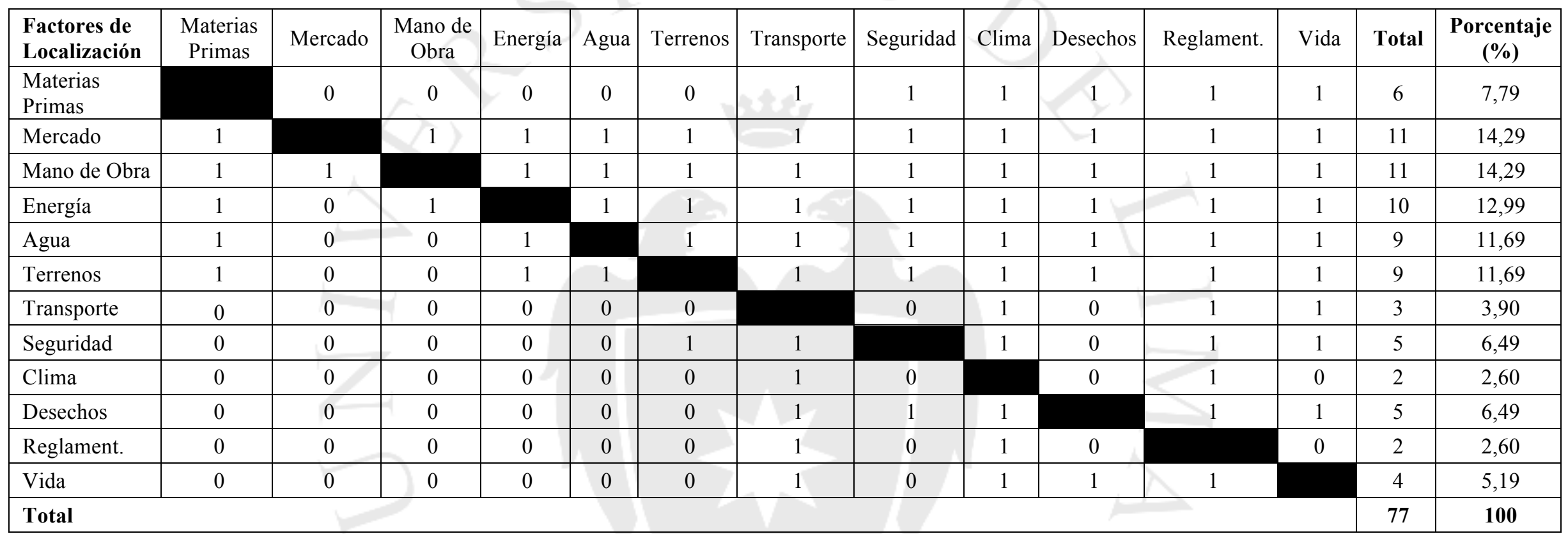

Elaboración Sropia 
Tabla 3.6

Ranking de Factores

\begin{tabular}{|l|c|c|c|c|c|c|c|}
\hline \multicolumn{1}{|c}{ Factores de Localización } & \multirow{2}{*}{$\begin{array}{c}\text { Ponderación } \\
(\mathbf{\%})\end{array}$} & \multicolumn{2}{c|}{ Miraflores } & \multicolumn{2}{c|}{ San Borja } & \multicolumn{2}{c|}{ Surco } \\
\cline { 5 - 9 } & Calificación & Puntaje & Calificación & Puntaje & Calificación & Puntaje \\
\hline Proximidad a las materias primas o insumos & 7,79 & 10 & 0,78 & 10 & 0,78 & 10 & 0,78 \\
\hline Cercanía al mercado & 14,29 & 10 & 1,43 & 10 & 1,43 & 10 & 1,43 \\
\hline Disponibilidad de mano de obra & 14,29 & 8 & 1,14 & 8 & 1,14 & 8 & 1,14 \\
\hline Abastecimiento de energía & 12,99 & 10 & 1,30 & 10 & 1,30 & 10 & 1,30 \\
\hline Abastecimiento de agua & 11,69 & 10 & 1,17 & 10 & 1,17 & 10 & 1,17 \\
\hline Terrenos & 11,69 & 4 & 0,47 & 6 & 0,70 & 8 & 0,94 \\
\hline Servicios de transporte & 3,90 & 6 & 0,23 & 6 & 0,23 & 6 & 0,23 \\
\hline Seguridad & 6,49 & 6 & 0,39 & 6 & 0,39 & 4 & 0,26 \\
\hline Clima & 2,60 & 8 & 0,21 & 6 & 0,16 & 6 & 0,16 \\
\hline Eliminación de desechos & 6,49 & 8 & 0,52 & 10 & 0,65 & 8 & 0,52 \\
\hline Reglamentaciones fiscales y legales & 2,60 & 8 & 0,21 & 8 & 0,21 & 8 & 0,21 \\
\hline Condiciones de vida & 5,19 & 8 & 0,42 & 10 & 0,52 & 8 & 0,42 \\
\hline Total & 100 & \multicolumn{2}{|c|}{$\mathbf{8 , 2 6}$} & & $\mathbf{8 , 6 8}$ & & $\mathbf{8 , 5 5}$ \\
\hline
\end{tabular}

Elaboración propia 
Luego de analizar las posibles ubicaciones a nivel de macrolocalización, se concluyó que el distrito más indicado para la ubicación del centro de rehabilitación física es San Borja, por tener el más alto puntaje luego de la evaluación realizada.

\subsubsection{Evaluación y selección de la microlocalización del servicio}

Para determinar una ubicación más exacta en donde se instalará el presente proyecto, se ha utilizado nuevamente el método de Ranking de Factores a un nivel de microlocalización, tomando solo algunos de los factores de localización analizados anteriormente, los cuales presentaban diferencias significativas dentro de las diferentes zonas del distrito de San Borja.

La selección de las zonas a evaluar para efectos de la microlocalización obedeció al índice de usos para la ubicación de actividades urbanas del Distrito de San Borja publicado en la Ordenanza $N^{\circ} 1429$ de la Municipalidad Metropolitana de Lima. A continuación se detallan las zonas seleccionadas:

Tabla: 3.7

Índice de usos para la ubicación de actividades urbanas en el distrito de San Borja

\begin{tabular}{|c|c|c|c|}
\hline Zonificación & $\begin{array}{c}\text { Residencial } \\
\text { Densidad Media } \\
\text { (RDM) }\end{array}$ & $\begin{array}{l}\text { Residencial } \\
\text { Densidad Alta } \\
\text { (RDA) }\end{array}$ & $\begin{array}{c}\text { Comercio } \\
\text { Zonal }(\mathrm{CZ})\end{array}$ \\
\hline $\begin{array}{l}\text { Actividades Urbanas } \\
\text { Actividades de hospitales } \\
\text { Actividades relacionadas } \\
\text { con la salud humana }\end{array}$ & AV. SAN LUIS & $\begin{array}{c}\text { AV. SAN BORJA } \\
\text { SUR }\end{array}$ & $\begin{array}{l}\text { AV. } \\
\text { GUARDIA } \\
\text { CIVIL }\end{array}$ \\
\hline $\begin{array}{l}\text { Centros de rehabilitación y } \\
\text { otras terapias }\end{array}$ & $\mathrm{OK}$ & OK & $\mathrm{OK}$ \\
\hline
\end{tabular}

Fuente: Municipalidad de San Borja Elaboración propia

Con las tres zonas seleccionadas se elaboró la matriz de enfrentamiento de los factores que presentaban diferencias significativas en dichas zonas, la cual se muestra a continuación: 
Tabla: 3.8

Matriz de enfrentamiento de los factores de microlocalización

\begin{tabular}{|l|c|c|c|c|c|c|c|}
\hline $\begin{array}{l}\text { Factores de } \\
\text { Localización }\end{array}$ & Energía & Terrenos & Transporte & Reglamentación & $\begin{array}{c}\text { Condiciones } \\
\text { de Vida }\end{array}$ & $\begin{array}{c}\text { Total } \\
\text { Porcentaje } \\
(\%)\end{array}$ \\
\hline Energía & & 1 & 1 & 1 & 1 & 4 & $25 \%$ \\
\hline Terrenos & 1 & & 1 & 1 & 1 & 4 & $25 \%$ \\
\hline Transporte & 0 & 0 & & 1 & 1 & 2 & $12,5 \%$ \\
\hline Reglamentación & 1 & 1 & 1 & 1 & 1 & 4 & $25 \%$ \\
\hline Condiciones de Vida & 0 & 0 & 1 & & & 2 & $12,5 \%$ \\
\hline Total & & & & & & 16 & $100 \%$ \\
\hline
\end{tabular}

Elaboración propia

Con los resultados de la tabla anterior, se procedió a calificar cada factor tomando en cuenta las siguientes acotaciones:

- La empresa Calidda en referencia al suministro de gas natural en el distrito de San Borja indicó que actualmente no cuenta con redes instaladas para uso comercial por donde circulen gas natural en dicho distrito pero que para el año 2016 iban a empezar a colocarlas por la zona colindante al distrito de San Isidro.

- Se realizó un estudio de aquellos terrenos disponibles y con un área aproximada a la requerida para la instalación del centro de rehabilitación en las tres zonas evaluadas, resultando la Av. Guardia Civil como aquella con mayor número de terrenos disponibles, seguida de la Av. San Luis y posteriormente la Av. San Borja Sur.

Tabla: 3.9

Número de terrenos disponibles para construcción en San Borja

\begin{tabular}{|l|c|c|c|}
\hline \multicolumn{1}{|c|}{ Terrenos disponibles } & $\begin{array}{c}\text { Av. San Luis } \\
\text { (Entre cdras 21 y 27) }\end{array}$ & $\begin{array}{c}\text { Av. San Borja Sur } \\
\text { (Entre cdras 3 Y 11) }\end{array}$ & $\begin{array}{c}\text { Av. Guardia Civil } \\
\text { (Entre cdras 1 y 8) }\end{array}$ \\
\hline Sin construcción & 5 & 1 & 5 \\
\hline Construidos solo 1 piso & 2 & 2 & 4 \\
\hline Total & $\mathbf{7}$ & $\mathbf{3}$ & $\mathbf{9}$ \\
\hline
\end{tabular}

Elaboración propia

- Se consultó a la Municipalidad de San Borja respecto a la Zonificación de las zonas evaluadas, teniendo registrada a la zona de la Av. Guardia Civil como 
Comercial Zonal para Centros de Rehabilitación y Otras Terapias. En cambio, las zonas de la Av. San Borja Sur y la Av. San Luis son zonas registradas como Residencial de Densidad Alta y Residencial de Densidad Media respectivamente.

- Se pudo comprobar que la zona de la Av. San Luis presenta menor tráfico en horas puntas que las zonas de las Av. Guardia Civil y Av. San Borja Sur.

- Se tiene conocimiento que la zona de la Av. San Borja Sur está cercana a una mayor cantidad de áreas verdes que la Av. San Luis, y ésta a su vez que la Av. Guardia Civil.

Tabla: 3.10

Ranking de factores de la microlocalización

\begin{tabular}{|l|c|c|c|c|c|c|c|}
\hline \multirow{2}{*}{$\begin{array}{c}\text { Factores de } \\
\text { Localización }\end{array}$} & \multirow{2}{*}{$\begin{array}{c}\text { Ponderación } \\
(\%)\end{array}$} & \multicolumn{2}{c|}{$\begin{array}{c}\text { Av Guardia } \\
\text { Civil (CZ) }\end{array}$} & \multicolumn{2}{c|}{$\begin{array}{c}\text { Av. San Borja } \\
\text { Sur (RDA) }\end{array}$} & \multicolumn{2}{c|}{$\begin{array}{c}\text { Av. San Luis } \\
\text { (RDM) }\end{array}$} \\
\cline { 3 - 9 } & & Calif. & Puntaje & Calif. & Puntaje & Calif. & Puntaje \\
\hline Energía & $25 \%$ & 6 & 1,5 & 4 & 1 & 2 & 0,5 \\
\hline Terrenos & $25 \%$ & 6 & 1,5 & 6 & 1,5 & 8 & 2 \\
\hline Reglamentación & $25 \%$ & 10 & 2,5 & 4 & 1 & 6 & 1,5 \\
\hline Transporte & $12,5 \%$ & 4 & 0,5 & 4 & 0,5 & 8 & 1 \\
\hline Condiciones de vida & $12,5 \%$ & 4 & 0,5 & 8 & 1 & 6 & 0,75 \\
\hline Total & $100 \%$ & \multicolumn{3}{|c|}{$\mathbf{6 , 5 0}$} & & $\mathbf{5 , 0 0}$ & \\
\hline
\end{tabular}

Elaboración propia

Finalmente, tomando los criterios antes mencionados, se concluye que la zona más adecuada según los factores evaluados para la instalación del presente proyecto, es la Av. Guardia Civil dentro del distrito de San Borja. 


\section{Capítulo IV: Dimensionamiento del servicio}

\subsection{Relación tamaño-mercado}

Como se mencionó anteriormente el mercado al cual nos dirigimos es el comprendido por los adultos mayores de nivel socioeconómico "A" que sufren enfermedades reumáticas como artrosis o artritis, osteoporosis y que recurren a los distintos tratamientos de rehabilitación física. Con la finalidad de limitar el tamaño del servicio se utilizará la demanda y su proyección al año 2021; plazo considerado para la evaluación del proyecto.

Tabla 4.1

Proyección de la demanda para el proyecto

\begin{tabular}{|c|c|c|c|}
\hline \multicolumn{4}{|c|}{ Proyección de la demanda para el proyecto } \\
\hline Año & $\begin{array}{c}\text { Tasa de } \\
\text { crecimiento }\end{array}$ & $\begin{array}{c}\text { Demanda } \\
\text { Potencial } \\
\text { (en hab.) }\end{array}$ & $\begin{array}{c}\text { Demanda } \\
\text { Potencial } \\
\text { (en sesiones) }\end{array}$ \\
\hline 2015 & $1,10 \%$ & 4.690 & 112.560 \\
\hline 2016 & $1,08 \%$ & 4.741 & 113.776 \\
\hline 2017 & $1,07 \%$ & 4.791 & 114.993 \\
\hline 2018 & $1,06 \%$ & 4.842 & 116.212 \\
\hline 2019 & $1,04 \%$ & 4.893 & 117.421 \\
\hline 2020 & $1,01 \%$ & 4.942 & 118.607 \\
\hline 2021 & $0,99 \%$ & 4.991 & 119.781 \\
\hline
\end{tabular}

Elaboración propia

La demanda para el proyecto al año 2021 es de 119.781 sesiones. El centro de rehabilitación física tendrá un horario de atención de lunes a sábado; es decir 6 días a la semana, atendiendo 6 horas por turno, con 2 turnos al día. Realizando el cálculo se obtiene que se deberá atender 32 sesiones por hora para satisfacer todo el mercado.

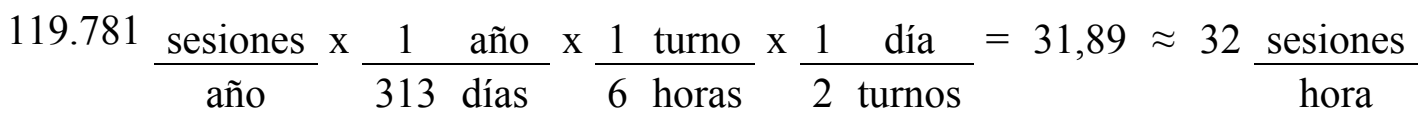




\subsection{Relación tamaño-recursos}

Como se observó en el capítulo III sobre los recursos necesarios para la implementación del centro, se indicó que el principal recurso para la atención es el recurso humano. En la ciudad de Lima existe un gran número de profesionales tecnólogos médicos capacitados para prestar sus servicios. Y a su vez existen diversas universidades que cada año generan profesionales de la salud especialistas en rehabilitación física. Por lo que el recurso humano está asegurado.

\subsection{Relación tamaño-tecnología}

La selección de la relación tamaño-tecnología estará determinada por la actividad de mayor duración dentro de las terapias de rehabilitación física, actividad conocida como "cuello de botella". Es así que se considerarán como actividades "cuello de botella" a la electroterapia dentro de la "terapia del alivio del dolor" y a la magnetoterapia dentro de la "terapia de restauración de la movilidad", pues son las actividades que tienen el mayor tiempo de duración dentro de estas dos terapias; éstas tardan un tiempo de 15 minutos por sesión cada una.

En base a esto; los equipos con los que se realizan estas terapias (electroestimulador y magneto) poseen un ratio de atención de 4 sesiones por hora. Dado que se pretende atender a la demanda del proyecto en su totalidad se requerirá de por lo menos 6 equipos con lo que la capacidad de atención será de 24 sesiones por hora.

Sin embargo, dichas actividades no determinan el ritmo de atención de las terapias pues la atención de las diferentes actividades que conforman cada terapia puede darse en cualquier orden de manera no secuencial dependiendo de la disponibilidad del equipo durante la atención de los pacientes. 


\subsection{Relación tamaño-punto de equilibrio}

La relación tamaño-punto de equilibrio determina el número mínimo de sesiones que se tienen que llevar a cabo para que el centro no genere ninguna pérdida; además indica también el nivel donde el centro no percibe beneficios; es decir todos los costos están cubiertos sin generar ningún ingreso. Para hallar el punto de equilibrio se utilizará la siguiente fórmula:

Fórmula Punto de Equilibrio

$$
Q=\frac{C F}{\text { Pvu. - Cvu. }}
$$

Dónde:

Q: Cantidad o Punto de equilibrio

CF: Costos Fijos

Pvu.: Precio de venta unitario

Cvu.: Costo de venta unitario

Todos los costos para la implementación del proyecto han sido determinados en el capítulo VII acerca de los aspectos económicos del proyecto. Los costos fijos del servicio son los relacionados a los sueldos administrativos, el costo de los servicios administrativos, depreciación, amortización de intangibles, gastos de servicios de terceros y los gastos de publicidad y promoción. Estos costos ascienden a S/. 2.974.454 para el primer año de operación.

Se consideran costos variables a aquellos que inciden directamente en el proceso del servicio como son los costos de insumos, sueldos de la mano de obra directa e indirecta y los costos de los servicios que implica la realización de las terapias. Siendo el costo variable unitario de S/.19,38. El precio de venta unitario está definido en función al precio promedio de la competencia como se verá en el capítulo VII y este asciende a $\mathrm{S} / .80$

Con estos datos se establece que el punto de equilibrio o el número mínimo de atenciones al primer año es de 49.064 sesiones, es decir, 13 sesiones por hora. 


\subsection{Selección de la dimensión del servicio}

Finalmente, comparando los resultados de la relación tamaño-mercado, tamañorecursos, tamaño-tecnología y tamaño-punto de equilibrio, se llegó a la conclusión que la dimensión del servicio del presente proyecto estará determinado por el ratio de la relación tamaño-mercado en el último año del proyecto el cual asciende a 32 sesiones por hora puesto que conduce a obtener los resultados más favorables en términos económicos para el proyecto. La tabla 4.2 muestra el análisis de los ratios mencionados anteriormente.

Tabla 4.2

Ratios del dimensionamiento del servicio

\begin{tabular}{|l|c|}
\hline \multicolumn{1}{|c|}{ Relación } & Ratio \\
\hline Tamaño-mercado & 32 sesiones / hora \\
\hline Tamaño-recursos & - \\
\hline Tamaño-tecnología & 24 sesiones / hora \\
\hline Tamaño-punto de equilibrio & 13 sesiones / hora \\
\hline
\end{tabular}

Elaboración: Propia 


\section{CAPÍTULO V: INGENIERÍA DEL PROYECTO}

\subsection{Definición del servicio basada en sus características de operación}

\subsubsection{Especificaciones técnicas del servicio}

Los servicios de fisioterapia que el centro brindará a sus pacientes, seguirán los criterios técnico - administrativos para su organización y funcionamiento establecidos en la "Norma Técnica de Salud de la Unidad Productora de Servicios de Medicina de Rehabilitación"; (NTS N 079-MINSA/DGSP-V.01) aprobada por el Ministerio de Salud (MINSA). En referencia a dicha norma, el centro estaría dentro del Segundo Nivel de Atención (II Nivel) y dentro de la categoría II-1 de establecimientos de salud, por lo que cumplirá con las siguientes condiciones:

- Infraestructura, equipamiento biomédico, recursos humanos y tecnología sanitaria necesarios para una prestación de servicios en condiciones razonables de seguridad y calidad.

- Sistema de comunicación interna, a través de teléfonos, anexos, circuito cerrado e intercomunicadores.

- Registro obligatorio de atenciones en la historia clínica de los pacientes.

- Proporcionar a los pacientes la información clara y oportuna, previa a todo acto o procedimiento de diagnóstico o ciclo terapéutico a realizarse, para lo cual es de uso obligatorio un formato del consentimiento informado.

- Disposición de información visible y clara para los pacientes, relacionada al horario de atención, rol del personal profesional y otras condiciones del servicio, la cual debe de ser publicada y colocada en lugares visibles para facilitar la información necesaria al paciente, familiares responsables o acompañantes.

- Implementación de los siguientes documentos:

- Manual de Organización y Funciones (MOF). 
- Manual de Procedimientos Administrativos y Asistenciales (MAPRO).

- Manual de Gestión de la Calidad.

- Guías de Práctica Clínica de los daños más frecuentes.

- Registro de los indicadores del servicio.

- Registro de la atención de Personas con Discapacidad (PCD).

- Registro de referencias y contrareferencias.

- Registro de Certificados de Discapacidad otorgados.

- Registro de Informes de Evaluación de la Incapacidad y/o Invalidez.

En relación a la infraestructura ecoeficiente con la que contará el centro, se mencionan a continuación las especificaciones técnicas requeridas para la construcción y las instalaciones del servicio:

- Empleo de materiales saludables para construcciones sustentables que posean características tales como bajo contenido energético, baja emisión de gases de efecto invernadero, ser reciclados y contener el mayor porcentaje de materiales de reutilización.

- Aprovechamiento de energía renovable donde la energía solar será aprovechada como iluminación natural mediante un correcto diseño de las ventanas, lo que será complementado con el uso de cristales insulados con la finalidad de brindar un mayor aislamiento térmico y acústico.

- Utilización de luminarias LED que reducirán en 50\% el consumo de energía y a la vez contribuyen con el cuidado del medio ambiente al no generar gases $\left(\mathrm{CO}_{2}\right)$ y calor

- Microsistemas para el tratamiento de aguas grises lo cual implica la captación del agua utilizada de los caños y duchas para su recirculación y utilización en actividades relacionadas a la limpieza del centro y el riego de los jardines.

Respecto a los recursos humanos, el equipo de salud estará constituido por profesionales de la salud, es decir, médicos especializados en Medicina de Rehabilitación y especialidades afines, registrados como hábiles en el colegio 
profesional. En caso de profesionales no médicos, contaran con el título profesional, registrados como hábiles en el colegio profesional respectivo.

Todo el personal antes mencionado deberá de ser monitoreado, supervisado y evaluado en las actividades que cada uno de estos preste. El personal del centro utilizará las "Guías de Práctica Clínica" aprobadas por la Autoridad Sanitaria Nacional en donde se indicarán los procedimientos médicos del servicio que el paciente requiera, lo cual conllevará a la estandarización de las terapias.

El centro contará con un área de atención del servicio al cliente cuya función principal será la de asistir con información a los posibles clientes o pacientes, así como de realizar la programación de las citas solicitadas mediante la página web del centro, en donde el cliente se suscribirá registrando sus datos, los teléfonos de contacto del centro o a través de la visita del cliente o paciente al centro.

La atención de las consultas médicas estará a cargo del médico fisiatra y el equipo multidisciplinario del centro, quién revisará la historia clínica para obtener información sobre o para el diagnóstico de su competencia. El médico realizará la anamnesis definida como la información recogida de todos los datos relacionados al paciente, la evaluación integral especializada, diagnóstico clínico, evaluación de deficiencias y discapacidades, pronóstico, metas e indicaciones de procedimientos médicos o terapéuticos, lo cual quedará registrado en la historia clínica respectiva. Asimismo, realizará igualmente los registros en el sistema de información. Además, entre los procedimientos de gestión médica asistenciales que se brindarán en el centro tenemos la certificación de discapacidad, informe médico y certificado médico.

Las sesiones terapéuticas, estarán a cargo de los tecnólogos médicos especializados en la atención de enfermedades físicas y discapacidades, quienes aplicarán las "Guías de Práctica Clínica” y/o "Guías de Procedimientos” que apruebe la Autoridad Sanitaria Nacional, según indicaciones del médico fisiatra. 
Respecto a las referencias y contrareferencias, de ser necesario referir algún paciente del centro a otro establecimiento de mayor complejidad, se debe tener en cuenta los criterios de oportunidad de la atención y capacidad resolutiva del establecimiento donde se referirá al paciente. Todo paciente referido que haya concluido sus prestaciones en el nivel de atención superior del establecimiento en donde fue atendido, deberá ser contrareferido al centro según sea el caso.

Los tratamientos terapéuticos que el centro de fisioterapia brindará, estarán relacionados a los siguientes tipos de rehabilitación:

\section{Rehabilitación Traumatológica}

Enfocada principalmente en tratar los trastornos y lesiones que afectan al sistema musculo-esquelético, así como la necesidad de rehabilitación post-quirúrgica. Este tipo de rehabilitación implica el tratamiento de lesiones músculo-esqueléticas como contracturas musculares, desgarros, tendinitis, fracturas, luxaciones, esguinces, contusiones, stress, tensión muscular, etc.

\section{Rehabilitación Neurológica}

Dirigido a personas con hemiplejias, parálisis facial, distrofias musculares, neuralgias, trastornos del movimiento como Parkinson, esclerosis múltiple, etc.

\section{Rehabilitación Reumatológica}

Enfocado a personas con enfermedades como la artritis, artrosis, osteoporosis, etc. el cual es nuestro principal giro de negocio. 
El centro de fisioterapia proporcionará diferentes tipos de terapias, las cuales tendrán como objetivo contribuir a la rehabilitación de los pacientes, mejorar su estado físico disminuyendo la fatiga y reduciendo la permanencia de contracturas, a la vez que se alivian los dolores musculares cotidianos, tanto reumáticos como los producidos por la artrosis, generando así un mejor estado anímico en los adultos mayores. Entre dichas terapias tenemos las siguientes:

Masoterapia: Consiste en la utilización de los masajes con fines curativos. Entre las técnicas que se manejan para la mejora del paciente se tienen el frote, los amasamientos, el drenaje linfático, las presiones y las tracciones manuales.

Electroterapia: La electroterapia utiliza corriente eléctrica controlada mediante equipos especializados para lograr un aumento de la fuerza y del tono muscular, disminución del dolor o también pueden actuar como un agente analgésico.

Ultrasonoterapia: La ultrasonoterapia es aquella aplicación terapéutica que utiliza las vibraciones sonoras de alta frecuencia, las cuales generan un efecto térmico y otro mecánico sobre el organismo, produciendo masajes localizados que ayudan a desinflamar los músculos y a regenerar los tejidos, así como a "soltar" las adherencias que se forman entre tejido y tejido.

Termoterapia: La termoterapia es el uso del calor como medio terapéutico. Esta técnica sirve para disminuir la contractura muscular, activar la circulación y mejorar el tono muscular. Para este fin se utilizan microondas, parafina y compresas frías y calientes que originan un efecto analgésico y relajante.

Hidroterapia: Las ventajas del trabajo dentro del agua son la relajación muscular que se produce en este medio y el hecho de poder realizar ejercicios que fuera del agua no serían posibles. Dicha terapia se llevará a cabo en una piscina acondicionada con un circuito de ejercicios destinado a mejorar la circulación y el movimiento de los pacientes. 
Laserterapia: Consiste en el uso de rayos láser para regenerar el tejido y en otros casos desinflamar. Se trabaja en articulaciones como también es utilizado para cicatrizar heridas después de una cirugía.

Magnetoterapia: Son ondas magnéticas para recuperar el tejido óseo. El magneto es un equipo que se utiliza para la consolidación ósea, éste acelera la mejoría de alguna fractura haciendo que el hueso se recupere.

Kinesioterapia: Consiste en realizar diversos tipos de ejercicios en zonas específicas para generar la movilización de los músculos.

Ondas de Choque: Son ondas que aceleran la cicatrización y calcificación del paciente.

Todas estas terapias estarán agrupadas en dos grandes grupos definidos por el beneficio que le brindan al paciente. A continuación se detalla los dos tipos de terapia que se proporcionarán en el centro:

Tabla 5.1

Tipos de Terapia

\begin{tabular}{|c|c|}
\hline Terapia de alivio del dolor & Terapia de restauración de la movilidad \\
\hline Electroterapia & Terapia de ondas de choque \\
\hline Ultrasonoterapia & Magnetoterapia \\
\hline Termoterapia & Laserterapia \\
\hline Masoterapia & Termoterapia \\
\hline Kinesioterapia & Hidroterapia \\
\hline
\end{tabular}

Elaboración propia

Los servicios de fisioterapia se complementarán con ecografías realizadas tanto al inicio como al final del tratamiento, con la finalidad de determinar la necesidad de cualquier otra terapia a futuro. Asimismo, se ofrecerá el servicio de transporte para pacientes que requieran ser trasladados al centro debido a su condición física. 


\subsection{Tecnología existente y proceso de realización del servicio}

\subsubsection{Naturaleza de la tecnología requerida}

Para la puesta en marcha del centro, es necesario evaluar la tecnología necesaria para la prestación de los servicios de fisioterapia. Por este motivo se procederá a evaluar las metodologías existentes para los diferentes tipos de servicios que se ofrecerán.

\subsubsection{Descripción de la tecnología existente}

La tecnología existente respecto al proceso de rehabilitación física radica en tres tipos de terapias que se presentan a continuación:

\section{Terapia manual}

En este tipo de terapia el médico fisiatra y/o tecnólogo médico es el que realiza todas las actividades necesarias para la prestación del servicio, utilizando sus manos para realizar masajes, direccionar movimientos de ejercicios y/o manipular vertebras y articulaciones.

Existen técnicas especializadas como la Terapia Manual Ortopédica (TMO) basadas en el estudio de la biomecánica donde se utiliza básicamente las manos como herramienta de rehabilitación. Este tipo de terapia involucra mayores tiempos de atención y presenta diferencias de calidad pues depende de la fuerza que sea aplicada por el personal médico. 
Figura 5.1

Terapia manual

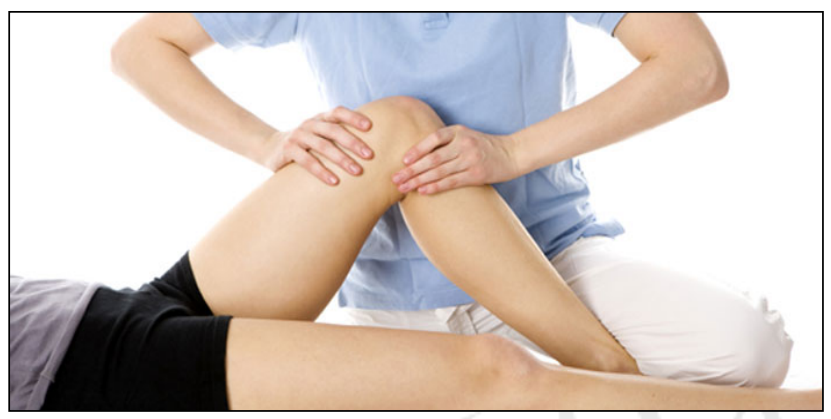

Fuente: Clínica Mejórate

Terapia manual asistida con equipos mecánicos

En este tipo de terapia el médico fisiatra y/o tecnólogo médico utiliza además de sus manos, equipos mecánicos destinados a provocar y dirigir movimientos corporales regulados en su fuerza, trayectoria y amplitud.

Para desarrollar este método se utilizan máquinas de tracción de tipo vertebral, cervical o lumbar con un sistema de correas donde el paciente puede encontrarse echado o sentado aplicándosele la tracción a fin de disminuir los dolores crónicos. Este tipo de terapia presenta una mejor estandarización de la calidad del servicio pero al igual que el proceso anterior involucra mayores tiempos de atención.

Figura 5.2

Terapia manual asistida con equipos mecánicos

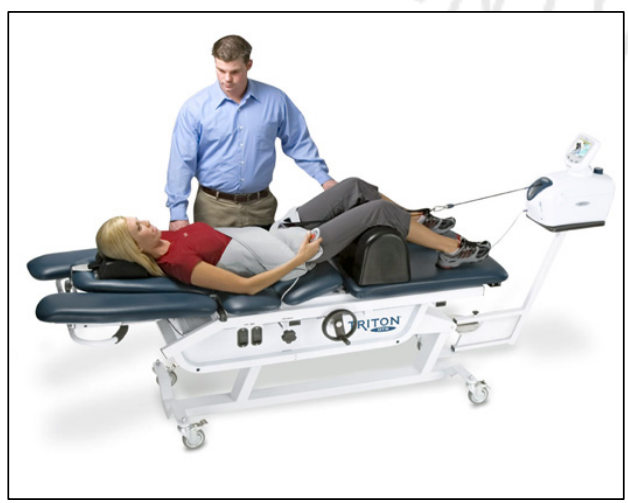

Fuente: Clínica de Fisioterapia Sabinci 
Terapia manual asistida con equipos eléctricos y medios de transmisión de energía

En este tipo de terapia el médico fisiatra y/o tecnólogo médico utiliza equipos con conexión eléctrica llamados agentes físicos para la aplicación de corrientes eléctricas, ultrasonido, onda corta, ondas magnéticas, entre otros, y medios de transmisión de energía como el calor y el frío.

A diferencia de la terapia manual, esta ofrece una mayor capacidad de atención de pacientes y permite obtener un servicio estandarizado y de mejor calidad. Sin embargo, este proceso requiere de mayor inversión, ya que los equipos tienen un costo de adquisición y de operación.

\section{Figura 5.3}

Terapia manual asistida con equipos eléctricos

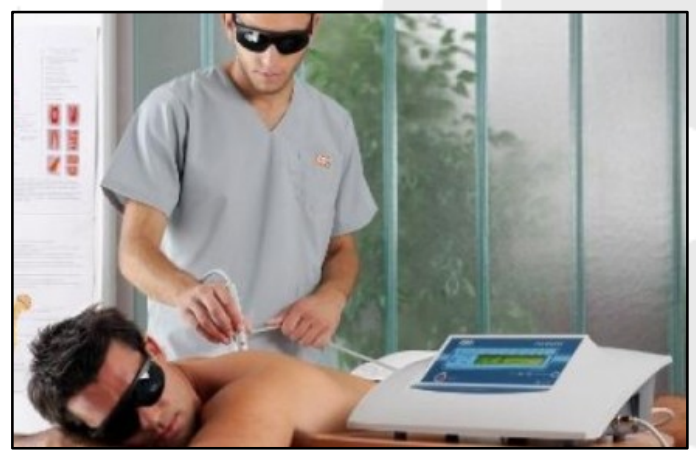

Fuente: Santa María Fisioterapia

Respecto a la tecnología ecoeficiente existente para las instalaciones del centro se presentan dos tipos de tecnología en relación a la generación de energía eléctrica y el servicio de agua caliente para la operación del centro.

Como se mencionó anteriormente, la energía eléctrica es la principal fuente necesaria para el funcionamiento y operación del centro puesto que se utilizarán equipos eléctricos para las terapias. Dentro de la tecnología ecoeficiente tenemos: 


\section{Paneles solares}

Es un sistema que utiliza energía solar (energía renovable) conformado por células fotovoltaicas que absorben la radiación solar para generar energía eléctrica. El sistema de paneles solares capta la radicación del sol a través de estas celdas solares hechas de silicio cristalino las cuales convierten la radiación en electricidad. Dicha electricidad se manifiesta en forma de corriente continua, la cual es controlada por un regulador que transmite la energía a una batería de acumuladores que la almacena; para poder utilizar esta energía en los dispositivos y artefactos eléctricos es necesario un inversor que convierta la corriente continua en corriente alterna.

Figura 5.4

Sistema de paneles solares

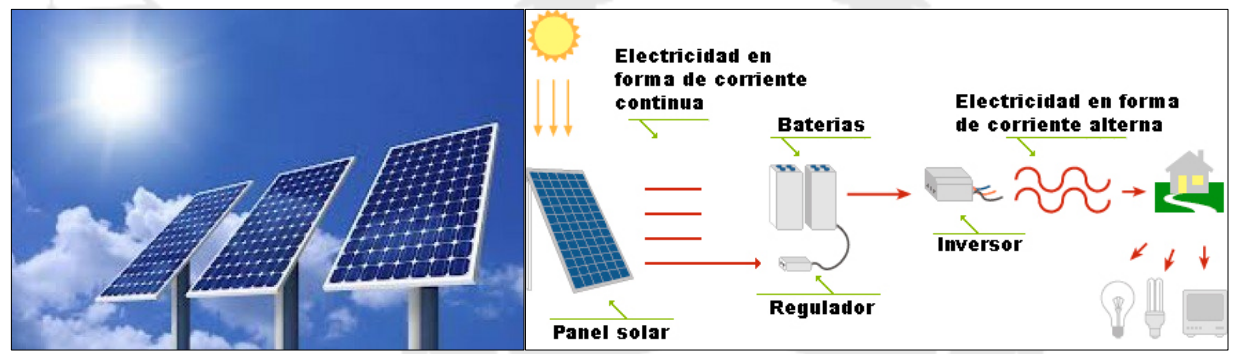

Fuente: Soliclima energía solar - Erenovable

\section{Energía eléctrica comercial con dispositivos LED}

La energía eléctrica comercial es proporcionada por la empresa distribuidora de electricidad Luz del Sur y mediante un pago mensual proporciona energía eléctrica necesaria para los equipos eléctricos y luminarias del centro. Cabe resaltar que se utilizarán luminarias LED la cual es considerada ecoeficiente a diferencia de los artefactos y dispositivos de iluminación incandescente o halógena que se utilizan normalmente. Entre los beneficios de esta tecnología se tiene:

- La tecnología LED tiene una duración de hasta 50.000 horas de funcionamiento comparado con las 2.000 horas de la iluminación convencioal. 
- Los fluorescentes LED usan 50\% menos energía que las bombillas incandescentes lo que conlleva a un ahorro en los costos de electricidad.

- Los materiales con que están hechas las bombillas LED son de estado sólido, a diferencia de los demás, por esto los LED son reciclables.

- Las luminarias LED’s poseen un encendido instantáneo y producen luz sin parpadeos (a diferencia de los tubos fluorescentes).

- Las bombillas LED no contienen mercurio ni plomo y no emiten prácticamente emisiones de $\mathrm{CO}_{2}$ a la atmosfera comparado con las bombillas normales.

- La tecnología LED no emite radiaciones ultravioletas ni infrarrojas a diferencia de la iluminación fluorescente que puede dañar ciertos tipos de piel sensible o provocar dolores de cabeza con el parpadeo.

- Al ser de ultra larga duración se evitan gastos de mantenimiento y sustitución.

- Al ser eficiente transforma prácticamente toda la energía en luz sin producir calor lo que ayuda a reducir costos en climatización (aire acondicionado).

En relación a la obtención de agua caliente para el centro se analizarán dos tipos de tecnología ecoeficiente que se explican a continuación:

\section{Termas solares}

Una terma solar es un artefacto que utiliza la energía proporcionada por la radiación solar para calentar agua que después es almacenada en un termo-tanque para su posterior utilización. La terma está conformada por cinco elementos: la placa colectora, el serpentín por donde pasa el agua, la placa transparente, el aislante térmico y el termo-tanque.

- La placa colectora es la que recibe los rayos del sol generando calor, el serpentín está unido a esta placa colectora por lo que el calor es transmitido hacia el serpentín. 
- El serpentín tiene una entrada por donde ingresa el agua fría la cual se calentará al pasar por la parte que está unida a la placa colectora y una vez caliente el agua sale del serpentín para almacenarse en el termo-tanque.

- La placa transparente tiene como función principal la de dejar entrar los rayos del sol al colector, pero no dejarlos salir, con lo que se logra un efecto invernadero que permite alcanzar mayores temperaturas.

- El aislante térmico es el que permite generar grandes temperaturas dentro de la terma, permitiendo que no se escape el calor producido.

- Por último el termo-tanque es el dispositivo donde se almacena el agua caliente para ser utilizada.

Figura 5.5

Sistema de terma solar

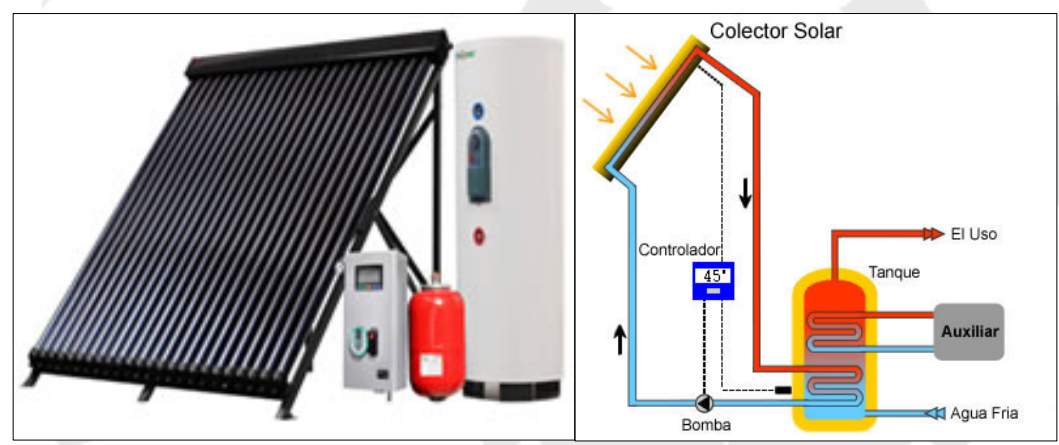

Fuente: MD Tech

\section{Calentador a gas natural}

Un calentador a gas natural consiste en un sistema automático donde al abrir cualquier llave de agua caliente hace que se active el dispositivo de arranque que abre la válvula de gas para calentar el serpentín del intercambiador de calor produciéndose a la vez la circulación del agua fría a través de este intercambiador para finalmente obtener agua caliente para el servicio. Cuando la llave de agua caliente es cerrada el calentador se apaga automáticamente. 
El gas natural es considerado uno de los combustibles más limpios ya que produce menos gases de efecto invernadero, además se consume de forma más limpia, eficiente y segura.

Figura 5.6

Sistema de calentador a gas

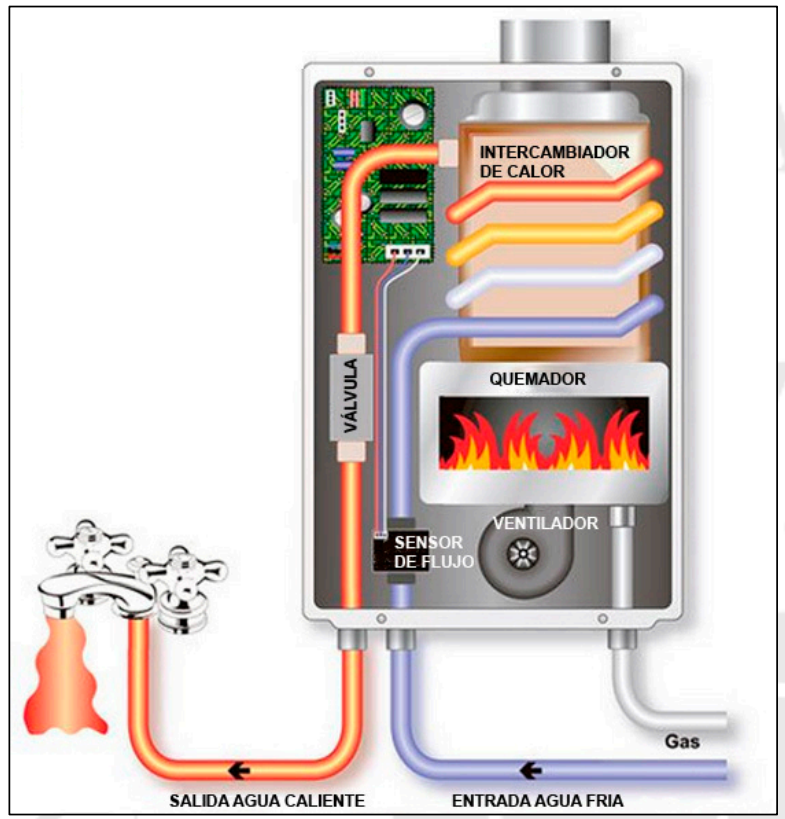

Fuente: AE Energy

\subsubsection{Selección de la tecnología}

Para la prestación de los servicios de fisioterapia se ha elegido la terapia manual asistida con equipos eléctricos y medios de transmisión de energía, debido a que la mayoría de procesos de fisioterapia se complementan con agentes físicos, lo cual permitirá mantener un estándar de calidad de los servicios y atender adecuadamente a la demanda del proyecto.

En la Tabla 5.2 se muestra para cada tipo de rehabilitación que atenderá el centro, las diferentes alternativas tecnológicas que se han considerado para cada una de estas y la tecnología final seleccionada. 
Tabla 5.2

Selección de la tecnología para la implementación del centro de rehabilitación física

\begin{tabular}{|c|c|c|}
\hline Etapa del proceso & Tecnología & Selección \\
\hline \multirow{3}{*}{ Programación de cita } & Teléfono & \multirow{3}{*}{ Todas } \\
\hline & Chat online vía página web & \\
\hline & Correo electrónico & \\
\hline \multirow{2}{*}{$\begin{array}{l}\text { Revisión y/o registro de } \\
\text { historia clínica del } \\
\text { paciente }\end{array}$} & Archivos físicos & \multirow{2}{*}{ Archivos electrónicos } \\
\hline & Archivos electrónicos & \\
\hline \multirow{3}{*}{ Ejecución de terapia } & Terapia manual & \multirow{3}{*}{$\begin{array}{l}\text { Terapia manual asistida } \\
\text { con equipos eléctricos }\end{array}$} \\
\hline & $\begin{array}{l}\text { Terapia manual asistida con } \\
\text { equipos mecánicos }\end{array}$ & \\
\hline & $\begin{array}{l}\text { Terapia manual asistida con } \\
\text { equipos eléctricos }\end{array}$ & \\
\hline
\end{tabular}

Elaboración propia

Con relación a la tecnología ecoeficiente tanto para la generación de energía eléctrica como el servicio de agua caliente para la operación del centro se realizó un pequeño análisis técnico-económico que se presenta a continuación:

\section{Generación de energía eléctrica}

El requerimiento de energía eléctrica necesaria para el funcionamiento del centro es de $182.380 \mathrm{Kw} . \mathrm{h}$ al año. Los paneles solares son capaces de producir desde 50w hasta 240w según la potencia máxima de cada panel. En la ciudad de Lima la radiación diaria promedio según el Servicio Nacional de Meteorología e Hidrología SENAMHI es de $4.09 \mathrm{Kw} . \mathrm{h} / \mathrm{m}^{2}$ por lo que un panel solar de $240 \mathrm{w}$ produce $0.982 \mathrm{Kw} . \mathrm{h}$ por día, es decir $353 \mathrm{Kw} . \mathrm{h}$ al año. Para tal requerimiento de energía es necesario instalar 517 paneles de una dimensión $1.6 \mathrm{~m}^{2}$ cada uno, necesitándose un área de $827 \mathrm{~m}^{2}$ que asciende a casi la totalidad el primer piso del centro y una inversión total de S/.597.135 ya que cada panel posee un costo de $\mathrm{S} /$. 1.155 según la empresa peruana de energía renovable ProViento S.A.C. 
Contratando los servicios de energía de la empresa distribuidora de electricidad Luz del Sur, el costo de la energía eléctrica (incluyendo los dispositivos LED) por el horizonte de vida del proyecto (5 años) sería de S/. 195.766, ahorrándose un total de S/.401.369 (205\%) y sin la necesidad de instalar ningún panel. Por tal motivo se selecciona la tecnología referida a la energía eléctrica comercial con dispositivos LED.

\section{Servicio de agua caliente}

Para la obtención de agua caliente se consideraron dos tipos de tecnología ecoeficiente: la utilización de termas solares y la instalación de un calentador a gas natural.

El requerimiento de agua caliente para el centro es de $40 \mathrm{~m}^{3}$ por día para la piscina terapéutica y $19,15 \mathrm{~m}^{3}$ diarios para los servicios de grifos y duchas lo que resulta un total de $59,15 \mathrm{~m}^{3}$ de agua caliente por día. Las termas solares tienen una capacidad de $1.1 \mathrm{~m}^{3}$ por lo que se necesitarán 54 termas solares. El costo de cada terma solar es de S/.12.540 según la empresa Solartec S.R.L. por lo que la inversión necesaria para contar con esta tecnología es de S/. 677.160.

Por otro lado, el costo de dos calentadores a gas natural (uno para el agua de la piscina y otro para el servicio de agua caliente) asciende a S/.84.600 y el costo total del gas natural necesario para calentar el agua requerida durante el periodo del proyecto ( 5 años) es de S/.162.215, lo que da un total de S/.246.815 a invertir en la tecnología a gas natural. Comparando estas dos tecnologías se produce un ahorro del $174 \%$ es decir $\mathrm{S} / .430 .345$ al utilizar la tecnología de calentadores a gas natural por lo que se selecciona dicha opción.

La Tabla 5.3 muestra la selección de esta tecnología para cada servicio necesario requerido en la operación del centro. 
Tabla 5.3

Selección de la tecnología ecoeficiente para las instalaciones del centro

\begin{tabular}{|c|c|c|}
\hline Servicios & Tecnología & Selección \\
\hline \multirow{2}{*}{$\begin{array}{l}\text { Generación de } \\
\text { energía eléctrica }\end{array}$} & Paneles solares & \multirow{2}{*}{$\begin{array}{c}\text { Energía eléctrica } \\
\text { comercial con dispositivos } \\
\text { LED }\end{array}$} \\
\hline & $\begin{array}{l}\text { Energía eléctrica comercial } \\
\text { con dispositivos LED }\end{array}$ & \\
\hline \multirow{2}{*}{$\begin{array}{l}\text { Servicio de agua } \\
\text { caliente }\end{array}$} & Termas solares & \multirow{2}{*}{ Calentadores a gas natural } \\
\hline & Calentadores a gas natural & \\
\hline
\end{tabular}

Elaboración propia

\subsubsection{Proceso de realización del servicio}

\subsubsection{Descripción del proceso del servicio}

Para dar inicio al servicio, el cliente tendrá tres formas de contratarlo ya sea vía internet, contacto telefónico o contacto directo en el centro. El primer método de contacto se canaliza ingresando a la página Web, el cliente tiene acceso a toda la información acerca de los servicios, terapias, especialistas, dirección del centro y teléfonos de contacto. A la vez en dicha página se podrán suscribir de forma preliminar registrando sus datos para luego dar respuesta a su solicitud de cita. La segunda forma de contacto es por teléfono, consultando el número telefónico en las páginas amarillas o la página Web. Esta modalidad es ideal para los clientes que desean conocer información más exacta o tienen dudas o consultas sobre el servicio. La tercera forma es el contacto directo donde el cliente se acerca al centro y tiene una entrevista con el personal de contacto, quienes le explicarán los beneficios de los servicios de rehabilitación, los médicos especialistas y los días en que podrán separar sus citas.

Una vez solicitada la cita por parte del cliente, la recepcionista de admisión será la encargada de verificar si dicho cliente posee una historia clínica. Si el cliente posee historia clínica se procederá a programar la cita con el especialista de turno, de no ser así la recepcionista generará una historia clínica con los datos generales del cliente, para luego programar la cita registrándola en la base de datos. El cliente pasa a realizar el pago del servicio por la evaluación integral que realizará el médico fisiatra; aquí 
recibirá el documento comercial correspondiente ya sea una boleta de venta o una factura. Luego el cliente pasa a la sala de espera para ser llamado a la brevedad posible.

El medico fisiatra es el que realiza la evaluación integral a la vez que registra el diagnóstico en la base de datos y decide si el cliente, llamado ahora paciente, pasa a recibir el tratamiento terapéutico o es referido a otro centro especializado ya que existen condiciones extremas de los pacientes que el centro no está capacitado para tratar, como por ejemplo enfermedades severas a la columna, entre otras.

Si el cliente puede ser atendido en el centro; el medico fisiatra diseña el tratamiento terapéutico especificando el tipo de terapia y la cantidad de sesiones necesarias para la rehabilitación del paciente. El paciente deberá pasar nuevamente por el área de admisión a realizar el pago de la terapia donde se le brindará la posibilidad de decidir su forma de pago, ya sea el precio paquete o el pago del costo individual por las terapias.

Después del pago del tratamiento establecido el cual será de dos modalidades según la conveniencia del cliente (pago por sesión o por la totalidad del tratamiento), el paciente pasa a recibir la rehabilitación mediante las sesiones que realizan los tecnólogos médicos registrándose los tratamientos en la base de datos; a la vez se hace el seguimiento de la enfermedad musculo-esquelética hasta efectuar una evaluación final la que indica si se extiende el tratamiento o se le da de alta al paciente.

Si el paciente necesita ampliar sus terapias; el tecnólogo medico realizará el tratamiento hasta que la evaluación indique que ya puede ser dado de alta con lo que se da por terminado el servicio.

\subsubsection{Diagrama de flujo del servicio}

A continuación se presenta el diagrama de flujo del proceso de atención al cliente: 
Figura 5.7

Diagrama de flujo del servicio

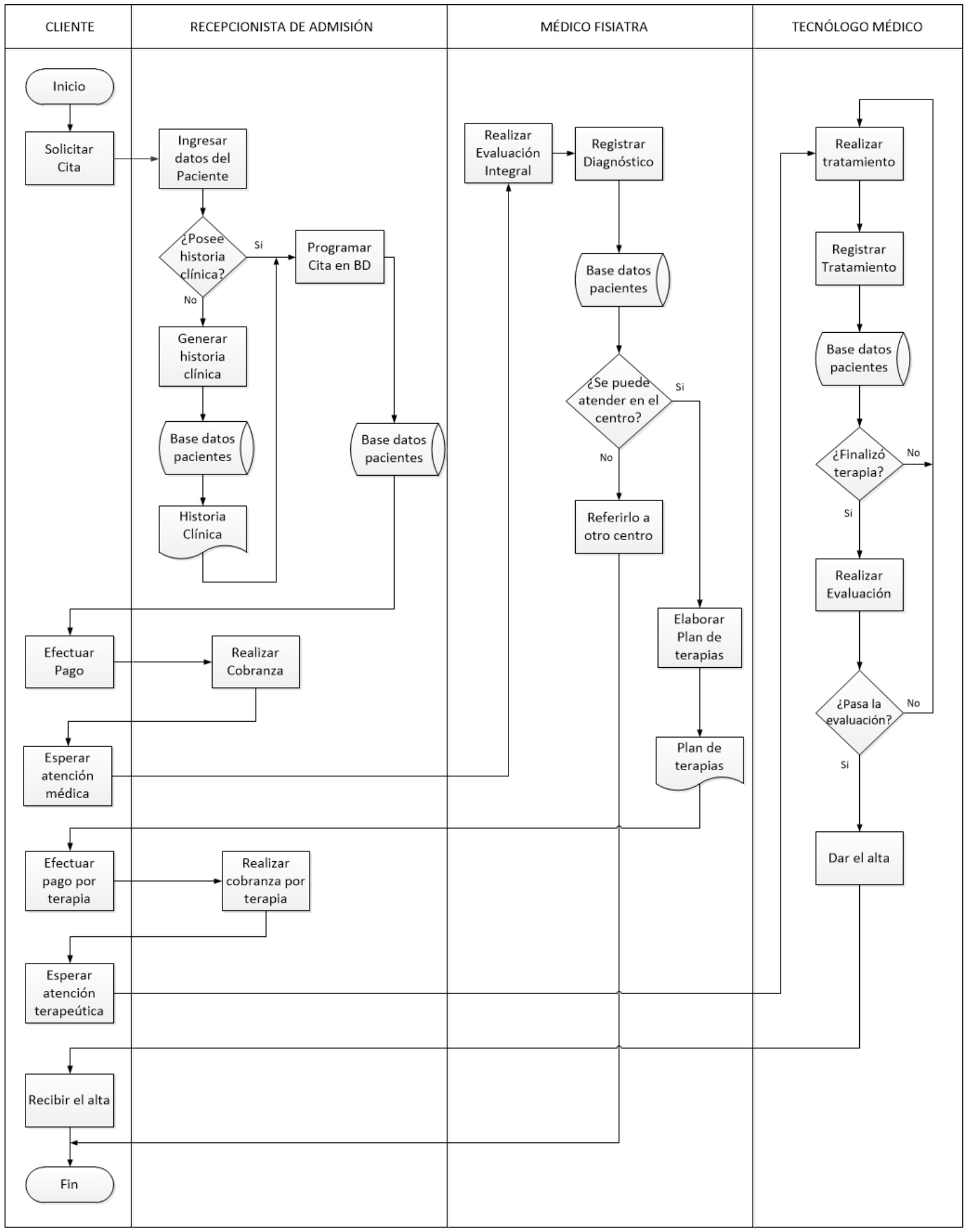

Elaboración propia 


\subsection{Características de las instalaciones y equipo}

\subsubsection{Selección de las instalaciones y equipo}

Las instalaciones donde se llevarán a cabo los servicios de rehabilitación física serán ecoeficientes gracias al desarrollo de un plan de manejo ambiental donde se describirán todas las acciones a tomar en cuenta para ahorrar significativamente el uso de los recursos; lo que se busca es utilizar materiales que posean características tales como bajo contenido energético, baja emisión de gases de efecto invernadero, reciclados, entre otros; equipos de bajo consumo de energía, luminarias LED, e iluminación natural por medio de un diseño especifico de ventanas que provean dicha iluminación en vez de utilizar energía eléctrica.

Las construcciones o remodelaciones del centro cumplirán con las disposiciones señaladas en la "Norma Técnica para el Diseño de Elementos de Apoyo para personas con Discapacidad en los Establecimientos de Salud" y el "Reglamento Nacional de Construcciones" vigente a la fecha, aplicables a oficinas, ambientes comunes como la piscina o el gimnasio, ingresos, rampas, escaleras, pasadizos, ascensores, servicios higiénicos, vestuarios, estacionamientos, etc.

De acuerdo a la tecnología seleccionada en cada una de las etapas del proceso de prestación de los servicios de fisioterapia, se procedió a elegir los equipos con capacidades acorde a los requerimientos de atenciones de pacientes según el tipo de enfermedad o dolencia presentada.

Para el proceso de programación de citas y registro de historias clínicas se utilizarán modernos equipos de cómputo, de telefonía y un sistema de alimentación de energía ininterrumpida en caso de algún corte del flujo eléctrico. 
Tabla 5.4

Equipos seleccionados en el proceso de programación de citas y registro de historias clínicas

\begin{tabular}{|l|l|}
\hline \multicolumn{1}{|c|}{ Equipos } & \multicolumn{1}{c|}{ Descripción } \\
\hline Teléfono para recepción & Marca: Avaya - Modelo: 2000 Series IP Deskphones \\
\hline Teléfono para oficinas & Grandstream GXP1405 \\
\hline Computadora desktop & Intel Core I5 4690 LGA1150 4ta generación I5 4690 \\
\hline Laptop & HP 14-R023LA \\
\hline UPS & Eaton 5S \\
\hline Impresora & Fotocopiadora Color Scanner / Fax Rocoh \\
\hline
\end{tabular}

Fuente: Infotec

Elaboración propia

Respecto al proceso referido a la ejecución de las terapias físicas para la rehabilitación de los clientes; se detalla a continuación los equipos que han sido seleccionados para la prestación de estos servicios:

Tabla 5.5

Equipos seleccionados en el proceso de rehabilitación física

\begin{tabular}{|l|l|}
\hline \multicolumn{1}{|c|}{ Equipos } & \multicolumn{1}{c|}{ Descripción } \\
\hline Electroestimulador o TENS & Marca: CEC - Modelo: Ultra Max \\
\hline Ultrasonido & Marca: Enraf Nonius - Modelo: Sonopuls 490 \\
\hline Magneto & Marca: ASA - Modelo: Quattro Pro Automático \\
\hline Equipo de ondas de choque & Marca: Chattanooga - Modelo: Intelect RPW \\
\hline Láser & Marca: Chattanooga - Modelo: Láser Intelect Mobile \\
\hline Onda corta & Marca: Chattanooga - Modelo: Intelect 100 \\
\hline Ecógrafo & Ecógrafo Portable blanco y Negro Edan DUS 60 \\
\hline Microondas & Radar RT 250 Digital \\
\hline Tanque de compresas calientes & Marca: Chattanooga - Modelo: M-2 \\
\hline Tanque de compresas frias & Marca: WHITEHALL - Modelo: GLACIER FREEZE \\
\hline Tanque de parafina & Marca: Enraf Nonius - Modelo: Baño de parafina \\
\hline Masajeador eléctrico & Masajeador Corporal Vibratorio U-Tech (F-833) \\
\hline Trotadora caminadora & Trotadora BE-6552Oxford \\
\hline
\end{tabular}

Fuente: J.P. Rehab S.R.L.

Elaboración propia

Todos estos equipos cumplen con la Ley de Promoción de Uso Eficiente de la Energía Ley $N^{o} 27345$ que establece que los equipos y artefactos que requieren suministro de energía, deben incluir en sus etiquetas, envases, empaques y publicidad, 
la información sobre su consumo energético en relación con los estándares de eficiencia energética. A la vez existe también la Normatividad y Etiquetado para la promoción del uso eficiente de la energía de la Dirección General de Eficiencia Energética del Ministerio de Energía y Minas donde se informa al usuario sobre el consumo de energía de un aparato, brindando así los beneficios en el ahorro económico y contribuyendo a mitigar el calentamiento global.

\subsubsection{Especificaciones de las instalaciones y equipo}

Las instalaciones donde se llevarán a cabo los servicios de rehabilitación física serán ecoeficientes, lo cual implica aprovechar los recursos naturales de tal modo que se minimice el impacto de las instalaciones sobre el medio ambiente y sus habitantes.

La creación y diseño de las instalaciones ecoeficientes, estarán a cargo de un equipo conformado por ingenieros civiles, arquitectos y diseñadores quienes moldearán el proyecto y sentarán las bases para la construcción de las instalaciones, la misma que estará a cargo de una empresa constructora.

Las instalaciones ecoeficientes implican características de sustentabilidad y es por ello que se ha tomado en cuenta las siguientes especificaciones para el centro de fisioterapia:

\section{Aprovechamiento de energía renovable}

Las instalaciones contemplarán el aprovechamiento de energías no contaminantes e inagotables, conocidas también como energías renovables. Es por ello que la energía solar será aprovechada como iluminación natural mediante un correcto diseño de las ventanas y mamparas de las instalaciones, lo que será complementado con el uso de cristales insulados con la finalidad de brindar un mayor aislamiento térmico y un aislamiento acústico que disminuya los ruidos molestos del exterior. 


\section{Microsistemas para el tratamiento de aguas}

Se ha considerado el sistema de aguas grises, el cual implica la captación del agua utilizada de los caños y duchas para su recirculación y utilización en actividades relacionadas a la limpieza del centro y el riego de los jardines.

\section{Empleo de materiales saludables}

Los materiales adecuados para construcciones sustentables, deben poseer características tales como bajo contenido energético, baja emisión de gases de efecto invernadero como $\mathrm{CO}_{2}-\mathrm{NO}_{\mathrm{x}}-\mathrm{SO}_{\mathrm{x}}-$ material particulado, ser reciclados y contener el mayor porcentaje de materiales de reutilización. Es por ello que las instalaciones del centro tendrán las siguientes características:

- Se evitará los aislamientos y pinturas de poro cerrado, plastificados, elementos retenedores de polvo electrostático y todos aquellos materiales que emiten gases tóxicos en su combustión. Se utilizarán pinturas al silicato, al agua, aceite de linaza, colofonia, ceras naturales, etc, y para los elementos decorativos, tratamientos de madera.

- En los elementos estructurales, se emplearán cementos naturales (concreto ecológico) o cal hidráulica. El uso del acero debe restringirse a lo imprescindible y deberá ser convenientemente derivado a tierra.

- En el caso de maderas no se emplearán las provenientes de bosques nativos, se utilizarán las maderas de cultivos como el pino, el eucalipto entre otras especies. Se usarán en algunos ambientes la madera plástica reciclada o los pisos de bambú como una alternativa. 


\section{Manejo de residuos, reciclado de estructuras y materiales}

Una construcción y arquitectura sustentable se centra en el uso y tratamiento de los residuos en el lugar, incorporando sistemas como el de tratamiento de aguas grises descrito anteriormente. Asimismo, las instalaciones deberán de tener un área de separación de residuos (vidrio, metal, plástico, orgánico) que facilite su reciclaje posterior.

Por otro lado se tratará de incorporar mariales reciclados o de segunda mano como la madera plástica reciclada en el equipamiento del edificio ya que la reducción del uso de materiales nuevos genera una reducción en el uso de la energía propia de cada material en su proceso de fabricación.

Las especificaciones de los equipos y sistemas ecoeficientes antes mencionados se detallan a continuación: 
Tabla 5.6

Equipos y sistemas ecoeficientes

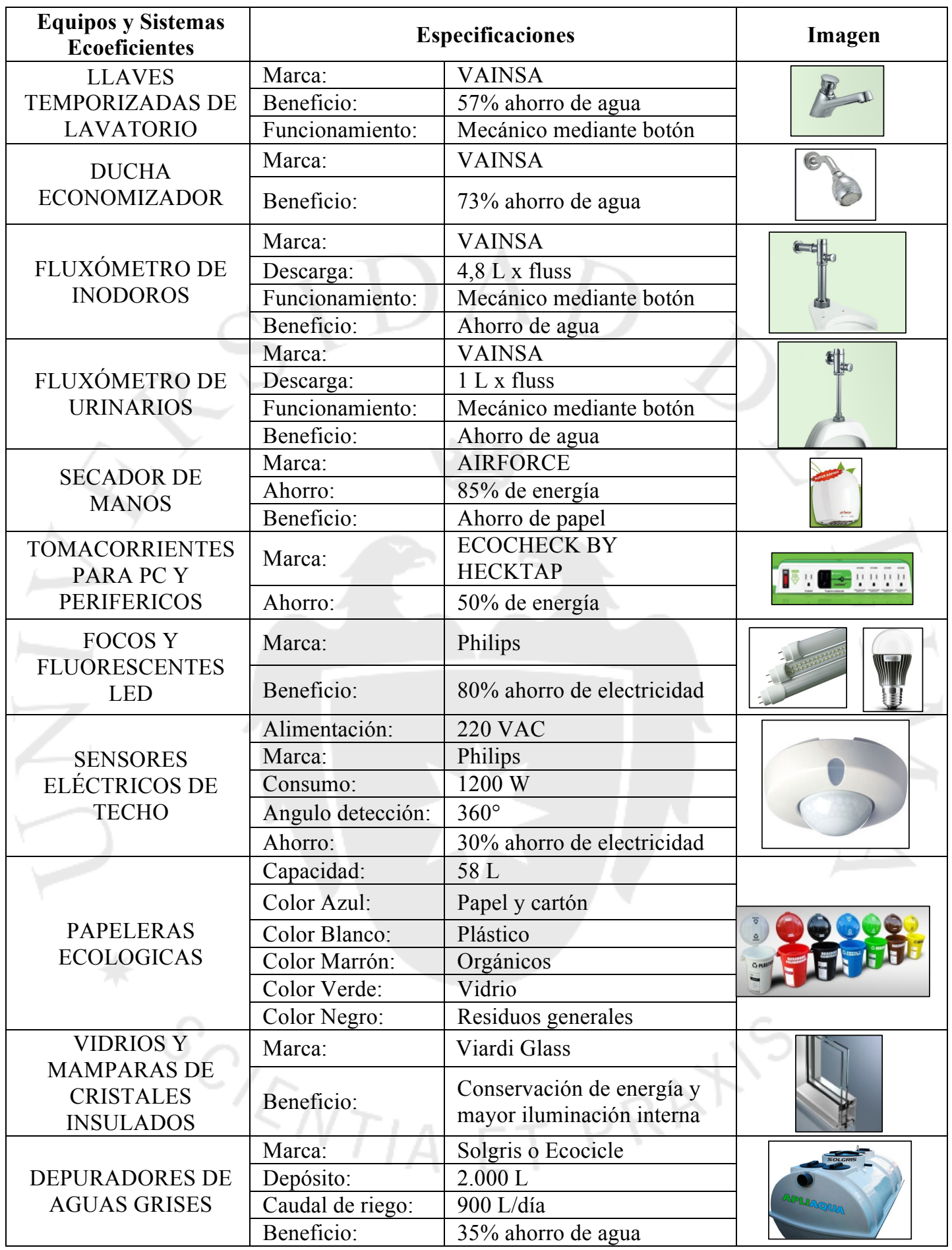

Fuente: Ministerio del Ambiente - Viardi Glass - Apliaqua Elaboración propia

Una de las principales instalaciones del centro de rehabilitación será la piscina terapéutica que permitirá la inmersión corporal total de los pacientes con una capacidad 
de 12 personas. La piscina estará temperada entre $30^{\circ} \mathrm{C}$ y $32^{\circ} \mathrm{C}$ lo que permite realizar los ejercicios físicos en un ambiente climatizado de confort para el paciente discapacitado o con lesiones físicas.

\section{Figura 5.8}

Piscina terapéutica

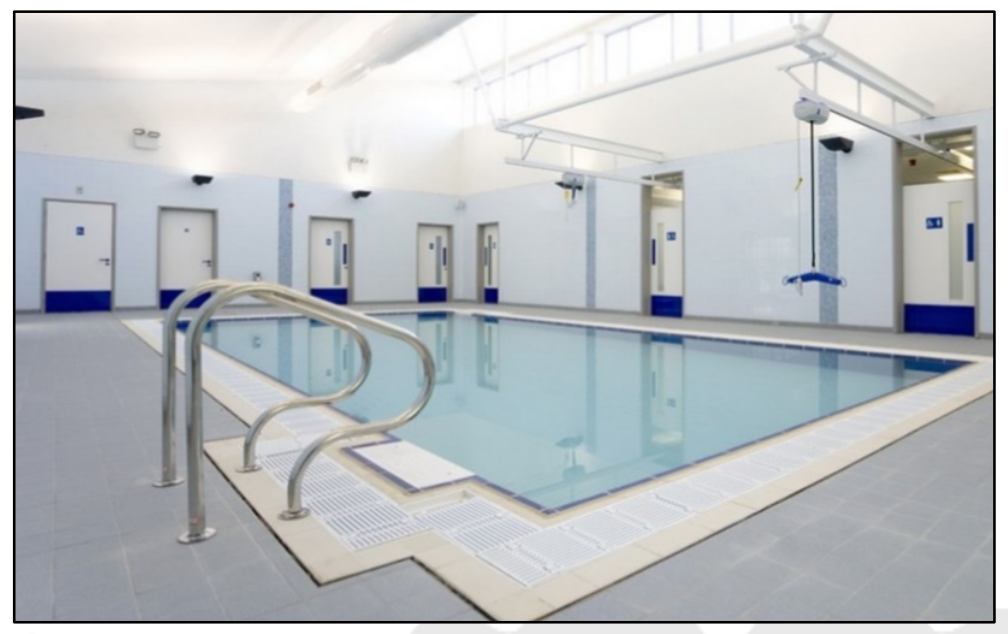

Fuente: Entorno Accesible

La piscina será de 8 metros de largo, 5 metros de ancho y 1 metro de profundidad equipada con un sistema de recirculación de agua con bombas, un filtro, dosificador de desinfección, válvulas, tablero de alimentación de energía y un calentador a gas para la climatización del agua a la temperatura terapéutica adecuada.

Accesorios especiales:

- Barandillas y pasamanos ergonómicos.

- Boquillas a distintas alturas para hidromasajes.

- Bancos sumergibles para las terapias.

- Pasillos externos para la asistencia en las actividades por el fisioterapeuta.

- Silla automática de acceso a piscina. 
Los equipos tanto del sistema de la piscina terapéutica, como los equipos utilizados para el registro de citas y las terapias están considerados como eficientes puesto que cumplen como se explicó anteriormente con la Ley de Promoción de Uso Eficiente de la Energía Ley $N^{o} 27345$ y la Normatividad y Etiquetado para la promoción del uso eficiente de la energía. A la vez el Ministerio del Ambiente define tres criterios necesarios para la selección final de los proveedores ecoeficientes; siendo necesario cumplir por los menos con uno de siguientes criterios:

- Ecoeficiencia en el diseño y características del producto

- Ecoeficiencia durante el proceso de producción o manufactura

- Buenas Prácticas ambientales, Certificaciones y Responsabilidad Social y Ambiental.

Por lo que los siguientes equipos que se mencionan a continuación cumplen con por lo menos uno de los requisitos mencionados anteriormente. 
Figura 5.9

Sistema y equipos de la piscina fisioterapéutica

SISTEMA DE RECIRCULACIÓN DE AGUA

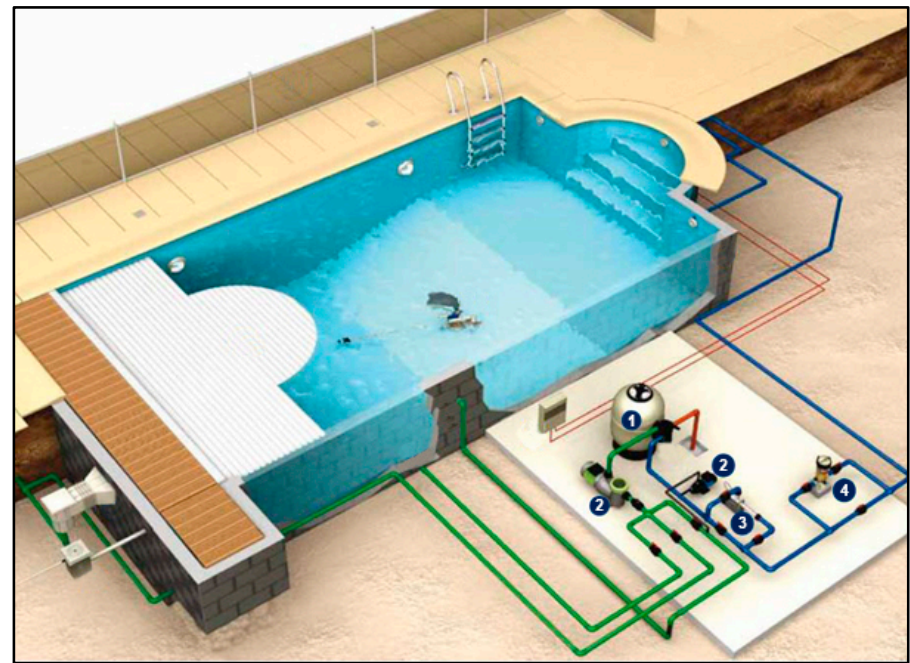

1. Filtro

2. Bombas

3. Calentador a gas

4. Dosificador de cloro

\section{FILTRO DEFENDER}

Está diseñado para el ahorro de agua de hasta el 90\% del agua de contralavado, $70 \%$ en reducción de espacio respecto a otros filtros con ahorro de energía y productos químicos.

\section{BOMBA DE AGUA HAYWARD}

Motor de alto rendimiento que incluye la ventilación de flujo de aire para el refrigerador. Bomba de funcionamiento silencioso. Características técnicas:

Monofásica $220 \mathrm{~V}, 60 \mathrm{~Hz}, 3.450 \mathrm{rpm}$.

Potencia: $1.5 \mathrm{HP}$

Salida: 2"

\section{CALENTADOR A GAS}

El calentador Fiero modelo FC-100 funciona a gas natural en forma totalmente automática, limpia y silenciosa, sus controles eléctricos apagan el equipo si hay falla de flama.

\section{DOSIFICADOR DE CLORO HAYWARD}

Funciona con tabletas de disolución lenta de cloro y bromo de mínimo mantenimiento con una malla de protección interior para evitar obturaciones en el sistema.

\section{SILLA DE ACCESO}

Está diseñada para transferir personas a y desde las piscinas, vestuarios y otros lugares de un modo sencillo, cómodo y seguro. Características técnicas:

Estructura de acero, estable y robusta.

Dimensiones: 120 × 50 x $125 \mathrm{~cm}$ con capacidad de elevación de $110 \mathrm{Kg}$ y un peso total de $120 \mathrm{Kg}$.
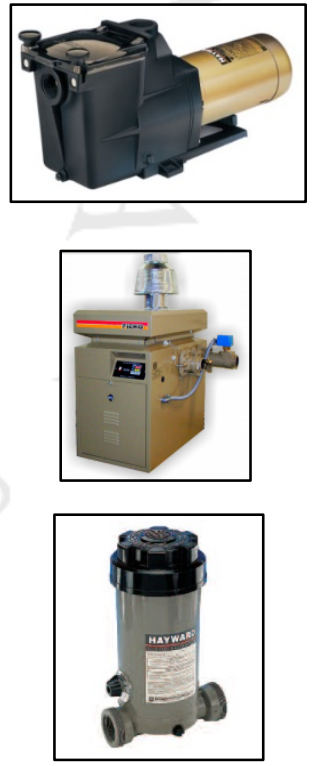

Fuente: Toledo Piscinas

Elaboración propia 
Para el proceso de programación de citas y registro de las historias clínicas de los pacientes se contara con:

Figura 5.10

Equipos para el proceso de programación de citas y registro de historias clínicas

\section{TELÉFONOS}

Teléfono para recepción marca: Avaya

Modelo: 2000 Series IP Deskphones.

Teléfono para oficinas administrativas marca:

Grandstream GXP1405.

\section{COMPUTADORA HP DESKTOP}

Procesador: core i5 $46903.5 \mathrm{ghz} 6 \mathrm{~m}$ lga1150 4ta generación Memoria RAM: kingston hyperx 8gb ddr3 1600 fury blue

Disco duro: seagate 1tb $7200 \mathrm{rpm}$ s-ata 3.5"

Video: $2 \mathrm{gb}$ asus strix gtx $960 \mathrm{ddr} 5$

Monitor: LG 21.5" LED IPS 22MP57HQ-P Full HD

Kit teclado, mouse, Microsoft wired 400 negro/USB

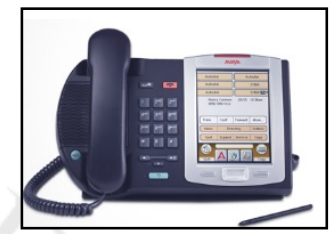

\section{LAPTOP HP 14-R023LA RETROILUMINACIÓN LED}

Procesador: Intel Core I5-4210U

Memoria RAM: 4GB DDR3L SDRAM $1600 \mathrm{MHz}$

Disco duro: 500 GB SATA 5400 rpm

Pantalla 14" LED 1366 x 768 HD

Interfaz de red LAN Ethernet 10/100 Base-T integrada

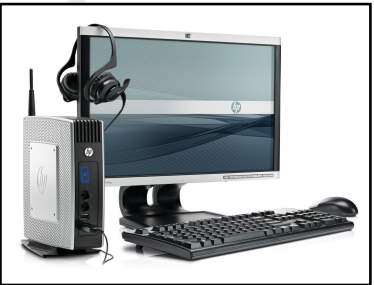

\section{SISTEMA DE ALIMENTACIÓN ININTERRUMPIDA DE ENERGÍA UPS}

Fuente de suministro eléctrico que posee una batería con el fin de seguir dando energía a un dispositivo en caso de interrupción eléctrica

Marca: Eaton 5S Small UPS

Potencia de salida $1.5 \mathrm{Kva}$

Voltaje; 120V, 208/230V

Frecuencia: $50 / 60 \mathrm{~Hz}$

Consumo: 1200 watts

Dimensiones: $24.9 \mathrm{~L}$ x $8.6 \mathrm{~A}$ x $38.1 \mathrm{H} \mathrm{cm}$.

Peso: $11,6 \mathrm{Kg}$.

Baterías de libre mantenimiento

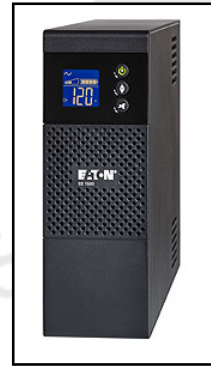

\section{FOTOCOPIADORA COLOR SCANNER / FAX / IMPRESORA DE RED}

Marca: Ricoh

Dimensiones: $45 \mathrm{~A}$ x $48.5 \mathrm{~L} \mathrm{x} 48.1 \mathrm{H} \mathrm{cm}$

Peso: Menos de $29 \mathrm{~kg}$ (con ARDF)

Fuente de energía: $120 \mathrm{~V}, 60 \mathrm{~Hz}, 8 \mathrm{~A}$

Consumo de energía: Máximo: Menos de $1.000 \mathrm{w}$

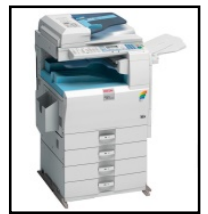

Fuente: Infotec - Powerquality - Onedirect

Elaboración propia 
Respecto a los equipos que se utilizarán en la etapa del proceso referida a la ejecución de las fisioterapias tenemos:

Figura 5.11

Equipo Ecógrafo

\section{ECÓGRAFO}

Marca: Edan / Modelo: DUS 60 /Procedencia: España

\section{Características:}

Ecógrafo portable en blanco y negro digital con 7 tipos de pseudocolores, pantalla TFT de 12 '1 pulgadas de alto contraste, con dos conectores de sonda, 2 puertos USB para archivo en memoria externa, puerto LAN, memoria cine hasta 256 fotogramas.

\section{Especificaciones técnicas:}

- Portable con pantalla en blanco y negro.

- Fuente de alimentación: $100-240 \mathrm{~V}-50 / 60 \mathrm{~Hz}$

- Peso: 7,1 Kg.

- Batería de Litio: Operación continua por más de 2 horas

- Dimensiones: $33 \mathrm{~L} \mathrm{x} 22 \mathrm{~A}$ x $32 \mathrm{H} \mathrm{cm}$.

- Consumo de energía: 45 Watts

\section{Accesorios:}

- Sonda C361-2 convexa (2,5-4,5 MHz)

- Cable de red eléctrica y bote de gel

Fuente: Quirumed

Figura 5.12

Equipo Electroestimulador

\section{ELECTROESTIMULADOR (TENS)}

Marca: CEC / Modelo: Ultra Max / Procedencia: Argentina

\section{Características:}

- Modo automático, simple y rápido, a través de los 80 programas preestablecidos y modo personal, ofrece al usuario la posibilidad de guardar 100 programas más.

- 2 exclusivos cabezales de ultrasonido dual $(9 \mathrm{~cm} 2$ y $1,5 \mathrm{~cm} 2)$, los cuales permiten elegir la frecuencia de tratamiento de $1 \mathrm{MHz}$ o $3 \mathrm{MHz}$

- Máx. corriente de salida (mA/1 kohm): Interferencial, TENS, rusas (100) / galvánica (30) / impulsos (80) / diadinámicas (70)

- 4 canales de estimulación corporal.

\section{Especificaciones técnicas:}

- Alimentación: 120 - 220V / 50 - $60 \mathrm{~Hz}$.

- Dimensiones: $30 \mathrm{~L}$ x $44 \mathrm{~A} \mathrm{x} 16 \mathrm{H} \mathrm{cm}$. Peso: 5, $4 \mathrm{Kg}$.

- Temporización: 0 a 60 min.

- Consumo: 35 watts

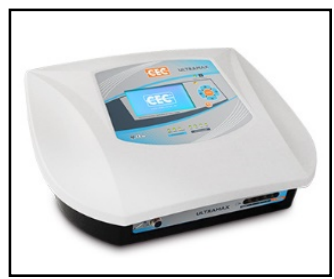

Fuente: JP. Rehab S.R.L. 
Figura 5.13

Equipo Ultrasonido

\section{ULTRASONIDO}

Marca: Roland / Modelo: Log-3 Band / Procedencia: Holanda

\section{Características:}

- 1-2-3 MHz unidad de ultrasonido multifrecuencia.

- Modulación de 1 a $200 \mathrm{~Hz}$.

- Multifrecuencia cabeza $5 \mathrm{~cm} 2$ 1-2-3 MHz trabajando en simple o combinada.

- $3 \mathrm{~W} \mathrm{~cm} 2$ en continuo y en los modos pulsados en tiempo real con dispositivo de indicación correcta de contacto entre el cabezal y el paciente.

- Cálculo automático de la profundidad y densidad de energía.

- Interruptor de apagado automático con temporizador de 30 minutos.

- Pantalla LCD color de 480 x 800 píxeles.

\section{Especificaciones técnicas:}

- Fuente de alimentación: $115-230 \mathrm{~V}-50 / 60 \mathrm{~Hz}$

- Dimensiones: $40 \mathrm{~L}$ x $40 \mathrm{~A}$ x $23 \mathrm{H} \mathrm{cm}$.

- Consumo de energía: 70 watts

\section{Accesorios:}

- $5 \mathrm{~cm} 2$ de cabeza multifrecuencia.

- Cable de alimentación y gel 250 gr.

Fuente: JP. Rehab S.R.L.

Figura 5.14

Equipo Magneto

\section{MAGNETO}

Marca: CEC / Modelo: Mag 3 Tunneling / Procedencia: Argentina

\section{Características:}

- Pantalla LCD.

- Capacidad de crear y almacenar hasta 100 programas nuevos.

- Indicador LED de emisión de campo magnetico activo.

- 4 canales de salida para poder utilizar hasta cuatro accesorios al mismo tiempo.

- Potencia de salida regulable hasta 200 Gauss.

- Frecuencia regulable de 3 a $100 \mathrm{HZ}$.

- Tiempo regulable de 0 a 60 minutos.

\section{Especificaciones técnicas:}

- Alimentación $230 \mathrm{~V}-50 / 60 \mathrm{~Hz}$

- Consumo: 110 watts

- Dimensiones: 39 x 23 x $15 \mathrm{H}$ cm. Pesos: $3.5 \mathrm{Kg}$.

\section{Accesorios:}

- 02 solenoides tipo túnel.

- 02 solenoides tipo disco plano

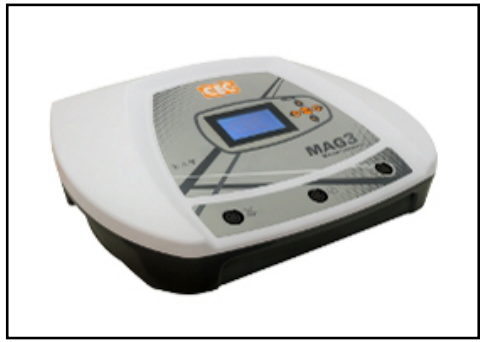

Fuente: JP. Rehab S.R.L. 
Figura 5.15

Equipo de Ondas de choque

\section{ONDAS DE CHOQUE}

Marca: Chattanooga / Modelo: Intelect RPW / Procedencia: USA

\section{Características:}

- Pantalla LCD táctil a todo color. Rotación pivotante de $360^{\circ}$.

- 200 memorias libres para almacenar los protocolos definidos por el usuario.

- Más de 80 protocolos clínicos incorporados.

- Dos canales permiten la conexión de dos aplicadores.

- Salida de aire comprimido: 1,4 - 5 bares.

- Amplitud de pulso: aprox. $2 \mathrm{~mm}$ a 3 bares.

- Duración de pulso: aprox. 6 - 12ms con frecuencia de pulso: $0,5-21 \mathrm{~Hz}$.

\section{Especificaciones Técnicas:}

- Fuente de alimentación: $230 \mathrm{~V}-50 \mathrm{~Hz}$

- Consumo de energía: 550 watts.

- Modo: único o continuo

- Fusibles: dos de $6,3^{\mathrm{a}}$, intervalo de tiempo $5 \times 20 \mathrm{~mm}$

- Clase de riesgo: lla según la normativa MDD 93/42/CEE

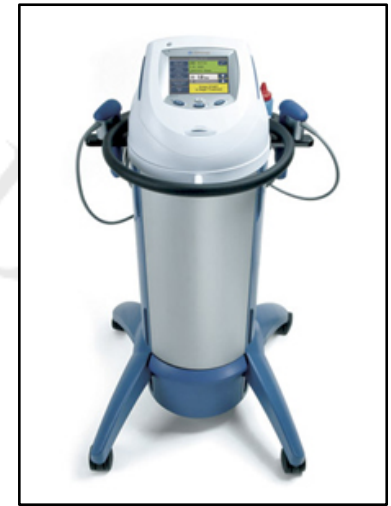

Fuente: JP. Rehab S.R.L.

Figura 5.16

Equipo Láser

\section{LÁSER}

Marca: Chattanooga / Modelo: Láser Intelect Mobile / Procedencia: USA

\section{Características:}

- Láser de bajo nivel clase 3B de 1,040mw

- Funcionamiento continuo y pulsado disponible.

- Sonda de grupo de 9 diodos, 1040mw.

- Amplia pantalla LCD, retro iluminada con variación de contraste a elección.

- Disparador de emisión de láser en el cabezal del equipo

- Puntero láser 904nm - AsGa

\section{Especificaciones técnicas:}

- Modo de emisión pulsado a $10 \mathrm{KHZ}$.

- Tiempo de trabajo 1 a 60 minutos.

- Alimentación bivoltio 100 / $240 \mathrm{VAC}-50$ a $60 \mathrm{~Hz}$.

- Consumo máximo: 30 watts.

- Dimensiones $30 \mathrm{~L}$ x $26 \mathrm{~A}$ x $6.5 \mathrm{H} \mathrm{cm}$.

\section{Accesorios:}

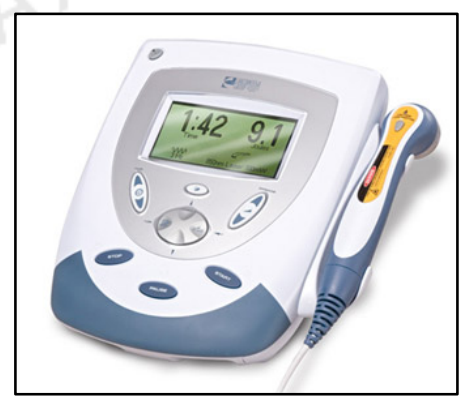

- 02 gafas protectora

- Aplicador de grupo de 9 diodos, $1040 \mathrm{~mW}$ Total: 5 x lásers $850 \mathrm{~nm} 200 \mathrm{~mW}$.

Fuente: JP. Rehab S.R.L. 
Figura 5.17

Equipo microondas

\section{MICROONDAS}

Marca: Radar / Modelo: RT 250 / Procedencia: USA

\section{Características:}

- Equipo con ruedas para un fácil desplazamiento.

- Pantalla a color de 240 x 128 píxeles.

- 50 programas de fácil aplicación en memoria y 10 para memorizar.

- Modalidad de emisión pulsada y continua.

- Brazo radar con pivote para posiciones múltiples de fácil fijación.

\section{Especificaciones técnicas:}

- Alimentación: 100 - $240 \mathrm{VAC} / 50 \mathrm{a} 60 \mathrm{~Hz}$.

- Dimensiones $30 \mathrm{~L}$ x $42 \mathrm{~A}$ x $90 \mathrm{H} \mathrm{cm}$.

- Potencia máxima: $250 \mathrm{w}$ en modo continuo y $1.600 \mathrm{w}$ en modo pulsado.

\section{Accesorios incluidos:}

- Brazo ortostático y antena circular modelo AC

- 2 fusibles de recambio

Fuente: JP. Rehab S.R.L.

Figura 5.18

Equipo Onda corta

\section{ONDA CORTA}

Marca: Chattanooga / Modelo: Intelect 100 / Procedencia: USA

\section{Características:}

- Interfaz con pantalla LCD táctil a todo color

- Configuración de tratamiento mediante disimetría térmica indicador de enlace directo, protocolos clínicos. 200 posiciones de protocolo.

- Frecuencia y amplitud de pulso ajustables con temporizador de tratamiento.

- Interfaz con rotación pivotante de $360^{\circ}$, amplitud de pulso $20-400$ u segundos.

- Frecuencia de pulso $10-800 \mathrm{~Hz}$ con ajuste automático de resonancia.

- Tiempo de tratamiento 1-60 minutos

\section{Especificaciones técnicas:}

- Fuente de alimentación de 100-240V AC / 50-60Hz

- Frecuencia de salida: $27.12 \mathrm{MHz}$

- Dimensiones: $61 \mathrm{~L}$ x $30.5 \mathrm{~A}$ x $115.5 \mathrm{H} \mathrm{cm}$. Peso: $27 \mathrm{Kg}$

- Potencia de salida: $100 \mathrm{w}$ modo continuo, pico de 200w en modo pulsado.

\section{Accesorios:}

- Electrodos capacitivos de $120 \mathrm{~mm}(2 \mathrm{x})$

- Tubo indicador de descarga

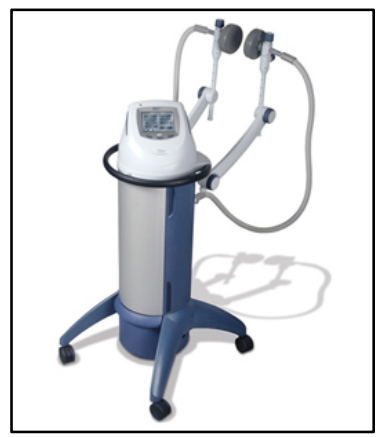

Fuente: JP. Rehab S.R.L. 
Figura 5.19

Tanque de compresas calientes

\section{TANQUE DE COMPRESAS CALIENTES}

Marca: Chattanooga / Modelo: M-2 / Procedencia: México

\section{Características:}

- Temperatura regulada con termostato

- Depósito aislado

- 12 compresas medianas tamaño estándar $25 \times 30 \mathrm{~cm}$

\section{Especificaciones técnicas:}

- Alimentación: $110-220 \mathrm{VCA} 60 \mathrm{~Hz}$

- Consumo: $1000 \mathrm{w}$

- Capacidad del tanque: 68,81 litros

- Temperatura normal de operación $71^{\circ} \mathrm{C}-74^{\circ} \mathrm{C}$

- Límite de seguridad: $82^{\circ} \mathrm{C}-85^{\circ} \mathrm{C}$

- Tiempo de calefacción: Llega a $70^{\circ} \mathrm{C}$ en 6 horas.

- Tiempo de enfriamiento 3 horas a partir de $70^{\circ} \mathrm{C}$

- Dimensiones: 40 x 67,5 x $85 \mathrm{~cm}$.

- Peso $37.32 \mathrm{~kg}$

Fuente: JP. Rehab S.R.L.

Figura 5.20

Tanque de compresas frías

\section{TANQUE DE COMPRESAS FRÍAS}

Marca: Whitehall / Modelo: Glacier Freeze / Procedencia: USA

\section{Características:}

- Bobinas de refrigeración interior diseñadas para paquetes fríos más rápidos.

- Con cinco pies cúbicos de capacidad espaciosa.

- Cuatro mangas cómodas de congelación rápida de acero inoxidable duradero.

- Bandejas y soportes de copa.

\section{Especificaciones técnicas:}

- Alimentación principal; $115 \mathrm{~V}, 50 \mathrm{~Hz}$ con auto transformador $220-240 \mathrm{~V}, 60 \mathrm{~Hz}$

- Consumo: $500 \mathrm{w}$

- Dimensiones: 61 x 55 x $86 \mathrm{~cm}$.

\section{Accesorios:}

- 04 compresas frías estándar

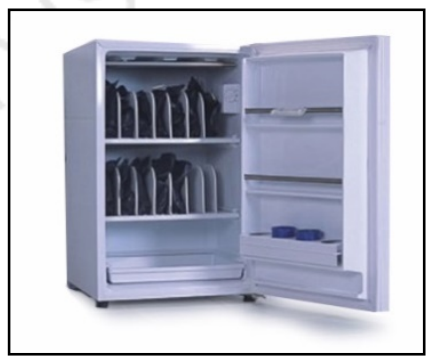

Fuente: JP. Rehab S.R.L. 
Figura 5.21

Tanque de Parafina

\section{TANQUE DE PARAFINA}

Marca: Enraf Nonius / Modelo: Baño de parafina / Procedencia: Holanda

\section{Características:}

El baño de parafina trabaja por el principio del baño maría; la parafina es calentada directamente por el calor transferido desde el líquido de transferencia de calor donde se realiza el calentamiento mucho más rápido distribuyendo mejor el calor. Prácticamente no hay fluctuaciones de temperatura en la parafina.

\section{Especificaciones técnicas:}

- Tanque interior de acero inoxidable con tapadera cubierta.

- Control de temperatura termostática $\left(30-90^{\circ} \mathrm{C}\right)$.

- Mecanismo de seguridad por sobrecalentamiento

- Rango de temperatura: $30-90{ }^{\circ} \mathrm{C}$

- Dimensiones internas: $50 \mathrm{~L}$ x $30 \mathrm{~A}$ x $21 \mathrm{H} \mathrm{cm} .(30 \mathrm{~L})$

- Dimensiones externas: $58 \mathrm{~L}$ x $32 \mathrm{~A}$ x $50 \mathrm{H} \mathrm{cm}$. (30 L)

- Voltaje de red: $230 \mathrm{~V}-50 / 60 \mathrm{~Hz}$

- Consumo: 200 Watts

\section{Accesorios:}

- 20 kilos de parafina terapéutica.

- 01 juego de guantes y botas de felpa.

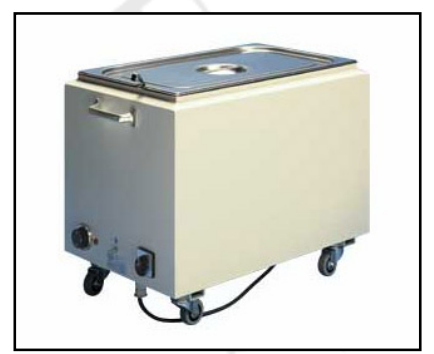

Fuente: JP. Rehab S.R.L.

Figura 5.22

Caminadora trotadora

\section{CAMINADORA TROTADORA}

Marca: Oxford / Modelo: BE-6552 / Procedencia: España

\section{Especificaciones Técnicas:}

- Motor: $2.0 \mathrm{hp}$

- Suela: 130 x $40 \mathrm{~cm}$

- Inclinación: Automática, $12 \%$

- Monitor: LCD sreen W/ luz de fondo azul provide 12

- Información de pantalla: Velocidad, tiempo, distancia, inclinación, calorías, pulsaciones

- Funciones: Pulso, grasa corporal

- Velocidad: De 0.1 a $16 \mathrm{~km} / \mathrm{h}$

- Ruedas frontales para transporte.

- Peso max. usuario: $100 \mathrm{~kg}$

- Dimensiones: $130 \mathrm{~A}$ x $73.5 \mathrm{~A}$ x $165.5 \mathrm{H} \mathrm{cm}$.

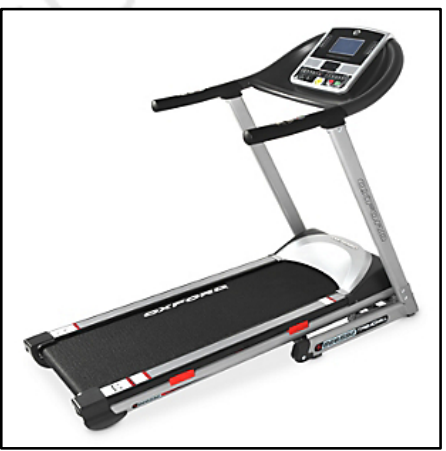

Fuente: JP. Rehab S.R.L. 
Figura 5.23

Masajeador corporal

\section{MASAJEADOR CORPORAL VIBRATORIO}

Marca: U-Tech / Modelo: F-833 / Procedencia: Argentina

Especificaciones Técnicas:

- Dimensiones: 39,5 L x 42,5 A x 83,5 H cm.

- Peso neto: $18,6 \mathrm{Kg}$.

- Frecuencias de vibración hasta $40 \mathrm{~Hz}$

- Características eléctricas de voltaje: 220V - 240V

- Frecuencia: $50 \mathrm{~Hz} / 60 \mathrm{~Hz}$

- Consumo: 60 watts.

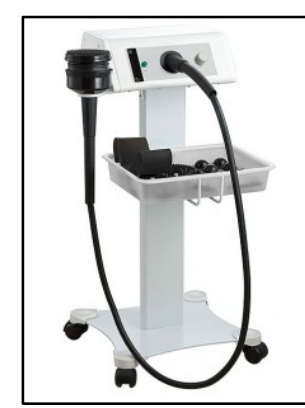

Fuente: JP. Rehab S.R.L.

\subsection{Capacidad instalada}

\subsubsection{Cálculo de la capacidad instalada del servicio}

La capacidad instalada del servicio se deberá calcular en función de la demanda requerida para el proyecto para el año 2021 de manera que se pueda cubrir con la atención del servicio en toda la vida útil del proyecto. La demanda del servicio para el año 2021 es de 4.991 adultos mayores traducidas en 119.781 sesiones.

Estas atenciones se dividirán en 2 tipos de terapia que son la "terapia de alivio del dolor" y la "terapia de restauración de la movilidad" con una duración de 55 minutos y 60 respectivamente; las cuales están conformadas por distintas actividades que se aplicarán en una sesión y no necesariamente de manera secuencial.

En las tablas 5.7 y 5.8 se detallan los tipos de terapia que se utilizan; los equipos y el tiempo que toma la atención de los tecnólogos médicos para efectuar una sesión: 
Tabla 5.7

Equipos y duración de la terapia de alivio del dolor

\begin{tabular}{|l|l|c|}
\hline $\begin{array}{c}\text { Terapia de alivio } \\
\text { del dolor }\end{array}$ & \multicolumn{1}{|c|}{ Equipo } & $\begin{array}{c}\text { Tiempo } \\
\text { (min) }\end{array}$ \\
\hline Electroterapia & Electroestimulador & 15 \\
\hline Ultrasonoterapia & Ultrasonido & 5 \\
\hline Termoterapia & Microondas & 10 \\
\hline Masoterapia & Masajeador & 5 \\
\hline Kinesioterapia & Caminadora & 20 \\
\hline Total & & $\mathbf{5 5}$ \\
\hline
\end{tabular}

Elaboración propia

Tabla 5.8

Equipos y duración de la terapia de restauración de la movilidad

\begin{tabular}{|l|l|c|}
\hline \multicolumn{1}{|c|}{$\begin{array}{c}\text { Terapia de restauración } \\
\text { de la movilidad }\end{array}$} & \multicolumn{1}{|c|}{ Equipo } & $\begin{array}{c}\text { Tiempo } \\
\text { (min) }\end{array}$ \\
\hline Magnetoterapia & Magneto & 15 \\
\hline Terapia de ondas de choque & Ondas de choque & 10 \\
\hline Laserterapia & Láser & 10 \\
\hline Termoterapia & Onda Corta & 10 \\
\hline Hidroterapia & Piscina & 15 \\
\hline Total & & $\mathbf{6 0}$ \\
\hline
\end{tabular}

Elaboración propia

La demanda al año 2021 es de 119.781 sesiones y se dividirá entre estos dos tipos de terapias por lo que se realizarán 59.891 sesiones por cada terapia. Teniendo en cuenta los tiempos de duración de las terapias y el número de equipos que se utilizarán para cubrir la demanda (el análisis para el cálculo del número de equipos se detalla en el punto 5.4.2); se procede a calcular la capacidad instalada del servicio.

Se considera para el cálculo el horario la atención del centro que será de lunes a sábado de 8:00 am a 8:00 pm lo que se resume en los siguientes puntos:

- Días: 313 días al año

- Horas: 6 horas por turno 
- Turnos: 2 turnos por día

- Utilización: 0,9

- Eficiencia: 0,8

Las siguientes tablas que se muestran a continuación muestran el cálculo de la capacidad instalada para los dos tipos de terapia que se brindarán en el centro:

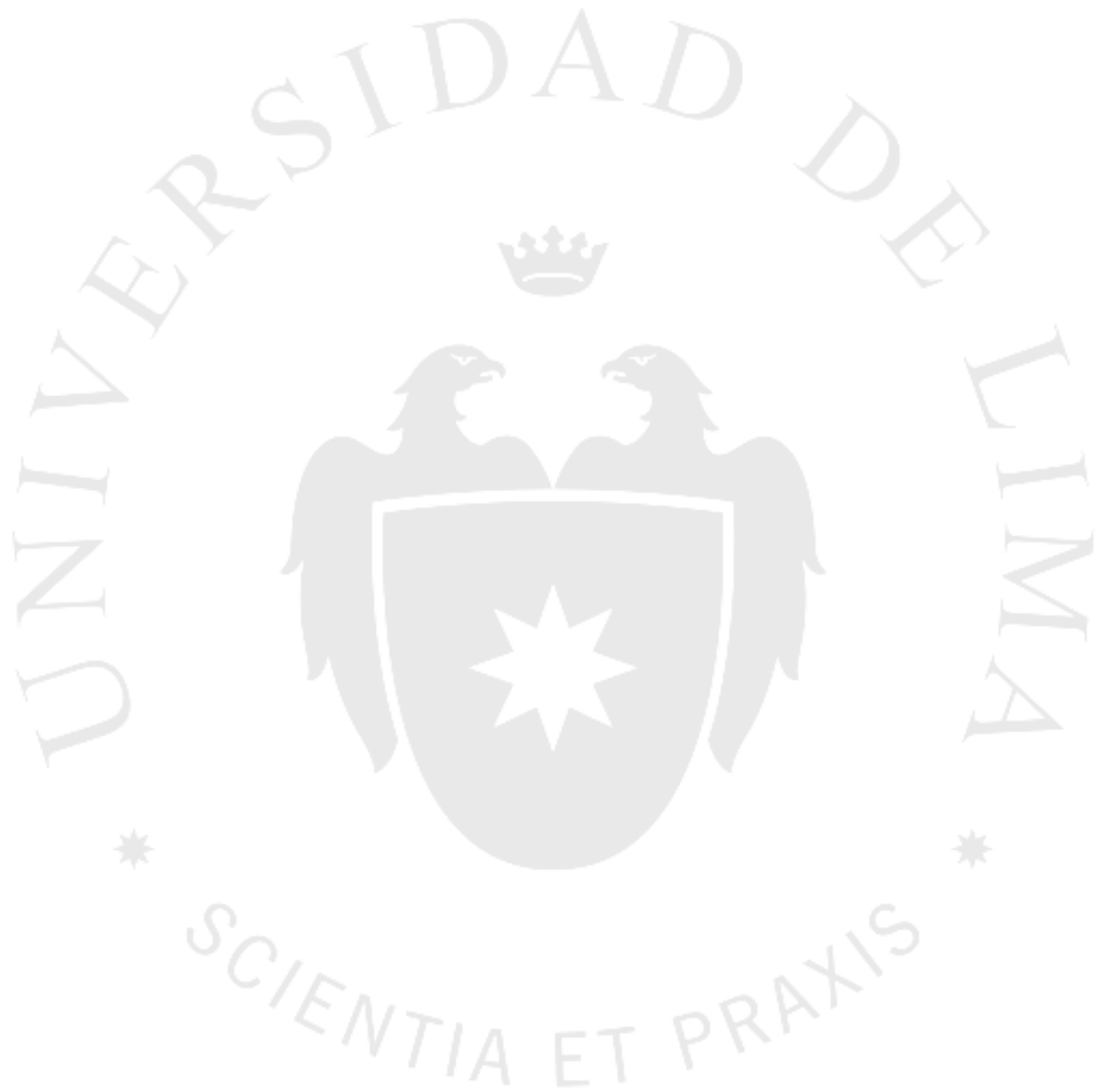


Tabla 5.9

Capacidad instalada de la terapia de alivio del dolor

\begin{tabular}{|c|c|c|c|c|c|c|c|c|c|c|c|}
\hline $\begin{array}{c}\text { Terapia de alivio } \\
\text { del dolor }\end{array}$ & Equipo & $\begin{array}{c}\text { Tiempo } \\
\text { (min) }\end{array}$ & $\begin{array}{c}\text { Tiempo } \\
\text { (hrs.) }\end{array}$ & $\begin{array}{c}\text { Sesiones/ } \\
\text { hora }\end{array}$ & $\begin{array}{l}\text { Nro Máq. } \\
\text { u Ope. }\end{array}$ & $\begin{array}{l}\text { Días/ } \\
\text { año }\end{array}$ & $\begin{array}{c}\text { Horas/ } \\
\text { turno }\end{array}$ & $\begin{array}{c}\text { Turnos/ } \\
\text { día }\end{array}$ & Util. & Efic. & $\begin{array}{l}\text { Capacidad } \\
\text { de atención }\end{array}$ \\
\hline Electroterapia & Electroestimulador & 15 & 0,25 & 4 & 6 & 313 & 6 & 2 & 0,9 & 0,8 & $64.903,7$ \\
\hline Ultrasonoterapia & Ultrasonido & 5 & 0,08 & 12 & 2 & 313 & 6 & 2 & 0,9 & 0,8 & $64.903,7$ \\
\hline Termoterapia & Microondas & 10 & 0,17 & 6 & 4 & 313 & 6 & 2 & 0,9 & 0,8 & $64.903,7$ \\
\hline Masoterapia & Masajeador & 5 & 0,08 & 12 & 2 & 313 & 6 & 2 & 0,9 & 0,8 & $64.903,7$ \\
\hline Kinesioterapia & Caminadora & 10 & 0,17 & 6 & 4 & 313 & 6 & 2 & 0,9 & 0,8 & $64.903,7$ \\
\hline Gimnasio & - & 10 & 0,17 & 72 & 1 & 313 & 6 & 2 & 0,9 & 0,8 & $1.168 .266,2$ \\
\hline Tecnólogos médicos & - & 60 & 1,00 & 3 & 8 & 313 & 6 & 2 & 0,9 & 0,8 & $64.903,7$ \\
\hline
\end{tabular}

Nota: Capacidad del gimnasio: 12 personas

Elaboración propia
Capacidad Terapia de alivio del dolor
$64.903,7 \approx 64.903$ sesiones/año
$17,3 \approx 17$ sesiones/hora

Tabla 5.10

Capacidad instalada de la terapia de restauración de la movilidad

\begin{tabular}{|c|c|c|c|c|c|c|c|c|c|c|c|}
\hline $\begin{array}{c}\text { Terapia de restauración } \\
\text { de la movilidad }\end{array}$ & Equipo & $\begin{array}{c}\text { Tiempo } \\
\text { (min) }\end{array}$ & $\begin{array}{c}\text { Tiempo } \\
\text { (hrs.) }\end{array}$ & $\begin{array}{c}\text { Sesiones/ } \\
\text { hora }\end{array}$ & $\begin{array}{l}\text { Nro Máq. } \\
\text { u Ope. }\end{array}$ & $\begin{array}{c}\text { Días/ } \\
\text { año }\end{array}$ & $\begin{array}{c}\text { Horas/ } \\
\text { turno }\end{array}$ & $\begin{array}{c}\text { Turnos/ } \\
\text { día }\end{array}$ & Util. & Efic. & $\begin{array}{r}\text { Capacidad } \\
\text { de atención }\end{array}$ \\
\hline Magnetoterapia & Magneto & 15 & 0,25 & 4 & 6 & 313 & 6 & 2 & 0,9 & 0,8 & $64.903,7$ \\
\hline Terapia de ondas de choque & Ondas de Choque & 10 & 0,17 & 6 & 4 & 313 & 6 & 2 & 0,9 & 0,8 & $64.903,7$ \\
\hline Laserterapia & Láser & 10 & 0,17 & 6 & 4 & 313 & 6 & 2 & 0,9 & 0,8 & $64.903,7$ \\
\hline Termoterapia & Onda Corta & 10 & 0,17 & 6 & 4 & 313 & 6 & 2 & 0,9 & 0,8 & $64.903,7$ \\
\hline Hidroterapia & Piscina & 15 & 0,25 & 60 & 1 & 313 & 6 & 2 & 0,9 & 0,8 & $649.036,8$ \\
\hline Tecnólogos médicos & - & 55 & 0,92 & 3 & 7 & 313 & 6 & 2 & 0,9 & 0,8 & $61.953,5$ \\
\hline
\end{tabular}

Nota: Capacidad del gimnasio: 15 personas

Elaboración propia 
Capacidad Terapia de restauración de la movilidad

$61.953 .5 \approx 61.953$ sesiones/año

$16,5 \approx 16$ sesiones/hora

Tabla 5.11

Capacidad instalada de las instalaciones

\begin{tabular}{|l|c|c|c|c|c|c|c|c|c|c|}
\hline Instalaciones & $\begin{array}{c}\text { Tiempo } \\
\text { (min) }\end{array}$ & $\begin{array}{c}\text { Tiempo } \\
\text { (hrs.) }\end{array}$ & $\begin{array}{c}\text { Capacidad } \\
\text { (sesiones) }\end{array}$ & $\begin{array}{c}\text { Nro } \\
\text { Insta. }\end{array}$ & $\begin{array}{c}\text { Días/ } \\
\text { año }\end{array}$ & $\begin{array}{c}\text { Horas/ } \\
\text { turno }\end{array}$ & $\begin{array}{c}\text { Turnos/ } \\
\text { día }\end{array}$ & Util. & Efic. & $\begin{array}{c}\text { Capacidad } \\
\text { de atención }\end{array}$ \\
\hline Cubículos & 45 & 0,75 & 1 & 34 & 313 & 6 & 2 & 0,9 & 0,8 & $122.595,8$ \\
\hline
\end{tabular}

Elaboración propia

Capacidad de cubículos

$$
\begin{array}{rlrl}
122.595,8 & \approx & 122.595 & \text { sesiones/año } \\
32,6 & \approx & 32 \text { sesiones/hora }
\end{array}
$$

\subsubsection{Cálculo detallado del número de recursos para el servicio}

Con la finalidad de calcular el número de equipos que se utilizarán para llevar a cabo el servicio de rehabilitación física se dividirá la demanda de las sesiones en los dos tipos de terapias; respecto al cálculo de las instalaciones y el número de recursos humanos que se necesitarán; estos si serán calculados con la totalidad del número de sesiones previstas en un año. A continuación se presentan las tablas referidas al cálculo detallado del número de recursos para los servicios del centro. 
Tabla 5.12

Cálculo del número de máquinas de la terapia de alivio del dolor

\begin{tabular}{|c|c|c|c|c|c|c|c|c|c|c|c|}
\hline $\begin{array}{c}\text { Terapia de } \\
\text { alivio del dolor }\end{array}$ & Equipo & $\begin{array}{c}\text { Demanda } \\
\text { (sesiones/año) }\end{array}$ & $\begin{array}{c}\text { Tiempo } \\
\text { (min) }\end{array}$ & $\begin{array}{c}\text { Tiempo } \\
\text { (hrs.) }\end{array}$ & $\begin{array}{l}\text { Días/ } \\
\text { año }\end{array}$ & $\begin{array}{c}\text { Horas/ } \\
\text { turno }\end{array}$ & $\begin{array}{c}\text { Turnos/ } \\
\text { día }\end{array}$ & Util. & Efic. & $\begin{array}{l}\text { Nro } \\
\text { Máq. }\end{array}$ & $\begin{array}{l}\text { Nro } \\
\text { Máq. }\end{array}$ \\
\hline Electroterapia & Electroestimulador & 59.891 & 15 & 0,25 & 313 & 6 & 2 & 0,9 & 0,8 & 5,54 & 6 \\
\hline Ultrasonoterapia & Ultrasonido & 59.891 & 5 & 0,08 & 313 & 6 & 2 & 0,9 & 0,8 & 1,85 & 2 \\
\hline Termoterapia & Microondas & 59.891 & 10 & 0,17 & 313 & 6 & 2 & 0,9 & 0,8 & 3,69 & 4 \\
\hline Masoterapia & Masajeador & 59.891 & 5 & 0,08 & 313 & 6 & 2 & 0,9 & 0,8 & 1,85 & 2 \\
\hline Kinesioterapia & Caminadora & 59.891 & 10 & 0,17 & 313 & 6 & 2 & 0,9 & 0,8 & 3,69 & 4 \\
\hline
\end{tabular}

Elaboración propia

\section{Tabla 5.13}

Cálculo del número de máquinas de la terapia de restauración de la movilidad

\begin{tabular}{|c|c|c|c|c|c|c|c|c|c|c|c|}
\hline $\begin{array}{c}\text { Terapia de restauración } \\
\text { de la movilidad }\end{array}$ & Equipo & $\begin{array}{c}\text { Demanda } \\
\text { (sesiones/año) }\end{array}$ & $\begin{array}{c}\text { Tiempo } \\
\text { (min) }\end{array}$ & $\begin{array}{c}\text { Tiempo } \\
\text { (hrs.) }\end{array}$ & $\begin{array}{l}\text { Días/ } \\
\text { año }\end{array}$ & $\begin{array}{c}\text { Horas/ } \\
\text { turno }\end{array}$ & $\begin{array}{c}\text { Turnos/ } \\
\text { día }\end{array}$ & Util. & Efic. & $\begin{array}{l}\text { Nro } \\
\text { Máq. }\end{array}$ & $\begin{array}{l}\text { Nro } \\
\text { Máq. }\end{array}$ \\
\hline Magnetoterapia & Magneto & 59,891 & 15 & 0.25 & 313 & 6 & 2 & 0.9 & 0.8 & 5.54 & 6 \\
\hline Terapia ondas de choque & Ondas de choque & 59,891 & 10 & 0.17 & 313 & 6 & 2 & 0.9 & 0.8 & 3.69 & 4 \\
\hline Laserterapia & Láser & 59,891 & 10 & 0.17 & 313 & 6 & 2 & 0.9 & 0.8 & 3.69 & 4 \\
\hline Termoterapia & Onda Corta & 59,891 & 10 & 0.17 & 313 & 6 & 2 & 0.9 & 0.8 & 3.69 & 4 \\
\hline
\end{tabular}

Elaboración propia

Tabla 5.14

Cálculo del número de instalaciones del centro

\begin{tabular}{|c|c|c|c|c|c|c|c|c|c|c|c|}
\hline Instalaciones & $\begin{array}{c}\text { Demanda } \\
\text { (sesiones/año) }\end{array}$ & $\begin{array}{c}\text { Capacidad } \\
\text { (sesiones) }\end{array}$ & $\begin{array}{c}\text { Tiempo } \\
(\min )\end{array}$ & $\begin{array}{c}\text { Tiempo } \\
\text { (hrs.) }\end{array}$ & $\begin{array}{c}\text { Días/ } \\
\text { año }\end{array}$ & $\begin{array}{c}\text { Horas/ } \\
\text { turno }\end{array}$ & $\begin{array}{c}\text { Turnos/ } \\
\text { día }\end{array}$ & Util. & Efic. & $\begin{array}{l}\text { Nro } \\
\text { Insta. }\end{array}$ & $\begin{array}{l}\text { Nro } \\
\text { Insta. }\end{array}$ \\
\hline Cubículos & 119.781 & 1 & 45 & 0,75 & 313 & 6 & 2 & 0,9 & 0,8 & 33,22 & 34 \\
\hline Gimnasio - Terapia de alivio del dolor & 59.891 & 15 & 10 & 0,17 & 313 & 6 & 2 & 0,9 & 0,8 & 0,25 & 1 \\
\hline Piscina - Terapia restauración movilidad & 59.891 & 12 & 15 & 0,25 & 313 & 6 & 2 & 0,9 & 0,8 & 0,46 & 1 \\
\hline
\end{tabular}

Elaboración propia 
Para el cálculo de los recursos humanos se tomó el dato proporcionado por la tecnólogo médico Diana Mundaca CTMP 8808, quien afirma que los tecnólogos médicos pueden atender tres sesiones por hora puesto que la mayoría de las actividades de cada terapia no requieren de la presencia de estos. 
Tabla 5.15

Cálculo del número de recursos humanos del centro

\begin{tabular}{|c|c|c|c|c|c|c|c|c|c|c|c|}
\hline Operarios & $\begin{array}{c}\text { Demanda } \\
\text { (sesiones/ año) }\end{array}$ & $\begin{array}{c}\text { Capacidad } \\
\text { (sesiones/ hora) }\end{array}$ & $\begin{array}{c}\text { Tiempo } \\
\text { (min) }\end{array}$ & $\begin{array}{c}\text { Tiempo } \\
\text { (hrs.) }\end{array}$ & $\begin{array}{l}\text { Días/ } \\
\text { año }\end{array}$ & $\begin{array}{c}\text { Hrs/ } \\
\text { turno }\end{array}$ & $\begin{array}{c}\text { Turnos/ } \\
\text { día }\end{array}$ & Util. & Efic. & $\begin{array}{l}\text { Nro } \\
\text { Oper. }\end{array}$ & $\begin{array}{l}\text { Nro } \\
\text { Oper. }\end{array}$ \\
\hline $\begin{array}{l}\text { Tecnólogos Terapia } \\
\text { alivio del dolor }\end{array}$ & 59.891 & 3 & 60 & 1 & 313 & 6 & 2 & 0,9 & 0,8 & 7,38 & 8 \\
\hline $\begin{array}{l}\text { Tecnólogos Terapia } \\
\text { restauración movilidad }\end{array}$ & 59.891 & 3 & 55 & 1 & 313 & 6 & 2 & 0,9 & 0,8 & 6,77 & 7 \\
\hline
\end{tabular}

Elaboración propia 
Finalmente se presenta a continuación el cuadro general del número de los recursos necesarios para la implementación del centro; como son el número de instalaciones, el número de equipos y recurso humano. Tener en cuenta que se requiere de 30 tecnólogos médicos por día de trabajo puesto que son 2 turnos por día trabajando solo 6 horas al día por disposición legal vigente para los profesionales de la salud.

Tabla 5.16

Número de los recursos para el servicio

\begin{tabular}{|l|c|}
\hline \multicolumn{1}{|c|}{ Recursos e Instalaciones } & Cant. \\
\hline Electroestimulador & 6 \\
\hline Ultrasonido & 2 \\
\hline Microondas & 4 \\
\hline Masajeador & 2 \\
\hline Caminadora & 4 \\
\hline Magneto & 6 \\
\hline Ondas de choque & 4 \\
\hline Láser & 4 \\
\hline Onda Corta & 4 \\
\hline Cubículos & 34 \\
\hline Gimnasio & 1 \\
\hline Piscina & 1 \\
\hline Tecnólogos médicos & 30 \\
\hline
\end{tabular}

Elaboración propia

\subsection{Resguardo de la calidad}

\subsubsection{Calidad del proceso y del servicio}

La propuesta de valor que el centro ofrecerá a sus pacientes tendrá como prioridades competitivas a la calidad y a la sostenibilidad a largo plazo. Es en base a estos aspectos que se buscará diferenciarse en el mercado local y ser sostenibles en el tiempo. Es por ello que la calidad del proceso y del servicio será gestionada tomando como base los principios del sistema ISO 9001, el cual se buscará implementar durante la etapa de desarrollo del proyecto. Es necesario englobar todo este sistema de gestión de calidad en el ciclo de mejora continua con la finalidad de brindar a nuestros pacientes un servicio de excelencia. 
Para alcanzar la mejora continua se deben llevar a cabo las 4 etapas esenciales de forma sistemática y cíclica:

Figura 5.24

Diagrama de Deming

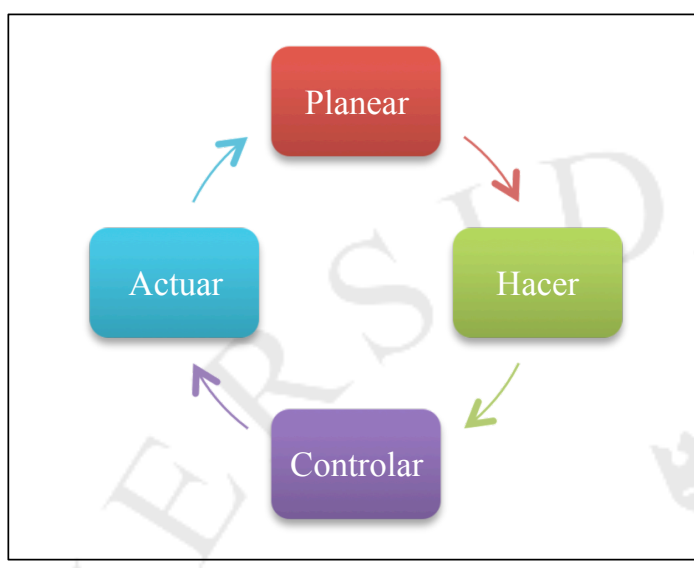

Fuente: Escuela Europea de Negocios Elaboración propia

El primer paso que el centro realizará será el definir la política de calidad, para después enunciarla en el "Manual de Calidad" que se implementará. Todo esto bajo la estrategia de la calidad total y mejora continua la cual involucrará todas las áreas y será liderada por el médico principal del centro quién será responsable, con participación de su equipo de trabajo y todo el personal del centro, en dirigir la implementación de las políticas de calidad y desarrollar los procedimientos operativos, los cuales contendrán las instrucciones y formatos que todo el personal del centro deberá de cumplir y utilizar para la óptima prestación de los servicios, con la finalidad de complacer a su clientes internos y externos.

Cuando el centro esté consolidado se plantea obtener la acreditación "Joint Commission International" (JCI), máxima certificación en el mundo en relación con la calidad, seguridad y cuidado del paciente. Para alcanzar esta acreditación; la certificadora evalúa los procesos con la finalidad de verificar el cumplimiento de los estándares requeridos para brindar un servicio de calidad y seguridad hacia el paciente. La certificación comprueba que en cada atención médica que se realiza intervienen 
procesos que contemplan todos los detalles necesarios para asegurar el máximo cuidado del paciente.

\subsubsection{Niveles de satisfacción del cliente}

En toda adquisición de un servicio, la persona experimentará uno de los siguientes tres tipos de niveles de satisfacción: insatisfacción, satisfacción y complacencia.

La importancia de la satisfacción al cliente radica en los beneficios que se genera para la empresa y estos son la lealtad de los clientes y por ende la posibilidad de venderle el mismo u otros servicios adicionales en el futuro; difusión gratuita que el cliente satisfecho realiza a sus familiares, amistades y conocidos; y la participación en el mercado del rubro del servicio.

Los niveles de satisfacción del cliente están asociados al grado de cumplimiento percibido versus sus expectativas, es por ello que resulta fundamental conocer las expectativas de los clientes del centro y determinar en base a estos el nivel de servicio que se ofrecerá.

El nivel de servicio es una de las herramientas más eficaces y usadas para diferenciarse de la competencia y lograr así una ventaja competitiva sostenible a largo plazo y lo que buscará el centro de fisioterapia es ofrecer un alto nivel de servicio para diferenciarse de sus competidores. Conceptualmente, el nivel de servicio se define como la probabilidad de entregar un producto o servicio al cliente cuando éste lo quiere, y dado que en el Perú el promedio es del $80 \%$, el centro de fisioterapia tendrá como estándar el 95\%. Como se mencionó anteriormente, esto involucrará a todos los miembros de la organización y toda la información relacionada será proporcionada al personal involucrado en la prestación de los servicios, que de esta manera se sentirá más motivado. 
Por otro lado, para el servicio de fisioterapia, las expectativas de los pacientes girarán en torno a los siguientes aspectos: profesionalidad del personal, accesibilidad para el contacto con el centro, cortesía del personal, comunicación, credibilidad y confianza que proyecta el centro, seguridad para la prestación del servicio, y conocimiento y comprensión del cliente. Adicionalmente, las expectativas serán complementadas por las experiencias de atenciones anteriores, opiniones de familiares, amistades u otras personas y promesas de competidores.

Lo que se busca en cuanto al nivel de satisfacción del cliente es superar sus expectativas llegando al $100 \%$ de satisfacción, completar el $100 \%$ de atenciones programadas por día, obtener cero accidentes de los pacientes dentro del centro de rehabilitación y lograr 0 quejas en la atención de los clientes.

\subsubsection{Medidas de resguardo de la calidad}

Entre las actividades de reguardo de la calidad que se implementarán para proporcionar la confianza adecuada de que los servicios superarán las expectativas de los clientes del centro de fisioterapia, son:

- Estudios de satisfacción de usuarios: Realización periódica de estudios de satisfacción de usuarios internos y externos, sirviendo los resultados para la toma de decisiones y aplicación de medidas correctivas.

- Auditoría de historias clínicas: Ejecutadas de manera periódica y aplicando la Norma Técnica de Salud correspondiente.

- Programas de capacitación del personal médico y fisioterapeuta.

- Uso de Guías de Práctica Clínica aprobadas por la Autoridad Sanitaria Nacional por parte de los médicos fisiatras y tecnólogos médicos, en donde se indicarán los procedimientos médicos que correspondan según el tipo de servicio de fisioterapia que se deba de atender. Todo ello con la finalidad de mantener un estándar de calidad en los servicios de fisioterapia. 
- Implementación de procedimientos de higiene y limpieza que todo el personal deberá de cumplir. Dichos procedimientos implican actividades como limpieza diaria de instalaciones, desinfección y esterilización de equipos cada vez que se utilicen, entre otros. Asimismo, los médicos tecnólogos deberán de estar especialmente vigilados en cuanto a su higiene personal y deberán ser provistos con ropa de trabajo adecuada. Dicho personal deberá tener un alto nivel de higiene personal consistente en una estricta higiene de manos, uñas y cabello, evitando personal con heridas o enfermedades infecto-contagiosas de origen intestinal o respiratorio. Por otra parte, la ropa normal de trabajo será de color claro, de tejido ligero y flexible, de fácil limpieza y desinfección y ajustable al cuerpo del trabajador, siendo de uso exclusivo para el trabajo; además deberán de conservarse en buen estado y limpiarse y esterilizarse diariamente.

La Tabla 5.17 muestra un pequeño resumen del tipo y la periodicidad con la que se debe hacer la limpieza en equipos, utensilios y personal.

Tabla 5.17

Periodicidad de limpieza en equipos y personal

\begin{tabular}{|c|l|l|}
\hline Elemento & \multicolumn{1}{|c|}{ Acción } & \multicolumn{1}{c|}{ Periodicidad y tiempo promedio } \\
\hline \multirow{2}{*}{ Equipos } & $\begin{array}{l}\text { Limpiar } \\
\text { Desinfectar } \\
\text { Desodorizar }\end{array}$ & $\begin{array}{l}\text { Diariamente } \\
20 \text { a } 30 \text { minutos por equipo }\end{array}$ \\
\hline Agentes físicos & $\begin{array}{l}\text { Limpiar } \\
\text { Desinfectar }\end{array}$ & $\begin{array}{l}\text { Después de su uso } \\
1 \text { a } 2 \text { minutos }\end{array}$ \\
\hline \multirow{2}{*}{ Personal } & $\begin{array}{l}\text { Lavado } \\
\text { antiséptico }\end{array}$ & $\begin{array}{l}\text { Cada vez que se atienda a un paciente } \\
3 \text { a } 5 \text { minutos }\end{array}$ \\
\hline
\end{tabular}

Fuente: MINSA

Elaboración propia

- Seguimiento a los pacientes ya sea vía telefónica, citas médicas y/o evaluando su performance utilizando su historial médico. Las finalidades del seguimiento son las siguientes:

- Conocer el estatus de satisfacción del paciente respecto a los servicios demandados, para determinar las acciones preventivas que ayudarán a resguardar y mejorar la calidad del servicio. 
- Mantener una comunicación constante para estrechar los lazos cliente empresa, realizando charlas y encuestas para mejorar el servicio y recibiendo las propuestas de mejora de los mismos pacientes.

- Mantener informado al paciente sobre su estatus médico, informando los logros físicos obtenidos con el fin de motivarlo a continuar con su revitalización.

- Ofrecer alternativas que incentiven el retorno de pacientes que dejaron el servicio o en todo caso detectar cuáles fueron las causas raíces de la decisión de no retomar los servicios, las cuales se registrarán en un historial que se utilizará para la toma de decisiones en la mejora de la calidad del servicio.

- Evaluación periódica de indicadores: lo que implica su procesamiento, análisis y base para la toma de decisiones orientadas a mejorar la calidad de atención del centro. Entre los indicadores a implementar tendremos:

Tabla 5.18

Indicadores de resguardo de la calidad

\begin{tabular}{|c|c|}
\hline INDICADOR & VALOR \\
\hline Nivel de servicio & Estándar $>=80 \%$ \\
\hline$\%$ de Deserción $(*)$ a las terapias & Estándar $<20 \%$ \\
\hline$\%$ de complicaciones $(* *)$ en las terapias & Estándar $<1 \%$ \\
\hline$\%$ de pacientes que completan la terapia indicada & Estándar $>80 \%$ \\
\hline
\end{tabular}

Nota: (*) Deserción: Paciente que abandona o que cumple con menos del $50 \%$ de las terapias indicadas y no acude a control médico posterior.

(**) Complicaciones: Paciente que presenta reacciones adversas o secundarias al procedimiento terapéutico.

Fuente: MINSA

Elaboración propia

\subsection{Impacto ambiental}

Se implementará un sistema de gestión ambiental que asegure que el centro actúe de manera responsable con el medio ambiente, que cumpla con la legislación, que optimice la utilización de recursos lo que supone una reducción en el consumo de electricidad, agua y suministro de algunos productos, que refuerce la imagen corporativa y mejore la relación con los clientes, los proveedores y con la sociedad. 
Antes de ejecutar cualquier acción se requiere realizar la evaluación de impactos ambientales que el proyecto pueda causar. Se identificarán los factores ambientales a los que se afectarán mediante las acciones que se ejecutarán para la implementación del centro. Esto se observa en la matriz de impactos ambientales utilizando la metodología de Leopold que se presenta a continuación:

Tabla 5.19

Matriz de Leopold

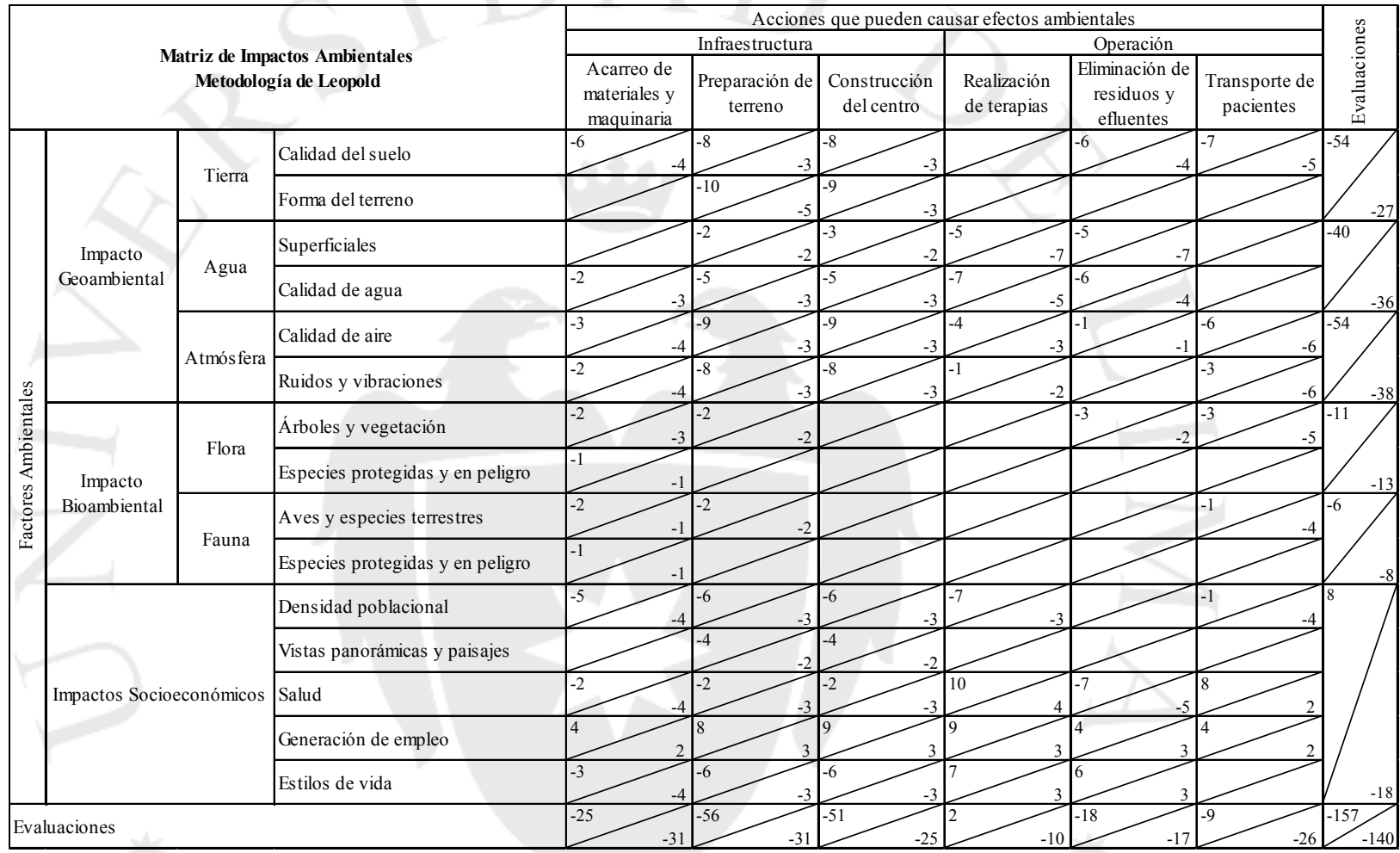

Elaboración propia

Como se observa las acciones que son más propensas a ocasionar impactos ambientales negativos son las referidos a la Infraestructura; es decir a la preparación del terreno y la construcción del centro ya que los valores negativos son los más altos; -56 y -51 respectivamente.

En base a esta evaluación se presentara una Declaración de Impacto Ambiental (DIA) exigida por la legislación peruana, el cual es un estudio cuyo propósito es evaluar los impactos ambientales y sociales causados por proyectos que no involucran potenciales impactos ambientales y sociales significativos. Dentro de los requerimientos 
de información que se solicitan se tienen: Información corporativa sobre políticas y organización, plan de manejo ambiental, plan de manejo social y un plan de cierre.

Lo que solicita una DIA es la presentación de los planes de mitigación y de manejo lo suficientemente detallados de modo que nos permitan minimizar los impactos ambientales negativos y potenciar los impactos positivos en beneficio tanto del medio ambiente como de los vecinos.

Es la razón de este proyecto el implementar un sistema de gestión ambiental basado en la ecoeficiencia lo cual implica un uso eficiente de los recursos, que conlleve a la menor producción de residuos y contaminación, a la vez que se reducen los costos operativos, contribuyendo así a la sostenibilidad y la minimización progresiva de impactos ambientales.

La gestión ambiental basada en la ecoeficiencia requiere liderazgo por tal motivo el compromiso de la alta gerencia es crítico para alcanzar el éxito siendo dicho compromiso traducido en una política ambiental de la empresa, lo que requiere posteriormente una planificación para su implementación y seguimiento mediante indicadores ambientales que nos permitan seguir mejorando continuamente. 
Figura 5.25

Secuencia de la Gestión Ambiental

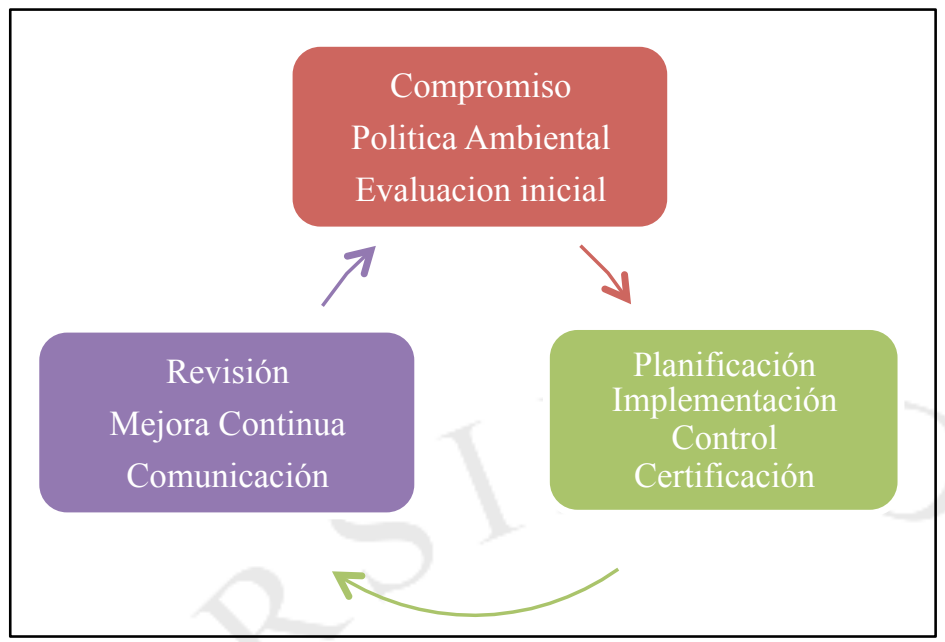

Fuente: Ministerio del ambiente Elaboración propia

Es así que se implementará un Sistema Ambiental de Ecoeficiencia Empresarial basado en las buenas prácticas ambientales para el uso eficiente de todos los recursos del centro.

Se deberá diseñar y desarrollar las políticas, lineamientos y compromisos que el centro debe cumplir para llevar a cabo un uso eficiente de los recursos. Se deberá también comunicar todos estos compromisos a las partes interesadas como son la directiva, empleados, contratistas, proveedores, clientes, para que tomen conciencia y cumplan con los lineamientos establecidos.

Se formará un comité de medio ambiente el mismo que se ocupe también de la seguridad y salud en el trabajo con la finalidad de motivar a los colaboradores al ahorro de los recursos y cuidado del medio ambiente a través de campañas de sensibilización y talleres que generen conciencia de la importancia del medio ambiente.

Toda la documentación de este proceso se realizará mediante programas para la vigilancia y monitoreo de todos los consumos del centro implementando indicadores y registros periódicos para el control de dichos consumos. 
La clave de este sistema se encuentra en llevar a cabo las buenas prácticas para el uso de los recursos las cuales se presentan a continuación:

\section{Buenas prácticas para el uso eficiente del agua}

- Se instalarán llaves temporizadoras en los lavatorios de los baños lo que nos permitirá un ahorro de agua del $57 \%$ respecto a otros sistemas.

- Las duchas serán economizadoras permitiendo un ahorro del $73 \%$ de agua.

- Se utilizarán inodoros de doble descarga en los servicios higiénicos los cuales utilizan una descarga parcial de 3,5 litros para evacuar líquidos y 6 litros para evacuar sólidos lo que supone un ahorro de hasta un $40 \%$.

- Se instalarán tanques depuradores para la reutilización de las aguas grises (agua de duchas y lavados) en el regadío de los jardines.

- Se regarán los jardines con aspersores programables y en las noches para evitar la pérdida de agua por evaporación.

- Se realizarán mantenimientos preventivos y acciones correctivas para la atención de fugas de agua existentes.

- Se capacitará al personal de limpieza para que utilice agentes de limpieza que no sean tóxicos y en concentración mínima para evitar contaminar el agua.

- Se motivará a los empleados a evitar utilizar el sanitario como basurero y a reportar fugas o goteos, para que puedan ser reparados a la brevedad.

\section{Buenas prácticas para el uso eficiente de la energía}

- Se dispondrán los puestos de trabajo para un mejor aprovechamiento de la luz natural y se pintarán de color blanco las paredes y techos del centro.

- Se instalarán luminarias LED (diodos emisores de luz) que ofrecen una mejor calidad de iluminación, disipan menos calor, utilizan menos energía ahorrando hasta un $80 \%$ y duran 8 veces más que un foco incandescente. 
- Se utilizarán sensores eléctricos de techo que funcionan en función del movimiento para encender la iluminación de una determinada zona lo que nos proporciona un ahorro del $30 \%$ en electricidad.

- Se deben apagar las computadoras y monitores en caso de recesos de más de 30 minutos y al final del día laboral.

- Se limpiarán periódicamente las luminarias, pantallas y ventanas para aumentar la luminosidad sin necesidad de aumentar la potencia.

- Se retirarán las lámparas quemadas y/o defectuosas para evitar un consumo innecesario de electricidad.

- Se utilizará el aire acondicionado solo cuando sea necesario y se controlará su temperatura a $21^{\circ} \mathrm{C}$ para disminuir el consumo energético teniendo las puertas y ventanas cerradas a fin de impedir pérdidas y derroche.

- Se deben utilizar gases refrigerantes ecológicos como el R410A en los equipos de aire acondicionado (no usar gas refrigerante R22) reduciendo así el factor de agotamiento de la capa de ozono.

- Se verificará el estado del aislamiento de las tuberías y accesorios del sistema de aire acondicionado a fin de prevenir pérdidas de energía.

- Se considerará utilizar interruptores programables para interrumpir el flujo de energía durante la noche.

- Se dispondrán de equipos eléctricos y electrónicos de mayor eficiencia energética que cumplan con la normativa de ahorro de energía.

La Ley de Promoción de Uso Eficiente de la Energía Ley No 27345 establece que los equipos y artefactos que requieren suministro de energía, deben incluir en sus etiquetas, envases, empaques y publicidad, la información sobre su consumo energético en relación con los estándares de eficiencia energética.

A la vez existe también la Normatividad y Etiquetado para la promoción del uso eficiente de la energía de la Dirección General de Eficiencia Energética del Ministerio de Energía y Minas donde se informa al usuario sobre el consumo de energía de un aparato o equipo para que pueda elegir el más eficiente, brindando así los beneficios en 
el ahorro económico, en la facturación, promoviendo el cambio de hábitos y contribuyendo a mitigar el calentamiento global.

Figura 5.26

Etiqueta de equipo sobre su consumo de energía

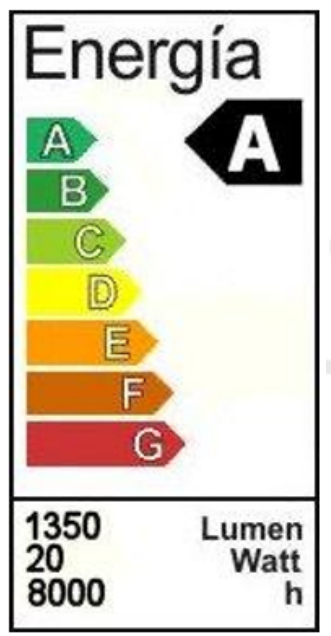

Fuente: Ministerio de Energía y Minas

\section{Buenas prácticas para la adquisición de suministros}

Se utilizará el catálogo de proveedores ecoeficientes para adquirir los productos y servicios necesarios para la implementación del centro y estar acorde con la política ambiental que adoptamos; así los bienes y servicios que ofertan estos proveedores además de cumplir con los criterios ecoeficientes que exige el ministerio del ambiente, se deben diferenciar de aquellos productos convencionales existentes en el mercado local.

Existen tres criterios de evaluación que define el Ministerio del Ambiente para la selección final de los proveedores ecoeficientes; es necesario cumplir por los menos con uno de los criterios, estos son: 
- Ecoeficiencia en el diseño y características del producto; el cual debe conllevar un menor uso de materia y energía, con empaques optimizados que permitan su posterior recuperación o reciclaje

- Ecoeficiencia durante el proceso de producción o manufactura donde se haga un eficiente uso de materias primas, insumos, agua, energía y un manejo sostenible de los recursos naturales.

- Buenas Prácticas ambientales, Certificaciones y Responsabilidad Social y Ambiental; es decir aquellas empresas que posean y desarrollen Manuales de Buenas Prácticas Ambientales, capacitaciones y desempeño del personal, certificaciones como ISO 9001, ISO 14001, OHSAS 18001, SA 8000 etc.

\section{Buenas Prácticas para el uso eficiente de materiales}

- Se dosificarán eficientemente los insumos utilizados en las terapias como el uso de geles, vendas, cremas, entre otros.

- Se utilizará papel $100 \%$ reciclado preferentemente.

- Se reducirá el consumo de papel imprimiendo si es estrictamente necesario y utilizando las dos caras de una misma hoja.

- Se fomentará el uso del Internet e intranet para enviar y/o recibir las comunicaciones internas y externas.

- Se promoverá el escaneado de todos los documentos recibidos evitando el fotocopiado.

- Se implementará el sistema de historias clínicas virtuales evitando el uso de papel.

\section{Buenas Prácticas para el manejo adecuado de residuos sólidos}

El manejo de residuos sólidos será gestionado bajo la Ley General de Residuos Sólidos Ley $\mathrm{N}^{\mathrm{o}} 27314$ donde se dan las directrices para la clasificación y disposición final de los residuos. 
Atender a los pacientes requiere de un alto consumo de insumos y materiales, por lo cual nuestras actividades generan importantes cantidades de residuos. Debido a este impacto ambiental, es esencial para nosotros asegurar un uso racional de los recursos y gestionar una disposición adecuada de los residuos que generemos a fin de minimizar nuestro impacto.

Lo primero es segregar o clasificar los residuos para su posterior uso nuevo o para una adecuada disposición final de los mismos. Esta gestión debe ir acompañada entre otras cosas, a reducir la cantidad de residuos que producimos, reusar al máximo los productos que consumimos, reciclar todo lo que se pueda, rechazar el uso de ciertos materiales sólidos y reparar antes de desechar. Nace aquí la práctica de las "5R" (Reducir, Reutilizar, Reciclar, Rechazar y Reparar) que se implementará como parte del sistema ecoeficiente del centro.

Tabla 5.20

"Las 5 Erres"

\begin{tabular}{|c|l|}
\hline Reducir & $\begin{array}{l}\text { Consiste en disminuir el volumen de nuestros residuos como } \\
\text { por ejemplo el papel utilizado en las oficinas. }\end{array}$ \\
\hline Reutilizar & $\begin{array}{l}\text { Consiste en volver a usar un elemento después que ha sido } \\
\text { utilizado por primera vez, en nuestro caso se reutilizará el agua } \\
\text { de las duchas y lavados para el riego de jardines. }\end{array}$ \\
\hline Reciclar & $\begin{array}{l}\text { Se reaprovecharán los residuos sólidos que se puedan recuperar } \\
\text { como el cartón, papel, plásticos, botellas, entre otros. }\end{array}$ \\
\hline Rechazar & $\begin{array}{l}\text { No se comprarán productos que dañen el ambiente como } \\
\text { aerosoles, poliestireno, o empaques que no se pueden reciclar. }\end{array}$ \\
\hline Reparar & $\begin{array}{l}\text { Antes de desechar algún equipo médico o de oficina se buscará } \\
\text { la forma de repararlo. }\end{array}$ \\
\hline
\end{tabular}

Fuente: Ministerio del ambiente

Elaboración propia

Para la clasificación de los residuos sólidos se implementará el uso de los tachos especiales utilizando el código de colores para su segregación consignado en la Norma Técnica Peruana NTP 900.058.2005 
Tabla 5.21

Código de colores para la segregación de residuos solidos

\begin{tabular}{|c|c|}
\hline Colores & Clasificación \\
\hline Amarillo & Metales \\
\hline Verde & Vidrio \\
\hline Azul & Papel y cartón \\
\hline Blanco & Plástico \\
\hline Marrón & Orgánicos \\
\hline Negro & Residuos comunes no reciclables \\
\hline Rojo & Residuos peligrosos \\
\hline
\end{tabular}

Fuente: INDECOPI

Elaboración propia

Figura 5.27

Tachos de recolección de residuos solidos

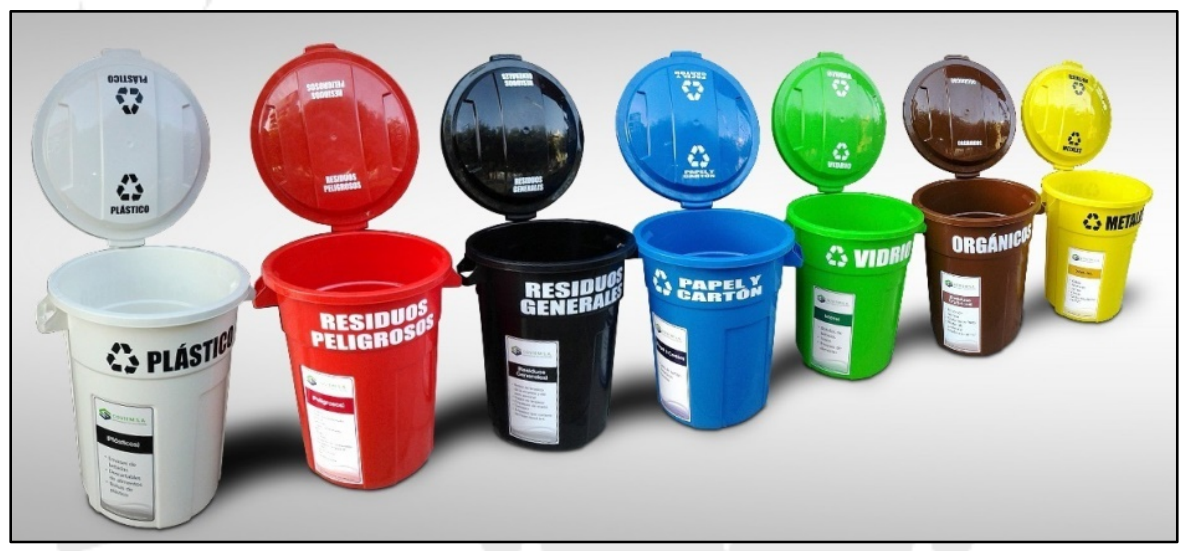

Fuente: Brick7

Al ser un centro de salud la normatividad vigente nos indica que se deberán utilizar recipientes especiales para la segregación de los materiales peligrosos; en este sentido se utilizaran los siguientes recipientes:

- Recipiente rojo para acopiar gasas, algodón, guantes de látex, materiales de curación, elementos infectados con fluidos biológicos, entre otros; su disposición final será en un relleno sanitario.

- Recipiente rígido donde se almacenarán agujas y materiales punzocortantes siendo su disposición final la trituración, incineración y/o un relleno sanitario. 
Figura 5.28

Recipientes materiales peligrosos

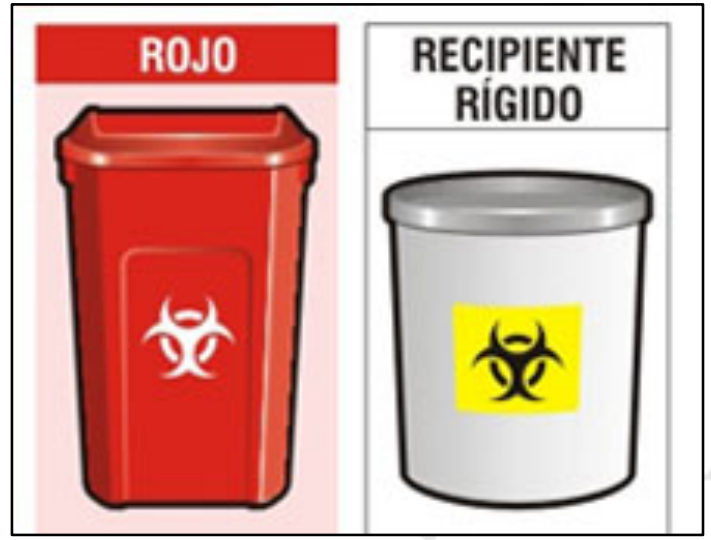

Fuente: Hospital con Alma Pablo Tobón Uribe

Existen otros residuos peligrosos como pilas, cartuchos de tinta, baterías, tubos fluorescentes que representan un tipo especial de categoría de desechos y serán dispuestos en tachos especiales para luego ser recolectados.

La recolección y disposición final de todos los residuos sólidos se realizará a través de las Empresas Prestadoras de Servicios de Residuos Sólidos (EPS-RS) debidamente registradas en el Ministerio de Salud.

\section{Buenas Prácticas para la eficiencia en la construcción del centro}

Se implementaran medidas que ayuden a la reducción del impacto ambiental en la etapa de construcción de la edificación. Se utilizarán de preferencia materiales procedentes de recursos renovables, materiales reciclados, y de bajo consumo energético.

Al momento de diseñar el centro de rehabilitación física se tendrá en cuenta las siguientes recomendaciones: 
- La forma y colocación del edificio debe aprovechar la luz natural, el calor solar y la ventilación.

- Los colores claros de los muros reflejan mejor la luz y permiten evitar un sobrecalentamiento en épocas de calor.

- Prever espacios suficientes para gestionar los residuos en todas las etapas del ciclo de vida del centro.

- Fijar áreas preferenciales para el parqueo de autos y bicicletas.

- Se recomienda que la empresa no emplee materiales de construcción como asbestos o productos que contengan CFC y cemento con alto contenido de aluminio, entre otros, que representen un alto riesgo tanto para la salud de los ocupantes como para el ambiente.

- En la etapa de construcción se tomarán medidas para que los contratistas cumplan con los requisitos de seguridad y se minimice el impacto ambiental, como las siguientes:

\section{Tabla 5.22}

Recomendaciones para minimizar el impacto ambiental en la construcción de edificaciones

\begin{tabular}{|l|l|}
\hline $\begin{array}{l}\text { Regar con agua las zonas de paso } \\
\text { de la maquinaria y limpiar los } \\
\text { camiones que salgan de la obra para } \\
\text { evitar emisiones de polvo. }\end{array}$ & $\begin{array}{l}\text { Separar los residuos peligrosos de los } \\
\text { no peligrosos instalando contenedores } \\
\text { específicos para cada tipo de residuo } \\
\text { que se genere. }\end{array}$ \\
\hline $\begin{array}{l}\text { Evitar vertimientos directos sobre el } \\
\text { suelo y flujos de agua e } \\
\text { impermeabilizar las zonas } \\
\text { dedicadas al mantenimiento y } \\
\text { abastecimiento de la maquinaria. }\end{array}$ & $\begin{array}{l}\text { Realizar el mantenimiento de la } \\
\text { maquinaria para minimizar el nivel de } \\
\text { ruido emitido, evitar consumo excesivo } \\
\text { de combustible y causar emisiones por } \\
\text { encima de lo permitido. }\end{array}$ \\
\hline $\begin{array}{l}\text { Proteger la carga de los camiones y } \\
\text { los acopios de materiales con lonas } \\
\text { para evitar contaminación del aire. }\end{array}$ & $\begin{array}{l}\text { No realizar las actividades de } \\
\text { excavación con demasiada antelación } \\
\text { para evitar una mayor erosión de la } \\
\text { zona. }\end{array}$ \\
\hline $\begin{array}{l}\text { Adaptar el horario de actividades } \\
\text { ruidosas (taladro por ejemplo) en } \\
\text { horas que molesten menos. }\end{array}$ & $\begin{array}{l}\text { Determinar vías de acceso de } \\
\text { maquinaria a las obras por zonas en las } \\
\text { que el impacto ambiental sea menor. }\end{array}$ \\
\hline
\end{tabular}

Fuente: Ministerio del Ambiente

Elaboración propia 


\section{Buenas prácticas para el uso eficiente del transporte}

- Se elegirá un vehículo a gas natural el cual es menos contaminante respecto a la gasolina o el diesel

- Se utilizará aceite liviano para motor; esto reduce el desgaste del motor y el consumo de combustible.

- Se realizarán los mantenimientos preventivos al vehículo acorde con las especificaciones del fabricante.

- Se dispondrán de lugares especiales para colocar las bicicletas de los empleados.

- Se implementarán técnicas de conducción eficiente, como por ejemplo:

- Evitar bajar las ventanillas.

- Evite conducir con el aire acondicionado encendido; esto aumenta el consumo un $30 \%$.

- Evitar frenazos y acelerones.

- Controlar la velocidad máxima.

- Usar neumáticos radiales y mantenerlos a la presión adecuada.

- Comprobar la correcta alineación de las ruedas.

- Evitar zonas congestionadas

\section{Indicadores ambientales}

Los indicadores ambientales son herramientas que permiten evaluar la forma en la cual varía en el tiempo la eficiencia en el uso de los recursos. Estos indicadores cuantifican importantes evoluciones en la protección ambiental y las hacen comparable años tras año permitiéndonos detectar tendencias que servirán para corregir y tomar decisiones acerca de cómo seguir mejorando en el cuidado del medio ambiente.

Los principales indicadores de desempeño ecoeficientes que se utilizarán para cuantificar los procesos se presentan a continuación: 
Tabla 5.23

Indicadores ecoeficientes de desempeño

\begin{tabular}{|l|c|}
\hline \multicolumn{1}{|c|}{ Indicadores de desempeño } & Fórmulas \\
\hline Indicador de consumo de energía & $\frac{\mathrm{Kw} . \mathrm{h}}{\mathrm{Nro \text {empleados }}}$ \\
\hline $\begin{array}{l}\text { Indicador de consumo de } \\
\text { combustibles }\end{array}$ & $\frac{\text { Gal.combustible }}{\text { Nro autos }}$ \\
\hline Indicador de consumo de agua & $\frac{\mathrm{m} 3 \text { de agua }}{\text { Nro empleados }}$ \\
\hline Indicador de consumo de papel & $\frac{\text { Kg.de Papel }}{\text { Nro empleados }}$ \\
\hline $\begin{array}{l}\text { Indicador de consumo de útiles } \\
\text { de oficina }\end{array}$ & $\frac{\text { Nro tintas, toner }}{\text { Nro empleados }}$ \\
\hline $\begin{array}{l}\text { Indicador de generación de } \\
\text { residuos solidos }\end{array}$ & $\frac{\text { Kg.Residuos Solidos }}{\text { Nro empleados }}$ \\
\hline \begin{tabular}{l} 
Indicador de emisión de $\mathrm{CO}_{2}$ \\
\hline
\end{tabular} & $\frac{\text { Kg.CO2 }}{\text { Nro empleados }}$ \\
\hline
\end{tabular}

Fuente: Ministerio del Ambiente

Elaboración propia

Finalmente se obtendrá la Certificación Internacional en Ecoeficiencia y Sostenibilidad otorgada por la "Council on Green", un ente internacional acreditado con sede en los Estados Unidos que certifica el compromiso que tiene una empresa de mejorar el impacto y la actuación ambiental que generan sus operaciones mediante la revisión y validación documental de por ejemplo, a evaluación de la calidad del aire, ahorro energético, proyectos de reciclaje, ahorro de agua, entre otros.

\subsection{Seguridad y salud ocupacional}

Se debe garantizar la seguridad y salud ocupacional de los trabajadores estableciendo políticas a fin de prevenir accidentes y evitar enfermedades ocupacionales inherentes a las actividades de fisioterapia. Dichas políticas estarán basadas en los principios y disposiciones generales del Reglamento de la Ley $\mathrm{N}^{0}$ 29783, Ley de Seguridad y Salud en el Trabajo D.S. No 005-2012-TR y los requisitos de las mejores 
prácticas en gestión de seguridad y salud en el trabajo de la norma internacional OHSAS 18001.

En el centro de rehabilitación física se deberá definir las zonas de seguridad, ubicación de los extintores, ubicación de las luces de emergencia, detectores de humo, zonas de escape, zonas de riesgo biológico y el depósito de residuos sólidos y hospitalarios. Todas las zonas serán señalizadas adecuadamente según la Norma Técnica Peruana NTP 399.010-1 Señales de Seguridad: Colores, símbolos, formas y dimensiones de señales de seguridad.

Figura 5.29

Tipos de señales de Seguridad

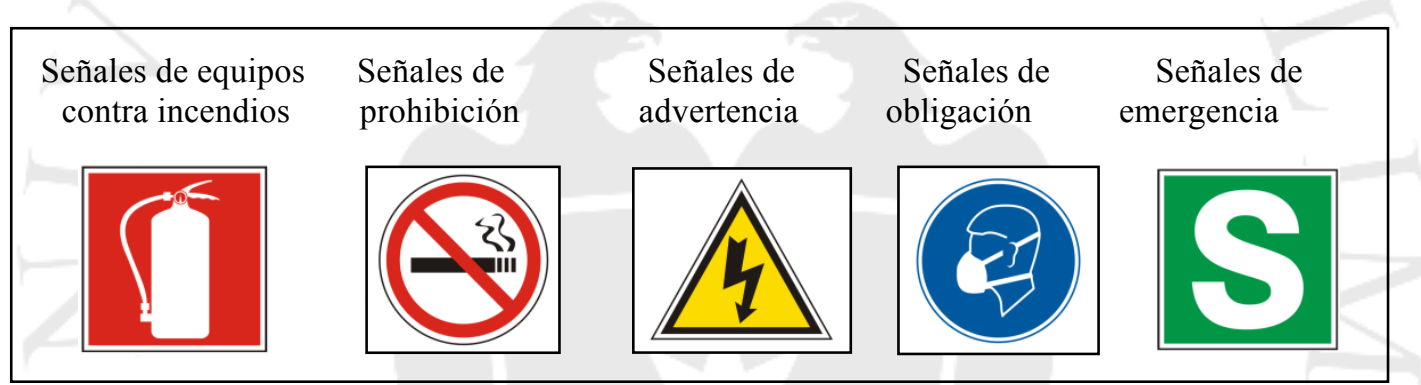

Fuente: INDECOPI

Elaboración propia

Respecto a la seguridad contra incendios se dispondrá de extintores de polvo químico seco PQS para fuego de clase $\mathrm{ABC}$; es decir: sólidos como maderas, papeles, plásticos; líquidos inflables como alcohol, gasolina y gases como propano o butano; y fuego que involucran equipos energizados como en nuestro caso todos los agentes físicos que se utilizan para las terapias (ultrasonido, magneto, láser, electroestimuladores, etc) 
Figura 5.30

Extintor PQS para clase de fuego ABC

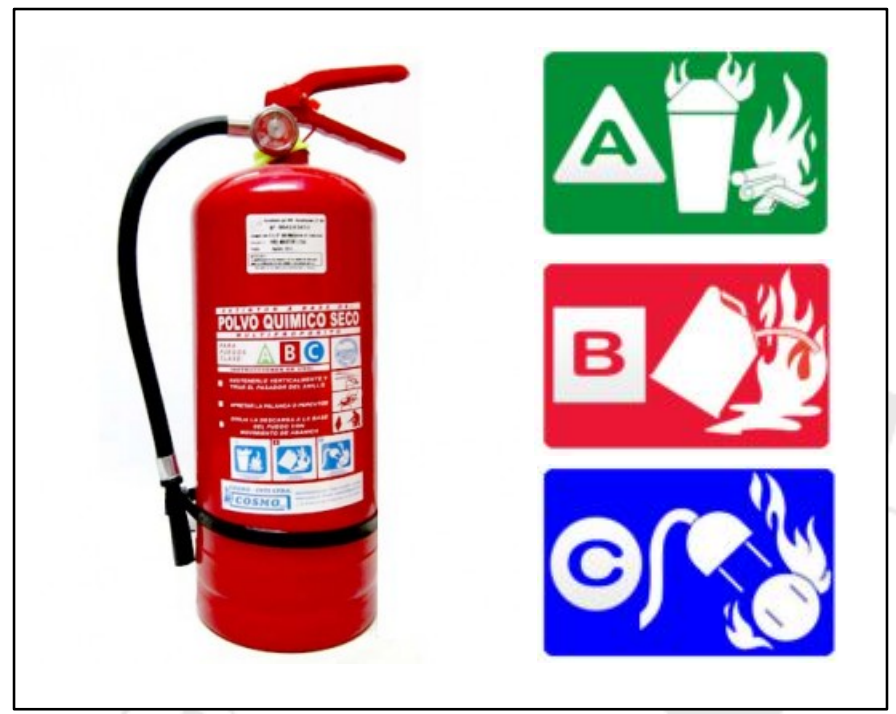

Fuente: INDECOPI

Elaboración propia

Figura 5.31

Altura de instalación de extintor

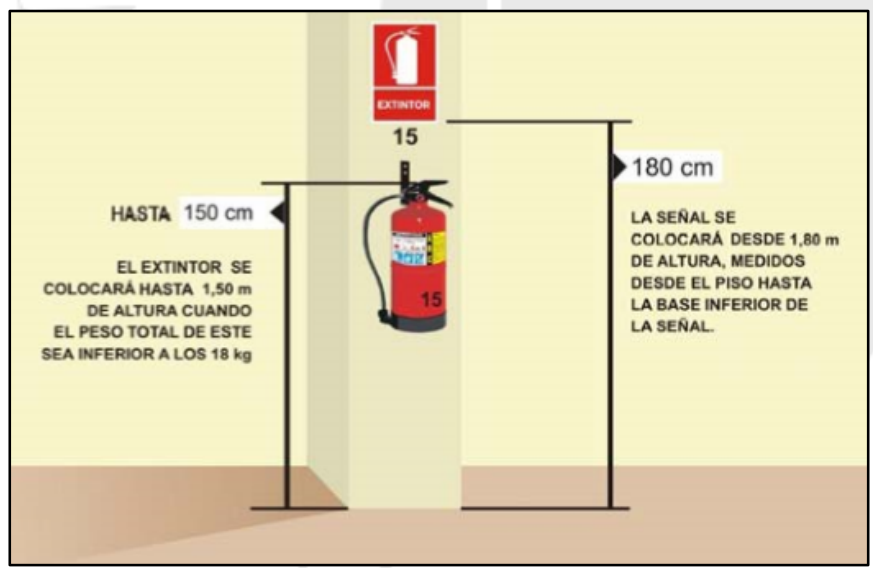

Fuente: INDECOPI

Elaboración propia

Según la Norma Técnica Peruana NTP 350.043-1 2011 Extintores Portátiles. Selección, distribución, inspección, mantenimiento, recarga y prueba hidrostática, el área máxima que cubre un extintor contra incendios está definida por un radio de 22,86 m. (75 pies) por lo que la distribución de estos dependerá de dicho radio. 
También se designará un Comité de Seguridad y Salud en el trabajo el cual incluirá una Brigada de Emergencias con conocimientos en primeros auxilios y manejo de extintores a fin de estar preparados ante cualquier accidente de trabajo, movimiento telúrico, incendio u otro aspecto que afecte la salud e integridad de los trabajadores. El comité será el encargado de elaborar el Plan de Seguridad el cual abarcará puntos básicos como:

1. Establecer mecanismos de prevención destinados a reducir los efectos que puedan producir situaciones de emergencia.

2. Organizar y coordinar acciones que deben llevarse a cabo para superar situaciones de emergencia como procedimientos de evacuación.

3. Contar con mecanismos efectivos de comunicación y señalización adecuada indicando las principales vías de evacuación.

4. Disponer con elementos básicos de primeros auxilios como botiquín de emergencia y camillas.

5. Contar con un directorio telefónico de líneas de emergencia como bomberos, policía nacional, serenazgo, ambulancias, entre otros y a la vez también contar con un sistema de alarma y alerta ante cualquier siniestro.

6. Programar acciones formativas, capacitaciones y simulacros de incendio y sismos.

7. Actualizar permanentemente el Plan de Seguridad.

Respecto al trabajo específico del tecnólogo médico, es contradictorio hablar de lesiones musculo-esqueléticas en los profesionales fisioterapeutas pero sin embargo estas se presentan por posturas inadecuadas o por factores de riesgo ergonómicos derivados del trabajo repetitivo; por tal motivo se debe implementar un manual de higiene ocupacional donde se dispongan las medidas preventivas para minimizar este tipo de enfermedades, disminuir la fatiga mental y física; y así mismo aumentar la satisfacción y la eficiencia del trabajador. 
Los riesgos más comunes a los que están expuestos los tecnólogos médicos están relacionados con la ergonomía del puesto de trabajo y la organización (distribución de tareas, descansos, etc) además de los problemas concernientes con los campos electromagnéticos que emiten los equipos electrónicos.

Asimismo, los trabajadores deberán usar equipos de protección personal para evitar el contacto con los pacientes a fin de que puedan transmitir enfermedades de diferente índole, dentro de los equipos de protección que se manejan se tienen mandiles, guantes de látex, mascarillas, entre otros.

En conclusión, se deben crear las mejores condiciones de trabajo posibles en el centro siendo necesario identificar y evaluar los peligros y riesgos a fin de establecer los controles necesarios y las medidas preventivas y correctivas para garantizar que las labores de los trabajadores sean más seguras.

A continuación se presenta la matriz de identificación de peligros y evaluación de riesgos en el centro de rehabilitación física teniendo en consideración los siguientes parámetros:

\section{Tabla 5.24}

Parámetros para la evaluación del riesgo (1)

$\begin{array}{|llll|}\begin{array}{l}\text { Nivel de Deficiencia (ND) } \\ \text { Calificación: }\end{array} & \text { Nivel de Exposición (NE) } & \begin{array}{l}\text { Nivel de Gravedad (NG) } \\ \text { Calificación: } 10: \text { Leve }\end{array} \\ \text { 2: Medio } & \text { Calificación: } & \text { 1: Esporádica } & \text { 25: Grave } \\ \text { 6: Alto } & & \text { 2: Ocasional } & \text { 60: Muy grave } \\ \text { 10: Muy Alto } & \text { 3: Frecuente } & \text { 100: Mortal }\end{array}$

Fuente: TECSUP

Elaboración propia 
Tabla 5.25

Parámetros para la evaluación del riesgo (2)

Nivel de Probabilidad (NP): NP $=$ ND $*$ NE

BAJA: 2 a 4

MEDIA: 6 a 8

ALTA: 10 a 20

MUY ALTA: 24 a 40
Nivel de Riesgo (NR): NR $=\mathrm{NP} * \mathrm{NG}$

NO ACEPTABLE: 600 A 4.000

ACEPTABLE CON CONTROL

ESPECÍFICO: 150 A 500

ACEPTABLE: 40 a 120

ACEPTABLE: 10 a 20

Fuente: TECSUP

Elaboración propia 
Tabla 5.26

Matriz de identificación de peligros y evaluación de riesgos - IPER

\begin{tabular}{|c|c|c|c|c|c|c|c|c|c|c|c|c|}
\hline \multirow[b]{2}{*}{ PELIGRO } & \multirow[b]{2}{*}{ RIESGO } & \multirow[b]{2}{*}{ EFECTOS } & \multirow[b]{2}{*}{ CONSECUENCIAS } & \multicolumn{8}{|c|}{ EVALUACIÓN DEL RIESGO } & \multirow[b]{2}{*}{$\begin{array}{l}\text { MEDIDAS PREVENTIVAS } \\
\text { Y CORRECTIVAS }\end{array}$} \\
\hline & & & & ND & NE & NP & $\begin{array}{l}\text { CALIF. DE } \\
\text { PROB. }\end{array}$ & NG & NR & $\begin{array}{l}\text { CALIF. } \\
\text { DEL NR }\end{array}$ & $\begin{array}{l}\text { VALORACIÓN } \\
\text { DE RIESGO }\end{array}$ & \\
\hline Tomacorrientes & $\begin{array}{l}\text { Contacto directo con } \\
\text { tomacorrientes de baja } \\
\text { tensión }\end{array}$ & $\begin{array}{l}\text { Electrocución } \\
\text { leve }\end{array}$ & $\begin{array}{l}\text { Quemaduras } \\
\text { superficiales }\end{array}$ & 2 & 1 & 2 & BAJO & 10 & 20 & IV & ACEPTABLE & $\begin{array}{l}\text { Mantenimiento de las } \\
\text { instalaciones eléctricas. } \\
\text { Protección de tomacorrientes. }\end{array}$ \\
\hline $\begin{array}{l}\text { Tuberías y } \\
\text { conexiones de } \\
\text { agua }\end{array}$ & $\begin{array}{l}\text { Inundaciones por } \\
\text { rompimiento de } \\
\text { tuberías }\end{array}$ & $\begin{array}{l}\text { Pérdidas } \\
\text { materiales, } \\
\text { accidentes. }\end{array}$ & $\begin{array}{l}\text { Inundación del área. } \\
\text { Pérdida de } \\
\text { información digital y } \\
\text { física. }\end{array}$ & 2 & 1 & 2 & BAJO & 10 & 20 & IV & ACEPTABLE & $\begin{array}{l}\text { Realizar inspecciones } \\
\text { periódicas del sistema de agua y } \\
\text { desagüe. }\end{array}$ \\
\hline $\begin{array}{l}\text { Ascensor } \\
\text { eléctrico }\end{array}$ & $\begin{array}{l}\text { Paralización del } \\
\quad \text { ascensor }\end{array}$ & Atrapamiento & $\begin{array}{l}\text { Pérdida del } \\
\text { conocimiento }\end{array}$ & 2 & 3 & 6 & MEDIO & 25 & 150 & II & $\begin{array}{l}\text { ACEPTABLE } \\
\text { CON CONTROL } \\
\text { ESPECIFICO }\end{array}$ & $\begin{array}{c}\text { Mantenimiento preventivo y } \\
\text { correctivo a los ascensores. } \\
\text { Ponta llamada a emergencias. } \\
\text { (Bomberos) }\end{array}$ \\
\hline Ruido & $\begin{array}{l}\text { Presencia de ruido } \\
\text { intermitente } \\
\text { ocasionada por los } \\
\text { teléfonos e } \\
\text { impresoras y la } \\
\text { puertas de acceso. }\end{array}$ & Desconcentración & Estrés & 2 & 3 & 6 & MEDIO & 10 & 60 & III & ACEPTABLE & $\begin{array}{c}\text { Teléfonos con volumen } \\
\text { moderado. } \\
\text { Mantenimiento de impresoras y } \\
\text { de puertas de acceso. }\end{array}$ \\
\hline $\begin{array}{l}\text { Digitación en } \\
\text { computadoras }\end{array}$ & Digitación Continua & Cansancio & $\begin{array}{l}\text { Síndrome del Tunal } \\
\text { carpiano }\end{array}$ & 2 & 4 & 8 & MEDIO & 25 & 200 & II & $\begin{array}{l}\text { ACEPTABLE } \\
\text { CON CONTROL } \\
\text { ESPECIFICO } \\
\end{array}$ & $\begin{array}{l}\text { Apoya muñecas para teclado. } \\
\text { Ajustar el puesto de trabajo de } \\
\text { acuerdo al trabajo de digitación. }\end{array}$ \\
\hline Escaleras & $\begin{array}{l}\text { Ascenso y descenso } \\
\text { de escaleras }\end{array}$ & Caídas & $\begin{array}{l}\text { Lesiones de tejidos } \\
\text { blandos, golpes y } \\
\text { contusiones. }\end{array}$ & 2 & 3 & 6 & MEDIO & 25 & 150 & II & $\begin{array}{l}\text { ACEPTABLE } \\
\text { CON CONTROL } \\
\text { ESPECIFICO }\end{array}$ & $\begin{array}{l}\text { Barandas. Cintas antideslizantes } \\
\text { en los peldaños de las escaleras. } \\
\text { Utilizar calzado antideslizante. }\end{array}$ \\
\hline $\begin{array}{l}\text { Suelo y } \\
\text { superficies }\end{array}$ & $\begin{array}{l}\text { Superficies resbalosas } \\
\text { por limpieza }\end{array}$ & Caídas & $\begin{array}{l}\text { Fracturas, Trauma en } \\
\text { tejidos blandos }\end{array}$ & 2 & 2 & 4 & BAJO & 25 & 100 & III & ACEPTABLE & $\begin{array}{c}\text { Aseo de áreas en horas de baja } \\
\text { circulación. Señalización sobre } \\
\text { piso mojado. }\end{array}$ \\
\hline Energía & Ausencia de Energía & Oscuridad & $\begin{array}{l}\text { Escasa visibilidad, } \\
\text { caídas }\end{array}$ & 2 & 1 & 2 & BAJO & 10 & 20 & IV & ACEPTABLE & $\begin{array}{c}\text { Mantenimientos preventivos y } \\
\text { correctivos de luces de } \\
\text { emergencia }\end{array}$ \\
\hline $\begin{array}{l}\text { Instrumentos } \\
\text { médicos y } \\
\text { herramientas }\end{array}$ & $\begin{array}{l}\text { Uso inadecuado de } \\
\text { instrumentos médicos } \\
\text { y herramientas }\end{array}$ & Heridas, Golpes & $\begin{array}{l}\text { Cortaduras, heridas } \\
\text { superficiales }\end{array}$ & 2 & 3 & 6 & MEDIO & 25 & 150 & & $\begin{array}{l}\text { ACEPTABLE } \\
\text { CON CONTROL } \\
\text { ESPECIFICO }\end{array}$ & $\begin{array}{c}\text { Capacitación en el uso de } \\
\text { instrumentos médicos. Cambio } \\
\text { inmediato cuando se encuentren } \\
\text { defectuosas. }\end{array}$ \\
\hline
\end{tabular}

Elaboración propia 
Tabla 5.27

Matriz de identificación de peligros y evaluación de riesgos - IPER (continuación)

\begin{tabular}{|c|c|c|c|c|c|c|c|c|c|c|c|c|}
\hline \multirow[b]{2}{*}{ PELIGRO } & \multirow[b]{2}{*}{ RIESGO } & \multirow[b]{2}{*}{ EFECTOS } & \multirow[b]{2}{*}{ CONSECUENCIAS } & \multicolumn{8}{|c|}{ EVALUACIÓN DEL RIESGO } & \multirow{2}{*}{$\begin{array}{l}\text { MEDIDAS PREVENTIVAS } \\
\text { Y CORRECTIVAS }\end{array}$} \\
\hline & & & & ND & $\mathbf{N E}$ & NP & $\begin{array}{l}\text { CALIF. DE } \\
\text { PROB. }\end{array}$ & NG & NR & $\begin{array}{l}\text { CALIF. } \\
\text { DEL NR }\end{array}$ & $\begin{array}{l}\text { VALORACIÓN } \\
\text { DE RIESGO }\end{array}$ & \\
\hline $\begin{array}{l}\text { Fenómenos } \\
\text { naturales }\end{array}$ & Sismo. Terremoto & $\begin{array}{c}\text { Pérdidas } \\
\text { materiales, } \\
\text { traumas, } \\
\text { aplastamiento. }\end{array}$ & Heridas graves, muerte & 2 & 1 & 2 & BAJO & 100 & 200 & II & $\begin{array}{l}\text { ACEPTABLE } \\
\text { CON CONTROL } \\
\text { ESPECIFICO }\end{array}$ & $\begin{array}{l}\text { Capacitación y simulacros en } \\
\text { caso de Sismos. Revisión del } \\
\text { plan de evacuación. }\end{array}$ \\
\hline $\begin{array}{l}\text { Instalaciones } \\
\text { eléctricas }\end{array}$ & Corto circuito & Incendio & Quemaduras, asfixia & 2 & 1 & 2 & BAJO & 100 & 200 & II & $\begin{array}{l}\text { ACEPTABLE } \\
\text { CON CONTROL } \\
\text { ESPECIFICO }\end{array}$ & $\begin{array}{c}\text { Capacitación en casos de } \\
\text { Incendio. Realizar simulacros } \\
\text { de evacuación. Mantenimiento } \\
\text { y recarga de extintores. } \\
\end{array}$ \\
\hline Biológico & $\begin{array}{l}\text { Riesgos biológicos por } \\
\text { contacto dérmico }\end{array}$ & Contagio & $\begin{array}{l}\text { Enfermedades de } \\
\text { transmisión cutánea }\end{array}$ & 2 & 4 & 8 & MEDIO & 25 & 200 & II & $\begin{array}{l}\text { ACEPTABLE } \\
\text { CON CONTROL } \\
\text { ESPECIFICO }\end{array}$ & $\begin{array}{l}\text { Utilización de equipos de } \\
\text { protección individual como } \\
\text { guantes de látex, mandiles y } \\
\text { mascarillas. }\end{array}$ \\
\hline Ergonómico & $\begin{array}{l}\text { Diseños inadecuados de } \\
\text { los lugares de trabajo }\end{array}$ & $\begin{array}{c}\text { Dolores, } \\
\text { inflación de } \\
\text { músculos y } \\
\text { articulaciones } \\
\end{array}$ & $\begin{array}{l}\text { Enfermedades } \\
\text { ocupacionales }\end{array}$ & 2 & 4 & 8 & MEDIO & 25 & 200 & II & $\begin{array}{l}\text { ACEPTABLE } \\
\text { CON CONTROL } \\
\text { ESPECIFICO }\end{array}$ & $\begin{array}{l}\text { Diseño ergonómico del puesto } \\
\text { de trabajo. Instalar camillas y } \\
\text { asientos regulables. }\end{array}$ \\
\hline Biomecánico & $\begin{array}{l}\text { Postura sedente } \\
\text { prolongada durante la } \\
\text { jornada laboral. }\end{array}$ & Cansancio & $\begin{array}{l}\text { Lumbalgia crónica. } \\
\text { Desordenes músculo } \\
\text { esqueléticos. }\end{array}$ & 6 & 3 & 18 & ALTO & 25 & 450 & II & $\begin{array}{l}\text { ACEPTABLE } \\
\text { CON CONTROL } \\
\text { ESPECIFICO } \\
\end{array}$ & $\begin{array}{l}\text { Sillas Ergonómicas. Uso de } \\
\text { reposa pies. Capacitación en } \\
\text { ergonomía. }\end{array}$ \\
\hline $\begin{array}{l}\text { Organización de } \\
\text { Trabajo }\end{array}$ & $\begin{array}{l}\text { Altos ritmos de trabajo } \\
\text { derivados de una } \\
\text { deficiente organización }\end{array}$ & Cansancio & Estrés & 2 & 3 & 6 & MEDIO & 25 & 150 & II & $\begin{array}{l}\text { ACEPTABLE } \\
\text { CON CONTROL } \\
\text { ESPECIFICO } \\
\end{array}$ & $\begin{array}{c}\text { Rotación e intercambio de } \\
\text { tareas para evitar sobrecarga } \\
\text { física. Planificar pausas y } \\
\text { disponer de áreas de descanso. }\end{array}$ \\
\hline $\begin{array}{l}\text { Trabajos de } \\
\text { kinesioterapia }\end{array}$ & Masajes repetitivos & $\begin{array}{c}\text { Dolores en las } \\
\text { manos y sus } \\
\text { articulaciones } \\
\end{array}$ & $\begin{array}{l}\text { Lesiones músculo } \\
\text { esqueléticas }\end{array}$ & 6 & 3 & 18 & ALTO & 25 & 450 & II & $\begin{array}{l}\text { ACEPTABLE } \\
\text { CON CONTROL } \\
\text { ESPECIFICO } \\
\end{array}$ & $\begin{array}{l}\text { Programas de ejercicios físicos } \\
\text { de estiramiento y calentamiento } \\
\text { muscular. }\end{array}$ \\
\hline $\begin{array}{l}\text { Campos } \\
\text { electromagnéticos } \\
\text { y radiaciones no } \\
\text { ionizantes }\end{array}$ & $\begin{array}{l}\text { Exposición a radiaciones } \\
\text { no ionizantes y campos } \\
\text { electromagnéticos } \\
\text { generados por los } \\
\text { equipos de tratamiento. }\end{array}$ & $\begin{array}{l}\text { Irritación de } \\
\text { ojos y piel }\end{array}$ & $\begin{array}{l}\text { Lesiones oculares y } \\
\text { dérmicas }\end{array}$ & 2 & 4 & 8 & MEDIO & 60 & 480 & II & $\begin{array}{l}\text { ACEPTABLE } \\
\text { CON CONTROL } \\
\text { ESPECIFICO }\end{array}$ & $\begin{array}{l}\text { Minimizar la exposición a los } \\
\text { campos electromagnéticos. } \\
\text { Adquirir equipos que posean } \\
\text { temporizadores. }\end{array}$ \\
\hline
\end{tabular}

Elaboración propia 
Figura 5.32

Plano de Seguridad
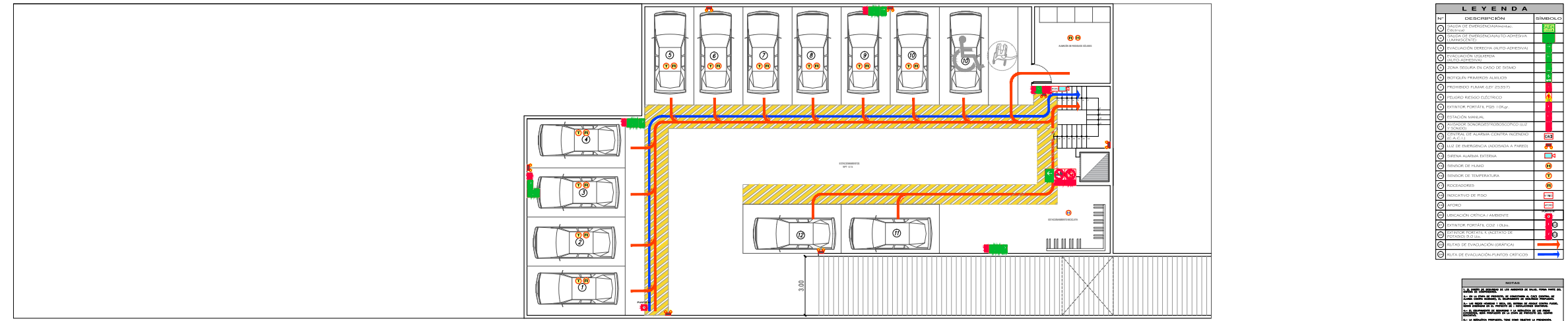

SÓTANO

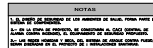

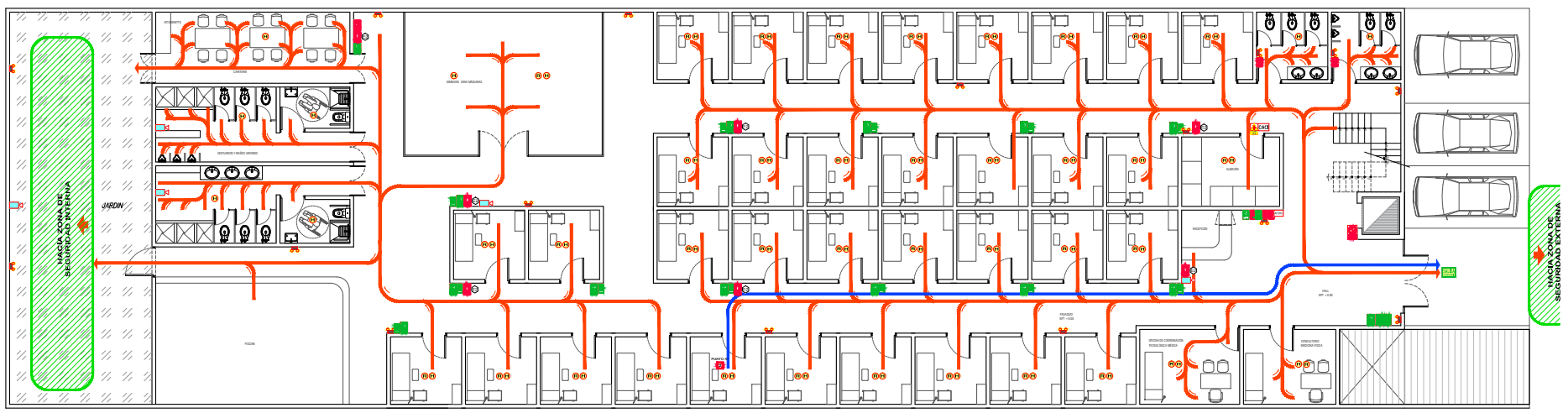

PRIMER PISO

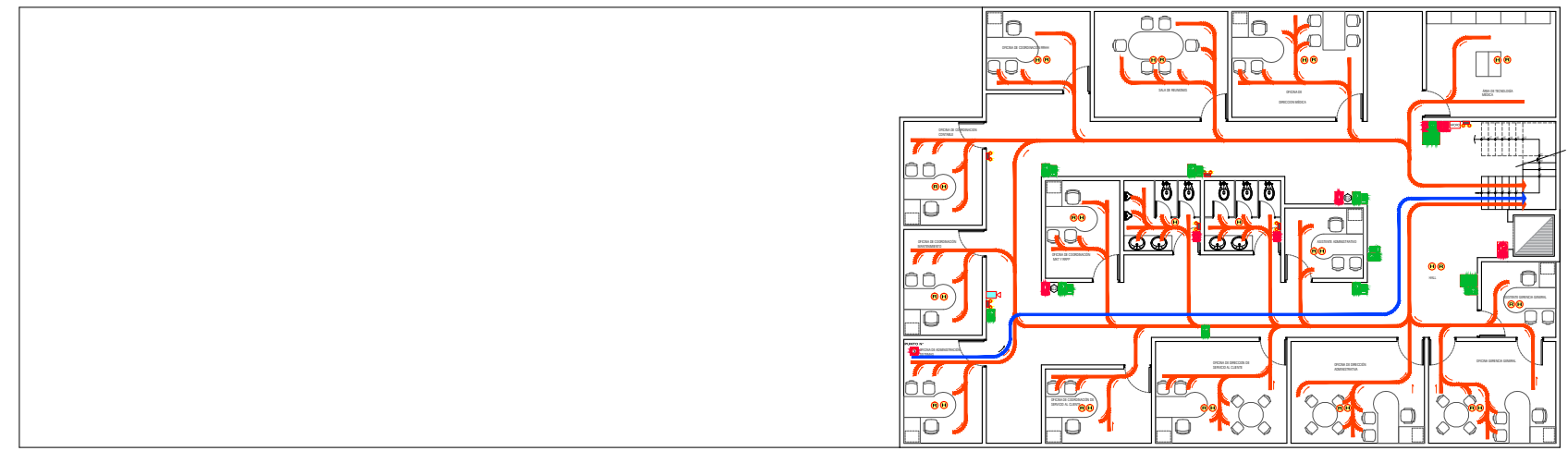




\subsection{Sistema de mantenimiento}

La gestión de mantenimiento tiene como principal reto prolongar el ciclo de vida de los activos e instalaciones mediante la conservación de todos los recursos que se utilizan para la operación del centro. Para tal fin se diseñará un sistema de mantenimiento que comprenderá tres tipos de mantenimiento que garanticen el buen funcionamiento y operación del centro. Estos son: Mantenimiento Reactivo, Correctivo y Preventivo.

Dicho sistema de mantenimiento estará basado en tareas básicas como limpieza, inspección y documentación de todos los equipos e instalaciones. El coordinador de mantenimiento es el encargado de generar procedimientos y protocolos ante cualquier falla de los equipos e instalaciones del centro.

Los tecnólogos médicos son principalmente los que utilizan los equipos médicos como son el magneto, ultrasonido, generadores de ondas de choque, entre otros y deben seguir todos los procedimientos establecidos ante cualquier avería.

Para evitar fallas por una mala manipulación de los equipos médicos se realizará una inducción acerca del uso de estos en base a procedimientos de utilización, un factor importante es seguir las instrucciones de los manuales de funcionamiento para garantizar su correcto uso y evitar desperfectos. Ante cualquier falla de los equipos o instalaciones se comunicará inmediatamente al área de mantenimiento.

Dentro de los tres tipos de mantenimiento se tiene: 


\section{Mantenimiento Reactivo}

Se realizarán las reparaciones de averías y fallas que se presenten tanto en la infraestructura del centro como en los equipos. Se tendrá en cuenta las garantías de los equipos nuevos al iniciar la operación para realizar los reclamos pertinentes a los proveedores en caso de fallas de fabricación.

Respecto a las instalaciones del centro, se tendrá una respuesta rápida ante las averías en el mobiliario, puertas, ventanas, cambio de luminarias, entre otros. Los equipos médicos que sufran algún desperfecto deberán ser reparados inmediatamente o en su defecto ser reemplazados.

\section{Mantenimiento Preventivo}

Es el mantenimiento programado que incluye actividades de inspección, conservación y sustitución de piezas y componentes considerando un periodo de tiempo según lo requiera el equipo. Dentro de este mantenimiento estarán el ascensor del centro y la camioneta utilizada para el traslado de los pacientes.

Un aspecto importante a tener en cuenta en la gestión de mantenimiento preventivo es la conservación de los pozos de puesta a tierra del centro puesto que dicho sistema resguarda la seguridad de los pacientes ante cualquier desperfecto que pueda sufrir algún equipo eléctrico.

Tanto los pacientes como los tecnólogos médicos están en contacto constante con los equipos eléctricos que se utilizan para las terapias, dichos equipos podrían sufrir fallas eléctricas con lo que cualquier descarga se debería conducir al pozo a tierra y no al paciente. La función del pozo a tierra es la disipación de la descarga emitida por el equipo que falla mediante electrodos enterrados en un ambiente que retiene la humedad 
con una mínima resistencia eléctrica. Para tal efecto se tendrá que realizar periódicamente el manteniendo tanto preventivo como correctivo a los pozos a tierra.

La Dirección General de Infraestructura, Equipamiento y Mantenimiento del Ministerio de Salud propone una "Guía Técnica para el Mantenimiento del Pozo de Puesta a Tierra en los Establecimientos de Salud" la cual tiene por finalidad establecer los requisitos y procedimientos mínimos para efectuar el mantenimiento preventivo y correctivo de los pozos a tierra. Nos valdremos de dicha guía para realizar el mantenimiento del sistema de protección eléctrica del centro.

La resistencia máxima para las actividades de medicina física y rehabilitación que recomienda la guía para los pozos a tierra es de 5 ohmios y tienen que ser medida por telurómetro calibrado; luego del mantenimiento de los pozos a tierra y corroborada la medida menor a 5 ohmios es necesario obtener el protocolo de mantenimiento de puesta a tierra firmado por un ingeniero eléctrico.

Tabla 5.28

Resistencias máximas del sistema de pozos de puesta a tierra

\begin{tabular}{|l|c|}
\hline \multicolumn{1}{|c|}{ Servicios médicos } & Resistencia \\
\hline Centro quirúrgico y cuidados intensivos & 5.0 Ohmios \\
\hline Emergencia y laboratorios & 5.0 Ohmios \\
\hline Sala de partos y neonatología & 5.0 Ohmios \\
\hline Banco de sangre, rayos X y resonancia magnética & 5.0 Ohmios \\
\hline Unidad de tomografía & 3.0 Ohmios \\
\hline Medicina física y rehabilitación & 5.0 Ohmios \\
\hline Sistemas de cómputo, comunicación y lavandería & 5.0 Ohmios \\
\hline Casa de fuerza y sub estación eléctrica & 15.0 Ohmios \\
\hline Ascensor & 5.0 Ohmios \\
\hline
\end{tabular}

Fuente: MINSA

Elaboración propia

El cronograma del mantenimiento preventivo de los equipos críticos se presenta a continuación: 
Tabla 5.29

Mantenimiento preventivo de los equipos críticos

\begin{tabular}{|l|c|c|c|}
\hline \multicolumn{4}{|c|}{ Cronograma de Mantenimiento Preventivo } \\
\hline Equipos & Trimestral & Semestral & Anual \\
\hline Ascensor & MP & & \\
\hline Sistema contra incendios sótano & & & MP \\
\hline Electroestimulador o TENS & & MP & \\
\hline Ultrasonido & & MP & \\
\hline Magneto & & MP & \\
\hline Equipo de ondas de choque & & MP & \\
\hline Laser de 1,040 mw & & MP & \\
\hline Ecógrafo & & MP & \\
\hline Microondas fisioterapéutico & & MP & \\
\hline Onda Corta & & MP & \\
\hline Silla de acceso a piscina & MP & & \\
\hline Calentador a gas & MP & & \\
\hline Filtro para piscina & MP & & \\
\hline Bomba de agua para piscina & MP & & \\
\hline Camioneta Van Transit Connect XLT & MP & & \\
\hline UPS & MP & & \\
\hline Aire acondicionado ducto 60.000 BTU & & & \\
\hline
\end{tabular}

Elaboración propia

\section{Mantenimiento Correctivo}

Es un mantenimiento planificado donde se busca mediante las inspecciones o el análisis de algún problema la detección de algún defecto antes que suceda la falla. Lo que se busca es corregir el defecto antes que suceda dicha falla para que el activo siga disponible de uso.

En el caso de los equipos médicos se busca corregir los defectos que se producen al descalibrarse los equipos, este defecto hace que se reduzcan los niveles de calor en los dispositivos de onda corta por ejemplo o que se tenga que aumentar los niveles de corriente eléctrica en los electroestimuladores para compensar la disminución. Por tal motivo los equipos deberán ser calibrados antes que ocurra la falla para garantizar su correcto funcionamiento. 


\subsection{Programa de operaciones del servicio}

\subsubsection{Consideraciones sobre la vida útil del proyecto}

La vida útil $\mathrm{u}$ horizonte del proyecto es el lapso en que se registran los beneficios y costos tomados en consideración para la evaluación del proyecto. $\mathrm{Su}$ duración será de 5 años puesto que se considerará la depreciación total de los equipos médicos en este periodo de tiempo y se espera a la vez recuperar la inversión.

Algunos factores que pueden afectar el proyecto dentro de su vida útil sería la posible alza de combustibles, tarifas eléctricas y de gas natural lo cual incidirá en los costos de operación del servicio aumentando nuestros gastos operativos.

Otro aspecto a tomar en cuenta es la aparición de nuevas tecnologías en el ámbito de la medicina y en los equipos de rehabilitación física que se utilizan lo que permitirá atender a los pacientes en un menor tiempo posible permitiendo que su recuperación sea más rápida.

5.9.2. Programa de operaciones del servicio durante la vida útil del proyecto

El programa de operaciones del servicio está elaborado considerando un ajuste de la demanda para el proyecto con el porcentaje de deserciones de las rehabilitaciones físicas que se den cada año. Este porcentaje es del 10\% que es el resultado de la mitad del estándar considerado en el capítulo de resguardo de la calidad. A continuación se presenta el programa de operaciones del servicio para la vida útil del proyecto. 
Tabla 5.30

Programa de operaciones del servicio

\begin{tabular}{|c|c|c|c|c|}
\hline Años & $\begin{array}{c}\text { Capacidad } \\
\text { instalada }\end{array}$ & $\begin{array}{c}\text { Demanda del } \\
\text { proyecto }\end{array}$ & $\begin{array}{c}\text { Programa de } \\
\text { operaciones }\end{array}$ & $\begin{array}{c}\text { \% de } \\
\text { Utilización }\end{array}$ \\
\hline 2017 & 122.595 & 114.993 & 103.494 & $84,42 \%$ \\
\hline 2018 & 122.595 & 116.212 & 104.591 & $85,31 \%$ \\
\hline 2019 & 122.595 & 117.421 & 105.679 & $86,20 \%$ \\
\hline 2020 & 122.595 & 118.607 & 106.746 & $87,07 \%$ \\
\hline 2021 & 122.595 & 119.781 & 107.803 & $87,93 \%$ \\
\hline
\end{tabular}

Elaboración propia

\subsection{Requerimiento de materiales, personal y servicios}

\subsubsection{Materiales para el servicio}

Los principales insumos y materiales que serán necesarios para llevar a cabo las terapias de rehabilitación física son los siguientes:

\section{Tabla 5.31}

Materiales e Insumos para el servicio

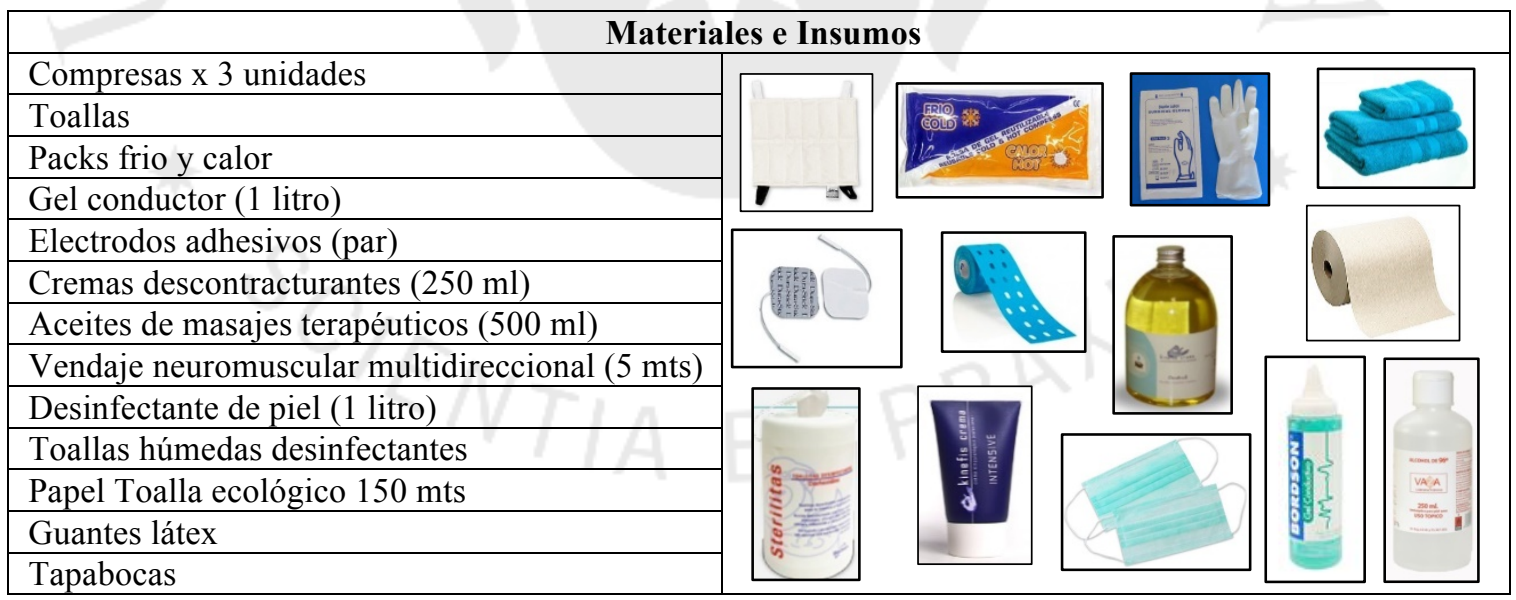

Fuente: Fisaude

Elaboración propia

Para el cálculo de los consumos de los insumos se tomará en cuenta los datos proporcionado por la tecnólogo médico Diana Mundaca CTMP 8808, quien afirma por experiencia médica que un paciente utiliza una botella de gel, una crema 
descontracturante, una botella de aceite para masajes, un par de electrodos y un vendaje neuromuscular durante un año, puesto que solo un paciente recibe 24 sesiones al año. Dicho cálculo está basado en la demanda para el proyecto la cual se incrementa año tras año.

El requerimiento de los insumos como el desinfectante para piel, las toallas húmedas desinfectantes y el papel toalla ecológico será la mitad respecto al número total de sesiones que un paciente recibe al año puesto que su capacidad alcanza para el doble de las sesiones que dicho paciente recibe al año según el especialista en rehabilitación física.

Respecto a los materiales como las compresas, toallas y packs de frio y calor se adquirirán cada dos años. Los guantes de látex y los tapabocas no son utilizados en todas las sesiones por lo que se considerará adquirir una cantidad anual que será la tercera parte de los principales insumos utilizados en las sesiones de rehabilitación física. A continuación se presenta el cuadro de los requerimientos de los materiales e insumos hasta el año 2021:

Tabla 5.32

Cantidad anual de materiales e insumos para el servicio

\begin{tabular}{|l|c|c|c|c|c|}
\hline \multirow{2}{*}{ Materiales e Insumos } & \multicolumn{5}{c|}{ Cantidad (Unid.) } \\
\cline { 2 - 6 } & $\mathbf{2 0 1 7}$ & $\mathbf{2 0 1 8}$ & $\mathbf{2 0 1 9}$ & $\mathbf{2 0 2 0}$ & $\mathbf{2 0 2 1}$ \\
\hline Gel conductor (1 litro) & 4.791 & 4.842 & 4.893 & 4.942 & 4.991 \\
\hline Electrodos adhesivos (par) & 4.791 & 4.842 & 4.893 & 4.942 & 4.991 \\
\hline Cremas descontracturantes (250 ml.) & 4.791 & 4.842 & 4.893 & 4.942 & 4.991 \\
\hline Aceites de masajes terapéuticos (500 ml.) & 4.791 & 4.842 & 4.893 & 4.942 & 4.991 \\
\hline Vendaje neuromuscular multidireccional (5 m.) & 4.791 & 4.842 & 4.893 & 4.942 & 4.991 \\
\hline desinfectante de piel (1 litro) & 2.396 & 2.421 & 2.447 & 2.471 & 2.496 \\
\hline Toallas húmedas desinfectantes & 2.396 & 2.421 & 2.447 & 2.471 & 2.496 \\
\hline Papel Toalla ecológico 150 m. & 2.396 & 2.421 & 2.447 & 2.471 & 2.496 \\
\hline Guantes látex & 1.597 & 1.614 & 1.631 & 1.647 & 1.664 \\
\hline Tapabocas & 1597 & 1.614 & 1.631 & 1.647 & 1.664 \\
\hline Compresas x 3 unidades & 200 & & 200 & & 200 \\
\hline Toallas & 200 & & 200 & & 200 \\
\hline Packs frio y calor & 200 & & 200 & & 200 \\
\hline
\end{tabular}

Elaboración propia 


\subsubsection{Determinación del requerimiento de personal de atención al cliente}

Según la Norma Técnica de Salud de la Unidad Productora de Servicios de Medicina de Rehabilitación; en la categoría de establecimientos de salud II-1, se exige que las prestaciones de servicios de salud en rehabilitación física deben ser realizadas por el siguiente personal:

- Médico especialista en medicina de rehabilitación.

- Licenciado en tecnología médica.

- Técnico en fisioterapia.

Para los servicios de rehabilitación física se contará con 2 médicos fisiatras, 2 coordinadores tecnólogo médico y 30 licenciados en tecnología médica que fueron definidos en el capítulo $\mathrm{V}$ referido al cálculo detallado del número de recursos para el servicio puesto que el principal recurso que se tiene es el humano. No se contratarán técnicos en fisioterapia porque se requiere brindar un servicio de calidad contratando a profesionales titulados en rehabilitación física.

A continuación se presenta el cuadro de los requerimientos del personal de atención al cliente y el personal administrativo: 
Tabla 5.33

Personal del servicio de rehabilitación física

\begin{tabular}{|l|c|}
\hline \multicolumn{1}{|c|}{ Personal del servicio } & Cant. \\
\hline Gerente General & 1 \\
\hline Asistente de Gerencia & 1 \\
\hline Director Médico & 1 \\
\hline Médico Fisiatra & 2 \\
\hline Coordinador Tecnólogo Médico & 2 \\
\hline Tecnólogo Médico o Fisioterapeuta & 30 \\
\hline Director de Servicio al Cliente & 1 \\
\hline Coordinador de Servicio al Cliente & 1 \\
\hline Recepcionista de admisión & 2 \\
\hline Coordinador de Marketing y RR.PP. & 1 \\
\hline Administrador de Sistemas & 1 \\
\hline Director Administrativo & 1 \\
\hline Asistente Administrativo & 1 \\
\hline Coordinador de Recursos Humanos & 1 \\
\hline Coordinador Contable & 1 \\
\hline Coordinador de Mantenimiento y Servicios Generales & 1 \\
\hline Conductor & 1 \\
\hline Total & $\mathbf{4 9}$ \\
\hline
\end{tabular}

Elaboración propia

\subsubsection{Servicios de terceros}

Los servicios considerados para su tercerización serán los siguientes:

- Servicios legales para la constitución de la empresa.

- Constructora encargada de la edificación y supervisión del edificio donde operará el centro de rehabilitación física.

- Empresa Prestadora de Servicios de Residuos Sólidos (EPRS) que realizará la disposición final de los residuos sólidos generados en el centro.

- Servicio de cafetería para los clientes y personal en general.

- Agentes de seguridad externa encargados de brindar la seguridad física al establecimiento como a los clientes y colaboradores.

- Limpieza del centro tanto los consultorios, áreas administrativas, baños, sala de recepción, entre otras; así como también la limpieza de las máquinas con que se realizan las terapias.

- Mantenimiento de la piscina terapéutica. 
- Mantenimiento de los equipos médicos e instalaciones eléctricas.

- Servicio de lavandería para las toallas utilizadas en el servicio.

- Empresa concesionaria de productos de ortopedia como los accesorios de compresión muscular, muñequeras, musleras, tobilleras, etc.

- Contratación de dominio y hosting lo que nos permitirá tener presencia en la Web.

\subsubsection{Otros: energía eléctrica, agua, transportes, etc.}

Dentro de los requerimientos referidos a los servicios necesarios para la operación del centro de rehabilitación física se tomará en cuenta los servicios de agua, energía, transporte y telefonía, cable e internet.

Las fuentes de consumo directas de agua serán principalmente las utilizadas para la hidroterapia que serán llevadas a cabo en la piscina del centro además de los consumos de agua de las duchas y lavatorios de los baños. El agua de la piscina será cambiada una vez al año por disposición de la empresa Nova Perú la cuál realizará el mantenimiento.

El requerimiento de agua necesario para la operación del centro está basado según el Reglamento Nacional de Edificaciones en su norma A.060, capítulo III de dotación de servicios donde se indica que el consumo de agua con servicio de aseo es de 100 litros por persona al día; dato que utilizaremos para el cálculo del requerimiento de agua de los pacientes y el consumo de agua de trabajadores en oficinas es de 20 litros por persona al día.

A continuación se presentan los cuadros del requerimiento de agua necesario para el servicio de fisioterapia y el requerimiento para los trabajadores de las oficinas en base a la demanda del último año. 
Tabla 5.34

Requerimiento de agua del servicio de rehabilitación física

\begin{tabular}{|l|c|c|c|c|c|c|}
\hline Consumo de agua del servicio & $\begin{array}{c}\text { (Litros/ } \\
\text { día) }\end{array}$ & $\begin{array}{c}\mathbf{m}^{\mathbf{3}} / \\
\text { día }\end{array}$ & Pacientes & $\begin{array}{c}\mathbf{m}^{\mathbf{3}} / \\
\text { día }\end{array}$ & $\begin{array}{c}\text { Días/ } \\
\text { año }\end{array}$ & $\begin{array}{c}\mathbf{m}^{\mathbf{3} /} \\
\text { año }\end{array}$ \\
\hline Consumo de agua pacientes & 100 & 0,1 & 383 & 38,3 & 313 & 11.988 \\
\hline Piscina $40 \mathrm{~m}^{3}$ & - & - & - & - & - & 40 \\
\hline Total & & & & & & 12.028 \\
\hline
\end{tabular}

Elaboración propia

Tabla 5.35

Requerimiento de agua de oficinas

\begin{tabular}{|c|c|c|c|c|c|c|}
\hline Consumo de agua de oficinas & $\begin{array}{c}\text { (Litros/ } \\
\text { día) }\end{array}$ & $\begin{array}{c}\mathbf{m}^{\mathbf{3}} / \\
\text { día }\end{array}$ & Trabajadores & $\begin{array}{c}\mathbf{m}^{\mathbf{3}} / \\
\text { día }\end{array}$ & $\begin{array}{c}\text { Días/ } \\
\text { año }\end{array}$ & $\begin{array}{c}\mathbf{m}^{\mathbf{3}} / \\
\text { año }\end{array}$ \\
\hline Consumo de agua del personal & 20 & 0,02 & 49 & 0.98 & 313 & 307 \\
\hline
\end{tabular}

Elaboración propia

Tabla 5.36

Requerimiento de agua anual

\begin{tabular}{|c|c|c|}
\hline Años & $\begin{array}{c}\text { Consumo de agua } \\
\text { del servicio } \mathbf{( m}^{\mathbf{3}} \mathbf{)}\end{array}$ & $\begin{array}{c}\text { Consumo total de } \\
\mathbf{a g u a} \mathbf{( m}^{\mathbf{3}} \mathbf{)}\end{array}$ \\
\hline 2017 & 11.527 & 11.834 \\
\hline 2018 & 11.652 & 11.959 \\
\hline 2019 & 11.778 & 12.084 \\
\hline 2020 & 11.903 & 12.209 \\
\hline 2021 & 12.028 & 12.335 \\
\hline
\end{tabular}

Elaboración propia

En el caso de la energía, se cuenta con dos matrices energéticas las cuales son la energía eléctrica y el gas natural. Nuestras principales fuentes de consumo respecto a la energía eléctrica son los equipos médicos utilizados para realizar las rehabilitaciones como el láser, magneto, equipo de ondas de choque entre otros; además de los equipos de aire acondicionado y otros consumos causados por la iluminación de ambientes tales como habitaciones, consultorios, oficinas, etc.

Según la tabla de iluminancias para ambientes al interior de los hospitales y centros médicos, la iluminancia en servicio de los consultorios a nivel de alumbrado local es de 750 lux por lo que se utilizará este dato en la fórmula para hallar el número de fuentes que se utilizará en cada cubículo de rehabilitación física. 
Como se verá más adelante, cada cubículo será de una dimensión de $9 \mathrm{~m}^{2}$. Se tomará en cuenta que un fluorescente LED tiene una potencia de 20 watts y un factor de conversión de 0,7. Según el fabricante Proluxz los fluorescentes LED ofrecen 95 lúmenes por watt por lo que se necesitará para cada cubículo 3 fuentes o luminarias; es decir 6 lámparas o fluorescentes LED. A continuación se presenta el cálculo del número de fuentes para cada cubículo:

$$
N=\frac{750 \frac{\text { lum }}{\mathrm{m} 2} \times 9 \mathrm{~m} 2}{0.7 \times 2 \frac{\text { lamp }}{\text { fuente }} \times 95 \frac{\text { lum }}{\text { lamp } \times \text { watts }} \times 20 \text { watts }}=2.54 \approx 3 \text { fuentes }
$$

Teniendo en cuenta lo anterior se ha calculado que para la iluminación total del centro se necesitarán 522 luminarias (Ver el cálculo en Anexo 3)

A continuación se muestra el cálculo de los requerimientos de Kw.h que se necesitan para los equipos del servicio y el cálculo de la energía eléctrica requerida para las oficinas en el último año. 
Tabla 5.37

Requerimiento de energía eléctrica del servicio de rehabilitación física

\begin{tabular}{|l|c|c|c|c|c|r|r|}
\hline $\begin{array}{c}\text { Consumo energía eléctrica del } \\
\text { servicio }\end{array}$ & Cant. & $\begin{array}{c}\text { Potencia } \\
(\mathbf{w})\end{array}$ & $\begin{array}{c}\text { Potencia } \\
(\mathbf{K w})\end{array}$ & $\begin{array}{c}\text { H-M/ } \\
\text { Turno }\end{array}$ & $\begin{array}{c}\text { Turnos/ } \\
\text { día }\end{array}$ & $\begin{array}{c}\text { Días/ } \\
\text { año }\end{array}$ & $\begin{array}{c}\text { Kw.h/ } \\
\text { año }\end{array}$ \\
\hline Electroestimulador o TENS & 6 & 35 & 0,035 & 6 & 2 & 313 & 789 \\
\hline Ultrasonido & 2 & 70 & 0,07 & 6 & 2 & 313 & 526 \\
\hline Magneto & 6 & 360 & 0,36 & 6 & 2 & 313 & 8.113 \\
\hline Equipo de ondas de choque & 4 & 550 & 0,55 & 6 & 2 & 313 & 8.263 \\
\hline Laser de 1,040 mw & 4 & 30 & 0,03 & 6 & 2 & 313 & 451 \\
\hline Ecógrafo & 1 & 45 & 0,045 & 6 & 2 & 313 & 169 \\
\hline Microondas terapéutico & 4 & 200 & 0,2 & 6 & 2 & 313 & 3.005 \\
\hline Onda Corta & 4 & 200 & 0,2 & 6 & 2 & 313 & 3.005 \\
\hline Tanque de compresas calientes & 2 & 1.000 & 1 & 6 & 2 & 313 & 7.512 \\
\hline Tanque de compresas frías & 2 & 500 & 0,5 & 6 & 2 & 313 & 3.756 \\
\hline Tanque de parafina & 2 & 200 & 0,2 & 6 & 2 & 313 & 1.502 \\
\hline Masajeador eléctrico & 2 & 60 & 0,06 & 6 & 2 & 313 & 451 \\
\hline Trotadora caminadora & 4 & 1.490 & 1,49 & 6 & 2 & 313 & 22.386 \\
\hline Aire acondicionado 60.000 BTU & 4 & 8.000 & 8 & 6 & 2 & 96 & 36.864 \\
\hline Lámparas fluorescentes LED & 222 & 20 & 0,02 & 6 & 2 & 313 & 16.677 \\
\hline Total & & & & & & 113.468 \\
\hline
\end{tabular}

Elaboración propia

Tabla 5.38

Requerimiento de energía eléctrica de oficinas

\begin{tabular}{|l|c|c|c|c|c|r|r|}
\hline $\begin{array}{c}\text { Consumo energía eléctrica en } \\
\text { oficinas }\end{array}$ & Cant. & $\begin{array}{c}\text { Potencia } \\
(\mathbf{w})\end{array}$ & $\begin{array}{c}\text { Potencia } \\
(\mathbf{K w})\end{array}$ & $\begin{array}{c}\text { H-M/ } \\
\text { Turno }\end{array}$ & $\begin{array}{c}\text { Turnos/ } \\
\text { día }\end{array}$ & $\begin{array}{c}\text { Días/ } \\
\text { año }\end{array}$ & $\begin{array}{c}\text { Kw.h/ } \\
\text { año }\end{array}$ \\
\hline Computadora desktop & 4 & 200 & 0,2 & 6 & 2 & 313 & 3.005 \\
\hline Laptop & 14 & 60 & 0,06 & 6 & 2 & 313 & 3.155 \\
\hline UPS & 1 & 1.350 & 1,35 & 6 & 2 & 313 & 5.071 \\
\hline Impresora & 2 & 900 & 0,9 & 6 & 2 & 313 & 6.761 \\
\hline Microondas & 2 & 1.100 & 1,1 & 6 & 2 & 313 & 8.263 \\
\hline Refrigeradora & 1 & 250 & 0,25 & 6 & 2 & 313 & 939 \\
\hline Aire acondicionado 60.000 BTU & 2 & 8.000 & 8 & 6 & 2 & 96 & 18.432 \\
\hline Televisor LED 50" & 2 & 100 & 0,1 & 6 & 2 & 313 & 751 \\
\hline Lámparas fluorescentes LED & 300 & 20 & 0,02 & 6 & 2 & 313 & 39.213 \\
\hline Total & & & & & & 88.913 \\
\hline
\end{tabular}

Elaboración propia 
Tabla 5.39

Requerimiento de energía eléctrica anual

\begin{tabular}{|c|c|c|}
\hline Años & $\begin{array}{c}\text { Consumo energía eléctrica } \\
\text { del servicio (Kw.h) }\end{array}$ & $\begin{array}{c}\text { Consumo total de energía } \\
\text { eléctrica (Kw.h) }\end{array}$ \\
\hline 2017 & 108.932 & 177.845 \\
\hline 2018 & 110.087 & 178.999 \\
\hline 2019 & 111.232 & 180.145 \\
\hline 2020 & 112.355 & 181.268 \\
\hline 2021 & 113.468 & 182.380 \\
\hline
\end{tabular}

Elaboración propia

Si no se utilizaran los equipos ecoeficientes LED y se emplearan los fluorescentes convencionales se requeriría de $221.593 \mathrm{Kw} . \mathrm{h}$ al año 2021 por lo que al utilizar dichos equipos LED se produce un ahorro del 21,5\% en el consumo total de energía.

Respecto al gas natural este será utilizado en el calentador de agua para la piscina y proporcionar agua caliente para las duchas; además de ser utilizado como combustible para la camioneta que transportará a los pacientes que no puedan ir por sus propios medios al centro.

Según la ficha técnica del calentador de piscina Fiero modelo FC-100, el consumo de gas natural es de $2,15 \mathrm{~m}^{3}$ por hora por lo que el requerimiento necesario de gas natural será de $8.075 \mathrm{~m}^{3}$ al año.

Tabla 5.40

Requerimiento de gas natural del calentador de piscina

\begin{tabular}{|c|c|c|c|c|c|}
\hline Equipo & $\mathbf{m}^{\mathbf{3}} / \mathbf{h}$ & $\begin{array}{c}\text { Horas/ } \\
\text { turno }\end{array}$ & $\begin{array}{c}\text { Turnos/ } \\
\text { día }\end{array}$ & $\begin{array}{c}\text { Días/ } \\
\mathbf{a n ̃ o}\end{array}$ & $\begin{array}{c}\text { Consumo de } \\
\text { gas natural } \\
\left(\mathbf{m}^{\mathbf{3}} / \mathbf{a n ̃ o}\right)\end{array}$ \\
\hline Calentador de Piscina & 2.15 & 6 & 2 & 313 & 8.075 \\
\hline
\end{tabular}

Elaboración propia

Para el cálculo del consumo de gas natural con la finalidad de calentar el agua de las duchas se asume que la mitad del consumo diario de agua destinada al servicio 
será calentada puesto que el gasto de agua en una ducha es de 50 litros aproximadamente por persona. Teniendo como premisa que para calentar $1 \mathrm{~m}^{3}$ de agua a $60{ }^{\circ} \mathrm{C}$ se necesita $6,1 \mathrm{~m}^{3}$ de gas natural y teniendo en cuenta la demanda diaria de pacientes por año se procederá a presentar el cuadro de requerimiento de gas natural.

Tabla 5.41

Requerimiento de gas natural para agua caliente

\begin{tabular}{|c|c|c|c|c|c|c|c|}
\hline Años & $\begin{array}{l}\text { Agua } \\
\text { (Litros/ } \\
\text { día) }\end{array}$ & $\begin{array}{l}\text { Agua } \\
\left(\mathbf{m}^{3} /\right. \\
\text { día }) \\
\end{array}$ & Personas & $\begin{array}{c}\begin{array}{c}\text { Agua a } \\
\text { calentar } \\
\left(\mathrm{m}^{3} / \text { día }\right)\end{array} \\
\end{array}$ & $\begin{array}{c}\text { Días/ } \\
\text { año }\end{array}$ & $\begin{array}{c}\text { Agua a } \\
\text { calentar } \\
\left(\mathrm{m}^{3} / \mathbf{a n ̃} 0\right)\end{array}$ & $\begin{array}{c}\text { Consumo de Gas } \\
\text { para agua caliente } \\
\left(\mathbf{m}^{3} / \mathbf{a n n o}\right)\end{array}$ \\
\hline 2017 & 50 & 0,05 & 367 & 18,35 & 313 & 5.744 & 35.036 \\
\hline 2018 & 50 & 0,05 & 371 & 18,55 & 313 & 5.806 & 35.418 \\
\hline 2019 & 50 & 0,05 & 375 & 18,75 & 313 & 5.869 & 35.799 \\
\hline 2020 & 50 & 0,05 & 379 & 18,95 & 313 & 5.931 & 36.181 \\
\hline 2021 & 50 & 0,05 & 383 & 19,15 & 313 & 5.994 & 36.563 \\
\hline
\end{tabular}

Elaboración propia

Tabla 5.42

Requerimiento de gas natural anual

\begin{tabular}{|c|c|c|c|}
\hline Años & $\begin{array}{c}\text { Consumo de Gas } \\
\text { para agua caliente } \\
\left(\mathbf{m}^{\mathbf{3}} / \mathbf{a n ̃ o}\right)\end{array}$ & $\begin{array}{c}\text { Consumo de Gas } \\
\text { del calentador de } \\
\text { piscina }\left(\mathbf{m}^{\mathbf{3}} / \mathbf{a n ̃} \mathbf{n}\right)\end{array}$ & $\begin{array}{c}\text { Consumo } \\
\text { total de Gas } \\
\left(\mathbf{m}^{3} / \mathbf{a n ̃ o}\right)\end{array}$ \\
\hline 2017 & 35.036 & 8.075 & 43.111 \\
\hline 2018 & 35.418 & 8.075 & 43.493 \\
\hline 2019 & 35.799 & 8.075 & 43.875 \\
\hline 2020 & 36.181 & 8.075 & 44.257 \\
\hline 2021 & 36.563 & 8.075 & 44.638 \\
\hline
\end{tabular}

Elaboración propia

Por otro lado, se utilizará gas natural vehicular para el transporte de los pacientes graves que no puedan acercarse por sus propios medios al centro para recibir sus terapias. Según la Cámara Peruana de Gas Natural Vehicular CPGNV el rendimiento de un vehículo a GNV es de $10 \mathrm{~km} / \mathrm{m}^{3}$ aproximadamente. Teniendo en cuenta que el recorrido diario del vehículo será de $100 \mathrm{~km}$ por día, se presenta a continuación el cuadro del consumo de GNV por año. 
Tabla 5.43

Requerimiento de gas natural vehicular

\begin{tabular}{|c|c|c|c|c|}
\hline Años & $\begin{array}{c}\text { Rendimiento } \\
\left(\mathbf{K m} / \mathbf{m}^{3}\right)\end{array}$ & $\begin{array}{c}\text { Recorrido } \\
\text { (km/día) }\end{array}$ & $\begin{array}{c}\text { Días/ } \\
\text { año }\end{array}$ & $\begin{array}{c}\text { Consumo de } \\
\text { GNV }\left(m^{3} / a n ̃ o\right)\end{array}$ \\
\hline 2017 & 10 & 100 & 313 & 3.130 \\
\hline 2018 & 10 & 100 & 313 & 3.130 \\
\hline 2019 & 10 & 100 & 313 & 3.130 \\
\hline 2020 & 10 & 100 & 313 & 3.130 \\
\hline 2021 & 10 & 100 & 313 & 3.130 \\
\hline
\end{tabular}

Elaboración propia

Finalmente se necesitará el servicio de telefonía, cable e internet para la comunicación interna y externa del centro.

\subsection{Soporte físico del servicio}

\subsubsection{Factor edificio}

El edificio del centro de rehabilitación física será considerado una edificación ecoeficiente ya que se accederá a la certificación LEED la cual es una acreditación internacional para edificios sustentables.

Dentro de las características ecoeficientes que posee el edificio se tiene:

- Aprovechamiento de energía renovable donde la energía solar pueda ser aprovechada como iluminación natural.

- Eficiencia energética mediante la utilización de luminarias LED que reducirán en $50 \%$ el consumo de energía y a la vez contribuyen con el cuidado del medio ambiente al no generar gases $\left(\mathrm{CO}_{2}\right)$ y calor.

- Ahorro de agua mediante la utilización de microsistemas para el tratamiento de aguas grises lo cual implica la captación del agua utilizada de los caños y duchas 
para su recirculación y utilización en actividades relacionadas a la limpieza del centro y el riego de los jardines.

- Empleo de materiales saludables para construcciones sustentables que posean características tales como bajo contenido energético, baja emisión de gases de efecto invernadero, ser reciclados y contener el mayor porcentaje de materiales de reutilización

- Manejo de residuos sólidos y hospitalarios donde se puedan reciclar o reutilizar los materiales utilizados.

La estructura dentro de la que se ubican todos los elementos que se utilizarán para la prestación de los servicios conformará el edificio del centro de fisioterapia, el cual será diseñado para permitir un flujo continuo de las operaciones, brindando seguridad a todo el personal interno y externo, así como a los pacientes.

Las construcciones o remodelaciones del centro cumplirán con las disposiciones señaladas en la "Norma Técnica para el Diseño de Elementos de Apoyo para personas con Discapacidad en los Establecimientos de Salud" y el "Reglamento Nacional de Construcciones" vigente a la fecha, aplicables a ambientes, ingresos, rampas, escaleras, pasadizos, ascensores, servicios higiénicos, vestuarios, estacionamientos, etc.

Como ya se mencionó, la construcción de las instalaciones estará a cargo de una empresa constructora, en la cual los ingenieros civiles, arquitectos y diseñadores que moldeen el proyecto de construcción, deberán de considerar los siguientes aspectos:

\section{Estudio de suelos}

Siguiendo lo estipulado en el Reglamento Nacional de Construcciones para edificaciones de salud, las principales características a tomarse en cuenta en el estudio del suelo (ensayo granulométrico) sobre el que se construirá las instalaciones son: 
- Ser predominantemente plano

- Estar alejado de zonas sujetas a erosión de cualquier tipo (aludes, huaycos, otros similares).

- Estar libres de fallas geológicas.

- Evitar hondonadas y terrenos susceptibles de inundaciones.

- Evitar terrenos arenosos, pantanosos, arcillosos, limosos, antiguos, lechos de ríos y/o con presencia de residuos orgánicos o rellenos sanitarios.

- Evitar terrenos con aguas subterráneas (se debe excavar mínimo 2 metros detectando que no aflore agua).

- El tipo ideal de suelo sobre el que se buscará construir las instalaciones es el limo-arcilloso pero en caso de no encontrarse en estado natural, se deberá realizar un tratamiento al suelo consistente en la elaboración de zapatas que se colocan bajo las columnas lo que les da una estabilidad a éstas y a la vez transmite el peso del edificio al suelo.

\section{Niveles y pisos de la edificación}

Dadas las limitaciones actuales de conseguir un terreno amplio en la ciudad de Lima, se ha considerado tener dos pisos en los cuales el primer piso se dispondrán todas las áreas operativas y que intervengan directamente con el servicio, con la finalidad de facilitar el traslado de los pacientes que por su misma edad no pueden estar expuestos a esfuerzos de subir escaleras o largos recorridos, así como de facilitar el traslado de los materiales, personal y elementos móviles que se utilizará en la prestación del servicio. Asimismo, en el segundo piso estarán ubicadas principalmente las áreas administrativas y en un sótano estarán ubicados los estacionamientos y equipos de gran tamaño como equipos de tratamiento de aguas grises, entre otros.

Respecto al tipo de piso, deberá de ser un piso impermeable, resistente, antideslizante y de fácil limpieza, por ello se utilizará porcelanato de alto tránsito, lo cual se ajustará a lo indicado en el Reglamento Nacional de Construcciones para 
Edificaciones de Salud y a la vez proporcionará un ambiente agradable para los colaboradores y pacientes del centro. Asimismo, las paredes deberán de estar cubiertas con material lavable fácil de limpiar o lavar.

\section{Vías de circulación}

Los pasadizos deberán contar con las siguientes características:

- Ancho libre mínimo de 1,80 metros.

- Pasamanos tubulares continuos de $3,8 \mathrm{~cm}\left(\begin{array}{ll}1 & 1 / 2 ")\end{array}\right)$ de diámetro que estarán colocados a $75 \mathrm{~cm}$. y $90 \mathrm{~cm}$. de altura, separados $5 \mathrm{~cm}$. de la pared y pintados de color contraste.

- Solo se permitirá la colocación de pasamanos tubulares en las circulaciones de uso público que comuniquen con los consultorios y las áreas administrativas.

- Los pasadizos contarán, con un sistema de alarma de emergencia que será a base de señales audibles y visibles con sonido intermitente y lámpara de destellos.

\section{Rampas}

Las rampas deberán tener las siguientes características:

- Ancho mínimo de 1,00 metro libre entre pasamanos.

- Pendiente no mayor de $6^{\circ}$.

- Bordes laterales de 0,05 $\mathrm{m}$ de altura.

- Deberán existir dos pasamanos a diferente altura, el primer pasamanos se colocará a $90 \mathrm{~cm}$. y el segundo pasamanos a $75 \mathrm{~cm}$. del nivel del piso terminado.

- Se debe instalar señalización que prohíba la obstrucción de la rampa con cualquier elemento. 
- A la entrada de la rampa se colocará el símbolo internacional de acceso a discapacitados.

- Los pasamanos estarán separados de la pared a una distancia de 0,05 metros.

- Los pasamanos deberán prolongarse $0,60 \mathrm{~cm}$. en el arranque y en la llegada.

- Los pasamanos serán confeccionados con tubos de fierro de 1 1⁄2" de diámetro.

- El acabado del pasamano deberá tener un color contrastante con respecto al elemento delimitante vertical.

- El piso deberá ser firme, uniforme y antideslizante.

- Si la longitud requerida sobrepasara los 6,00 metros, se considerarán descansos intermedios de 1,50 metros y el área de llegada y arranque será de 1,80 metros mínimo.

\section{Escaleras}

Las escaleras deberán tener las siguientes características:

- El ancho mínimo será de 1,80 metros.

- La zona de aproximación a la escalera será de 1,20 metros de ancho, con textura diferente al piso predominante.

- La proporción entre las dimensiones de pasos y contrapasos responderá a la fórmula: $2 \mathrm{c}+\mathrm{h}=60 \mathrm{~cm}$. hasta $64 \mathrm{~cm}$. enunciado en el Reglamento Nacional de Construcciones.

- Se considerarán como medidas máximas $14 \mathrm{~cm}$. para contrapasos y $32 \mathrm{~cm}$. para pasos.

- Las escaleras contarán con un desarrollo de quince pasos como máximo.

- Los contrapasos será verticales o con una inclinación máxima de $2,5 \mathrm{~cm}$. tanto para los contrapasos como para los primeros $5 \mathrm{~cm}$. del paso. 
- Los pasamanos serán colocados en ambos lados a $75 \mathrm{~cm}$. y $90 \mathrm{~cm}$. del nivel de piso y prolongados $60 \mathrm{~cm}$. en el arranque y llegada.

\section{Puertas de acceso y salida}

Para el acceso a zonas exteriores del centro se considerará las siguientes características:

- Entrada al nivel del piso, sin diferencias de niveles entre el interior y el exterior, cuando no sea posible los ingresos contarán con rampas.

- Para indicar la proximidad a las rampas y otros cambios de nivel, el piso tendrá una textura diferente con respecto al predominante, en una distancia no menor de 1,20 m el mismo que será del ancho de la rampa o escalera.

- Las puertas contarán con 1,00 metro de ancho libre como mínimo.

- Las puertas tendrán cerraduras con manijas tipo palanca.

- Los marcos de las puertas irán en color de alto contraste para enmarcar el acceso.

- Se contará con señalización que indique el acceso a perros guía.

Por otra parte, para el acceso a zonas interiores del centro se considerará las siguientes características:

- Las puertas deben contar con colores de alto contraste entre el muro y el marco.

- Las puertas deberán contar con 1,00 metro de ancho libre como mínimo.

- Las puertas tendrán cerraduras con manijas tipo palanca.

- Si la puerta se encuentra ubicada en esquina, deberá abatir hacia al muro más cercano.

- Se contará con señalización normativa y en relieve. 
- Señalización escrita y por símbolos, que permita la ubicación e identificación de los ambientes y zonas de seguridad, salidas de emergencia y avisos de no fumar.

Por otro lado, las instalaciones contarán con salidas de emergencia, las cuales deberán contar con señalización en relieve y color contrastante con el fondo y a la vez las puertas deberán abatir hacia el exterior.

\section{Techos y ventanas}

No será necesario que los techos sean acústicos, pues los equipos no producen una cantidad perjudicial de ruido. Se considera una altura mínima de tres metros para los techos desde el nivel del piso, pues el tanque de aguas residuales es el equipo de mayor tamaño. Asimismo, se requerirá de amplios ventanales debido a que se busca aprovechar la luz natural y proporcionar una buena iluminación en las diferentes áreas de trabajo.

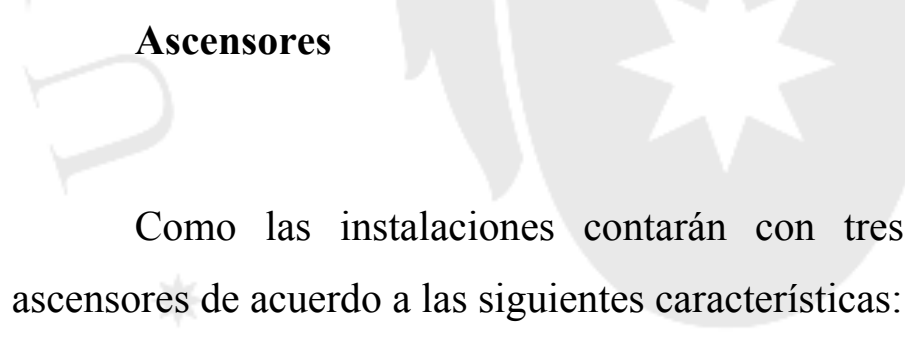

- Ubicación cercana al ingreso principal.

- El área interior libre será de 150 x $150 \mathrm{~cm}$. como mínimo.

- La puerta debe tener un ancho mínimo de $100 \mathrm{~cm}$.

- Los controles de llamada deben ser colocados a $120 \mathrm{~cm}$. del nivel del piso a la parte superior.

- Los tableros de control de niveles (03) deben estar colocados en ambos lados de la puerta. En elevadores existentes con dimensiones menores a las especificadas, uno de los tableros se colocará en la pared lateral a la altura indicada. 
- Las barandas interiores estarán colocadas a 75 y $90 \mathrm{~cm}$. de altura en tres lados separados.

- Los botones contarán con números arábigos en relieve.

- Los mecanismos automáticos de cierre de puertas deberán tener 15 segundos de apertura como mínimo para el paso de una persona con discapacidad.

- El ascensor deberá tener una exactitud en la parada con relación al nivel del piso.

- Deberá existir señalización del número del piso en relieve a $120 \mathrm{~cm}$ de altura

- Deberá existir señalización del número de piso en relieve colocado en el canto de la puerta a una altura de $140 \mathrm{~cm}$. del nivel del piso.

- Se dispondrá de señales audibles y visibles de aviso anticipado de llegada.

Finalmente, se obtendrá la certificación LEED Liderazgo en Energía y Diseño Ambiental, el cual es un sistema de certificación de edificios sostenibles otorgado por el USGBC (Consejo de Construcción Verde de los Estados Unidos) la cual nos acredita como un edificio ecoeficiente sostenible en diseño, construcción y operación basados en principios energéticos y medioambientales aceptados internacionalmente con lo que demuestra nuestro compromiso con el cuidado del medio ambiente afianzando de esta manera nuestra imagen institucional de un centro sostenible.

Para acceder a la certificación LEED se realizará una evaluación de la eficiencia medioambiental del edificio a partir de la acumulación de puntos que se deben cumplir para satisfacer diversos criterios específicos de construcción sustentable en seis categorías las cuales son: Sitios sustentables, ahorro de agua, Energía y atmósfera, Materiales y recursos, Calidad ambiental de los Interiores e Innovación en el diseño. Los niveles de certificación son los que se presentan a continuación: 
Tabla 5.44

Niveles de Certificación LEED

\begin{tabular}{|l|c|}
\hline \multicolumn{1}{|c|}{ Certificación } & Puntaje \\
\hline Certificado (LEED Certificate) & $40-49$ puntos \\
\hline Plata (LEED Silver), & $50-59$ puntos \\
\hline Oro (LEED Gold) & $60-79$ puntos \\
\hline Platino (LEED Platinum). & 80 puntos y más \\
\hline
\end{tabular}

Fuente: U.S. Green Building Council

Elaboración propia

\subsubsection{El ambiente del servicio}

El ambiente del servicio estará conformado por el servicio relativo al personal, a la maquinaria y al edificio. Respecto al servicio relativo al personal, se considerarán lo siguiente:

\section{Vías de acceso}

El acceso al centro estará claramente señalizado, permitiendo su identificación a distancia, cumpliendo las normas de Ingeniería Hospitalaria para tal fin. Como ya se mencionó, se contarán con puertas de acceso y salida tanto para las zonas exteriores como interiores de las instalaciones, así como salidas de emergencia.

\section{Instalaciones sanitarias}

Los servicios higiénicos contarán con las siguientes características:

- Pisos antideslizantes.

- Muros de ladrillo en cubículos para personas con discapacidad.

- Circulaciones internas de 1,50 metros de ancho.

- Puertas de cubículos con abatimiento hacia afuera. 
- Barras de apoyo de fierro galvanizado esmaltado de 1 1/2" de diámetro.

- La cantidad de aparatos sanitarios se determinará de acuerdo a lo normado en el Reglamento Nacional de Construcciones y Normas Técnicas para Proyectos de Arquitectura Hospitalaria.

- Cuando se trate de adaptaciones para la instalación de aparatos sanitarios para personas con discapacidad en los servicios higiénicos existentes que cuenten con cubículos metálicos, se usará barras de apoyo horizontales dobles.

- Inodoro para personas con discapacidad con muletas o bastones con las siguientes especificaciones:

- Ancho libre mínimo del cubículo $90 \mathrm{~cm}$.

- Puerta de $90 \mathrm{~cm}$. de ancho como mínimo.

- Barras de apoyo lateral combinadas horizontal - vertical, colocadas a 1,50 metros de altura en la parte superior y a $40 \mathrm{~cm}$. del muro posterior del inodoro.

- Barras de apoyo lateral horizontal colocadas a $75 \mathrm{~cm}$. de altura y a $30 \mathrm{~cm}$ del muro posterior del inodoro.

- Gancho para colgar muletas, colocado a 1,60 metros de atura.

- Inodoro para personas con discapacidad en silla de ruedas con las siguientes especificaciones:

- Los cubículos serán de 2,00 metros de fondo por 1,60 metros de ancho.

- Las puertas de 1,00 metro de ancho mínimo.

- El inodoro debe estar colocado a $56 \mathrm{~cm}$. de su eje al muro más cercano y a $52 \mathrm{~cm}$. de altura sobre el nivel de piso terminado.

- Las barras de apoyo horizontales de $90 \mathrm{~cm}$. de longitud colocadas a $50 \mathrm{~cm}$. y $90 \mathrm{~cm}$. de altura del lado de la pared más cercana al inodoro y a $30 \mathrm{~cm}$. del muro posterior.

- La barra de apoyo esquinera combinada horizontal y vertical colocada a 75 $\mathrm{cm}$. de altura del lado de la pared más cercana al inodoro.

- Urinarios con las siguientes especificaciones: 
- El urinario estará colocado a $45 \mathrm{~cm}$. del eje al paño de los elementos limitantes.

- Contarán con barras verticales de apoyo de $75 \mathrm{~cm}$. de longitud, colocadas en la pared posterior a $30 \mathrm{~cm}$. del eje del urinario en ambos lados del mismo, a una altura de 1,60 metros en la parte superior.

- Se colocarán ganchos para colgar muletas, de $12 \mathrm{~cm}$. de longitud a una altura de 1,60 metros.

- Lavabos con las siguientes especificaciones:

- El lavabo estará colocado a $76 \mathrm{~cm}$. de altura libre, anclado al muro para soportar el peso de una persona de $100 \mathrm{~kg}$.

- El desagüe deberá estar instalado hacia la pared posterior para permitir el paso de las piernas de la persona con discapacidad en silla de ruedas.

- La distancia entre lavabos será de $90 \mathrm{~cm}$. a ejes.

- La grifería se colocará a $35 \mathrm{~cm}$. de la pared separada $20 \mathrm{~cm}$. entre sí.

- Los manubrios de la grifería serán tipo aleta.

- Los accesorios como toallero y secador de manos irán colocados a 1 metro como máximo sobre el nivel de piso terminado.

- Se colocarán ganchos para colgar muletas, de $12 \mathrm{~cm}$. de longitud a una altura de 1,60 metros en ambos lados del lavabo.

- Duchas en los baños para pacientes con las siguientes especificaciones:

- Las dimensiones serán de 1,10 metros de ancho a 1,30 metros de largo.

- La puerta de 1 metro de ancho mínimo.

- Contarán con barras de apoyo esquineros de 11/2" de diámetro y $90 \mathrm{~cm}$. de largo a cada lado de las esquinas colocadas horizontalmente en la esquina más cercana a la ducha a $80 \mathrm{~cm} ., 120 \mathrm{~cm}$. y $150 \mathrm{~cm}$. sobre el nivel del piso.

- Con bancas de transferencia de paciente. 


\section{Servicios de alimentación}

Según las características de infraestructura de la Unidad Productora de los Servicios de Medicina de Rehabilitación, se deberá contar con un espacio preferentemente de 2,24 metros por 1,00 metro para personas con discapacidad, por cada 20 asientos, debiendo estar cerca al acceso con las siguientes características:

- Un área libre bajo la mesa de 0,76 metros de altura libre por 0,80 metros de ancho.

- Asientos removibles

\section{Iluminación}

Una buena iluminación será determinante para que el fisioterapeuta trabaje adecuadamente ayudando a minimizar errores y optimizar tiempos. Además de contar con amplios ventanales, las paredes se pintaran de color blanco humo para tener una mayor luminosidad, y las fuentes de luz serán limpiadas y reemplazadas oportunamente.

\section{Ventilación}

Se contará con un sistema de aire acondicionado que brinde una adecuada ventilación y/o calefacción. Además, se deberá de contar con un sistema de oxígeno para pacientes y personal del centro.

El gas refrigerante que se utilizará para los equipos de aire acondicionado será el gas ecológico R410 que reemplaza al gas R22 que está siendo descontinuado por producir daño a la capa de ozono. 


\section{Estacionamiento}

Se reservará áreas exclusivas de estacionamiento para los vehículos que transportan o son conducidos por personas con discapacidad con las siguientes características:

- Un estacionamiento para discapacitados por cada 25 estacionamientos regulares.

- Ubicados lo más cercano posible a la entrada principal.

- Las medidas de cajón serán 5,00 metros por 3,80 metros de ancho.

- La señalización estará pintada en el piso con el símbolo internacional de acceso a discapacitados de 1,60 metros en medio del cajón.

- El letrero con el mismo símbolo de 0,40 x 0,60 metros estará colocado a 2,00 metros de altura.

Respecto al servicio relativo a la maquinaria, se considerarán lo siguiente:

\section{Instalaciones eléctricas}

Todos los operarios serán capacitados en conocimientos básicos sobre las instalaciones eléctricas. Se tendrán extintores para incendios eléctricos cerca de las tomas eléctricas principales y se contarán con los siguientes sistemas y equipos:

- Sistema eléctrico empotrado.

- Sistema de tomacorriente, considerando tomacorrientes de alto amperaje para ciertos equipos. 


\section{Protección contra incendios}

Se capacitará sobre prevención y medidas a tomar en caso de incendios. Se contará con un sistema de protección contra incendios en el sótano del edificio, equipos contra incendios, como extintores y sensores de humo especialmente en las zonas con mayor riesgo. Se tendrá una disposición adecuada de extintores y se realizaran trabajos de mantenimiento en las instalaciones eléctricas, detectores, alarmas, etc. Se distribuirán carteles y señales indicando procedimientos de seguridad, sitios seguros, posibles riesgos y peligros, etc.

Respecto al servicio relativo al edificio, se considerarán lo siguiente:

\section{Señalización de seguridad}

Se contará con señales de prohibición, seguridad, advertencia y obligatoriedad, las cuales se especifican a continuación:

- Prohibido fumar: Ubicada en la entrada, estacionamiento y cafetería.

- Prohibido ingresar con armas: Ubicado en la entrada.

- Prohibido ingresar con alimentos: En la salida de la cafetería hacia el centro.

- Señales de seguridad: En la zona segura en caso de sismo, extintores, salida de emergencia, de acuerdo a las recomendaciones de Defensa Civil.

- Señales de advertencia: Tales como advertencia de piso resbaloso, advertencia de riesgo eléctrico, entre otras.

- Señales de medidas obligatorias: Uso de mascarilla, uniforme, mandil, red de pelo, obligatorio lavarse las manos. 


\subsection{Disposición de la instalación del servicio}

\subsubsection{Disposición general}

Como se mencionó anteriormente el centro especializado de rehabilitación física consta de 3 niveles: un sótano con estacionamientos, el primer piso donde se desarrollaran todas las actividades del servicio y el segundo piso donde se construirán las oficinas para las labores administrativas.

Con la finalidad de definir el área específica donde se realizarán las terapias físicas se realizará el cálculo de las superficies de distribución utilizando el método de Guerchet para la evaluación del espacio físico. Se considerarán para el cálculo del área de los cubículos los dos tipos de terapias físicas que se realizarán en el centro:

Cálculo del área de cubículo de terapia de alivio del dolor:

Tabla 5.45

Cálculo de dimensiones de elementos móviles de cubículo de terapia de alivio del dolor

\begin{tabular}{|l|c|c|c|c|c|c|c|}
\hline Elementos móviles & L & A & H & ss & $\mathbf{n}$ & ss*n*h & ss*n \\
\hline Electroestimulador & 0,40 & 0,50 & 0,80 & 0,20 & 1 & 0,16 & 0,20 \\
\hline Ultrasonido & 0,40 & 0,50 & 0,80 & 0,20 & 1 & 0,16 & 0,20 \\
\hline Microondas & 0,30 & 0,42 & 0,90 & 0,13 & 1 & 0,11 & 0,13 \\
\hline Masajeador & 0,40 & 0,43 & 0,84 & 0,17 & 1 & 0,14 & 0,17 \\
\hline Silla de ruedas & 1,10 & 0,65 & 1,30 & 0,72 & 1 & 0,93 & 0,72 \\
\hline Paciente & & & 1,65 & 0,50 & 1 & 0,83 & 0,50 \\
\hline Fisioterapeuta & & & 1,65 & 0,50 & 1 & 0,83 & 0,50 \\
\hline TOTAL & & & & 3,15 & 2,41 \\
\hline
\end{tabular}

Nota: Los equipos de ultrasonido y electroestimulador estarán sobre un carro movible por lo que se considera las medidas del equipo sobre el carro movible. Elaboración propia 
Tabla 5.46

Cálculo de superficie de cubículo para terapia de alivio del dolor

\begin{tabular}{|c|c|c|c|c|c|c|c|c|c|c|c|c|c|}
\hline Elementos estáticos & $\mathbf{L}$ & $\mathbf{a}$ & h & $\mathbf{N}$ & $\mathbf{n}$ & Ss & Sg & ss*n & $s s * n * h$ & $\mathbf{K}$ & Se & Stu & ST \\
\hline Camilla & 1,90 & 0,70 & 0,85 & 2 & 1 & 1,33 & 2,66 & 1,33 & 1,13 & 0,74 & 2,97 & 6,96 & 6,96 \\
\hline Taburetes giratorios & 0,56 & 0,33 & 0,14 & 1 & 1 & 0,18 & 0,185 & 0,18 & 0,03 & 0,74 & 0,28 & 0,64 & 0,64 \\
\hline Vitrina de dos cuerpos & 0,80 & 0,38 & 1,60 & 1 & 1 & 0,30 & 0,304 & 0,30 & 0,49 & 0,74 & 0,45 & 1,06 & 1,06 \\
\hline Peldaño & 0,30 & 0,23 & 0,25 & 1 & 1 & 0,07 & 0,069 & 0,07 & 0,02 & 0,74 & 0,10 & 0,24 & 0,24 \\
\hline \multicolumn{8}{|l|}{ TOTAL } & 1,89 & 1,66 & & & & 8,91 \\
\hline
\end{tabular}

Elaboración propia

\begin{tabular}{|l|l|}
\hline Hem & 1,309 \\
\hline Hee & 0,879 \\
\hline K & 0,744 \\
\hline
\end{tabular}

\begin{tabular}{|ll|}
\hline AREA TOTAL & $\mathbf{9} \mathbf{~ m}^{\mathbf{2}}$ \\
\hline Largo & $3 \mathrm{~m}$. \\
\hline Ancho & $3 \mathrm{~m}$. \\
\hline
\end{tabular}

Cálculo del área de cubículo terapia de restauración de la movilidad:

Tabla 5.47

Cálculo de dimensiones de elementos móviles de cubículo de terapia de restauración de la movilidad

\begin{tabular}{|l|c|c|c|c|c|c|c|}
\hline Elementos móviles & $\mathbf{L}$ & $\mathbf{A}$ & $\mathbf{h}$ & $\mathbf{s s}$ & $\mathbf{n}$ & $\mathbf{s s *} * \mathbf{h}$ & $\mathbf{s s * n}$ \\
\hline Ondas de Choque & 0,61 & 0,31 & 1,16 & 0,19 & 1 & 0,21 & 0,19 \\
\hline Magneto & 0,40 & 0,50 & 0,80 & 0,20 & 1 & 0,16 & 0,20 \\
\hline Láser & 0,40 & 0,50 & 0,80 & 0,20 & 1 & 0,16 & 0,20 \\
\hline Onda Corta & 0,61 & 0,31 & 1,16 & 0,19 & 1 & 0,21 & 0,19 \\
\hline Silla de ruedas & 1,10 & 0,65 & 1,30 & 0,72 & 1 & 0,93 & 0,72 \\
\hline Paciente & & & 1,65 & 0,50 & 1 & 0,83 & 0,50 \\
\hline Fisioterapeuta & & & 1,65 & 0,50 & 1 & 0,83 & 0,50 \\
\hline TOTAL & & & & 3,33 & 2,49 \\
\hline
\end{tabular}

Nota: Los equipos de magneto y láser estarán sobre un carro movible por lo que se considera las medidas del equipo sobre el carro movible.

Elaboración propia 
Tabla 5.48

Cálculo de superficie de cubículo para terapia de restauración de la movilidad

\begin{tabular}{|c|c|c|c|c|c|c|c|c|c|c|c|c|c|}
\hline Elementos estáticos & L & $\mathbf{a}$ & h & $\mathbf{N}$ & $\mathbf{n}$ & ss & Sg & ss*n & ss*n*h & $\mathbf{K}$ & Se & Stu & ST \\
\hline Camilla & 1,90 & 0,70 & 0,85 & 2 & 1 & 1,33 & 2,66 & 1,33 & 1,13 & 0,76 & 3,04 & 7,03 & 7,03 \\
\hline Taburetes giratorios & 0,56 & 0,33 & 0,14 & 1 & 1 & 0,18 & 0,185 & 0,18 & 0,03 & 0,76 & 0,28 & 0,65 & 0,65 \\
\hline Vitrina de dos cuerpos & 0,80 & 0,38 & 1,60 & 1 & 1 & 0,30 & 0,304 & 0,30 & 0,49 & 0,76 & 0,46 & 1,07 & 1,07 \\
\hline Peldaño & 0,30 & 0,23 & 0,25 & 1 & 1 & 0,07 & 0,069 & 0,07 & 0,02 & 0,76 & 0,11 & 0,24 & 0,24 \\
\hline \multicolumn{8}{|l|}{ TOTAL } & 1,89 & 1,66 & & & & 8,99 \\
\hline
\end{tabular}

Elaboración propia

\begin{tabular}{|l|l|}
\hline Hem & 1,339 \\
\hline Hee & 0,879 \\
\hline K & 0,761 \\
\hline
\end{tabular}

\begin{tabular}{|ll|}
\hline AREA TOTAL & $\mathbf{9} \mathbf{~ m}^{\mathbf{2}}$ \\
\hline Largo & $3 \mathrm{~m}$. \\
\hline Ancho & $3 \mathrm{~m}$. \\
\hline
\end{tabular}

Después de realizar el cálculo de las áreas de los cubículos se concluye que el área a utilizar será de $9 \mathrm{~m}^{2}$, siendo las medidas de $3 \mathrm{~m}$. de largo y $3 \mathrm{~m}$. de ancho. Al ser 34 cubículos necesarios para satisfacer la demanda del proyecto el área total de estos será de $380 \mathrm{~m}^{2}$.

Según las especificaciones de construcción de la Norma Técnica de Salud de la Unidad Productora de Servicios de Medicina de Rehabilitación el área requerida del gimnasio será de $50 \mathrm{~m}^{2}$. En cuanto a la piscina como se mencionó anteriormente será de $8 \mathrm{~m}$. de largo por $5 \mathrm{~m}$. de ancho y $1 \mathrm{~m}$. de profundidad.

Respecto a los consultorios, la norma indica que las dimensiones mínimas de un consultorio médico deberán ser de $12 \mathrm{~m}^{2}$ por lo que el consultorio del médico fisiatra será de $16 \mathrm{~m}^{2}$ para brindar una mejor atención al paciente. La oficina del coordinador tecnólogo médica tendrá $12 \mathrm{~m}^{2}$ y el depósito de materiales $15 \mathrm{~m}^{2}$. Los baños tendrán un ambiente individual para discapacitados de $2 \mathrm{~m}$. por 1,60 m. con un ancho mínimo de puerta de $1 \mathrm{~m}$. según el actual Reglamento Nacional de Construcción. 
El área de las oficinas administrativas se definirá según la información consultada en el libro "Instalaciones de Manufactura" donde se precisa las dimensiones de las oficinas y estaciones de trabajo necesarias para llevar a cabo las labores administrativas. La oficina de gerencia será de $25 \mathrm{~m}^{2}$ y las oficinas de los directores de $20 \mathrm{~m}^{2}$. Todas las oficinas de coordinación serán de $12 \mathrm{~m}^{2}$ y las de los asistentes tendrán un área de $9 \mathrm{~m}^{2}$.

Finalmente la recepción del centro tendrá un área de $30 \mathrm{~m}^{2}$ y el área de los tecnólogos médicos será de $20 \mathrm{~m}^{2}$. El Reglamento Nacional de Edificaciones indica que el ancho mínimo de los pasadizos y corredores debe ser de $1,8 \mathrm{~m}$. por lo que para el proyecto se considerará $2 \mathrm{~m}$. de ancho de corredores para la comodidad de traslado tanto de los pacientes como de los equipos destinados a las terapias físicas.

En resumen, el primer piso tendrá un área total de $896 \mathrm{~m}^{2}$, el segundo piso contará con un área de $372 \mathrm{~m}^{2}$ y el sótano se construirá en un área total de $456 \mathrm{~m}^{2}$ con una capacidad para 12 estacionamientos de 2,50 m. de ancho por $5 \mathrm{~m}$. de largo según el Reglamento Nacional de Edificaciones; a la vez que se considerará un estacionamiento para discapacitados en la primera planta de $3,80 \mathrm{~m}$. de ancho por $5 \mathrm{~m}$. de largo. Cabe señalar que existirá un almacén de residuos sólidos de $16 \mathrm{~m}^{2}$ en el sótano con la finalidad de almacenar tanto los residuos sólidos como los hospitalarios para su segregación y recojo.

A continuación se presentan los cuadros de las áreas definidas: 
Tabla 5.49

Área total del primer piso

\begin{tabular}{|l|c|}
\hline \multicolumn{1}{|c|}{ Áreas del Servicio } & $\mathbf{m}^{\mathbf{2}}$ \\
\hline Consultorio medicina física & 16 \\
\hline Oficina de coordinación tecnológica médica & 12 \\
\hline Cubículos & 306 \\
\hline Gimnasio & 50 \\
\hline Piscina & 40 \\
\hline Vestuario y baños (hombres y mujeres) & 42 \\
\hline Recepción & 30 \\
\hline Almacén & 15 \\
\hline Cafetería & 18 \\
\hline Pasadizos y corredores & 271 \\
\hline Jardín & 96 \\
\hline Área Total & $\mathbf{8 9 6}$ \\
\hline
\end{tabular}

Elaboración propia

Tabla 5.50

Área total del segundo piso

\begin{tabular}{|l|c|}
\hline \multicolumn{1}{|c|}{ Áreas de las oficinas } & $\mathbf{m}^{\mathbf{2}}$ \\
\hline Oficina de gerencia general & 25 \\
\hline Oficina de dirección medica & 20 \\
\hline Oficina de dirección de servicio al cliente & 20 \\
\hline Oficina de dirección administrativa & 20 \\
\hline Oficina de coordinador de servicio al cliente & 12 \\
\hline Oficina de coordinación de Marketing y RR.PP. & 12 \\
\hline Oficina de coordinación de Recursos Humanos & 12 \\
\hline Oficina de coordinación contable & 12 \\
\hline Oficina de coordinación Mantenimiento y Servicios Generales & 12 \\
\hline Oficina de administración de sistemas & 12 \\
\hline Sala de reuniones & 20 \\
\hline Baños (hombres y mujeres) & 18 \\
\hline Área de tecnología médica & 20 \\
\hline Oficina de asistencia de gerencia & 9 \\
\hline Oficina de asistencia administrativa & 9 \\
\hline Pasadizos y corredores & 139 \\
\hline Área Total & $\mathbf{3 7 2}$ \\
\hline
\end{tabular}

Elaboración propia

\section{Tabla 5.51}

Área total del sótano

\begin{tabular}{|l|c|}
\hline \multicolumn{1}{|c|}{ Áreas del sótano } & $\mathbf{m}^{\mathbf{2}}$ \\
\hline Estacionamientos & 440 \\
\hline Almacén de residuos solidos & 16 \\
\hline Área Total & $\mathbf{4 5 6}$ \\
\hline
\end{tabular}

Elaboración propia 
Luego de realizar el cálculo de las áreas requeridas para el centro se procederá a definir la disposición de dichas áreas mediante el análisis relacional utilizando la tabla relacional, el diagrama relacional, la tabla de valor de proximidad y la lista de razones o motivos que se presentan a continuación:

Tabla 5.52

Identificación de relaciones

\begin{tabular}{|l|c|c|c|}
\hline \multicolumn{1}{|c|}{ Área } & Actividad & Orden & Símbolo \\
\hline Recepción & Control & 1 & \\
\hline Consultorio médico & Control & 2 & \\
\hline Cubículos para las terapias & Operación & 3 & \\
\hline Piscina & Operación & 4 & \\
\hline Gimnasio & Operación & 5 & \\
\hline Oficinas administrativas & Administración & 6 & \\
\hline Servicios higiénicos & Servicios & 7 & \\
\hline Cafetería & Servicios & 8 & \\
\hline Almacén de materiales & Almacenaje & 9 & \\
\hline Estacionamiento & Transporte & 10 & \\
\hline
\end{tabular}

Elaboración propia

\section{Tabla 5.53}

Nomenclatura de proximidades

\begin{tabular}{|c|c|c|}
\hline Código & Proximidad & Líneas \\
\hline A & Absolutamente necesario & 4 rectas rojas \\
\hline E & Especialmente necesario & 3 rectas amarillas \\
\hline I & Importante & 2 rectas verdes \\
\hline O & Normal & 1 recta azul \\
\hline U & Sin importancia & (no se traza) \\
\hline $\mathrm{X}$ & No deseable & 1 zigzag plomo \\
\hline $\mathrm{XX}$ & Altamente no deseable & 2 zigzag negros \\
\hline
\end{tabular}

Fuente: Bertha Díaz - Benjamín Jarufe - María Teresa Noriega Elaboración propia

\section{Tabla 5.54}

Tabla de razones o motivos

\begin{tabular}{|c|c|}
\hline Código & Motivo \\
\hline 1 & Rapidez de atención \\
\hline 2 & Limpieza e higiene \\
\hline 3 & Generación de RR.SS. y efluentes \\
\hline 4 & Flujo de materiales \\
\hline 5 & Sin relación \\
\hline
\end{tabular}

Fuente: Bertha Díaz - Benjamín Jarufe - María Teresa Noriega Elaboración propia 
Tabla 5.55

Tabla relacional

\begin{tabular}{|c|c|c|}
\hline SIMB. & ÁREA & \\
\hline & RECEPCIÓN & \\
\hline & CONSULTORIO MÉDICO & \\
\hline & CUBÍCULOS DE FISIOTERAPIA & \\
\hline & PISCINA & \\
\hline & GIMNASIO & \\
\hline & OFICINAS & \begin{tabular}{|lllllllll}
5 & $E$ & 2 & $x x$ & 2 & 1 & 4 & 0 & 1 \\
1 & 2 & 0 & 3 & 0 & 4 & 0 & 5 \\
\end{tabular} \\
\hline & SS.HH. Y VESTUARIOS & \begin{tabular}{|l|l|l|l|l|l|l|l|}
2 & 0 & 5 & 0 & 4 & 0 & 5 \\
0 & 5 & 0 & 4 & 0 & 5 \\
\end{tabular} \\
\hline & CAFETERÍA & \begin{tabular}{|lllll}
2 & 4 & 4 & 0 & 5 \\
$u$ & 5 & $u^{4}$ & 5 \\
\end{tabular} \\
\hline 9 & ALMACÉN & 5 \\
\hline$\square$ & ESTACIONAMIENTO & \\
\hline
\end{tabular}

Elaboración propia

El resultado del análisis relacional arroja los siguientes valores de proximidad con lo que se procederá a realizar el diagrama relacional que se presenta a continuación:

Tabla 5.56

Valores de proximidad

\begin{tabular}{|c|l|}
\hline A & $(1,2) ;(3,4) ;(3,5) ;(4,7)$ \\
\hline E & $(1,3) ;(2,3) ;(5,7)$ \\
\hline I & $(1,7) ;(1,10) ;(2,7) ;(3,7) ;(3,9) ;(6,7) ;(9,10)$ \\
\hline O & $(1,5) ;(1,9) ;(2,6) ;(2,9) ;(4,5) ;(4,9) ;(5,9) ;(6,9) ;(7,8)$ \\
\hline U & $\begin{array}{l}(1,6) ;(1,8) ;(2,4) ;(2,5) ;(2,10) ;(3,6) ;(3,10) ;(4,10) ; \\
(5,6) ;(5,8) ;(5,10) ;(6,8) ;(7,9) ;(7,10) ;(8,9) ;(8,10)\end{array}$ \\
\hline X & $(1,4) ;(2,8) ;(3,8)$ \\
\hline XX & $(4,6) ;(4,8)$ \\
\hline
\end{tabular}

Elaboración propia

Finalmente se presenta a continuación el diagrama relacional donde se define la disposición de las áreas del servicio: 
Figura 5.33

Diagrama relacional

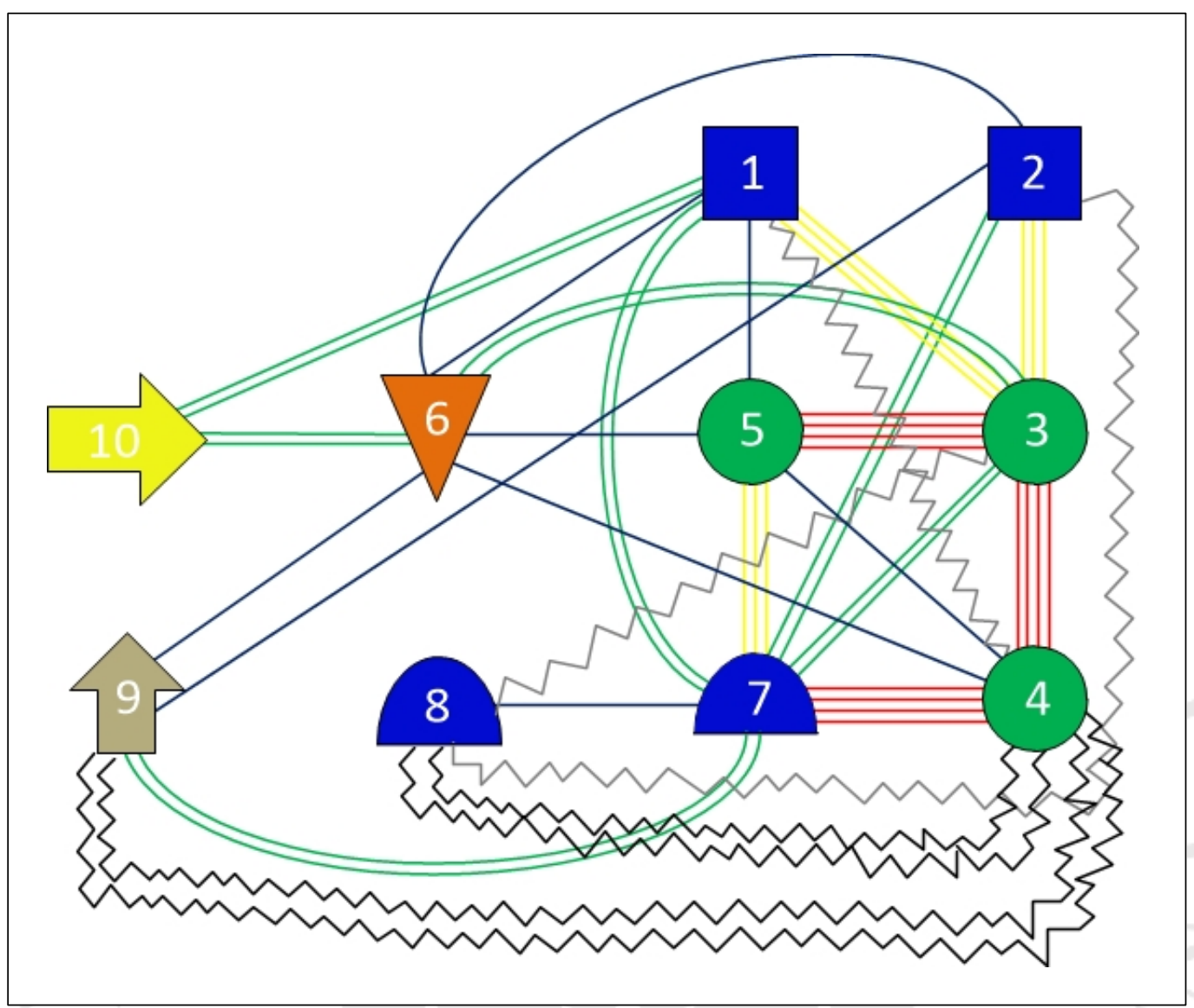

Elaboración propia

\subsubsection{Disposición de detalle}

El plano de distribución se presenta en la siguiente hoja 
Figura 5.34

Plano de Distribucion

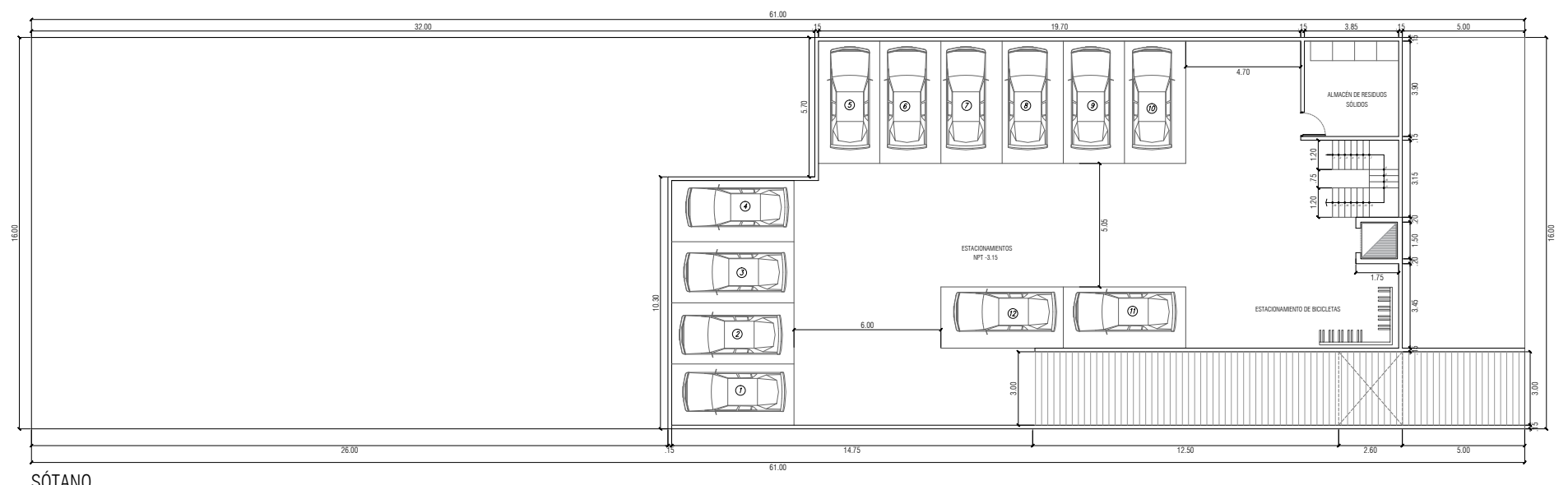

SÓTANO

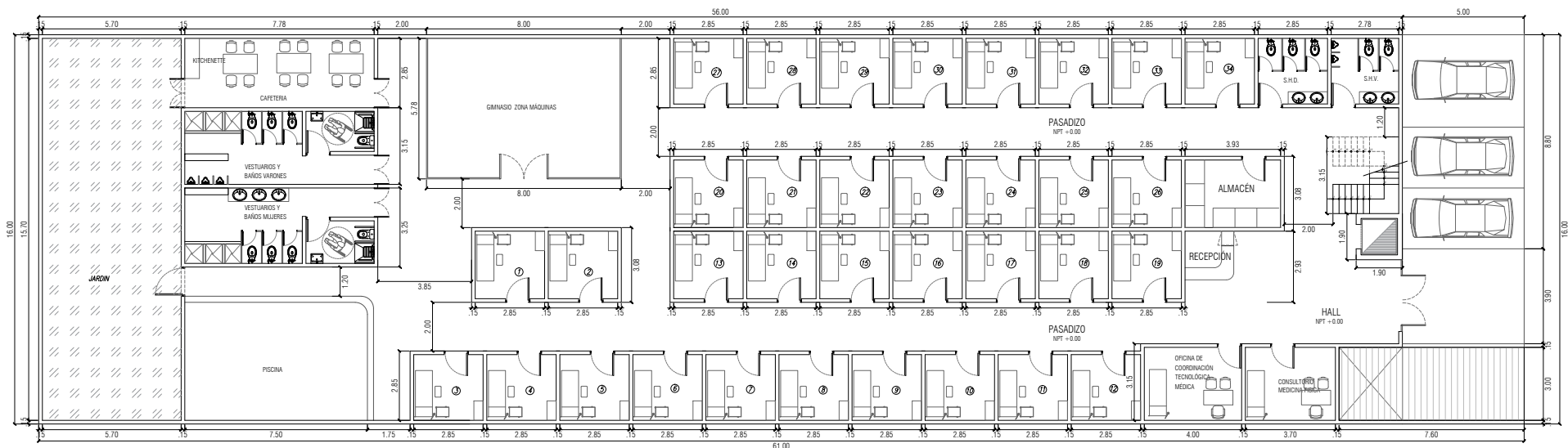

PRIMER PISO

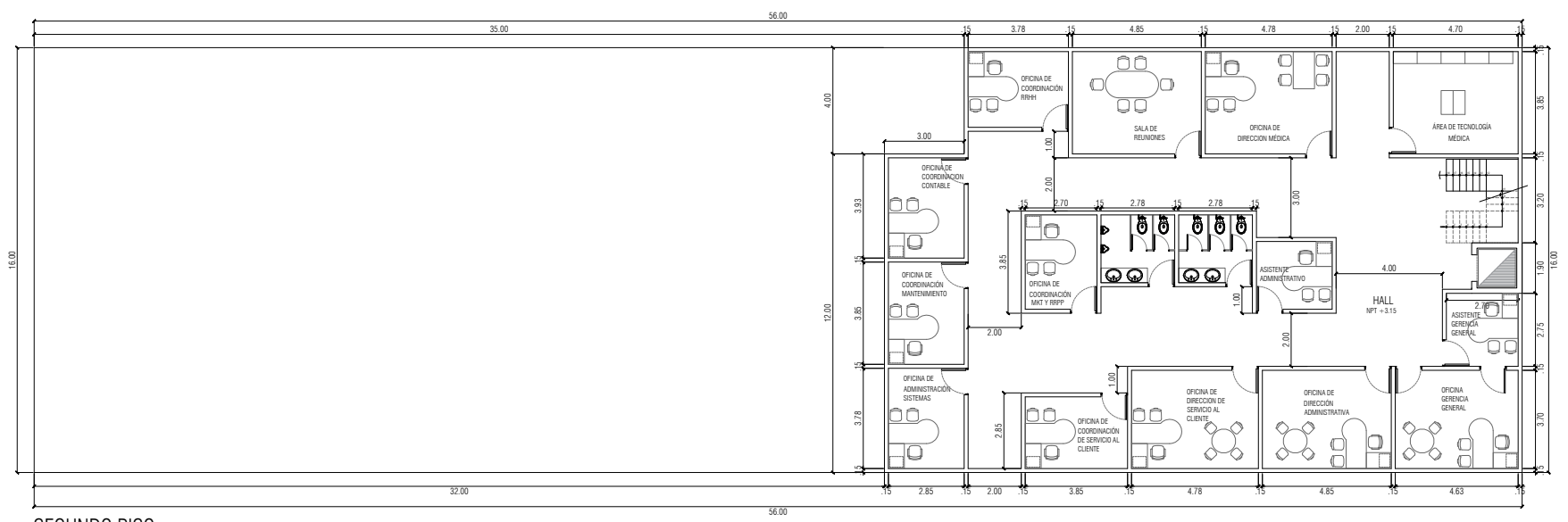

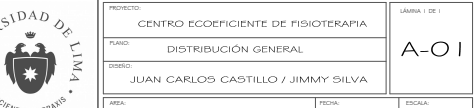




\subsection{Cronograma de implementación del proyecto}

Se programarán las actividades necesarias para realizar el cronograma de implementación del proyecto mediante el diagrama de Gantt. Se tiene previsto iniciar la implementación del proyecto con los estudios previos el 1 de setiembre del 2015 y culminar con la puesta en marcha a finales del año 2016.

Figura 5.35

Cronograma de implementación del proyecto

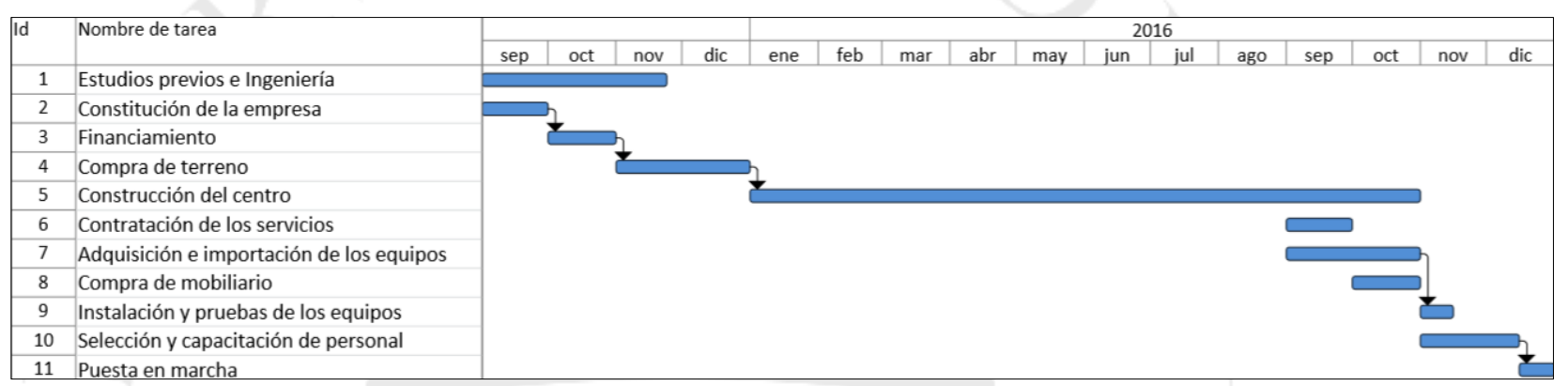

Elaboración propia 


\section{Capítulo VI: Organización administrativa}

\subsection{Organización empresarial}

La empresa será constituida como una sociedad anónima cerrada con fines de lucro, orientada al cliente, a la mejora continua en su atención a los pacientes y bajo una política de cuidado y protección del medio ambiente.

Las Sociedades Anónimas Cerradas S.A.C. están amparadas bajo la Ley General de Sociedades Ley $N^{\circ} 26887$ las cuales se constituyen como mínimo con dos personas y pueden llegar a tener hasta 20 socios como máximo; dichos socios no responden con su patrimonio personal.

Para la inscripción del centro en la Superintendencia Nacional de Registros Públicos (SUNARP) se deberán realizar los trámites de búsqueda y reserva del nombre en INDECOPI, la elaboración de la minuta de la empresa que luego de ser avalada por un notario, se convertirá en escritura pública y la apertura de una cuenta corriente a nombre del centro en una institución bancaria local.

A partir de esto la Superintendencia Nacional de Administración Tributaria (SUNAT) podrá otorgar a la empresa, mediante los respectivos trámites, el Registro Único de Contribuyentes (RUC) con lo que se procederá a la formalización de los libros societarios y libros contables y la autorización del libro de planillas ante el Ministerio de Trabajo y Promoción del Empleo.

La obtención de la licencia municipal de funcionamiento dependerá de la información favorable de Instituto Nacional de Defensa Civil el cual emitirá el certificado de inspección de INDECI para luego de esto dar inicio a las operaciones. 
El centro deberá ser inscrito también en el Registro Nacional de Instituciones Prestadoras de Servicios de Salud en el módulo de inscripción del portal de la Superintendencia Nacional de Salud SUSALUD donde se realiza la categorización del centro médico; en nuestro caso el tipo de establecimiento es un Servicio Médico de Apoyo de clasificación: Medicina Física y Rehabilitación.

Con la finalidad de orientar mejor las acciones de todos los miembros del centro y de afrontar de forma óptima los imprevistos que se puedan presentar es necesario definir quiénes somos y hacia donde queremos llegar en un futuro por lo que se presenta a continuación la Misión, Visión y Filosofía de la empresa:

\section{Misión}

Logar el bienestar de los adultos mayores mejorando su calidad de vida dentro de los mejores estándares de calidad de servicio y protección del medio ambiente.

\section{Visión}

Ser reconocida como el mejor centro de rehabilitación física ecoeficiente especializado en el adulto mayor.

\section{Filosofía}

La filosofía del centro está enfocada brindar la mejor atención al cliente excediendo sus expectativas en cuanto a calidad de servicio todo esto bajo los mejores lineamientos de cuidado del medio ambiente

\subsection{Requerimientos de personal directivo, administrativo y de soporte interno del servicio}

Los requerimientos de personal para que el centro de rehabilitación física funcione adecuadamente se presentan a continuación: 
Junta General de Accionistas: Conformada por los miembros propietarios de la empresa que poseen participaciones en forma de acciones. Dichos miembros fiscalizan y toman decisiones en base a los resultados de la compañía.

Gerente General: Su labor se centra en la planificación estratégica y la gestión del centro siendo el representante legal y responsable de la misma, encargado de la elaboración del presupuesto general y el plan anual de inversiones, toma de decisiones y llevar a cabo el plan de manejo ambiental basado en la ecoeficiencia.

Asistente de Gerencia: Es un puesto de alta confianza que tiene la finalidad de dar apoyo a la gerencia y a la dirección médica y a la vez coordinar toda comunicación entre la gerencia general y todos los colaboradores del centro.

Director Médico: Es el encargado de gestionar el área médica que comprende a los médicos fisiatras y los tecnólogos médicos; su función es la de planificar, organizar y dirigir el programa general de fisioterapia. El director médico debe lograr la mayor eficiencia y calidad en el proceso médico y controlar los reportes de gestión.

Médico Fisiatra: Su función radica en la evaluación física de los pacientes y realizar el diagnóstico del mismo con la finalidad de planificar el programa de tratamientos.

Coordinador Tecnólogo Médico: Supervisa el trabajo del cuerpo médico que en este caso son los tecnólogos médicos.

Tecnólogo Médico o Fisioterapeuta: Ejecuta el programa de tratamiento individualizado mediante las terapias y procedimientos médicos y supervisa permanentemente el avance de los pacientes; a la vez que realiza la evaluación final y el alta del mismo. También realiza la evaluación global de las lesiones del paciente y el establecimiento de planes de tratamiento individualizados. 
Director de Servicio al Cliente: Tiene como labor gestionar y planificar los planes de servicio al cliente enfocados en la retención y fidelización de estos diseñando los instrumentos de recopilación de información para la mejora continua de la calidad del servicio y los canales de comunicación entre la organización y los clientes. Es el responsable también de definir los procedimientos que permitirán tener la capacidad para tomar decisiones de cara al cliente, teniendo las respuestas inmediatas que permitan su completa satisfacción.

Coordinador de Servicio al Cliente: Es el encargado de gestionar y dar respuesta a los reclamos y sugerencias de los clientes coordinando con cada área los lineamientos de mejora del servicio gracias a la retroalimentación adquirida de los clientes mediante los estudios de consulta de opinión como son las encuestas.

Recepcionista de admisión: El puesto de recepcionista de admisión es de mucha importancia porque es la "cara" del centro; es el primer contacto que realiza el cliente con la empresa. Tiene como principal función la de administrar los sistemas de admisión y atención de los clientes; brindando toda la información acerca de todos los servicios que ofrece el centro para luego generar la apertura de la historia clínica digital de los pacientes y consignar los datos de filiación del mismo. También es la encargada de la programación de las citas y la coordinación de las mismas como el cobro de los servicios que brinda el centro, responsable del dinero que ingresa y encargada de emitir los documentos tributarios.

Coordinador de Marketing y Relaciones Públicas: Es el encargado de la implementación, desarrollo y seguimiento de las actividades de marketing, creando estrategias de posicionamiento y comunicación para ampliar la cartera de clientes, fidelizarlos y satisfacer sus necesidades. A la vez tiene la función de coordinar el contacto externo con los diferentes medios de comunicación, instituciones y público en general con la finalidad de mejorar la imagen de la empresa. 
Administrador de Sistemas: $\mathrm{Su}$ principal tarea es la de garantizar el buen funcionamiento de las redes internas como externas del centro. Su función es desarrollar, implementar y mantener el software requerido para la óptima conectividad de la organización entre los colaboradores y también con sus clientes como son el sistema de citas por internet y las historias clínicas digitales.

Director Administrativo: Su labor es la de planificar, organizar, dirigir y controlar los procesos administrativos manteniendo el equilibrio financiero del centro y a la vez optimizar los procesos de compra y mejorar los procedimientos administrativos.

Asistente Administrativo: Realiza el apoyo administrativo al director administrativo realizando las actividades de recepción y clasificación de toda la información del centro.

Coordinador de Recursos Humanos: Su función radica en la selección del personal, diagnóstico y planes de mejora de clima laboral y el diseño y desarrollo de los programas de capacitación enfocados principalmente al servicio del cliente, nuevas técnicas en fisioterapia y seminarios sobre ecología y cuidado del medio ambiente.

Coordinador Contable: $\mathrm{Su}$ labor se centra en supervisar y controlar todas las operaciones bancarias y los movimientos contables del centro como son los registros de ventas, compras, planillas, tramites tributarios entre otros; y a la vez encargado de elaborar los estados financieros e informes contables de la empresa.

Coordinador de Mantenimiento y Servicios Generales: Es el gestor del mantenimiento general de la infraestructura y maquinaria del centro; es el encargado de la formulación, ejecución y control del Plan de Mantenimiento y supervisor de las actividades relacionadas con la mantención del edificio. También coordina el retiro de todos los desechos y el manejo de residuos. 
Conductor: Su principal función es el traslado de los pacientes críticos que no pueden movilizarse para realizar sus terapias de su domicilio al centro y viceversa; a la vez de llevar los indicadores de la camioneta del centro e informar cualquier incidencia que ocurra.

\subsection{Estructura organizacional}

A continuación se muestra la estructura organizacional del centro de rehabilitación física mediante un organigrama:

Figura 6.1

Estructura Organizacional

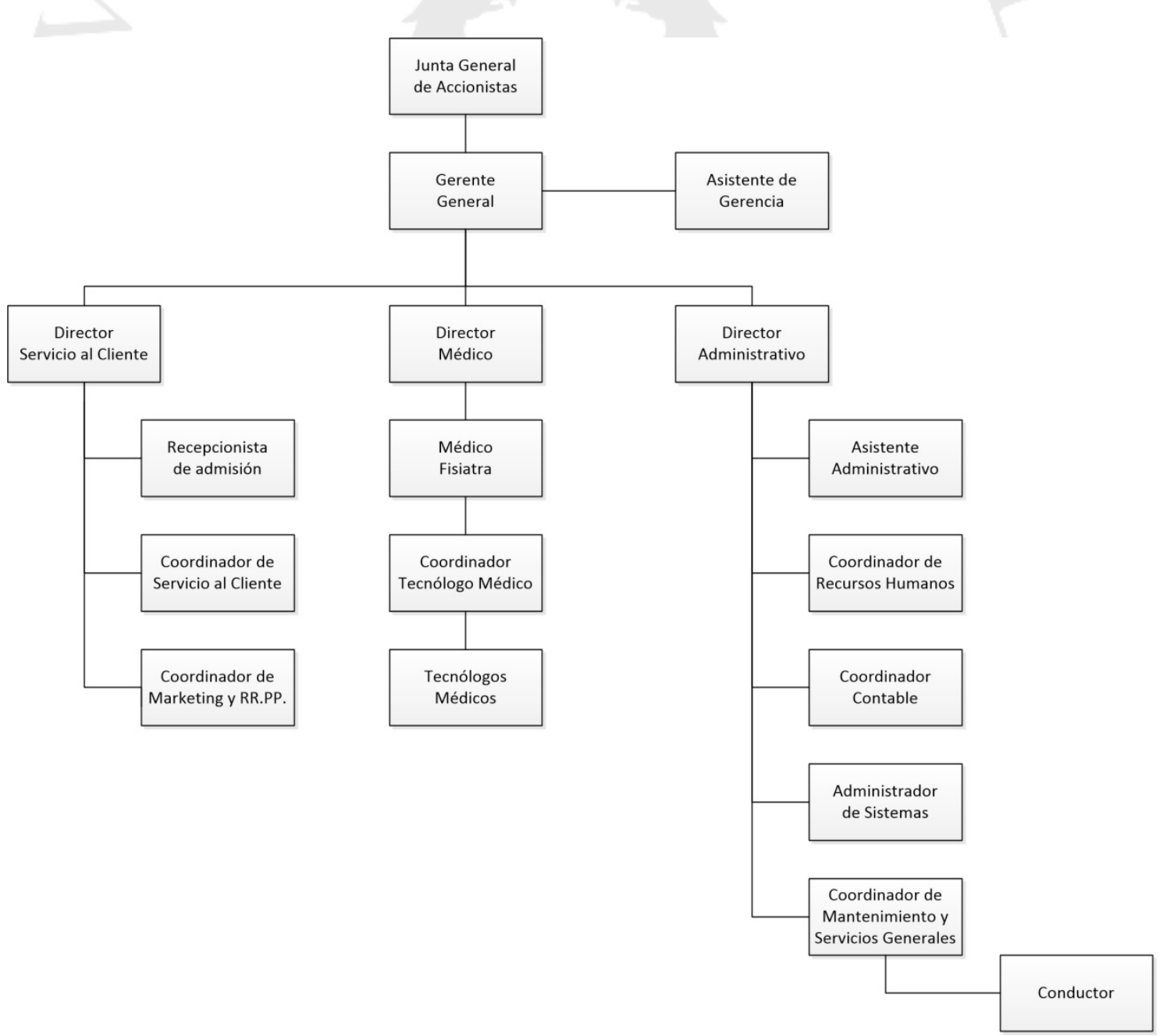

Elaboración propia 


\section{CAPÍTULO VII: ASPECTOS ECONÓMICOS}

\subsection{Inversiones}

El proyecto será financiado en parte por la Corporación Financiera de Desarrollo (COFIDE) mediante el programa multisectorial de inversión PROBID el cual financia a mediano y largo plazo los proyectos de inversión del sector privado dirigidos a la adquisición de activo fijo, maquinaria, equipo y ejecución de obras civiles además de capital de trabajo asociado al proyecto. Esta corporación financia hasta el 100\% de un monto no mayor a los 20 millones de dólares a un plazo máximo de 15 años.

La estructura de financiamiento considerará que el accionista aporte el 35\% del monto requerido y el $65 \%$ será financiado por COFIDE. La tasa de interés y comisiones del programa PROBID; que se utilizará para el financiamiento del proyecto se presenta en la siguiente tabla:

\section{Tabla 7.1}

Tasa de interés COFIDE

\begin{tabular}{|l|c|}
\hline \multicolumn{1}{|c|}{ Concepto } & Tasa (\%) \\
\hline VAC & $3,02 \%$ \\
\hline Tasa & $6,50 \%$ \\
\hline Comisiones & $1,75 \%$ \\
\hline TEA & $\mathbf{1 1 , 2 7 \%}$ \\
\hline
\end{tabular}

Nota: VAC es la tasa ajustada por la inflación Fuente: COFIDE Elaboración propia

\subsubsection{Inversión en la infraestructura para el servicio}

Según la Cámara Peruana de la Construcción CAPECO el costo de construcción para edificaciones por $\mathrm{m}^{2}$ es de aproximadamente US\$ 600 pero se considera un aumento del $35 \%$ para la implementación de un edificio de características ecoeficientes, con instalaciones, equipos y accesorios necesarios que reduzcan el impacto ambiental lo 
que resulta US\$ 800 por $\mathrm{m}^{2}$ para la construcción del edificio, esto según el Ing. Civil Manuel Salas CIP 76982, consultor en Infraestructura. En referencia a la excavación que será necesaria para la construcción del sótano se considera US\$ 1.000 por $\mathrm{m}^{2}$. A continuación se presenta la tabla con los costos asociados a la adquisición del terreno y construcción de la infraestructura del centro.

Tabla 7.2

Inversión en la Infraestructura

\begin{tabular}{|l|c|c|c|}
\hline \multicolumn{1}{|c|}{ Infraestructura } & Área $\mathbf{( m}^{\mathbf{2}} \mathbf{)}$ & S/./ $\mathbf{~ m}^{\mathbf{2}}$ & \multicolumn{1}{c|}{ Total $\mathbf{( S / . )}$} \\
\hline Terreno & 896 & S/. 7.275 & S/. 6.518.400 \\
\hline Obras civiles 1er y 2do piso & 1.268 & S/. 2.520 & S/. 3.195.360 \\
\hline Excavación y construcción sótano & 456 & S/. 3.150 & S/. 1.436.400 \\
\hline Ascensor & - & - & S/. 57.497 \\
\hline Sistema contra incendios sótano & - & - & S/. 183.263 \\
\hline Total & & & S/. 11.390.920 \\
\hline
\end{tabular}

Nota: Tipo de cambio: S/. 3.15

Fuente: CAPECO - CYPE Ingenieros

Elaboración propia

Respecto a la inversión fija tangible para la implementación del proyecto se considerarán los equipos y muebles y enseres tanto del servicio como de las oficinas. A continuación se presentan las tablas de dicha inversión y el consolidado de inversión total fija tangible. 
Tabla 7.3

Inversión en los equipos del servicio

\begin{tabular}{|c|c|c|c|}
\hline Equipos del servicio & Cant. & $\begin{array}{l}\text { Costo } \\
\text { Unit. }\end{array}$ & Total (S/.) \\
\hline Electroestimulador o TENS & 6 & $\mathrm{~S} / .4 .885$ & $\mathrm{~S} / .29 .310$ \\
\hline Ultrasonido & 2 & $\mathrm{~S} / .11 .435$ & $\mathrm{~S} / .22 .870$ \\
\hline Magneto & 6 & S/. 7.623 & $\mathrm{~S} / .45 .738$ \\
\hline Equipo de ondas de choque & 4 & $\mathrm{~S} / .48 .855$ & S/. 195.420 \\
\hline Laser de $1,040 \mathrm{mw}$ & 4 & S/. 7.220 & $\mathrm{~S} / .28 .880$ \\
\hline Ecógrafo & 1 & $\mathrm{~S} / .13 .640$ & $\mathrm{~S} / .13 .640$ \\
\hline Microondas fisioterapéutico & 4 & $\mathrm{~S} / .10 .145$ & $\mathrm{~S} / .40 .580$ \\
\hline Onda Corta & 4 & $\mathrm{~S} / .17 .500$ & $\mathrm{~S} / .70 .000$ \\
\hline Tanque de compresas calientes & 2 & $\mathrm{~S} / .5 .229$ & $\mathrm{~S} / .10 .458$ \\
\hline Tanque de compresas frías & 2 & $\mathrm{~S} / .8 .540$ & $\mathrm{~S} / .17 .080$ \\
\hline Tanque de parafina & 2 & $\mathrm{~S} / .2 .650$ & $\mathrm{~S} / .5 .300$ \\
\hline Masajeador eléctrico & 2 & $\mathrm{~S} / .1 .230$ & $\mathrm{~S} / .2 .460$ \\
\hline Trotadora caminadora & 4 & $\mathrm{~S} / .2 .700$ & $\mathrm{~S} / .10 .800$ \\
\hline Silla de acceso a piscina & 1 & $\mathrm{~S} / .18 .900$ & $\mathrm{~S} / .18 .900$ \\
\hline Calentador a gas & 2 & $\mathrm{~S} / .42 .300$ & $\mathrm{~S} / .84 .600$ \\
\hline Filtro para piscina & 1 & S/. 14.175 & $\mathrm{~S} / .14 .175$ \\
\hline Bomba de agua para piscina & 2 & $\mathrm{~S} / .4 .725$ & $\mathrm{~S} / .9 .450$ \\
\hline Aire acondicionado ducto $60.000 \mathrm{BTU}$ & 4 & $\mathrm{~S} / .11 .781$ & S/. 47.124 \\
\hline Total & & & S/. 666.785 \\
\hline
\end{tabular}

Fuente: JP Rehab S.R.L. - Toledo Piscinas

Elaboración propia

Tabla 7.4

Inversión en los equipos de oficina

\begin{tabular}{|l|c|r|r|}
\hline \multicolumn{1}{|c|}{ Equipos de oficina } & Cant. & Costo Unit. & \multicolumn{1}{c|}{ Total (S/.) } \\
\hline Teléfono para recepción & 1 & $\mathrm{~S} / .1 .260$ & $\mathrm{~S} / .1 .260$ \\
\hline Teléfono para oficinas & 17 & $\mathrm{~S} / .190$ & $\mathrm{~S} / .3 .230$ \\
\hline Computadora desktop & 4 & $\mathrm{~S} / .4 .330$ & $\mathrm{~S} / .17 .320$ \\
\hline Laptop & 14 & $\mathrm{~S} / .1 .989$ & $\mathrm{~S} / .27 .846$ \\
\hline UPS & 1 & $\mathrm{~S} / .1 .080$ & $\mathrm{~S} / .1 .080$ \\
\hline Impresora & 2 & $\mathrm{~S} / .4 .515$ & $\mathrm{~S} / .9 .030$ \\
\hline Televisor LED 50" & 2 & $\mathrm{~S} / .2 .500$ & $\mathrm{~S} / .5 .000$ \\
\hline Refrigeradora & 1 & $\mathrm{~S} / .3 .000$ & $\mathrm{~S} / .3 .000$ \\
\hline Microondas & 2 & $\mathrm{~S} / .300$ & $\mathrm{~S} / .600$ \\
\hline Aire acondicionado ducto 60.000 BTU & 2 & $\mathrm{~S} / .11 .781$ & $\mathrm{~S} / .23 .562$ \\
\hline Extintores & 6 & $\mathrm{~S} / .250$ & $\mathrm{~S} / .1 .500$ \\
\hline Total & & $\mathrm{S} / .93 .428$ \\
\hline
\end{tabular}

Fuente: Infotec - Powerquality - Onedirect

Elaboración propia 
Tabla 7.5

Inversión en el mobiliario y enseres del servicio

\begin{tabular}{|l|r|r|r|}
\hline \multicolumn{1}{|c|}{ Mobiliario y enseres del servicio } & Cant. & Costo Unit. & Total (S/.) \\
\hline Camillas terapeuticas & 34 & $\mathrm{~S} / .450$ & $\mathrm{~S} / .15 .300$ \\
\hline Taburetes giratorios & 34 & $\mathrm{~S} / .120$ & $\mathrm{~S} / .4 .080$ \\
\hline Coche con una gaveta & 18 & $\mathrm{~S} / .150$ & $\mathrm{~S} / .2 .700$ \\
\hline Vitrina de dos cuerpos & 34 & $\mathrm{~S} / .150$ & $\mathrm{~S} / .5 .100$ \\
\hline Peldaño de un paso & 34 & $\mathrm{~S} / .30$ & $\mathrm{~S} / .1 .020$ \\
\hline Negatoscopio & 4 & $\mathrm{~S} / .50$ & $\mathrm{~S} / .200$ \\
\hline Barras paralelas & 2 & $\mathrm{~S} / .250$ & $\mathrm{~S} / .500$ \\
\hline Colchonetas & 15 & $\mathrm{~S} / .40$ & $\mathrm{~S} / .600$ \\
\hline Pelotas Bobath & 15 & $\mathrm{~S} / .45$ & $\mathrm{~S} / .675$ \\
\hline Tirantes musculares & 15 & $\mathrm{~S} / .210$ & $\mathrm{~S} / .3 .150$ \\
\hline Escalera sueca & 3 & $\mathrm{~S} / .50$ & $\mathrm{~S} / .150$ \\
\hline Rueda para hombros & 2 & $\mathrm{~S} / .120$ & $\mathrm{~S} / .240$ \\
\hline Silla de ruedas & 3 & $\mathrm{~S} / .360$ & $\mathrm{~S} / .1 .080$ \\
\hline Total & & & $\mathrm{S} / .34 .795$ \\
\hline
\end{tabular}

Fuente: Fisaude

Elaboración propia

Tabla 7.6

Inversión en el mobiliario y enseres de oficinas

\begin{tabular}{|l|c|r|r|}
\hline \multicolumn{1}{|c|}{ Mobiliario y enseres de oficinas } & Cant. & \multicolumn{1}{c|}{ Costo Unit. } & \multicolumn{1}{c|}{ Total (S/.) } \\
\hline Sillones de espera & 5 & $\mathrm{~S} / .600$ & $\mathrm{~S} / .3 .000$ \\
\hline Lockers & 32 & $\mathrm{~S} / .120$ & $\mathrm{~S} / .3 .840$ \\
\hline Sillones de descanso & 4 & $\mathrm{~S} / .350$ & $\mathrm{~S} / .1 .400$ \\
\hline Escritorios & 16 & $\mathrm{~S} / .450$ & $\mathrm{~S} / .7 .200$ \\
\hline Silla giratoria & 16 & $\mathrm{~S} / .160$ & $\mathrm{~S} / .2 .560$ \\
\hline Mesa sala de reuniones & 1 & $\mathrm{~S} / .1 .500$ & $\mathrm{~S} / .1 .500$ \\
\hline Sillas sala de reuniones & 15 & $\mathrm{~S} / .150$ & $\mathrm{~S} / .2 .250$ \\
\hline Total & & $\mathrm{S} / .21 .750$ \\
\hline
\end{tabular}

Fuente: Muebles Z-Art

Elaboración propia

Tabla 7.7

Inversión en Vehículos

\begin{tabular}{|l|c|c|c|}
\hline \multicolumn{1}{|c|}{ Vehículos } & Cant. & Costo Unit. & Total (S/.) \\
\hline Camioneta Van Transit Connect XLT & 1 & S/. 75.143 & S/. 75.143 \\
\hline Total & & & S/. 75.143 \\
\hline
\end{tabular}

Fuente: Ford

Elaboración propia 
Tabla 7.8

Inversión Total Fija Tangible

\begin{tabular}{|l|r|}
\hline \multicolumn{1}{|c|}{ Inversión Total Fija Tangible } & \multicolumn{1}{c|}{ Total (S/.) } \\
\hline Edificio & $\mathrm{S} / .11 .390 .920$ \\
\hline Vehículos & $\mathrm{S} / .75 .143$ \\
\hline Equipos del servicio & $\mathrm{S} / .666 .785$ \\
\hline Mobiliario y enseres del servicio & $\mathrm{S} / .34 .795$ \\
\hline Equipos de oficina & $\mathrm{S} / .93 .428$ \\
\hline Mobiliario y enseres de oficinas & $\mathrm{S} / .21 .750$ \\
\hline Total & S/. 12.282.821 \\
\hline
\end{tabular}

Elaboración propia

En relación a la inversión fija intangible; según el Ing. Civil Manuel Salas CIP 76982, consultor en Infraestructura los estudios previos e ingeniería tienen un costo de $\mathrm{S} / .25$ por $\mathrm{m}^{2}$, y la supervisión de obra puede llegar a costar $\mathrm{S} / .6 .600$ por mes. Por otro lado los costos referidos a las licencias y permisos municipales se recabarán del Texto único de procedimientos administrativos TUPA de la municipalidad de San Borja donde se indica todos los procedimientos necesarios para realizar el proyecto tales como la consulta del anteproyecto, licencia de edificación nueva, conexiones de servicios públicos, conformidad de obras en vía pública, declaratoria de edificación, certificado de parámetros urbanísticos, entre otros con un costo total de S/. 1.154.

Respecto a los costos de las certificaciones, estos ascienden para la obtención de la certificación ISO 9001 a S/. 15.750. Según Cristina Gamboa del Consejo colombiano de construcción sostenible el costo estimado de la certificación LEED para edificios sustentables es el $0.76 \%$ de la inversión total por lo que resulta $\mathrm{S} / .93 .349$ y el promedio para obtener la acreditación "Joint Commission International" para hospitales y clínicas relacionados a la calidad y cuidado del paciente asciende a S/.163.800. En total la inversión para las certificaciones del centro es de S/.272.899.

A continuación se presenta el cuadro de la inversión fija intangible. 
Tabla 7.9

Inversión Total Fija Intangible

\begin{tabular}{|l|r|}
\hline \multicolumn{1}{|c|}{ Inversión Total Fija Intangible } & \multicolumn{1}{c|}{ Total (S/.) } \\
\hline Estudios previos e Ingeniería & $\mathrm{S} / .43 .100$ \\
\hline Constitución de la empresa & $\mathrm{S} / .1 .500$ \\
\hline Supervisión & $\mathrm{S} / .66 .000$ \\
\hline Licencias y permisos municipales & $\mathrm{S} / .1 .154$ \\
\hline Gastos de implementación & $\mathrm{S} / .8 .000$ \\
\hline Certificaciones & $\mathrm{S} / .272 .899$ \\
\hline Software & $\mathrm{S} / .25 .000$ \\
\hline Capacitación al personal & $\mathrm{S} / .3 .500$ \\
\hline Gastos puesta en marcha & $\mathrm{S} / .15 .000$ \\
\hline Contingencias (10\%) & $\mathrm{S} / .43 .615$ \\
\hline Total & S/.479.769 \\
\hline
\end{tabular}

Fuente: Ing. Manuel Salas - Municipalidad de San Borja Elaboración propia

Finalmente se presenta la Inversión total necesaria para la implementación del proyecto del centro especializado de rehabilitación física.

Tabla 7.10

Inversión Total

\begin{tabular}{|l|r|}
\hline \multicolumn{1}{|c|}{ Inversión Total } & \multicolumn{1}{c|}{ Total (S/.) } \\
\hline Activo fijo tangible & $\mathrm{S} / .12 .282 .821$ \\
\hline Activo fijo intangible & $\mathrm{S} / .479 .769$ \\
\hline Capital de trabajo & $\mathrm{S} / .941 .249$ \\
\hline Inversión total & $\mathrm{S} / \mathbf{1 3 . 7 0 3 . 8 3 9}$ \\
\hline
\end{tabular}

Elaboración propia

\subsubsection{Capital de trabajo}

El monto necesario para cubrir los gastos ordinarios como insumos, sueldos, servicios, materiales, entre otros gastos que se generan antes de que la empresa perciba ingresos por ventas será calculado considerando un periodo de 3 meses ya que al ser un servicio los pagos de los clientes serán por adelantado para poder hacer uso de dicho servicio, lo que nos da mayor liquidez para operar el negocio sin contratiempos monetarios. 
Tabla 7.11

Capital de Trabajo

\begin{tabular}{|l|c|}
\hline Capital de Trabajo & Mensual (S/.) \\
\hline Materiales e Insumos & $\mathrm{S} / .41 .324$ \\
\hline Sueldos & $\mathrm{S} / .244 .416$ \\
\hline Servicios & $\mathrm{S} / .13 .176$ \\
\hline Servicios de terceros & $\mathrm{S} / 14.833$ \\
\hline Total mensual & $\mathrm{S} / .313 .750$ \\
\hline Meses & 3 \\
\hline Capital de Trabajo & S/.941.249 \\
\hline
\end{tabular}

Elaboración propia

\subsection{Costos de las operaciones del servicio}

Los costos de las operaciones del servicio serán presentados por cada año en el que se desarrollará el proyecto. Se han proyectado los costos a lo largo del horizonte del proyecto; es decir a partir del año 2017 hasta el año 2021.

\subsubsection{Costos de materiales del servicio}

Como se indicó en el capítulo $\mathrm{V}$ sobre los requerimientos de materiales para el servicio, el costo de los insumos serán calculados cada año y los materiales serán adquiridos cada dos años. A continuación se presenta la tabla del costo de los materiales e insumos del proyecto. 
Tabla 7.12

Costo de materiales e insumos

\begin{tabular}{|c|c|c|c|c|c|}
\hline \multirow{2}{*}{ Materiales e Insumos } & \multicolumn{5}{|c|}{ Costo anual (S/.) } \\
\hline & 2017 & 2018 & 2019 & 2020 & 2021 \\
\hline Gel conductor (1 litro) & $\mathrm{S} / .71 .865$ & $\mathrm{~S} / .72 .630$ & $\mathrm{~S} / .73 .395$ & $\mathrm{~S} / .74 .130$ & $\mathrm{~S} / .74 .865$ \\
\hline Electrodos adhesivos (par) & $\mathrm{S} / .11 .978$ & $\mathrm{~S} / .12 .105$ & $\mathrm{~S} / .12 .233$ & $\mathrm{~S} / .12 .355$ & $\mathrm{~S} / .12 .478$ \\
\hline Cremas descontracturantes $(250 \mathrm{ml})$ & $\mathrm{S} / .86 .238$ & $\mathrm{~S} / .87 .156$ & $\mathrm{~S} / .88 .074$ & $\mathrm{~S} / .88 .956$ & $\mathrm{~S} / .89 .838$ \\
\hline Aceites de masajes terapeuticos $(500 \mathrm{ml})$ & $\mathrm{S} / .86 .238$ & $\mathrm{~S} / .87 .156$ & $\mathrm{~S} / .88 .074$ & $\mathrm{~S} / .88 .956$ & $\mathrm{~S} / .89 .838$ \\
\hline Vendaje neuromuscular (5 mts) & S/. 114.984 & $\mathrm{~S} / .116 .208$ & $\mathrm{~S} / .117 .432$ & $\mathrm{~S} / .118 .608$ & $\mathrm{~S} / .119 .784$ \\
\hline desinfectante de piel (1 litro) & S/. 21.560 & $\mathrm{~S} / .21 .789$ & $\mathrm{~S} / .22 .019$ & $\mathrm{~S} / .22 .239$ & $\mathrm{~S} / .22 .460$ \\
\hline Toallas húmedas desinfectantes & $\mathrm{S} / .28 .746$ & $\mathrm{~S} / .29 .052$ & $\mathrm{~S} / .29 .358$ & S/. 29.652 & $\mathrm{~S} / .29 .946$ \\
\hline Papel Toalla ecológico $150 \mathrm{mts}$ & $\mathrm{S} / .59 .888$ & S/. 60.525 & S/. 61.163 & $\mathrm{~S} / .61 .775$ & $\mathrm{~S} / .62 .388$ \\
\hline Guantes látex & $\mathrm{S} / .799$ & $\mathrm{~S} / .807$ & $\mathrm{~S} / .816$ & $\mathrm{~S} / .824$ & $\mathrm{~S} / .832$ \\
\hline Tapabocas & S/. 399 & $\mathrm{~S} / .404$ & $\mathrm{~S} / .408$ & $\mathrm{~S} / .412$ & S/. 416 \\
\hline Compresas x 3 unidades & $\mathrm{S} / .4 .000$ & - & $\mathrm{S} / .4 .000$ & - & $\mathrm{S} / .4 .000$ \\
\hline Toallas & $\mathrm{S} / .8 .000$ & - & $\mathrm{S} / .8 .000$ & 8 & $\mathrm{~S} / .8 .000$ \\
\hline Packs frio y calor & $\mathrm{S} / .1 .200$ & - & $\mathrm{S} / .1 .200$ & 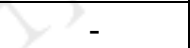 & $\mathrm{S} / .1 .200$ \\
\hline Total & $\mathrm{S} / .495 .893$ & $\mathrm{~S} / . \mathbf{4 8 7 . 8 3 2}$ & S/. 506.170 & $\mathrm{S} / .497 .907$ & S/. 516.043 \\
\hline
\end{tabular}

Elaboración propia

7.2.2. Costo de los servicios (energía eléctrica, agua, transporte, etc.)

El costo de los servicios está en función de las tarifas de Luz del Sur, SEDAPAL, Calidda, entre otros servicios que fueron tipificadas en el capítulo III acerca de los factores de localización y serán calculados para cada año de operación. El costo de telefonía fija e internet se ha fijado en S/. 6.000 al año teniendo como base un costo mensual de S/. 500 al mes. Los costos de todos los servicios necesarios para la operación del centro se presentan a continuación.

Tabla 7.13

Costo anual de energía eléctrica

\begin{tabular}{|c|c|c|c|c|c|}
\hline Años & $\begin{array}{c}\text { Consumo total de } \\
\text { energía eléctrica } \\
\text { (Kw.h) }\end{array}$ & $\begin{array}{c}\text { Cargo fijo } \\
\text { anual (S/.) }\end{array}$ & $\begin{array}{c}\text { Costo de energía } \\
\text { eléctrica del } \\
\text { servicio (S/.) }\end{array}$ & $\begin{array}{c}\text { Costo de energía } \\
\text { eléctrica del } \\
\text { ascensor (S/.) }\end{array}$ & $\begin{array}{c}\text { Costo total de } \\
\text { energía } \\
\text { eléctrica (S/.) }\end{array}$ \\
\hline 2017 & 177.845 & $\mathrm{~S} / .36,36$ & $\mathrm{~S} / .22 .930$ & $\mathrm{~S} / .1 .200$ & $\mathrm{~S} / .38 .673$ \\
\hline 2018 & 178.999 & $\mathrm{~S} / .36,36$ & $\mathrm{~S} / .23 .173$ & $\mathrm{~S} / .1 .200$ & $\mathrm{~S} / .38 .916$ \\
\hline 2019 & 180.145 & $\mathrm{~S} / .36,36$ & $\mathrm{~S} / .23 .414$ & $\mathrm{~S} / .1 .200$ & $\mathrm{~S} / .39 .157$ \\
\hline 2020 & 181.268 & $\mathrm{~S} / .36,36$ & $\mathrm{~S} / .23 .651$ & $\mathrm{~S} / .1 .200$ & $\mathrm{~S} / .39 .393$ \\
\hline 2021 & 182.380 & $\mathrm{~S} / .36,36$ & $\mathrm{~S} / .23 .885$ & $\mathrm{~S} / .1 .200$ & $\mathrm{~S} / .39 .627$ \\
\hline
\end{tabular}

Elaboración propia 
Tabla 7.14

Costo anual de agua

\begin{tabular}{|c|c|c|c|c|c|}
\hline Años & $\begin{array}{c}\text { Consumo total } \\
\text { de agua }\left(\mathbf{m}^{\mathbf{3}}\right)\end{array}$ & $\begin{array}{c}\text { Cargo fijo } \\
\text { anual (S/.) }\end{array}$ & $\begin{array}{c}\text { Costo de Agua } \\
\text { Potable (S/.) }\end{array}$ & $\begin{array}{c}\text { Costo de } \\
\text { Alcantarillado (S/.) }\end{array}$ & $\begin{array}{c}\text { Costo total de } \\
\text { agua (S/.) }\end{array}$ \\
\hline 2017 & 11.834 & $\mathrm{~S} / .58,63$ & $\mathrm{~S} / .53 .134$ & $\mathrm{~S} / .23 .218$ & $\mathrm{~S} / .76 .411$ \\
\hline 2018 & 11.959 & $\mathrm{~S} / .58,63$ & $\mathrm{~S} / .53 .696$ & $\mathrm{~S} / .23 .464$ & $\mathrm{~S} / .77 .218$ \\
\hline 2019 & 12.084 & $\mathrm{~S} / .58,63$ & $\mathrm{~S} / .54 .286$ & $\mathrm{~S} / .23 .721$ & $\mathrm{~S} / .78 .066$ \\
\hline 2020 & 12.209 & $\mathrm{~S} / .58,63$ & $\mathrm{~S} / .54 .889$ & $\mathrm{~S} / .23 .985$ & $\mathrm{~S} / .78 .932$ \\
\hline 2021 & 12.335 & $\mathrm{~S} / .58,63$ & $\mathrm{~S} / .55 .492$ & $\mathrm{~S} / .24 .248$ & $\mathrm{~S} / .79 .799$ \\
\hline
\end{tabular}

Elaboración propia

Tabla 7.15

Costo anual de gas natural

\begin{tabular}{|c|c|c|c|c|c|c|c|}
\hline \multirow[b]{2}{*}{ Años } & \multirow{2}{*}{$\begin{array}{c}\text { Consumo } \\
\text { de Gas } \\
\text { Natural } \\
\left(\mathbf{m}^{3} / \mathbf{a n ̃ o}\right) \\
\end{array}$} & \multicolumn{2}{|c|}{ Tarifas únicas de distribución } & \multirow{2}{*}{$\begin{array}{c}\text { Tarifa de } \\
\text { transporte } \\
\text { red principal } \\
(\mathrm{S} / .)\end{array}$} & \multirow{2}{*}{$\begin{array}{c}\text { Gas } \\
\text { natural } \\
(\mathbf{G J})\end{array}$} & \multirow[b]{2}{*}{$\begin{array}{l}\text { Precio Gas } \\
\text { en boca de } \\
\text { pozo (S/.) }\end{array}$} & \multirow[b]{2}{*}{$\begin{array}{c}\text { Costo } \\
\text { Total de } \\
\text { Gas (S/.) }\end{array}$} \\
\hline & & $\begin{array}{c}\text { Margen fijo de } \\
\text { comercialización } \\
\text { (S/.) }\end{array}$ & $\begin{array}{c}\text { Margen variable } \\
\text { de distribución } \\
(\mathrm{S} / .)\end{array}$ & & & & \\
\hline 2017 & 43.111 & $\mathrm{~S} / .946,42$ & $\mathrm{~S} / .8 .781$ & $\mathrm{~S} / .5 .089$ & 1723,27 & S/. 17.079 & $\mathrm{~S} / .31 .895$ \\
\hline 2018 & 43.493 & S/. 946,42 & $\mathrm{~S} / .8 .858$ & $\mathrm{~S} / .5 .134$ & 1738,54 & $\mathrm{~S} / .17 .230$ & $\mathrm{~S} / .32 .169$ \\
\hline 2019 & 43.875 & $\mathrm{~S} / .946,42$ & $\mathrm{~S} / .8 .936$ & $\mathrm{~S} / .5 .179$ & 1753,80 & $\mathrm{~S} / .17 .381$ & $\mathrm{~S} / .32 .443$ \\
\hline 2020 & 44.257 & $\mathrm{~S} / .946,42$ & $\mathrm{~S} / .9 .014$ & $\mathrm{~S} / .5 .224$ & 1769,07 & S/. 17.533 & S/. 32.717 \\
\hline 2021 & 44.638 & S/. 946,42 & $\mathrm{~S} / .9 .092$ & $\mathrm{~S} / .5 .269$ & 1784,33 & S/. 17.684 & $\mathrm{~S} / .32 .991$ \\
\hline
\end{tabular}

Elaboración propia

Los costos anuales por el servicio de transporte para los pacientes graves que necesitan ser llevados al centro para sus terapias están en función del consumo de GNV que se utiliza en el recorrido de la camioneta. Se ha calculado que el consumo de GNV será de $3.130 \mathrm{~m}^{3}$ de GNV por cada año de operación.

Tabla 7.16

Costo anual de gas natural vehicular

\begin{tabular}{|c|c|c|c|}
\hline Año & $\begin{array}{c}\text { Consumo GNV } \\
\left(\mathbf{m}^{\mathbf{3}} / \mathbf{a n ̃ o}\right)\end{array}$ & $\begin{array}{c}\text { Costo } \\
\mathbf{G N V / \mathbf { m } ^ { 3 }}\end{array}$ & $\begin{array}{c}\text { Costo Total de } \\
\text { GNV (S/.) }\end{array}$ \\
\hline 2017 & 3.130 & $\mathrm{~S} / .1,45$ & $\mathrm{~S} / .4 .539$ \\
\hline 2018 & 3.130 & $\mathrm{~S} / .1,45$ & $\mathrm{~S} / .4 .539$ \\
\hline 2019 & 3.130 & $\mathrm{~S} / .1,45$ & $\mathrm{~S} / .4 .539$ \\
\hline 2020 & 3.130 & $\mathrm{~S} / .1,45$ & $\mathrm{~S} / .4 .539$ \\
\hline 2021 & 3.130 & $\mathrm{~S} / .1,45$ & $\mathrm{~S} / .4 .539$ \\
\hline
\end{tabular}

Elaboración propia 
El costo total de los servicios del centro especializado de rehabilitación física se presenta en la siguiente tabla:

Tabla 7.17

Costo total de los servicios

\begin{tabular}{|c|c|c|c|c|c|c|}
\hline Año & $\begin{array}{c}\text { Costo total de } \\
\text { energía } \\
\text { eléctrica (S/.) }\end{array}$ & $\begin{array}{c}\text { Costo total } \\
\text { de agua } \\
(\mathbf{S} / .)\end{array}$ & $\begin{array}{c}\text { Costo total } \\
\text { de Gas } \\
(\mathbf{S} / .)\end{array}$ & $\begin{array}{c}\text { Costo total } \\
\text { de GNV } \\
(\mathbf{S} / .)\end{array}$ & $\begin{array}{c}\text { Costo total de } \\
\text { Internet, cable } \\
\text { y telefonía (S/.) }\end{array}$ & $\begin{array}{c}\text { Costo total de } \\
\text { los servicios } \\
\text { (S/.) }\end{array}$ \\
\hline 2017 & $\mathrm{~S} / .38 .673$ & $\mathrm{~S} / .76 .411$ & $\mathrm{~S} / .31 .895$ & $\mathrm{~S} / .4 .539$ & $\mathrm{~S} / .6 .600$ & $\mathrm{~S} / .158 .116$ \\
\hline 2018 & $\mathrm{~S} / .38 .916$ & $\mathrm{~S} / .77 .218$ & $\mathrm{~S} / .32 .169$ & $\mathrm{~S} / .4 .539$ & $\mathrm{~S} / .6 .600$ & $\mathrm{~S} / .159 .441$ \\
\hline 2019 & $\mathrm{~S} / .39 .157$ & $\mathrm{~S} / .78 .066$ & $\mathrm{~S} / .32 .443$ & $\mathrm{~S} / .4 .539$ & $\mathrm{~S} / .6 .600$ & $\mathrm{~S} / .160 .804$ \\
\hline 2020 & $\mathrm{~S} / .39 .393$ & $\mathrm{~S} / .78 .932$ & $\mathrm{~S} / .32 .717$ & $\mathrm{~S} / .4 .539$ & $\mathrm{~S} / .6 .600$ & $\mathrm{~S} / .162 .181$ \\
\hline 2021 & $\mathrm{~S} / .39 .627$ & $\mathrm{~S} / .79 .799$ & $\mathrm{~S} / .32 .991$ & $\mathrm{~S} / .4 .539$ & $\mathrm{~S} / .6 .600$ & $\mathrm{~S} / .163 .556$ \\
\hline
\end{tabular}

Elaboración propia

En relación a los costos de los servicios de terceros se considerará a diversas empresas en los rubros necesarios para la operación del servicio; entre dichas empresas tenemos: Hibu, la cual brindará los servicios de dominio web y hosting, Piscinas Nova para el mantenimiento de la piscina terapéutica, Empresa de Seguridad V13 la cual será la encargada de la seguridad externa del centro, Empresa de Limpieza Limpium, Lavandería Jardín, Grupo Acciona Perú aquella que brindará el mantenimiento general del edificio y los equipos, Empresa de cuidado de jardines llamada Paisajes y bosques y la EPS-RS Soluciones ambientales la cual se hará cargo de los residuos sólidos y hospitalarios que se generen en el centro; entre otras empresas.

A continuación se presentan los costos de los servicios de terceros: 
Tabla 7.18

Costo de los servicios de terceros

\begin{tabular}{|l|c|r|}
\hline \multicolumn{1}{|c|}{ Servicios de terceros } & \multicolumn{1}{c|}{$\begin{array}{c}\text { Costo } \\
\text { mensual (S/.) }\end{array}$} & $\begin{array}{c}\text { Costo anual } \\
(\mathbf{S} / .)\end{array}$ \\
\hline Dominio & - & $\mathrm{S} / .52$ \\
\hline Hosting web & - & $\mathrm{S} / .948$ \\
\hline Mantenimiento piscina & $\mathrm{S} / .378$ & $\mathrm{~S} / .4 .536$ \\
\hline Mantenimiento General & $\mathrm{S} / .2 .020$ & $\mathrm{~S} / .24 .240$ \\
\hline Lavandería & $\mathrm{S} / .1 .600$ & $\mathrm{~S} / .19 .200$ \\
\hline Recolección de residuos solidos & $\mathrm{S} / .1 .440$ & $\mathrm{~S} / .17 .280$ \\
\hline Vigilancia & $\mathrm{S} / .2 .707$ & $\mathrm{~S} / .32 .484$ \\
\hline Limpieza & $\mathrm{S} / .5 .848$ & $\mathrm{~S} / .70 .176$ \\
\hline Jardinería & $\mathrm{S} / .550$ & $\mathrm{~S} / .6 .600$ \\
\hline Uniformes & - & $\mathrm{S} / .2 .480$ \\
\hline Total & $\mathrm{S} / . \mathbf{1 4 . 5 4 3}$ & $\mathrm{S} / . \mathbf{1 7 7 . 9 9 6}$ \\
\hline
\end{tabular}

Elaboración propia

Tabla 7.19

Costo anual de los servicios de terceros

\begin{tabular}{|c|c|}
\hline Años & Costo Anual (S/.) \\
\hline 2017 & S/. 177.996 \\
\hline 2018 & S/. 177.996 \\
\hline 2019 & S/. 177.996 \\
\hline 2020 & S/.177.996 \\
\hline 2021 & S/.177.996 \\
\hline
\end{tabular}

Elaboración propia

\subsubsection{Costo del personal}

Tanto el personal de atención al cliente como el personal de soporte interno del servicio estarán en planilla con 14 sueldos al año, beneficios sociales, CTS y Essalud.

\subsubsection{Personal de atención al cliente}

El personal de atención al cliente está dividido en mano de obra directa (MOD) la cual está conformada por los tecnólogos médicos que realizan las terapias y mano de obra indirecta (MOI) que son las recepcionistas de admisión y los médicos fisiatra 
encargados de la evaluación previa antes de recibir las terapias. A continuación se presentan las tablas de los costos del personal de atención al cliente.

Tabla 7.20

Costo anual de Mano de Obra Directa (MOD)

\begin{tabular}{|c|c|c|c|c|c|c|}
\hline $\begin{array}{c}\text { Mano de Obra } \\
\text { Directa (MOD) }\end{array}$ & $\begin{array}{c}\text { Nro de } \\
\text { trabaj. }\end{array}$ & $\begin{array}{c}\text { Remuneración } \\
\text { mensual }\end{array}$ & Gratific. & CTS & $\begin{array}{c}\text { Essalud } \\
(\mathbf{9 \%} / \mathbf{)}\end{array}$ & $\begin{array}{c}\text { Costo anual } \\
\text { (S/.) }\end{array}$ \\
\hline Tecnólogo médico & 30 & $\mathrm{~S} / .2 .500$ & $\mathrm{~S} / .150 .000$ & $\mathrm{~S} / .75 .000$ & $\mathrm{~S} / .81 .000$ & $\mathrm{~S} / .1 .206 .000$ \\
\hline Total & & & $\mathrm{S} / . \mathbf{1 . 2 0 6 . 0 0 0}$ \\
\hline
\end{tabular}

Fuente: Tecnólogo Médico Diana Mundaca

Elaboración propia

Tabla 7.21

Costo anual de Mano de Obra Indirecta (MOI)

\begin{tabular}{|l|c|c|c|c|c|c|}
\hline $\begin{array}{c}\text { Mano de Obra } \\
\text { Indirecta (MOI) }\end{array}$ & $\begin{array}{c}\text { Nro de } \\
\text { trabaj. }\end{array}$ & $\begin{array}{c}\text { Remuneración } \\
\text { mensual }\end{array}$ & Gratific. & CTS & $\begin{array}{c}\text { Essalud } \\
(9 \%)\end{array}$ & $\begin{array}{c}\text { Costo anual } \\
\text { (S/.) }\end{array}$ \\
\hline Médico fisiatra & 2 & $\mathrm{~S} / .7 .000$ & $\mathrm{~S} / .28 .000$ & $\mathrm{~S} / .14 .000$ & $\mathrm{~S} / .15 .120$ & $\mathrm{~S} / .225 .120$ \\
\hline $\begin{array}{l}\text { Coordinador } \\
\text { tecnólogo médico }\end{array}$ & 2 & $\mathrm{~S} / .3 .500$ & $\mathrm{~S} / .14 .000$ & $\mathrm{~S} / .7 .000$ & $\mathrm{~S} / .7 .560$ & $\mathrm{~S} / .112 .560$ \\
\hline $\begin{array}{l}\text { Recepcionista de } \\
\text { admisión }\end{array}$ & 2 & $\mathrm{~S} / .1 .500$ & $\mathrm{~S} / .6 .000$ & $\mathrm{~S} / .3 .000$ & $\mathrm{~S} / .3 .240$ & $\mathrm{~S} / .48 .240$ \\
\hline Total & \multicolumn{7}{|l}{} & & & S/.385.920 \\
\hline
\end{tabular}

Fuente: Tecnólogo Médico Diana Mundaca Elaboración propia

\subsubsection{Personal de soporte interno del servicio}

El costo del personal de soporte interno del servicio o personal administrativo está definido en base a las remuneraciones promedio que dicta el mercado laboral actual. 
Tabla 7.22

Costo anual del personal administrativo

\begin{tabular}{|c|c|c|c|c|c|c|}
\hline Personal administrativo & $\begin{array}{l}\text { Nro de } \\
\text { trabaj. }\end{array}$ & $\begin{array}{l}\text { Remun. } \\
\text { mensual }\end{array}$ & Gratific. & CTS & $\begin{array}{c}\text { Essalud } \\
(9 \%)\end{array}$ & $\begin{array}{c}\text { Costo anual } \\
\text { (S/.) }\end{array}$ \\
\hline Gerente general & 1 & $\mathrm{~S} / .15 .000$ & $\mathrm{~S} / .30 .000$ & $\mathrm{~S} / .15 .000$ & S/. 16.200 & S/. 241.200 \\
\hline Director médico & 1 & $\mathrm{~S} / .12 .000$ & $\mathrm{~S} / .24 .000$ & $\mathrm{~S} / .12 .000$ & $\mathrm{~S} / .12 .960$ & S/. 192.960 \\
\hline Director administrativo & 1 & $\mathrm{~S} / .10 .000$ & $\mathrm{~S} / .20 .000$ & $\mathrm{~S} / .10 .000$ & $\mathrm{~S} / .10 .800$ & $\mathrm{~S} / .160 .800$ \\
\hline Director de servicio al cliente & 1 & S/. 9.000 & S/. 18.000 & S/. 9.000 & S/. 9.720 & S/. 144.720 \\
\hline Coordinador de servicio al cliente & 1 & $\mathrm{~S} / .4 .500$ & $\mathrm{~S} / .9 .000$ & $\mathrm{~S} / .4 .500$ & $\mathrm{~S} / .4 .860$ & $\mathrm{~S} / .72 .360$ \\
\hline Coordinador de MKT y RR.PP. & 1 & $\mathrm{~S} / .6 .000$ & $\mathrm{~S} / .12 .000$ & $\mathrm{~S} / .6 .000$ & $\mathrm{~S} / .6 .480$ & S/. 96.480 \\
\hline Coordinador de RR.HH. & 1 & $\mathrm{~S} / .6 .000$ & $\mathrm{~S} / .12 .000$ & $\mathrm{~S} / .6 .000$ & $\mathrm{~S} / .6 .480$ & S/. 96.480 \\
\hline Coordinador contable & 1 & S/. 5.200 & S/. 10.400 & S/. 5.200 & S/. 5.616 & $\mathrm{~S} / .83 .616$ \\
\hline Coordinador de mantenimiento & 1 & $\mathrm{~S} / .4 .500$ & $\mathrm{~S} / .9 .000$ & $\mathrm{~S} / .4 .500$ & $\mathrm{~S} / .4 .860$ & $\mathrm{~S} / .72 .360$ \\
\hline Administrador de sistemas & 1 & S/. 6.000 & S/. 12.000 & S/. 6.000 & S/. 6.480 & S/. 96.480 \\
\hline Asistente de gerencia & 1 & $\mathrm{~S} / .2 .000$ & $\mathrm{~S} / .4 .000$ & $\mathrm{~S} / .2 .000$ & $\mathrm{~S} / .2 .160$ & S/. 32.160 \\
\hline Asistente dirección administrativa & 1 & $\mathrm{~S} / .2 .000$ & $\mathrm{~S} / .4 .000$ & $\mathrm{~S} / .2 .000$ & $\mathrm{~S} / .2 .160$ & $\mathrm{~S} / .32 .160$ \\
\hline Conductor & 1 & $\mathrm{~S} / .1 .200$ & $\mathrm{~S} / .2 .400$ & $\mathrm{~S} / .1 .200$ & S/. 1.296 & S/. 19.296 \\
\hline Total & & 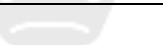 & & +2 & & S/. 1.341.072 \\
\hline
\end{tabular}

Fuente: Pricewaterhouse Coopers

Elaboración propia

A continuación se presentan los costos de los sueldos totales por año:

Tabla 7.23

Costo anual de los sueldos

\begin{tabular}{|c|c|}
\hline Año & Costo Anual (S/.) \\
\hline 2017 & S/. 2.932.992 \\
\hline 2018 & $\mathrm{~S} / .2 .932 .992$ \\
\hline 2019 & $\mathrm{~S} / .2 .932 .992$ \\
\hline 2020 & $\mathrm{~S} / .2 .932 .992$ \\
\hline 2021 & $\mathrm{~S} / .2 .932 .992$ \\
\hline
\end{tabular}

Elaboración propia

\subsection{Presupuesto de ingresos y egresos}

\subsubsection{Presupuesto de ingreso por ventas}

El precio se fijará en base a los costos y principalmente a los precios de la oferta de mercado mediante un benchmarking de la competencia. Como se indicó en el 
capítulo II en referencia a los precios actuales y niveles del servicio actualmente los precios de los servicios de rehabilitación física de las clínicas y los centros especializados considerados como la competencia se encuentran alrededor de $\mathrm{S} / .85$ en promedio por consulta y en cuanto a las terapias el costo es de S/. 70. Para el proyecto se ha fijado un precio de S/. 100 por consulta y S/. 80 por terapia de rehabilitación puesto que se le entrega al paciente un valor agregado que se traduce en el precio. Para la evaluación del proyecto se considerará un precio constante a lo largo de su vida útil.

Un aspecto importante a tomar en cuenta para elaborar el presupuesto de ingresos por ventas son los paquetes promocionales con descuentos los cuales consisten en ofrecer pagar un determinado número de sesiones por adelantado y ser acreedor a una sesión de gracia; en este caso se otorgará una sesión de gracia por cada periodo de terapia ( 8 sesiones); es decir los pacientes serán acreedores a una sesión gratis y solo se cobrarán 7 sesiones. Se considerará para el cálculo que el 80\% de los pacientes pagarán por adelantado al ser de un grupo socioeconómico alto (NSE A) y el $20 \%$ realizará el pago normal después de cada sesión. Teniendo en cuenta esta premisa se presenta el presupuesto de ingresos por ventas.

Tabla 7.24

Presupuesto de ingresos por ventas

\begin{tabular}{|l|c|c|c|c|c|}
\hline \multicolumn{1}{|c|}{ Presupuesto de ventas } & $\mathbf{2 0 1 7}$ & $\mathbf{2 0 1 8}$ & $\mathbf{2 0 1 9}$ & $\mathbf{2 0 2 0}$ & $\mathbf{2 0 2 1}$ \\
\hline Precio por consulta & $\mathrm{S} / .100$ & $\mathrm{~S} / .100$ & $\mathrm{~S} / .100$ & $\mathrm{~S} / .100$ & $\mathrm{~S} / .100$ \\
\hline Precio por terapia & $\mathrm{S} / .80$ & $\mathrm{~S} / .80$ & $\mathrm{~S} / .80$ & $\mathrm{~S} / .80$ & $\mathrm{~S} / .80$ \\
\hline Nro consultas & 4.791 & 4.842 & 4.893 & 4.942 & 4.991 \\
\hline Nro terapias & 114.993 & 116.212 & 117.421 & 118.607 & 119.781 \\
\hline Ingreso por Ventas & S/.8.758.634 & S/.8.851.481 & S/.8.943.566 & S/.9.033.900 & S/.9.123.320 \\
\hline
\end{tabular}

Elaboración propia

\subsubsection{Presupuesto operativo de costos}

Previo a la elaboración del presupuesto operativo de los costos relacionado al servicio se debe realizar el cálculo de la depreciación de los activos fijos tangibles; los cuales serán considerados como un costo dentro de dicho presupuesto. A continuación se presentan los cuadros de la depreciación y el presupuesto operativo de costos. 
Tabla 7.25

Depreciación anual de activos fijos tangibles

\begin{tabular}{|c|c|c|c|c|c|c|c|c|c|c|}
\hline $\begin{array}{c}\text { Depreciación Activo } \\
\text { Fijo Tangible }\end{array}$ & Importe & $\begin{array}{l}\text { Vida útil } \\
\text { (años) }\end{array}$ & $\begin{array}{c}\text { Deprec. } \\
(\%)\end{array}$ & 2017 & 2018 & 2019 & 2020 & 2021 & $\begin{array}{c}\text { Depreciación } \\
\text { Total (S/.) }\end{array}$ & $\begin{array}{c}\text { Valor } \\
\text { Residual(S/.) }\end{array}$ \\
\hline Terreno & $\mathrm{S} / .6 .518 .400$ & - & $0 \%$ & - & - & 8 & - & - & - & S/. 6.518 .400 \\
\hline Edificación & $\mathrm{S} / .4 .631 .760$ & 30 & $3 \%$ & S/. 138.953 & S/. 138.953 & $\mathrm{~S} / .138 .953$ & $\mathrm{~S} / .138 .953$ & S/. 138.953 & S/. 694.764 & S/. 3.936 .996 \\
\hline Ascensor & $\mathrm{S} / .57 .497$ & 10 & $10 \%$ & $\mathrm{~S} / .5 .750$ & $\mathrm{~S} / .5 .750$ & $\mathrm{~S} / .5 .750$ & $\mathrm{~S} / .5 .750$ & $\mathrm{~S} / .5 .750$ & $\mathrm{~S} / .28 .749$ & $\mathrm{~S} / .28 .749$ \\
\hline Sistema contra incendio & $\mathrm{S} / .183 .263$ & 10 & $10 \%$ & $\mathrm{~S} / .18 .326$ & S/. 18.326 & S/. 18.326 & S/. 18.326 & $\mathrm{~S} / .18 .326$ & S/. 91.631 & $\mathrm{~S} / .91 .631$ \\
\hline Equipos del servicio & S/. 666.785 & 5 & $20 \%$ & S/. 133.357 & S/. 133.357 & $\mathrm{~S} / .133 .357$ & S/. 133.357 & $\mathrm{~S} / .133 .357$ & S/. 666.785 & $\mathrm{~S} / .0$ \\
\hline Vehículos & $\mathrm{S} / .75 .143$ & 5 & $20 \%$ & $\mathrm{~S} / .15 .029$ & $\mathrm{~S} / .15 .029$ & $\mathrm{~S} / .15 .029$ & $\mathrm{~S} / .15 .029$ & $\mathrm{~S} / .15 .029$ & S/. 75.143 & $\mathrm{~S} / .0$ \\
\hline Equipos de oficina & S/. 93.428 & 5 & $20 \%$ & S/. 18.686 & S/. 18.686 & S/. 18.686 & S/. 18.686 & S/. 18.686 & $\mathrm{~S} / .93 .428$ & $\mathrm{~S} / .0$ \\
\hline Mobiliario del servicio & $\mathrm{S} / .34 .795$ & 10 & $10 \%$ & $\mathrm{~S} / .3 .480$ & $\mathrm{~S} / .3 .480$ & $\mathrm{~S} / .3 .480$ & $\mathrm{~S} / .3 .480$ & $\mathrm{~S} / .3 .480$ & S/. 17.398 & S/. 17.398 \\
\hline Mobiliario de oficinas & $\mathrm{S} / .21 .750$ & 10 & $10 \%$ & $\mathrm{~S} / .2 .175$ & $\mathrm{~S} / .2 .175$ & $\mathrm{~S} / .2 .175$ & $\mathrm{~S} / .2 .175$ & $\mathrm{~S} / .2 .175$ & $\mathrm{~S} / .10 .875$ & $\mathrm{~S} / .10 .875$ \\
\hline Total & $\mathrm{S} / . \mathbf{1 2 . 2 8 2 . 8 2 1}$ & & & S/. 335.755 & S/. 335.755 & S/. 335.755 & S/. 335.755 & S/.335.755 & $\mathrm{S} / . \mathbf{1 . 6 7 8 . 7 7 3}$ & S/. 10.604.048 \\
\hline Depreciación fabril & & & & S/. 290.818 & S/. 290.818 & S/. 290.818 & S/. 290.818 & S/. 290.818 & $\mathrm{~S} / .1 .454 .090$ & \\
\hline Depreciación no fabril & & & & $\mathrm{S} / .44 .937$ & $\mathrm{~S} / .44 .937$ & S/. 44.937 & S/. 44.937 & S/. 44.937 & $\mathrm{~S} / .224 .683$ & \\
\hline
\end{tabular}

Elaboración propia

Tabla 7.26

Presupuesto operativo de costos

\begin{tabular}{|c|c|c|c|c|c|}
\hline Presupuesto operativo de costos & 2017 & 2018 & 2019 & 2020 & 2021 \\
\hline Materiales e Insumos & $\mathrm{S} / .495 .893$ & $\mathrm{~S} / .487 .832$ & S/. 506.170 & S/. 497.907 & S/. 516.043 \\
\hline Sueldo MOD & $\mathrm{S} / .1 .206 .000$ & $\mathrm{~S} / .1 .206 .000$ & $\mathrm{~S} / .1 .206 .000$ & $\mathrm{~S} / .1 .206 .000$ & S/. 1.206 .000 \\
\hline Sueldo MOI & $\mathrm{S} / .385 .920$ & $\mathrm{~S} / .385 .920$ & $\mathrm{~S} / .385 .920$ & $\mathrm{~S} / .385 .920$ & $\mathrm{~S} / .385 .920$ \\
\hline Servicios del servicio & S/. 140.336 & $\mathrm{~S} / .141 .661$ & S/. 142.984 & S/. 144.303 & $\mathrm{~S} / .145 .619$ \\
\hline Depreciación fabril & $\mathrm{S} / .290 .818$ & $\mathrm{~S} / .290 .818$ & S/. 290.818 & $\mathrm{~S} / .290 .818$ & S/. 290.818 \\
\hline Total & S/. 2.518.967 & $\mathrm{S} / . \mathbf{2 . 5 1 2 . 2 3 1}$ & $\mathrm{S} / . \mathbf{2 . 5 3 1 . 8 9 2}$ & S/. 2.524.947 & $\mathrm{S} / . \mathbf{2 . 5 4 4 . 4 0 0}$ \\
\hline
\end{tabular}

Elaboración propia 


\subsubsection{Presupuesto operativo de gastos administrativos}

Para presentar el presupuesto operativo de gastos administrativos se debe elaborar primero el cálculo de la amortización de los activos fijos intangibles los cuales serán considerados como gastos administrativos dentro de este presupuesto.

A continuación se presentan las tablas de la amortización y el presupuesto operativo de gastos administrativos: 
Tabla 7.27

Amortización anual de activos fijos intangibles

\begin{tabular}{|c|c|c|c|c|c|c|c|c|c|c|}
\hline $\begin{array}{c}\text { Amortización Activo Fijo } \\
\text { Intangible }\end{array}$ & $\begin{array}{l}\text { Importe } \\
(\mathrm{S} / .)\end{array}$ & $\begin{array}{l}\text { Vida útil } \\
\text { (años) }\end{array}$ & $\begin{array}{c}\text { Deprec. } \\
(\%)\end{array}$ & 2017 & 2018 & 2019 & 2020 & 2021 & $\begin{array}{l}\text { Amortización } \\
\text { Total (S/.) }\end{array}$ & $\begin{array}{c}\text { Valor } \\
\text { Residual (S/.) }\end{array}$ \\
\hline Estudios previos e Ingeniería & $\mathrm{S} / .43 .100$ & 10 & $10 \%$ & $\mathrm{~S} / .4 .310$ & $\mathrm{~S} / .4 .310$ & $\mathrm{~S} / .4 .310$ & $\mathrm{~S} / .4 .310$ & $\mathrm{~S} / .4 .310$ & $\mathrm{~S} / .21 .550$ & $\mathrm{~S} / .21 .550$ \\
\hline Constitución de la empresa & $\mathrm{S} / .1 .500$ & 10 & $10 \%$ & $\mathrm{~S} / .150$ & $\mathrm{~S} / .150$ & $\mathrm{~S} / .150$ & $\mathrm{~S} / .150$ & $\mathrm{~S} / .150$ & $\mathrm{~S} / .750$ & $\mathrm{~S} / .750$ \\
\hline Supervisión & $\mathrm{S} / .66 .000$ & 10 & $10 \%$ & $\mathrm{~S} / .6 .600$ & $\mathrm{~S} / .6 .600$ & $\mathrm{~S} / .6 .600$ & $\mathrm{~S} / .6 .600$ & $\mathrm{~S} / .6 .600$ & $\mathrm{~S} / .33 .000$ & $\mathrm{~S} / .33 .000$ \\
\hline Licencias y permisos municipales & $\mathrm{S} / .1 .154$ & 10 & $10 \%$ & $\mathrm{~S} / .115$ & $\mathrm{~S} / .115$ & $\mathrm{~S} / .115$ & $\mathrm{~S} / .115$ & $\mathrm{~S} / .115$ & $\mathrm{~S} / .577$ & $\mathrm{~S} / .577$ \\
\hline Gastos de implementación & $\mathrm{S} / .8 .000$ & 10 & $10 \%$ & $\mathrm{~S} / .800$ & $\mathrm{~S} / .800$ & $\mathrm{~S} / .800$ & $\mathrm{~S} / .800$ & $\mathrm{~S} / .800$ & $\mathrm{~S} / .4 .000$ & $\mathrm{~S} / .4 .000$ \\
\hline Certificaciones & S/. 272.899 & 10 & $10 \%$ & $\mathrm{~S} / .27 .290$ & $\mathrm{~S} / .27 .290$ & $\mathrm{~S} / .27 .290$ & $\mathrm{~S} / .27 .290$ & $\mathrm{~S} / .27 .290$ & S/. 136.450 & S/. 136.450 \\
\hline Software & $\mathrm{S} / .25 .000$ & 10 & $10 \%$ & $\mathrm{~S} / .2 .500$ & $\mathrm{~S} / .2 .500$ & $\mathrm{~S} / .2 .500$ & $\mathrm{~S} / .2 .500$ & $\mathrm{~S} / .2 .500$ & $\mathrm{~S} / .12 .500$ & $\mathrm{~S} / .12 .500$ \\
\hline Capacitación al personal & $\mathrm{S} / .3 .500$ & 10 & $10 \%$ & $\mathrm{~S} / .350$ & $\mathrm{~S} / .350$ & $\mathrm{~S} / .350$ & $\mathrm{~S} / .350$ & $\mathrm{~S} / .350$ & $\mathrm{~S} / .1 .750$ & $\mathrm{~S} / .1 .750$ \\
\hline Gastos puesta en marcha & $\mathrm{S} / .15 .000$ & 10 & $10 \%$ & $\mathrm{~S} / .1 .500$ & $\mathrm{~S} / .1 .500$ & $\mathrm{~S} / .1 .500$ & $\mathrm{~S} / .1 .500$ & $\mathrm{~S} / .1 .500$ & $\mathrm{~S} / .7 .500$ & $\mathrm{~S} / .7 .500$ \\
\hline Contingencias $(10 \%)$ & S/. 43.615 & 10 & $10 \%$ & $\mathrm{~S} / .4 .362$ & $\mathrm{~S} / .4 .362$ & $\mathrm{~S} / .4 .362$ & $\mathrm{~S} / .4 .362$ & $\mathrm{~S} / .4 .362$ & S/. 21.808 & $\mathrm{~S} / .21 .808$ \\
\hline Total & S/.479.769 & & & S/. 47.977 & S/. 47.977 & S/. 47.977 & S/. 47.977 & S/. 47.977 & S/.239.884 & S/. 239.884 \\
\hline
\end{tabular}

Elaboración propia

Tabla 7.28

Presupuesto operativo de gastos administrativos

\begin{tabular}{|c|c|c|c|c|c|}
\hline Presupuesto operativo de gastos administrativos & 2017 & 2018 & 2019 & 2020 & 2021 \\
\hline Sueldos personal administrativo & $\mathrm{S} / .1 .341 .072$ & $\mathrm{~S} / .1 .341 .072$ & $\mathrm{~S} / .1 .341 .072$ & $\mathrm{~S} / .1 .341 .072$ & $\mathrm{~S} / .1 .341 .072$ \\
\hline Servicios de oficina & $\mathrm{S} / .17 .780$ & $\mathrm{~S} / .17 .780$ & S/. 17.820 & $\mathrm{~S} / .17 .878$ & $\mathrm{~S} / .17 .937$ \\
\hline Servicios terceros & S/. 177.996 & S/. 177.996 & S/. 177.996 & S/. 177.996 & S/. 177.996 \\
\hline Depreciación no fabril & S/. 44.937 & $\mathrm{~S} / .44 .937$ & $\mathrm{~S} / .44 .937$ & S/. 44.937 & S/. 44.937 \\
\hline Amortización de intangibles & $\mathrm{S} / .47 .977$ & S/. 47.977 & S/. 47.977 & S/. 47.977 & $\mathrm{~S} / .47 .977$ \\
\hline Publicidad y promoción & S/. 50.000 & $\mathrm{~S} / .30 .000$ & $\mathrm{~S} / .30 .000$ & S/. 30.000 & $\mathrm{~S} / .30 .000$ \\
\hline Total & S/. 1.679.762 & S/. 1.659.762 & $\mathrm{S} / . \mathbf{1 . 6 5 9 . 8 0 1}$ & $\mathrm{S} / .1 .659 .860$ & S/.1.659.919 \\
\hline
\end{tabular}

Elaboración propia 


\subsection{Flujo de fondos netos}

\subsubsection{Flujo de fondos económicos}

El flujo de fondos económicos tiene la particularidad de considerar que la inversión aportada por el inversionista para el proyecto es del 100\%. A continuación se presenta el estado de resultados y el flujo de fondos económicos: 
Tabla 7.29

Estado de Resultados y Flujo de Fondos Económicos

\begin{tabular}{|c|c|c|c|c|c|c|}
\hline Estado de Resultados Económicos & Año 0 & Año 1 & Año 2 & Año 3 & Año 4 & Año 5 \\
\hline Ingreso de ventas & & $\mathrm{S} / .8 .758 .634$ & $\mathrm{~S} / .8 .851 .481$ & $\mathrm{~S} / .8 .943 .566$ & $\mathrm{~S} / .9 .033 .900$ & $\mathrm{~S} / .9 .123 .320$ \\
\hline (-) Costo de ventas & & $\mathrm{S} / .2 .518 .967$ & $\mathrm{~S} / .2 .512 .231$ & $\mathrm{~S} / .2 .531 .892$ & $\mathrm{~S} / .2 .524 .947$ & $\mathrm{~S} / .2 .544 .400$ \\
\hline Utilidad Bruta & & S/. 6.239.666 & $\mathrm{S} / .6 .339 .250$ & S/. 6.411.674 & $\mathrm{S} / .6 .508 .953$ & S/. 6.578 .920 \\
\hline (-) Gastos administrativos y ventas & & $\mathrm{S} / .1 .679 .762$ & $\mathrm{~S} / .1 .659 .762$ & $\mathrm{~S} / .1 .659 .801$ & $\mathrm{~S} / .1 .659 .860$ & $\mathrm{~S} / .1 .659 .919$ \\
\hline Utilidad Operativa & & $\mathrm{S} / .4 .559 .905$ & S/. 4.679 .488 & $\mathrm{~S} / .4 .751 .873$ & $\mathrm{~S} / .4 .849 .093$ & $\mathrm{~S} / .4 .919 .001$ \\
\hline$(+)$ Venta activos tangibles & & 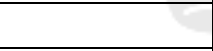 & 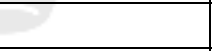 & & & $\mathrm{S} / .10 .604 .048$ \\
\hline (-) Gastos por enajenación (valor en libros) & & & & & & $\mathrm{S} / .10 .843 .933$ \\
\hline Utilidad antes impuesto y participaciones & & $\mathrm{S} / .4 .559 .905$ & $\mathrm{~S} / .4 .679 .488$ & $\mathrm{~S} / .4 .751 .873$ & $\mathrm{~S} / .4 .849 .093$ & $\mathrm{~S} / .4 .679 .117$ \\
\hline (-) Participación de trabajadores $(10 \%)$ & & $\mathrm{S} / .455 .990$ & S/. 467.949 & $\mathrm{~S} / .475 .187$ & S/. 484.909 & $\mathrm{~S} / .467 .912$ \\
\hline Utilidad antes de impuesto & & S/. 4.103.914 & $\mathrm{S} / .4 .211 .540$ & S/. 4.276 .686 & S/. 4.364.184 & S/. 4.211.205 \\
\hline (-) Impuesto a la renta $(30 \%)$ & & $\mathrm{S} / .1 .231 .174$ & S/. 1.263 .462 & $\mathrm{~S} / .1 .283 .006$ & $\mathrm{~S} / .1 .309 .255$ & $\mathrm{~S} / .1 .263 .362$ \\
\hline Utilidad antes de reserva legal & & $\mathrm{S} / .2 .872 .740$ & S/. 2.948.078 & $\mathrm{S} / .2 .993 .680$ & S/. 3.054 .929 & $\mathrm{~S} / .2 .947 .844$ \\
\hline (-) Reserva legal (10\%) & & $\mathrm{S} / .287 .274$ & S/. 294.808 & $\mathrm{~S} / .299 .368$ & $\mathrm{~S} / .305 .493$ & S/. 294.784 \\
\hline Utilidad Disponible & 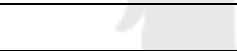 & $\mathrm{S} / .2 .585 .466$ & $\mathrm{~S} / .2 .653 .270$ & $\mathrm{~S} / .2 .694 .312$ & $\mathrm{~S} / .2 .749 .436$ & $\mathrm{~S} / .2 .653 .059$ \\
\hline \multicolumn{7}{|l|}{ 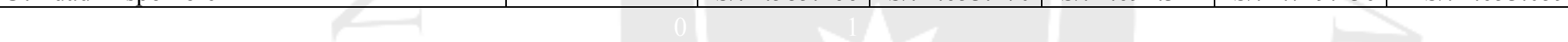 } \\
\hline Flujo de Fondos Económicos & Año 0 & Año 1 & Año 2 & Año 3 & Año 4 & Año 5 \\
\hline Utilidad antes de reserva legal & +2 & $\mathrm{~S} / .2 .872 .740$ & $\mathrm{~S} / .2 .948 .078$ & $\mathrm{~S} / .2 .993 .680$ & $\mathrm{~S} / .3 .054 .929$ & S/. 2.947.844 \\
\hline$(+)$ Depreciación de tangibles & & $\mathrm{S} / .335 .755$ & $\mathrm{~S} / .335 .755$ & $\mathrm{~S} / .335 .755$ & $\mathrm{~S} / .335 .755$ & $\mathrm{~S} / .335 .755$ \\
\hline (+) Amortización de intangibles & & S/. 47.977 & $\mathrm{~S} / .47 .977$ & S/. 47.977 & S/. 47.977 & S/. 47.977 \\
\hline (+) Gastos por enajenación (valor en libros) & & & & & & S/. 10.843 .933 \\
\hline (-) Inversión total & $\mathrm{S} / .13 .703 .839$ & & & & & \\
\hline$(+)$ Capital de trabajo & & & & & 3 & $\mathrm{~S} / .941 .249$ \\
\hline Total & $-\mathrm{S} / . \mathbf{1 3 . 7 0 3 . 8 3 9}$ & $\mathrm{S} / . \mathbf{3 . 2 5 6 . 4 7 1}$ & $\mathrm{S} / . \mathbf{3 . 3 3 1 . 8 0 9}$ & $\mathrm{S} / . \mathbf{3 . 3 7 7 . 4 1 2}$ & $\mathrm{S} / . \mathbf{3 . 4 3 8 . 6 6 0}$ & $\mathrm{S} / . \mathbf{1 5 . 1 1 6 . 7 5 7}$ \\
\hline
\end{tabular}

Elaboración propia

$(7)$




\subsubsection{Flujo de fondos financieros}

Como se mencionó anteriormente el proyecto será financiado en parte por COFIDE mediante el programa multisectorial de inversión PROBID el cual fija una tasa efectiva anual TEA del $11,27 \%$, financiado a 5 años por un monto del $65 \%$ de la inversión; es decir S/. 8.907.495. Se ha considerado el pago en una cuota fija anual de S/. 2.426.495.

Tabla 7.30

Plan de cuotas

\begin{tabular}{|c|c|c|c|c|}
\hline Años & Amortización & Interés & Cuota & Principal \\
\hline 0 & & & & S/. 8.907.495 \\
\hline 1 & $\mathrm{~S} / .1 .422 .620$ & $\mathrm{~S} / .1 .003 .875$ & $\mathrm{~S} / .2 .426 .495$ & $\mathrm{~S} / .7 .484 .875$ \\
\hline 2 & $\mathrm{~S} / .1 .582 .949$ & $\mathrm{~S} / .843 .545$ & $\mathrm{~S} / .2 .426 .495$ & $\mathrm{~S} / .5 .901 .926$ \\
\hline 3 & $\mathrm{~S} / .1 .761 .348$ & $\mathrm{~S} / .665 .147$ & $\mathrm{~S} / .2 .426 .495$ & $\mathrm{~S} / .4 .140 .578$ \\
\hline 4 & $\mathrm{~S} / .1 .959 .852$ & $\mathrm{~S} / .466 .643$ & $\mathrm{~S} / .2 .426 .495$ & $\mathrm{~S} / .2 .180 .727$ \\
\hline 5 & $\mathrm{~S} / .2 .180 .727$ & $\mathrm{~S} / .245 .768$ & $\mathrm{~S} / .2 .426 .495$ & $\mathrm{~S} / .0$ \\
\hline
\end{tabular}

Fuente: COFIDE

Elaboración propia

A continuación se presenta el estado de resultados y el flujo de fondos financieros: 
Tabla 7.31

Estado de Resultados y Flujo de Fondos Financieros

\begin{tabular}{|c|c|c|c|c|c|c|}
\hline Estado de Resultados Financieros & Año 0 & Año 1 & Año 2 & Año 3 & Año 4 & Año 5 \\
\hline Ingreso de ventas & & $\mathrm{S} / .8 .758 .634$ & $\mathrm{~S} / .8 .851 .481$ & S/. 8.943.566 & $\mathrm{S} / .9 .033 .900$ & $\mathrm{~S} / .9 .123 .320$ \\
\hline (-) Costo de ventas & & $\mathrm{S} / .2 .518 .967$ & $\mathrm{~S} / .2 .512 .231$ & $\mathrm{~S} / .2 .531 .892$ & $\mathrm{~S} / .2 .524 .947$ & $\mathrm{~S} / .2 .544 .400$ \\
\hline Utilidad Bruta & & $\mathrm{S} / .6 .239 .666$ & $\mathrm{~S} / .6 .339 .250$ & S/. 6.411.674 & $\mathrm{S} / .6 .508 .953$ & S/. 6.578 .920 \\
\hline (-) Gastos administrativos y ventas & & $\mathrm{S} / .1 .679 .762$ & $\mathrm{~S} / .1 .659 .762$ & $\mathrm{~S} / .1 .659 .801$ & $\mathrm{~S} / .1 .659 .860$ & S/. 1.659.919 \\
\hline Utilidad Operativa & & $\mathrm{S} / .4 .559 .905$ & $\mathrm{~S} / .4 .679 .488$ & $\mathrm{~S} / .4 .751 .873$ & $\mathrm{~S} / .4 .849 .093$ & $\mathrm{~S} / .4 .919 .001$ \\
\hline (-) Gastos Financieros & & $\mathrm{S} / .1 .003 .875$ & S/. 843.545 & S/. 665.147 & S/. 466.643 & S/. 245.768 \\
\hline$(+)$ Venta activos tangibles & & & & & & S/. 10.604 .048 \\
\hline (-) Gastos por enajenación (valor en libros) & & & 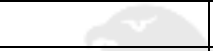 & & & $\mathrm{S} / .10 .843 .933$ \\
\hline Utilidad antes impuesto y participaciones & & $\mathrm{S} / .3 .556 .030$ & $\mathrm{~S} / .3 .835 .943$ & $\mathrm{~S} / .4 .086 .726$ & $\mathrm{~S} / .4 .382 .450$ & $\mathrm{~S} / .4 .433 .349$ \\
\hline (-) Participación de trabajadores $(10 \%)$ & & $\mathrm{S} / .355 .603$ & S/. 383.594 & S/. 408.673 & $\mathrm{~S} / .438 .245$ & $\mathrm{~S} / .443 .335$ \\
\hline Utilidad antes de impuesto & & S/. 3.200 .427 & $\mathrm{~S} / .3 .452 .349$ & S/. 3.678.054 & $\mathrm{S} / .3 .944 .205$ & S/. 3.990.014 \\
\hline$(-)$ Impuesto a la renta $(30 \%)$ & & S/. 960.128 & $\mathrm{~S} / .1 .035 .705$ & $\mathrm{~S} / .1 .103 .416$ & $\mathrm{~S} / .1 .183 .261$ & S/. 1.197.004 \\
\hline Utilidad antes de reserva legal & & $\mathrm{S} / .2 .240 .299$ & $\mathrm{~S} / .2 .416 .644$ & $\mathrm{~S} / .2 .574 .637$ & $\mathrm{~S} / .2 .760 .943$ & $\mathrm{~S} / .2 .793 .010$ \\
\hline (-) Reserva legal $(10 \%)$ & 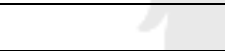 & $\mathrm{S} / .224 .030$ & S/. 241.664 & S/. 257.464 & $\mathrm{~S} / .276 .094$ & S/. 279.301 \\
\hline Utilidad Disponible & & S/. 2.016.269 & $\mathrm{S} / .2 .174 .980$ & $\mathrm{~S} / .2 .317 .174$ & $\mathrm{~S} / .2 .484 .849$ & $\mathrm{~S} / .2 .513 .709$ \\
\hline Flujo de Fondos Financieros & Año 0 & Año 1 & Año 2 & Año 3 & Año 4 & Año 5 \\
\hline Utilidad antes de reserva legal & & $\mathrm{S} / .2 .240 .299$ & $\mathrm{~S} / .2 .416 .644$ & $\mathrm{~S} / .2 .574 .637$ & $\mathrm{~S} / .2 .760 .943$ & $\mathrm{~S} / .2 .793 .010$ \\
\hline$(+)$ Depreciación de tangibles & & S/. 335.755 & S/. 335.755 & S/. 335.755 & S/. 335.755 & S/. 335.755 \\
\hline$(+)$ Amortización de intangibles & & S/. 47.977 & $\mathrm{~S} / .47 .977$ & $\mathrm{~S} / .47 .977$ & S/. 47.977 & $\mathrm{~S} / .47 .977$ \\
\hline (+) Gastos por enajenación (valor en libros) & & & (2) & & & $\mathrm{S} / .10 .843 .933$ \\
\hline (-) Amortización préstamo COFIDE & & $\mathrm{S} / .1 .422 .620$ & $\mathrm{~S} / .1 .582 .949$ & $\mathrm{~S} / .1 .761 .348$ & $\mathrm{~S} / .1 .959 .852$ & S/. 2.180.727 \\
\hline (-) Inversión total & $\mathrm{S} / .13 .703 .839$ & & & & & \\
\hline$(+)$ Financiamiento & S/. 8.907.495 & & & & $\mathrm{C}$ & \\
\hline$(+)$ Capital de trabajo & 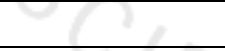 & & & +2 & & S/. 941.249 \\
\hline Total & $-\mathrm{S} / . \mathbf{4 . 7 9 6 . 3 4 4}$ & $\mathrm{S} / .1 .201 .410$ & S/. 1.217.426 & $\mathrm{S} / . \mathbf{1 . 1 9 7 . 0 2 1}$ & $\mathrm{S} / . \mathbf{1 . 1 8 4 . 8 2 3}$ & S/. 12.781.196 \\
\hline
\end{tabular}

Elaboración propia 


\section{CAPÍTULO VIII: EVALUACIÓN ECONÓMICA Y FINANCIERA DEL PROYECTO}

En este capítulo se determinará si el proyecto es factible en su implementación tanto económica como financieramente.

\subsection{Evaluación económica: VAN, TIR, B/C, PR}

Para la evaluación económica se tendrá como tasa de descuento para trasladar los flujos al presente el costo de oportunidad del accionista (COK) que se calculará mediante la siguiente fórmula:

$$
C O K=R f+\beta(R m-R f)+R \cdot p a i ́ s
$$

Donde la $\mathrm{Rf}$ es la tasa libre de riesgo, $\mathrm{Rm}$ la tasa riesgo de mercado, $\beta$ el coeficiente de riesgo del sector $(\beta)$ y R.país el grado de riesgo para las inversiones extranjeras llamado Riesgo País.

Según los estudios económicos del Scotiabank la tasa libre de riesgo para el Perú en el año 2015 es de 5,79\% y la tasa de riesgo de mercado es de 13,88\% según el índice bursátil Standard \& Poor's 500 considerado el índice más representativo de la situación real de mercado. Por otro lado, el índice Riesgo país a junio del 2015 es de 1,75 puntos porcentuales calculado por el banco de inversión JP Morgan.

Finalmente se tomará el valor de riesgo del sector Beta en base a la información recabada de la Escuela de Negocios de la Universidad de New York donde el factor de riesgo para el sector de Servicios de Soporte de Salud es de 1,05. Luego de realizar los cálculos según la fórmula del costo de oportunidad del inversionista el valor COK resulta $16,03 \%$. 
Tabla 8.1

Costo de Oportunidad del Inversionista (COK)

\begin{tabular}{|l|c|}
\hline \multicolumn{2}{|c|}{$\begin{array}{c}\text { Costo de oportunidad del inversionista } \\
\text { (COK) }\end{array}$} \\
\hline Tasa libre de riesgo & $5,79 \%$ \\
\hline Riesgo del sector $(\beta)$ & 1,05 \\
\hline Tasa de riesgo de mercado & $13,88 \%$ \\
\hline Riesgo país & $1,75 \%$ \\
\hline COK & $\mathbf{1 6 , 0 3 \%}$ \\
\hline
\end{tabular}

Fuente: Scotiabank - JP Morgan - S\&P 500 - NYU

Elaboración propia

Con esta tasa de descuento se procederá a realizar la evaluación económica hallando el Valor Actual Neto (VAN), la Tasa Interna de Retorno (TIR) el indicador Beneficio Costo (B/C) y el Periodo de Recupero (PR)

Tabla 8.2

Valores de la Evaluación Económica

\begin{tabular}{|l|c|}
\hline VAN $(16.03 \%)$ & S/. 2.822.544 \\
\hline TIR & $22,55 \%$ \\
\hline B/C (16.03\%) & 1,21 \\
\hline PR & 4 años, 7 meses \\
\hline
\end{tabular}

Elaboración propia

\subsection{Evaluación financiera: VAN, TIR, B/C, PR}

Respecto a la evaluación financiera; ésta tomará como tasa de descuento el Costo Promedio Ponderado de Capital (CPPC) el cual se obtiene realizando la ponderación de las fuentes de financiamiento con sus respectivas tasas de rentabilidad. A continuación se presenta el cálculo del Costo Promedio Ponderado de Capital (CPPC). 
Tabla 8.3

Costo Promedio Ponderado de Capital (CPPC)

\begin{tabular}{|l|c|c|c|}
\hline Fuente de Financiamiento & Monto & \% Part. & Tasa (\%) \\
\hline Propia & S/. 4,796,344 & $35 \%$ & $16.03 \%$ \\
\hline COFIDE & S/. 8,907,495 & $65 \%$ & $11.27 \%$ \\
\hline Total & S/. 13,703,839 & $100 \%$ & - \\
\cline { 2 - 4 } & CPPC & $\mathbf{1 2 . 9 4 \%}$ \\
\hline
\end{tabular}

Elaboración propia

Con el CPPC se procederá a realizar la evaluación financiera hallando el Valor Actual Neto (VAN), la Tasa Interna de Retorno (TIR) el indicador Beneficio Costo (B/C) y el Periodo de Recupero (PR)

Tabla 8.4

Valores de la Evaluación Financiera

\begin{tabular}{|l|c|}
\hline VAN (12,94\%) & S/. 5.737.486 \\
\hline TIR & $38,39 \%$ \\
\hline B/C (12,94\%) & 2,20 \\
\hline PR & 4 años, 2 meses \\
\hline
\end{tabular}

Elaboración propia

\subsection{Análisis de los resultados económicos y financieros del proyecto}

En relación a los resultados económicos el Valor Actual Neto (VAN) es de S/. 2.822.544 por lo que se considera que la rentabilidad en valores monetarios supera la rentabilidad deseada cubriendo la inversión inicial y los costos. La Tasa Interna de Retorno (TIR) es de $22,55 \%$ la cual es mayor que el costo de oportunidad del accionista (COK) 16,03\%. El indicador Beneficio Costo (B/C) es de 1,21 por lo que se acepta el proyecto ya que dicho indicador es mayor a 1 y el tiempo en que se recupera la inversión incluyendo el costo de capital involucrado es de 4 años y 7 meses. En conclusión, el proyecto según la evaluación económica es factible.

Los resultados financieros también son favorables; esto se explica porque el Valor Actual Neto (VAN) es de S/. 5.737.486, la Tasa Interna de Retorno (TIR) es de 
38,39\% excediendo al Costo Promedio Ponderado de Capital (CPPC) el cual es de 12,94\%. El indicador Beneficio Costo (B/C) es de 2,20 el cual excede en 1,20 puntos al valor requerido para aceptar el proyecto y el Periodo de Recupero (PR) es de 4 años y 2 meses.

Finalmente se determina que el proyecto será financiado ya que el Valor Actual Neto Financiero (S/. 5.737.486) es mayor que el Valor Actual Neto Económico (S/. 2.822.544), la Tasa Interna de Retorno Financiera $(38,39 \%)$ es mayor que la Tasa Interna de Retorno Económica (22,55\%), el indicador Beneficio Costo Financiero $(2,20)$ también es mayor que el Económico $(1,21)$ y el Periodo de Recupero Financiero (4 años y 2 meses) es menor que el Periodo de Recupero Económico el cual asciende a 4 años y 7 meses.

\subsection{Análisis de sensibilidad del proyecto}

El análisis de sensibilidad del proyecto se lleva a cabo con la finalidad de determinar el riesgo no considerado dentro del estudio de viabilidad. En este análisis se simulan posibles escenarios que afectan la rentabilidad del proyecto a través del tiempo cuando las variables o condiciones económicas cambian drásticamente.

Los escenarios que se analizarán están en función a la variación de las condiciones más críticas que en nuestro caso será la variación de la demanda de mercado. Para esto se considerarán 3 posibles escenarios los cuales se presentan a continuación:

- Escenario Pesimista: La demanda del proyecto disminuye en un $20 \%$

- Escenario Esperado: Es la situación real del proyecto

- Escenario Optimista: La demanda del proyecto aumenta en un $20 \%$ 
Luego de realizar los cálculos necesarios dentro de los flujos tanto económicos como financieros para hallar los indicadores de cada evaluación, se presentan los resultados de cada escenario en la siguiente tabla:

Tabla 8.5

Análisis de Sensibilidad

\begin{tabular}{|c|c|c|c|c|c|}
\hline \multicolumn{2}{|c|}{ ESCENARIO PESIMISTA } & \multicolumn{2}{|c|}{ ESCENARIO ESPERADO } & \multicolumn{2}{|c|}{ ESCENARIO OPTIMISTA } \\
\hline \multicolumn{2}{|c|}{ Demanda disminuye en $20 \%$} & \multicolumn{2}{|c|}{ Demanda del proyecto } & \multicolumn{2}{|c|}{ Demanda aumenta en $20 \%$} \\
\hline \multicolumn{2}{|c|}{ EVALUACION ECONOMICA } & \multicolumn{2}{|c|}{ EVALUACION ECONOMICA } & \multicolumn{2}{|c|}{ EVALUACION ECONOMICA } \\
\hline VAN $(16,03 \%)$ & $-\mathrm{S} / .637 .387$ & VAN $(16,03 \%)$ & $\mathrm{S} / .2 .822 .544$ & VAN $(16,03 \%)$ & S/. 6.282 .475 \\
\hline TIR & $14,55 \%$ & TIR & $22,55 \%$ & TIR & $30,45 \%$ \\
\hline B/C $(16,03 \%)$ & 0,95 & $\mathrm{~B} / \mathrm{C}(16,03 \%)$ & 1,21 & B/C $(16,03 \%)$ & 1,46 \\
\hline PR & No se recupera & PR & 4 años, 7 meses & PR & 4 años, 2 meses \\
\hline \multicolumn{2}{|l|}{ 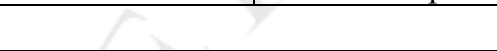 } & \multicolumn{2}{|l|}{ 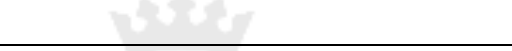 } & \multicolumn{2}{|l|}{$y$} \\
\hline \multicolumn{2}{|c|}{ EVALUACION FINANCIERA } & \multicolumn{2}{|c|}{ EVALUACION FINANCIERA } & \multicolumn{2}{|c|}{ EVALUACION FINANCIERA } \\
\hline VAN $(12,94 \%)$ & $\mathrm{S} / .2 .005 .305$ & VAN $(12,94 \%)$ & S/. 5.737.486 & VAN $(12,94 \%)$ & S/. 9.469.666 \\
\hline TIR & $21,48 \%$ & TIR & $38,39 \%$ & TIR & $56,47 \%$ \\
\hline B/C $(12,94 \%)$ & 1,42 & B/C $(12,94 \%)$ & 2,20 & B/C $(12,94 \%)$ & 2,97 \\
\hline PR & 4 años, 8 meses & PR & 4 años, 2 meses & PR & 2 años, 8 meses \\
\hline
\end{tabular}

Elaboración propia

Figura 8.1

Variación del Valor Actual Neto (VAN) en los distintos escenarios

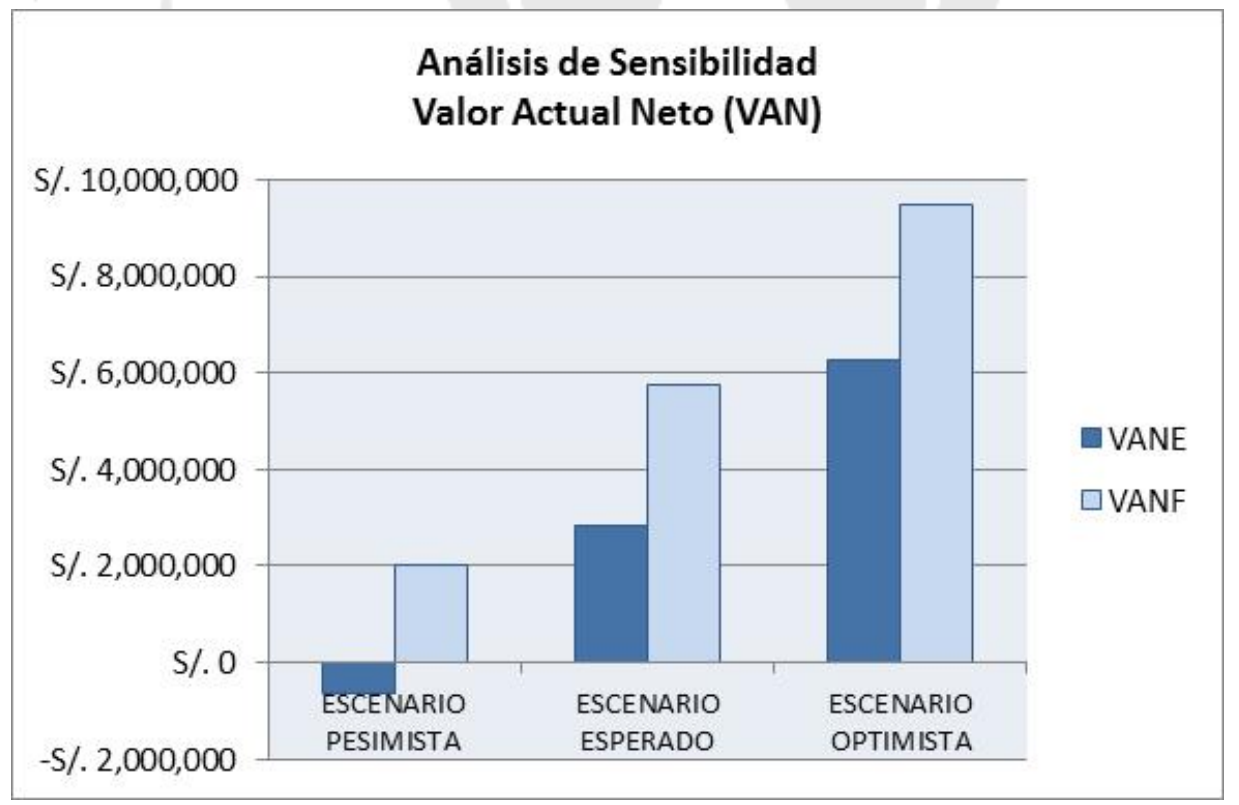

Elaboración propia 
Figura 8.2

Variación de la Tasa Interna de Retorno Económica (TIRE)

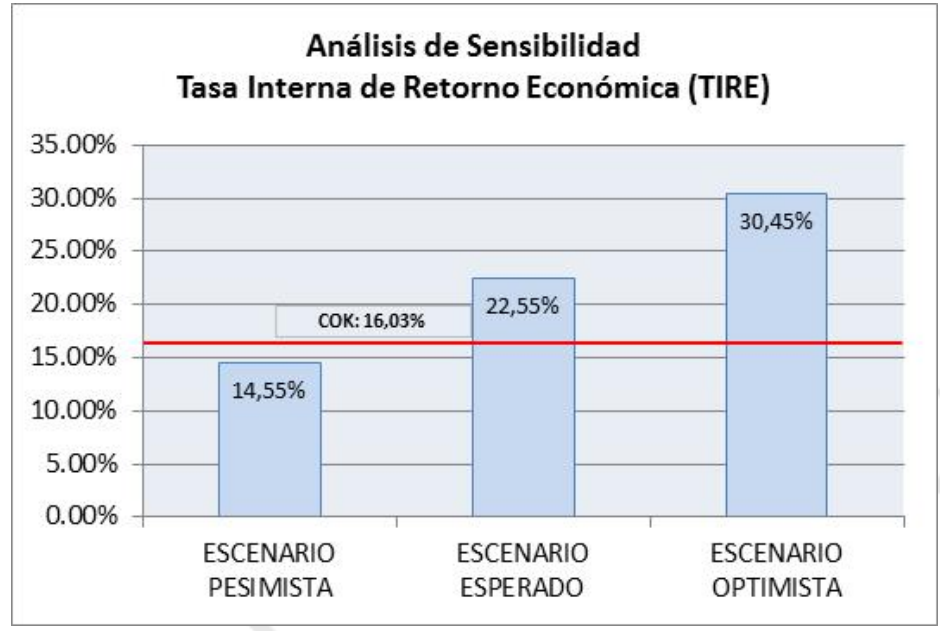

Elaboración propia

Figura 8.3

Variación de la Tasa Interna de Retorno Financiera (TIRF)

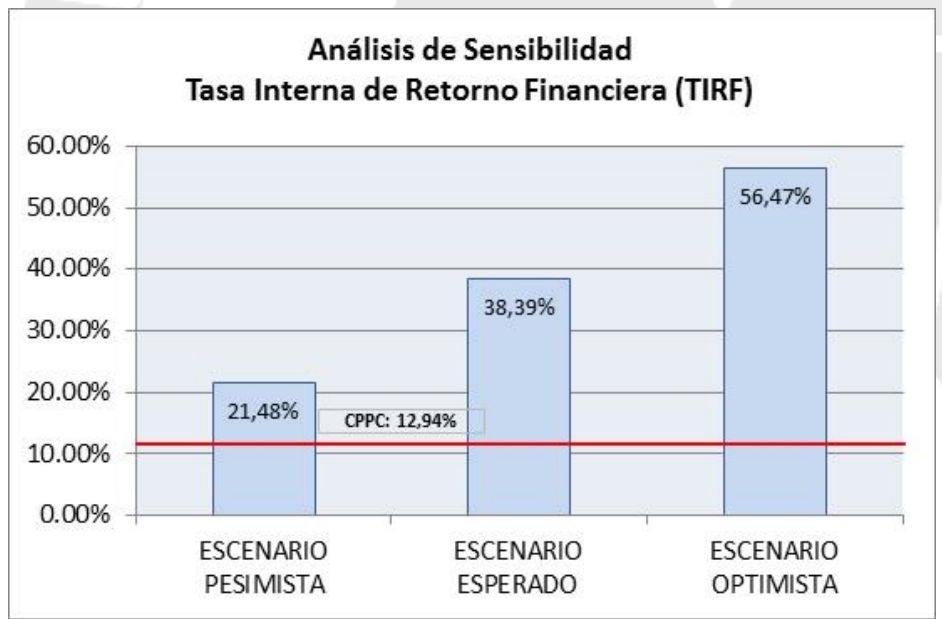

Elaboración propia

En un Escenario Pesimista donde la demanda disminuye en un $20 \%$ el proyecto no sería aceptado ya que los indicadores de la evaluación económica no son favorables presentando un VAN negativo (-S/. 637.387), una Tasa Interna de Retorno menor a la rentabilidad esperada del accionista $(14,55 \%<\mathrm{COK}: 16,03 \%)$ un indicador Beneficio Costo menor a $1(0,95)$ y la no recuperación de la inversión. Sin embargo, según la evaluación financiera el proyecto sería todavía rentable si se financia. 
El escenario esperado es el ya analizado en el acápite anterior sobre los análisis de los resultados económicos y financieros dando como resultado la aceptación del proyecto con resultados rentables.

En un escenario Optimista donde la demanda para el proyecto aumenta en un $20 \%$ el proyecto sigue siendo rentable tanto en su evaluación económica como financiera sobresaliendo los indicadores de la evaluación financiera la cual arroja un VAN de S/. 9.469.666, una TIR de 56,47\%, un indicador B/C de 2,97 y un periodo de recupero de 2 años y 8 meses. 


\section{Capítulo IX: Evaluación social del proyecto}

\subsection{Identificación de las zonas y comunidades de influencia del proyecto}

La zona de influencia del proyecto comprende el espacio del territorio donde se ubicarán las instalaciones del centro y las zonas aledañas a éste, que en este caso será el distrito de San Borja en la ciudad de Lima.

Respecto a las comunidades que se verán influenciadas por el desarrollo del proyecto destaca en primer lugar los vecinos cuyas viviendas se ubican en las zonas aledañas al centro, en segundo lugar los adultos mayores que sean clientes del centro y los familiares de éstos y finalmente todo el personal que laborará en la empresa.

Figura 9.1

Zona de influencia: Distrito de San Borja

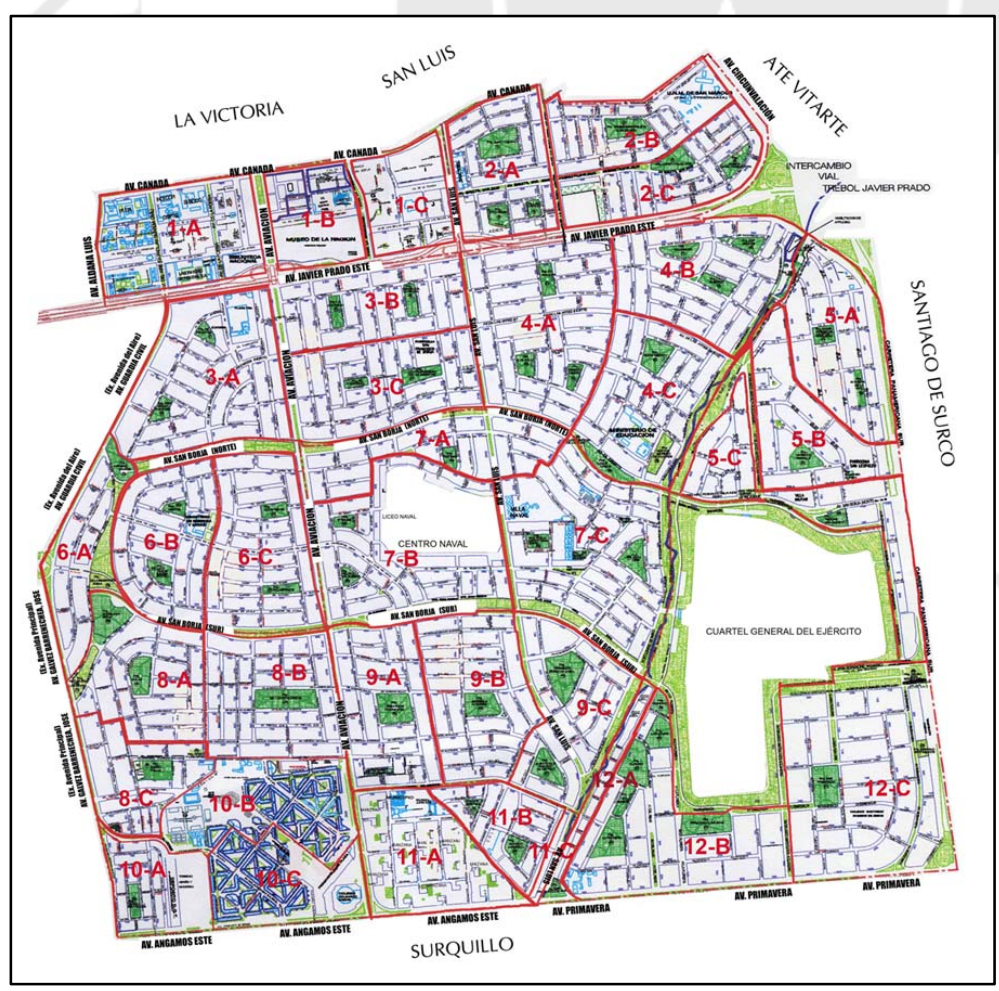

Fuente: Lic. Luis Pérez 


\subsection{Impacto en la zona de influencia}

Tal y como se ha comentado anteriormente, las instalaciones donde se llevarán a cabo los servicios de rehabilitación física serán ecoeficientes y por ello el impacto de éstas sobre el medio ambiente y sus habitantes será mínimo. Esto gracias a la eficiencia en el uso de los recursos necesarios para prestación de los servicios, utilización de materiales de construcción y equipos con bajo contenido y consumo energético, aprovechamiento de energía renovable, manejo de residuos y tratamiento de aguas, entre otras actividades. Sin embargo, cuando los estacionamientos se encuentren llenos $\mathrm{y}$ genere que los clientes, personal del centro y proveedores se estacionen en los alrededores de las instalaciones del centro, podría originar molestias en los vecinos y contribuir en la generación de tráfico vehicular.

\subsection{Impacto social del proyecto}

El impacto social del presente proyecto se ve reflejado en diferentes aspectos que a continuación se detallan:

- Satisfacción de las necesidades de la sociedad mediante la prestación de servicios de fisioterapia, enfocado al segmento de los adultos mayores del nivel socioeconómico "A".

- Generación de empleos por contratación de personal para el centro y tercerización de servicios.

- Contribución a la sostenibilidad y minimización del impacto ambiental de la zona de influencia del proyecto en beneficio de las futuras generaciones.

- Fomento entre clientes y sus familiares, así como entre el personal del centro, en la aplicación de actividades ecoeficientes en el ámbito doméstico.

Desde la perspectiva social se puede evaluar el impacto del proyecto mediante los indicadores de Densidad de Capital, Intensidad de Capital, Relación Producto 
Capital y Productividad de la mano de obra en base al valor agregado que se genera en beneficio de la sociedad.

Se utilizará la tasa social de descuento aprobada por la Resolución Directoral del Ministerio de Economía y Finanzas $\mathrm{N}^{\circ}$ 006-2012-EF/63.01 donde se establecen disposiciones especiales para proyectos de inversión pública que incluyen el establecimiento de una Tasa Social de Descuento de 9\% sin distinguir el corto del largo plazo.

Tabla 9.1

Indicadores de Evaluación Social

\begin{tabular}{|l|c|}
\hline Densidad de Capital & S/.279.670 \\
\hline Intensidad de Capital & 0,46 \\
\hline Relación Producto-Capital & 2,16 \\
\hline Productividad de mano de obra & S/. 182.493 \\
\hline
\end{tabular}

Elaboración propia

El indicador de Densidad de Capital muestra como la inversión influye en la generación de empleos y en este caso indica que por cada S/. 279.670 invertidos se genera un empleo y la Intensidad de capital permite visualizar el tamaño del valor agregado que se genera en el servicio siendo este de 0,46 veces. Por otro lado, la Relación producto-capital mide la relación entre el valor agregado generado y la inversión total la cual es de 2,16 veces y la Productividad de mano de obra es la relación entre las ventas del servicio y el número de trabajadores lo cual indica que se genera S/. 182.493 por cada trabajador. 


\section{CONCLUSIONES}

- Se demuestra la viabilidad técnica, económica y de mercado para la instalación de un centro ecoeficiente de fisioterapia dirigido al adulto mayor en la ciudad de Lima, que contribuye a mejorar la calidad de vida de dichas personas y a la vez favorece a la sostenibilidad del medio ambiente.

- El alto estándar de calidad en los servicios de fisioterapia, la especialización en el adulto mayor y la implementación de un plan de manejo ambiental basado en la ecoeficiencia, generará que el centro se diferencie de sus competidores y se atienda a aquella población de adultos mayores con enfermedades músculo-esqueléticas inherentes de su edad y que se encuentra insatisfecha con los actuales niveles de servicio que ofrece el mercado.

- La población del adulto mayor para los servicios de fisioterapia es la más atractiva debido a que dicha población se encuentra en pleno crecimiento, representan un mercado más fiel y constante por la recurrencia de las enfermedades músculoesqueléticas y son más propensos a sufrir lesiones físicas por su misma edad.

- El estudio de mercado determinó una demanda para el proyecto de 4.690 adultos mayores traducidas en 112.560 sesiones para el año 2015 por lo que se garantiza la viabilidad de mercado y puesta en marcha del proyecto.

- El centro de rehabilitación física se construirá en el distrito de San Borja el cual brinda la mejor ubicación en cuanto a la cercanía al mercado y los servicios básicos y principalmente las condiciones de vida relacionadas a sus políticas medioambientales propicias para la implementación del proyecto. 
- Se determinó el requerimiento tanto del personal de atención al cliente como del personal administrativo y de soporte interno del servicio el cual asciende a 49 colaboradores.

- Se implementó un sistema ambiental de ecoeficiencia empresarial basado en las buenas prácticas para el uso eficiente de los recursos que permitirá su ahorro y a la vez contribuirá con la sostenibilidad del medio ambiente lo que generará maximizar la rentabilidad como empresa.

- Actualmente al existir una arraigada y creciente preocupación por el medio ambiente y la ecología, las empresas están adoptando compromisos medio ambientales que contribuyen al desarrollo sostenible y mitigación del impacto ambiental en su área de influencia. Es por ello que el presente proyecto buscará generar conciencia ambiental entre los pacientes, sus familiares y público en general respecto a estos temas y se visualice al centro de fisioterapia como un referente en su sector.

- A través del traslado de los adultos mayores con lesiones graves desde sus domicilios hacia el centro y del otorgamiento de sesiones gratis por pago anticipado de terapias, se brinda un valor agregado a los pacientes del centro.

- La inversión total para el proyecto asciende a S/.13.703.839 siendo viable económicamente tal como lo demuestran los resultados financieros arrojando un Valor Actual Neto de S/. 5.737.486, una Tasa Interna de Retorno de 38,39\% mayor al CPPC (12,94\%), un indicador Beneficio Costo de 2,20 y un Periodo de Recupero de 4 años y 2 meses. 


\section{RECOMENDACIONES}

- Evaluar la generación de estrategias de fidelización de clientes dirigidas a los familiares de los pacientes del centro a fin de evitar que estos se vean influenciados por estrategias de marketing de las empresas competidoras.

- Firmar acuerdos de confidencialidad con los diferentes proveedores que suministren equipos y servicios relacionados al plan de manejo ambiental que el centro implementará a fin de evitar que otras empresas competidoras los puedan implementar fácilmente.

- Crear la marca del centro de fisioterapia en base a un concepto que sea fácilmente identificado por los clientes y público en general.

- Obtener el acceso al nuevo sistema de historias clínicas del Perú a partir del 2016, año de su implementación en aras de realizar una mejor atención al paciente, ahorrando tiempos en el procedimiento de búsqueda de documentos y a la vez reduciendo el consumo de papel garantizando el cuidado del medio ambiente.

- Evaluar la posibilidad de crear nuevos servicios con aplicaciones terapéuticas relacionadas a las actividades que realizan los adultos mayores como es el arte marcial Taichi.

- Evaluar la creación de sucursales del centro de fisioterapia en otros distritos de Lima a fin de buscar tener acceso a más clientes.

- Adquirir más móviles para el traslado de los adultos mayores con lesiones graves desde sus domicilios hacia el centro cuando se identifique un aumento del servicio de movilidad entre los clientes del centro. 
- Actualizar periódicamente la información referente a nuevas tecnologías en los equipos y materiales utilizados para la prestación de servicios de fisioterapia, con el fin de evaluar la renovación de los mismos y mejorar así la calidad de los servicios que el centro prestará. 


\section{REFERENCIAS}

AE Energy. (2015). Recuperado de http://www.aeenergy.com.pe/servicios/ahorro-deenergia/uso-de-gas-en-aplicaciones-electricas/

Apliaqua. (2015). Recuperado de http://depuraciondelagua.com/aguas-grises

Arellano, R. (29 de setiembre de 2010). Sección Negocios. El Comercio. Recuperado de http://www.elcomercio.pe

Asociación de Clínicas Particulares del Perú. (2015). Asociados. Recuperado de http://www.acp.org.pe/asociados

Austermühle, S. (2012). Sostenibilidad y ecoeficiencia en la empresa moderna. 1era ed. Lima, Universidad Peruana de Ciencias Aplicadas (UPC).

Body Healing Fisioterapia (2014). Recuperado de http://bodyhealing.com.mx/es/ servicios/fisioterapia.html

Brick7 (2015). Recuperado de http://venta.brick7.com.pe/Tachos+De+Plasticos+Lima

Calidda Gas Natural del Perú. (2014). Pliego tarifario del servicio de distribución de gas natural. Recuperado de http://www.calidda.com.pe/descarga/pliego_tarifario/ Pliego_tarifario_julio_2015.pdf

Cámara Peruana de la Construcción (CAPECO). (2014). Costos y Presupuestos en Edificación.

Clínica de Fisioterapia Sabinci. (2015). Recuperado de http://www.clinicasabinci.com/ cama-traccion.php

Clínica Mejórate. (2015). Recuperado de http://www.clinicamejorate.com/blog/

Corporación Financiera de Desarrollo (COFIDE). (2015). Tasas de interés y comisiones a las instituciones financieras intermediarias de los programas y líneas de financiamiento de Cofide. Recuperado de http://www.cofide.com.pe

CYPE Ingenieros. (2015). Generador de Precios Perú. Software para arquitectura, ingeniería y construcción. Recuperado de http://www.peru.generadordeprecios. info/obra_nueva/Instalaciones/Transporte/Ascensores/Ascensor_para_personas. html

De la Quintana, J. (9 marzo de 2015). Especial Salud. Suplemento Día 1. Diario El Comercio, Lima.

Díaz, B., Jarufe, B., y Noriega, M. (2007). Disposición de Planta. 2da ed. Lima. Fondo Editorial Universidad de Lima. 
Doctoralia. (2015). Clínicas de Medicina Física y Rehabilitación. Recuperado de http://www.doctoralia.pe/centros-medicos/especialidad/medicina+fisica $+\mathrm{y}+$ rehabilitacion-2673

Empresas ecoeficientes son el nuevo enfoque de productividad. (2013). Empresas y Negocios. Año 12, N 564. Pág. 23.

Entorno Accesible. (2015). Recuperado de http://www.entornoaccesible.es/productos-yservicios/piscinas-y-spas-accesibles/piscinas-terapeuticas/

Erenovable (2015). Recuperado de http://erenovable.com./paneles-solares-refrigeracion

Escuela de Medicina Pontificia Universidad Católica de Chile. (Marzo, 2014). Algunos Cambios Asociados al envejecimiento. Boletín Vol. 29, Nro. 1-2. Departamento de Medicina Interna. Recuperado de http://escuela.med.puc.cl/publ/boletin/ geriatria/algunoscambios.html.

Escuela Europea de Negocios. (2014). Recuperado de http://www.een.edu/blog/elciclo-de-deming-y-como-aplicarlo-en-una-pyme.html

Fisaude, tienda de salud. (2015). Material de Fisioterapia. Recuperado de http://tienda.fisaude.com/fisioterapia-c-334.html

Ford. (2015). Recuperado de http://es.ford.com/trucks/transitconnect/trim/vanxlt/

Garrido, J. (9 mayo de 2014). El Cliente. Personas claves en una compra. Diario Peru21, Lima.

Gutiérrez V. (2012). La ecoeficiencia y su impacto en el medio ambiente. Revista PAIDEIA XXI. Vol. 2, N³.

Hospital con Alma Pablo Tobón Uribe (2015). Recuperado de http://www.hptu.org.co/ $\mathrm{hptu} /$ nosotros/324-codigo-de-colores-recipientes.html

Infotec. (2014). Venta de computadoras. Recuperado de http://www.infotec.com.pe

Instituto de Biomecánica de Valencia. (2007). Manual para la prevención de riesgos ergonómicos y psicosociales en los centros de atención a personas en situación de dependencia. Recuperado de http://ciapat.org/biblioteca/pdf

Instituto Nacional de Defensa de la Competencia y de la Protección de la Propiedad Intelectual (INDECOPI). (2004). Norma Técnica Peruana NTP 399.010-1 Señales de Seguridad. Colores, símbolos, formas y dimensiones de señales de seguridad. Lima Perú.

Instituto Nacional de Defensa de la Competencia y de la Protección de la Propiedad Intelectual (INDECOPI). (2005). Norma Técnica Peruana NTP 900.058. Comisión de Reglamentos Técnicos y Comerciales. Lima, Perú. Recuperado de http://www.epsgrau.com.pe/archivos/NTP 
Instituto Nacional de Defensa de la Competencia y de la Protección de la Propiedad Intelectual (INDECOPI). (2011). Norma Técnica Peruana NTP 350.043-1 Extintores Portátiles. Selección, distribución, inspección, mantenimiento, recarga y prueba hidrostática. Extintores de agentes halógenos. Lima Perú.

Instituto Nacional de Estadística e Informática (INEI). (2013). Primera Encuesta Nacional Especializada sobre Discapacidad.

Instituto Nacional de Estadística e Informática (INEI). (2014). Población y Vivienda. Magnitud y Crecimiento Poblacional. Recuperado de https://www.inei.gob.pe/ estadisticas/indice-tematico/poblacion-y-vivienda/

Ipsos Marketing. (2014) Perfil del adulto mayor de Lima Metropolitana.

JP Rehab S.R.L. (2011). Equipos de Rehabilitación. Recuperado de http://jprehab.com/ productos/equipos-rehabilitacion-fisioterapia

Lira, J. (24 de agosto de 2014). A todo pulmón, el crecimiento del sector salud y del aseguramiento. Diario Gestión. Recuperado de http://www.gestion.pe

Lira, J. (26 de junio de 2015). Riesgo país de Perú sube cuatro puntos básicos a 1.75 puntos porcentuales. Diario Gestión. Recuperado de http://www.gestion.pe

Luz del Sur. (2014). Precios para la venta de energía eléctrica. Recuperado de https://www.luzdelsur.com.pe/media/pdf/faq/tarifas_tabla.pdf

MD Tech. (2012). Energía Solar. Recuperado de http://www.peruindustrial.com/ mdtech/news1/ lanza1.php

Ministerio de Desarrollo e Inclusión Social. (2012). Resultados de la Encuesta de Salud y Bienestar del Adulto Mayor. Dirección General de Seguimiento y Evaluación.

Ministerio de Energía y Minas. (2010). Dirección General de Eficiencia Energética. La normatividad y etiquetado para la promoción del uso eficiente de la energía.

Ministerio de Salud (MINSA) (2009). Norma Técnica de Salud de la unidad productora de servicios de medicina de rehabilitación NTS-079 - MINSA.V.01. Recuperado de http://www.minsa.gob.pe/portada/transparencia/normas.asp.

Ministerio de Salud (MINSA) (2012). Análisis de la demanda y el acceso a los servicios de salud en el Perú. Dirección General de epidemiología. Recuperado de http://www.dge.gob.pe/publicaciones/pub_asis/asis31.pdf

Ministerio de Salud (MINSA) (2015). Guía técnica para el mantenimiento del pozo de puesta a tierra en los establecimientos de salud. Recuperado de http://www.minsa.gob.pe/portada/transparencia/normas.asp.

Ministerio del Ambiente. (2012). Catálogo de Proveedores de Productos y Servicios Ecoeficientes. Recuperado de http://www.minam.gob.pe/calidadambiental/wpcontent/uploads/sites/22/2014/02/Cat\%C3\%A1logo-de-proveedores-y-servicosecoefientes-2012.pdf 
Muebles Z-art. (2015). Venta de Muebles. Recuperado de http://www.zartmuebles.com

Mundaca Chávez, D. Tecnólogo Medico CTMP 8808. [Fecha de la entrevista: 28 de febrero de 2015]

New York University. (NYU). (2015). Betas by sector. Escuela de Negocios. Recuperado de http://pages.stern.nyu.edu/ adamodar/New Home_Page/ datafile/Betas.html

Onedirect. (2015). Venta de Equipos Telefónicos. Recuperado de http://www.onedirect.es

Pérez, L. y Egaña, L. (2015). El origen del Río Surco. Recuperado de http://www.riosurco.galeon.com/aficiones1226878.html

Porter, M. (2010). Ventaja competitiva: creación y sostenibilidad de un rendimiento superior. Madrid. Ediciones Pirámide.

Powerquality. (2015). Venta de Equipos de Energía de Respaldo (UPS Eaton). Recuperado de http://powerquality.eaton.com/LAS/Default.asp?CX=17

Pricewaterhouse Coopers. (PWC). (2015). Encuesta de Remuneraciones.

Proinversión. (13 de mayo de 2015). Como establecer una empresa en el Perú. Recuperado de http://www.proinversion.gob.pe/

Quirumed. (2014). Material Médico, productos para la salud. Recuperado de http://www.quirumed.com/es/fisioterapia-y-masaje

Salas Paulet, M. Ingeniero Civil CIP 76982. [Fecha de la entrevista: 22 de Julio de 2015]

Santa María Fisioterapia. (2015). Recuperado de http://fisioterapiasantamaria.com/pterapia-fisica-y-rehabilitación/

Servicio de Agua Potable y Alcantarillado de Lima (SEDAPAL). (2014). Estructura Tarifaria al 5.3.14. Recuperado de http://www.sedapal.com.pe/c/document library/get_file?uuid=e52230b3-8b48-4f56-8af4-10e7fcb849e8\&groupld=29544

Scotiabank (2015). Estudios Económicos. Recuperado de http://es.slideshare.net/ jpsalced/modelo-capm

Silva Bazán, R. Tecnólogo Medico CTMP 8586. [Fecha de la entrevista: 7 de abril de 2014]

Soliclima energía solar (2015). Recuperado de http://www.soliclima.es/fotovoltaicaaislada

Superintendencia Nacional de Aseguramiento en Salud (SUNASA) (2011). Resumen de encuesta de satisfacción de los usuarios del AUS. Lima. 
Superintendencia Nacional de Salud. (SUNASA). (2011). Resumen de Encuesta de Satisfacción de los Usuarios del Aseguramiento Universal en Salud. Recuperado de http://www.sunasa.gob.pe/publicaciones/estudios/estudiodetalle.asptipo=146

TECSUP. (2007). Procedimiento para la identificación de peligros y evaluación de riesgos (IPER) PR-GA-001. Gerencia administrativa. Recuperado de http://app.tecsup.edu.pe/file/intranet/publicacion/iper_procedimiento.pdf

Toledo Piscinas. (2015). Tratamiento del agua. Recuperado de http://toledopiscinas.es/ Construccion-piscinas/tratamiento-agua

URBECORP. (2015). Precio de Terrenos en Lima Metropolitana. Recuperado de http://gestion.pe/inmobiliaria/miraflores-y-surco-empiezan-perder-atractivoinmobiliario-2119589

U.S. Green Building Council. (2009). LEED para nueva construcción y grandes remodelaciones. Versión 3.0

Viardi Glass. (2015). Soluciones integrales en sistemas de acristalamiento y aislamiento acústico. Recuperado de http://viardi.pe/Principal/Productos

Westreicher G. (19 de enero de 2015). Banca y salud son los sectores más atractivos para la inversión de las grandes empresas. Diario Gestión. Recuperado de http://www.gestion.pe 


\section{BIBLIOGRAFÍA}

Alcaide, J., y Soriano, C. (2006). Marketing de Servicios Profesionales. España, Ediciones Pirámide.

Asociación Peruana de Empresas de Investigación de Mercados (APEIM) (2014). Niveles Socioeconómicos. Lima.

Calderón Cano, C., Ota Elliott, E. (2012). Estudio preliminar para instalación de un centro de rehabilitación física y entretenimiento para el adulto mayor. Universidad de Lima.

Costa López, L. (2008). Estudio de prefactibilidad para la puesta en marcha de un centro de gimnasia y terapia geriátrica. Universidad de Lima.

Delgado Menéndez, M. (2012). Estudio de prefactibilidad para la gestión de un proyecto inmobiliario que implica la construcción de un edificio ecológico en Lima. (Tesis para optar el título de Ingeniero Industrial). Pontificia Universidad Católica del Perú.

Hoffman, D., y Bateson, J. (2011). Marketing de servicios. Conceptos, estrategias y casos. 4 ta ed. México, Cengage Learning.

Kotler, P., y Armstrong, G. (2013). Fundamentos de marketing. 11era ed. México, Pearson educación.

Larrea Cardozo, A., Quevedo Chávez, M. (2012). Estudio preliminar para la implementación de un centro geriátrico de cuidado de pacientes con demencia senil. Universidad de Lima.

Martínez de Pinillos Figueroa, V., Patiño La Noire, K. (2011). Estudio preliminar para la instalación de un ecolodge mediante la utilización de servicios ecoeficientes. Universidad de Lima.

Ministerio de Vivienda. (2006). Reglamento Nacional de Edificaciones.

Ministerio del Ambiente. (2009). Guía de ecoeficiencia para empresas.

Ramos Quispe, R., Sáenz Molina, D. (2010). Estudio preliminar para la implementación de un centro de residencia y atención para adultos mayores de 70 años. Universidad de Lima. 


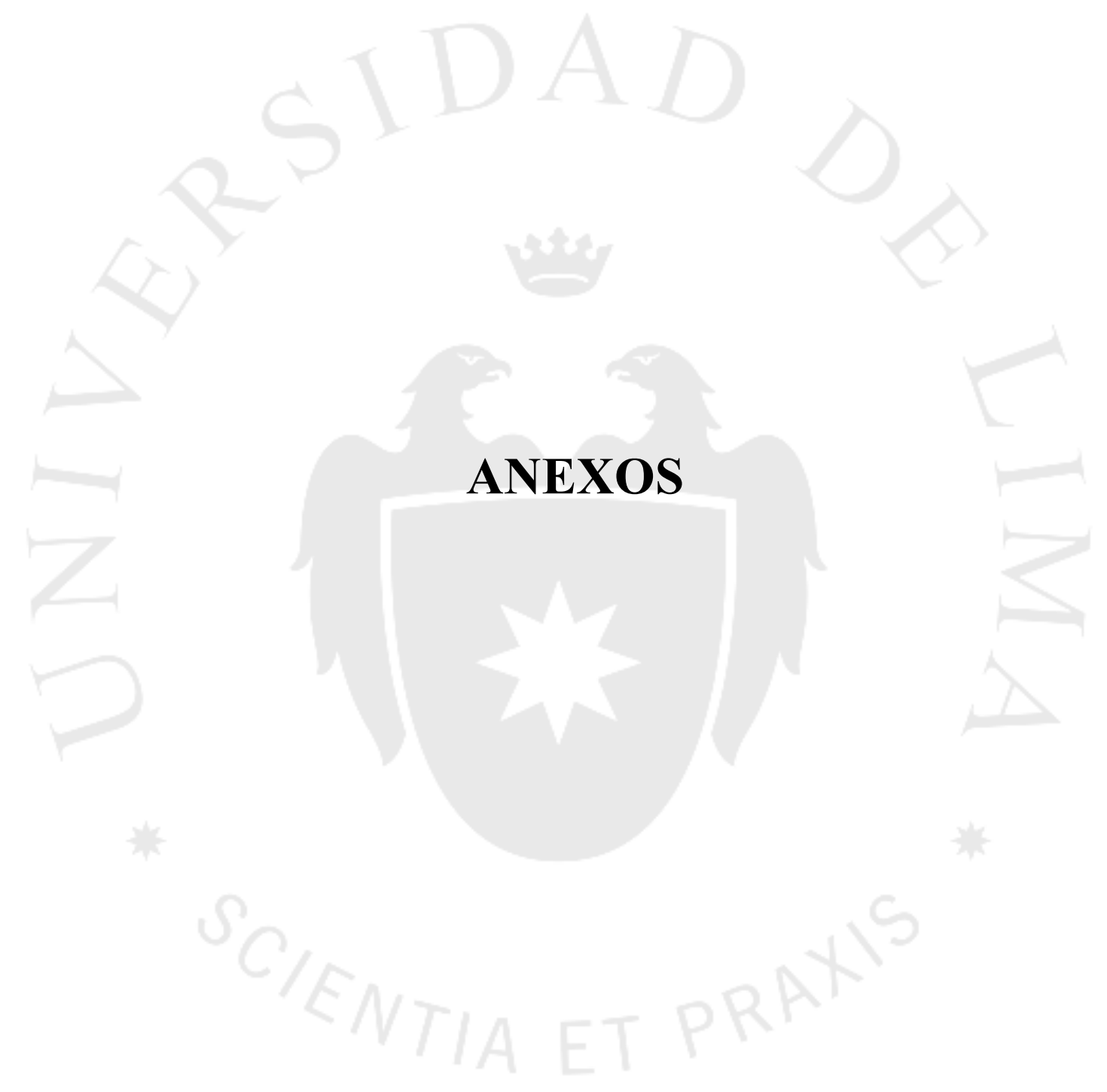




\section{ANEXO 1: ENCUESTA}

\section{REHABILITACIÓN FÍSICA ECOEFICENTE PARA EL ADULTO MAYOR}

1. ¿Tiene usted más de 60 años o algún familiar adulto mayor (personas mayores de 60 años)?
1. SI ( )
2. NO ( )

Si su respuesta fue NO, finalizar encuesta, caso contrario pasar a la siguiente pregunta.

2. ¿Tiene usted o su familiar adulto mayor algún problema muscular que requiera rehabilitación física?

$\begin{array}{lll}\text { 1. } & \text { SI } & (\text { ) } \\ \text { 2. } & \text { NO } & (\text { ( ) }\end{array}$

3. ¿Usted o su familiar adulto mayor se encuentra actualmente o ha tomado en algún momento algún servicio de rehabilitación física?

1. SI ( )

2. NO ( )

Si su respuesta fue NO, finalizar encuesta, caso contrario pasar a la siguiente pregunta.

4. ¿Dónde toma o ha tomado usted o su familiar adulto mayor los servicios de rehabilitación física?
1. Hospital ( )
3. Posta médica
( )
5. Fisioterapeuta independiente ( )
2. Clínica ( )
4. Centro especializado ( )

5. ¿Con qué frecuencia usted o su familiar adulto mayor toma o ha tomado los servicios de rehabilitación física?
1. Semanal
( ) 3. 3 veces a la semana
( ) 1 vez al mes (
( ) 6. Trimestral (
7. Semestral (
2. 2 veces a la semana
() 4uincenal

( ). Trimestral ( ) 8. Anual

6. ¿Cuánto paga por una sesión de rehabilitación física?
1. Menos de S/. 30
( ) 3. Entre S/. 50 y S/. 60 ( )
5. Más de S/. 70
2. Entre S/. 40 y S/. 50
( )
4. Entre S/. 60 y S/. $70($ )

7. ¿Utiliza usted algún tipo de seguro para solicitar los servicios de rehabilitación física?
1. EPS
3. ESSALUD
( )
5. No utiliza segur
2. SIS
( )
4. Seguro particular
( )

8. ¿Cómo califica usted los centros de rehabilitación física donde ha recibido el servicio?
1. Muy Bueno
3. Regular ( )
5. Muy malo
( )
2. Bueno
$($ )
4. Malo

9. Cuando toma usted un servicio de rehabilitación física, ¿qué tan importante es cada uno de los siguientes atributos? (ordenar del 1 al 6, siendo 1 el más importante y 6 el menos importante)
1. Prestigio del fisioterapeuta ( )
3. Ubicación
( ) 5. Tecnología ( )
2. Disponibilidad de atención ( )
4. Comodidad de instalaciones
)
6. Precio (

10. ¿Estaría dispuesto a atenderse o llevar a sus familiares a un centro de rehabilitación física especializado en la atención al adulto mayor con políticas y planes de manejo medio ambiental?

1. SI ( )

2. NO ( )

11. En la escala del 1-10, por favor señale el grado de intensidad de su probable toma del servicio, siendo 1 muy poco probable y 10 de todas maneras (marcar con un círculo).

$$
1
$$

3

4

5

6

7

8

9




\title{
ANEXO 2: ENTREVISTAS A EXPERTOS
}

\author{
Preguntas
}

1. ¿Cuál es la labor de un fisioterapeuta?

2. ¿Cuáles son las lesiones físicas más recurrentes de las personas que requieren rehabilitación física?

3. ¿Cuándo una persona requiere de algún tratamiento de fisioterapia se le deriva al médico especialista del mismo centro de salud en que fue atendido o el paciente escoge el lugar donde atenderse?

4. ¿Los adultos mayores están más propensos a sufrir lesiones de tipo musculares? ¿Por qué?

5. ¿Cuáles son las enfermedades a nivel físico más comunes en los adultos mayores?

6. ¿Los tiempos de recuperación del adulto mayor son más lentos que los de una persona adulta?

7. ¿Cuáles son las diferencias (si existiesen) entre los tratamientos para personas adultas y adultos mayores?

8. ¿Cuándo una persona adulto mayor requiere de algún tratamiento de rehabilitación física acude solo o acompañado?

9. En su experiencia ¿Cuál es la relación que tienen los adultos mayores con sus hijos y con los fisioterapeutas?

10. ¿Cuáles son los procedimientos administrativos y médicos por los que pasan los pacientes?

11. ¿Que contienen las historias clínicas de los pacientes?

12. Con respecto a los precios, de toda la gama de hospitales, clínicas y centros, ¿cuáles son las diferencias de precios?

13. ¿Cuál es su opinión acerca de la instalación de un centro de rehabilitación física basado en la ecoeficiencia de sus instalaciones que permite un ahorro de recursos y cuidado del medio ambiente?

\section{Entrevista a experto 1}

Nombre: Rubén Silva Bazán. Licenciado en Tecnología Médica. CTMP 8586

1. ¿Cuál es la labor de un fisioterapeuta?

La labor de un fisioterapeuta es lograr que nuestros pacientes puedan reintegrarse a su vida diaria mediante los procedimientos que le proporcionamos, lo que se quiere es que las personas que atendemos regresen a realizar las cosas que dejaron de hacer por estar lesionados, como caminar, correr.

2. ¿Cuáles son las lesiones físicas más recurrentes de las personas que requieren rehabilitación física?

Las más recurrentes son la Lumbalgia: dolor en la zona lumbar, Cervicalgia: dolor de cuello y las fracturas en los miembros tanto superiores como inferiores.

3. ¿Cuándo una persona requiere de algún tratamiento de fisioterapia se le deriva al médico especialista del mismo centro de salud en que fue atendido o el paciente escoge el lugar donde atenderse?

Puede elegir cualquier centro, puede ser en el mismo centro de salud como en cualquier otro lugar.

4. ¿Los adultos mayores están más propensos a sufrir lesiones de tipo musculares? ¿Por qué? Por supuesto porque tienen la densidad ósea más delgada y porque sus músculos ya están desgastados conforme van pasando los años, pierden calcio y miofibrillas.

5. ¿Cuáles son las enfermedades a nivel físico más comunes en los adultos mayores? La Osteoporosis y algún tipo de lesión de movimiento, mayormente en las articulaciones.

6. ¿Cuáles son los métodos utilizados para rehabilitar a los pacientes?

Dentro de los agentes físicos tenemos el ultrasonido, laserterapia, magnetoterapia, masoterapia, kinesioterapia, electroterapia, compresas húmedas calientes y frías. La laserterapia se emplea para regenerar el tejido, la magnetoterapia mejora la calidad ósea y la recuperación del tejido óseo en una fractura, las compresas preparan el tejido celular 
superficial, la kinesioterapia consiste en ejercicios para movilizar músculos y ganar rango articular, la masoterapia son masajes terapéuticos que ayudan a liberar el tejido muscular, el ultrasonido consiste en generar sonido en intensidad tan alta que va a generar un masaje interno dentro del musculo y la electroterapia es aplicar corriente controlada como analgésico para aliviar el dolor.

7. ¿Los tiempos de recuperación del adulto mayor son más lentos que los de una persona adulta?

En realidad depende del paciente, pero en general hay una pequeña diferencia, por ahí que los adultos mayores necesitan más sesiones para recuperarse pero también depende mucho de la lesión que tengan.

8. ¿Cuáles son las diferencias (si existiesen) entre los tratamientos para personas adultas y adultos mayores?

No, en realidad en cuanto a los equipos ninguna, en cuanto a la programación de los equipos podría ser, más que por la edad; por lo patológico, no es lo mismo tratar a un adulto con una degeneración de las caídas articulares de la rodilla, que a un adulto mayor; se le aplica lo mismo pero la diferencia radicaría en la cantidad de sesiones que tendría que pasar el paciente para recuperarse, el adulto mayor requiere más sesiones por su misma condición de adulto mayor.

9. ¿Cuándo una persona adulto mayor requiere de algún tratamiento de rehabilitación física acude solo o acompañado?

Usualmente va acompañado, es lo mejor, porque de repente se puede descompensar o puede tener algún tipo de hipertensión, de repente sale con algún tipo de dolor, entonces es mejor que un adulto o algún familiar lo acompañe. Es una forma de protegernos también a nosotros mismos, si le pasa algo puede venir un familiar y decir, usted le hizo esto o lo otro cuando no es exactamente lo correcto.

10. En su experiencia ¿Cuál es la relación que tienen los adultos mayores con sus hijos y con los fisioterapeutas?

Básicamente la de informar al familiar cuales son los pasos de recuperación y como va mejorando el adulto mayor.

11. ¿Cuáles son los procedimientos administrativos y médicos por los que pasan los pacientes?

Cuando un paciente se acerca al centro tiene dos opciones, una es pasar con el medico fisiatra o pasar una evaluación terapéutica con el tecnólogo médico, los dos tienen sustento legal para atenderlo, después de eso pasan a hacer la terapia, primero van a caja con su tarjeta de orden de terapia a cancelar y luego regresan al servicio. Las sesiones dependen de la patología, usualmente son seis si es algo leve pueden ser ocho o diez hasta treinta sesiones en los casos más graves. Cuando terminan las sesiones el alta se maneja de una manera sintomática, las radiografías y ecografías son medios auxiliares para poder reconfirmar una lesión.

12. ¿Que contienen las historias clínicas de los pacientes?

Poseen en primer lugar los datos de filiación del paciente, nombre, sexo, edad, grado de instrucción, luego se colocan signos vitales, un relato del por qué asistió a terapia, exámenes auxiliares si lo requiere, el tratamiento, los medicamentos, entre otros.

13. Con respecto a los precios, de toda la gama de hospitales, clínicas y centros, ¿cuáles son las diferencias de precios?

Varían desde 20 soles en postas, hasta 150 soles en institutos especializados pero en promedio el precio varía entre 50 y 60 soles.

14. ¿Cuál es su opinión acerca de la instalación de un centro de rehabilitación física basado en la ecoeficiencia de sus instalaciones que permite un ahorro de recursos y cuidado del medio ambiente?

Obviamente sería un plus para la empresa en cuanto a su economía, aparte definitivamente hay algunos pacientes, sobre todo los adultos mayores son más altruistas y piensan en el medio ambiente. Por ahí podría haber un plus en beneficio a la captación de pacientes pero a la larga todo es para la mejora de la empresa. 


\section{Entrevista a experto 2}

Nombre: Diana Mundaca Chávez. Licenciada en Tecnología Médica. CTMP 8808

1. ¿Cuál es la labor de un fisioterapeuta?

La labor del fisioterapeuta en líneas generales es tratar que el paciente logre una mejor calidad de vida, pueda realizar sus actividades de la vida diaria de la mejor forma posible. Cuando el paciente llega al servicio de rehabilitación física no solo llega con una dolencia física, sino también va asociado con un trastorno sicológico, él no solamente va a buscar a alguien que le alivie el dolor sino también alguien con quien pueda contar y conversar y que lo ayude en base a consejos de cómo debe actuar en casa, ya sea en parte física como en salud mental. Nosotros no solo hacemos un trabajo en el consultorio donde se le aplica todos los agentes físicos y la terapia manual sino también se le da ciertas tareas que el paciente tiene que realizar en casa, no lo hacen todos pero la idea es concientizar al paciente que si él mejora su estilo de vida, su calidad de vida a futuro va a ser mucho mejor; es reeducar y concientizar a nuestro paciente y en algunos casos a la familia.

2. ¿Cuáles son las lesiones físicas más recurrentes de las personas que requieren rehabilitación física?

En caso de las personas adultas en general son todos los problemas músculo-esqueléticos y los traumatológicos como las lumbalgias y cervicalgias, problemas por factor de stress y lesiones traumatológicas como esguinces de tobillos o las torceduras de alguna articulación y las caídas. En un primer momento estos pacientes van a pasar por un médico traumatólogo que va a enyesar u operar y definitivamente la persona va a requerir una terapia física. En el caso de los problemas neurológicos que hoy en día se dan, tenemos los accidentes cerebro vasculares (ACV); es común estos accidentes por el factor de stress, por problemas de la presión arterial, pacientes que lamentablemente se descuidan, no toman la medicación, o simplemente nunca fueron al médico, y las secuelas son muy discapacitantes. En el caso de los niños se pueden dividir en dos grandes grupos; los niños que nacen con trastornos congénitos y los niños que tienen problemas musculo esqueléticos; pero en la mayoría de los casos tienen corrección.

3. ¿Cuándo una persona requiere de algún tratamiento de fisioterapia se le deriva al médico especialista del mismo centro de salud en que fue atendido o el paciente escoge el lugar donde atenderse?

En nuestro caso el paciente llega al hospital y es derivado al fisioterapeuta del mismo hospital, pero si llega por recomendación necesariamente tiene que pasar con el médico fisiatra y luego por la rehabilitación. Tiene que haber primero una evaluación para llenar una historia clínica y después realizar la rehabilitación todo en el mismo centro.

4. ¿Los adultos mayores están más propensos a sufrir lesiones de tipo musculares? ¿Por qué?

En realidad no es tanto el problema muscular, es más el problema tipo articular, lo cual lo va a llevar a un problema muscular porque los adultos mayores comienzan con las degeneraciones óseas, las articulaciones se van desgastando y deformando, se van debilitando lo cual te lleva al que el paciente tenga problemas de dolor o debilidad muscular. El mismo desgaste óseo conlleva a los pacientes a tener la osteoporosis y por ende es propenso a las fracturas sobretodo de muñeca o de cadera, entonces tiene que ser operado o enyesado y tiene que pasar definitivamente por terapia física. El problema necesariamente inicia por un problema articular.

5. ¿Cuáles son las enfermedades a nivel físico más comunes en los adultos mayores?

A los adultos mayores los vamos a atender siempre de artrosis, que es el desgaste del cartílago articular, generalmente son de grandes articulaciones, en rodillas y caderas sobretodo. También se presentan la artritis reumatoide que son las inflamaciones de las pequeñas articulaciones que tienden a deformarse por ejemplo las articulaciones de la mano. El gran problema de los adultos mayores son las enfermedades reumáticas, como son la artrosis, la artritis y estas no tienen cura, son enfermedades progresivas, empiezan y van complicándose con el tiempo. Lo que nosotros hacemos es aliviar los síntomas como el dolor, rigidez articular, debilidad muscular y evitar que la enfermedad avance a pasos acelerados, el paciente llega a tener un alivio en cuanto a los síntomas mas no una cura porque no existe cura para las enfermedades reumáticas.

6. ¿Cuáles son los métodos utilizados para rehabilitar a los pacientes?

Tenemos primero los agentes físicos como son las compresas calientes, las compresas frías, ultrasonido, corrientes estimulantes, laser y magneto; aparte de las técnicas manuales que 
aplicamos según ciertos métodos. Con respecto al ultrasonido, consiste en ondas que ingresas al cuerpo para soltar las adherencias que se forman entre tejido y tejido, lo que hace es "despegar" el tejido de otro. El láser es un equipo que su función es regenerar el tejido y en otros casos desinflamar, se trabaja en articulaciones como también es utilizado para cicatrizar heridas después de una cirugía. El magneto es un equipo que se utiliza para consolidación ósea, acelera la mejoría de alguna fractura, ante una fractura hace que el hueso se recupere. Las corrientes son analgésicas, alivian el dolor o estimulan el tejido en el caso que se requiera estimular alguna musculatura para fortalecerla. En cuanto a las nuevas tecnologías tenemos las ondas de choque que lo que hacen es acelerar el proceso de cura del paciente, se curan en menor tiempo por ende son menos sesiones.

7. ¿Los tiempos de recuperación del adulto mayor son más lentos que los de una persona adulta?

No, es relativo en los pacientes y depende mucho de su estilo de vida. En el adulto mayor tenemos la certeza que él va a llegar a su casa a descansar, si le indicamos un descanso; en cambio en una persona adulta no. El adulto mayor si tiene una enfermedad reumática va a presentar los dolores cada cierto tiempo, sobretodo en el invierno, en cambio en un adulto, pues si no tiene una enfermedad reumática se puede controlar con medicamentos y mejorar su estilo de vida. Pero en realidad el tiempo de cura es relativo de acuerdo a cada paciente, según su organismo y según su estilo de vida.

8. ¿Cuáles son las diferencias (si existiesen) entre los tratamientos para personas adultas y adultos mayores?

Depende mucho de los antecedentes en cuanto a enfermedades que tenga el paciente, para saber con qué equipos vamos a trabajar y cuánto lo podemos manipular. Si un paciente presenta un cáncer no se le puede poner el ultrasonido o el equipo magnético que son equipos que podrían ser perjudicial para su salud. La diferencia radica mucho más en los antecedentes del paciente que en la edad.

9. ¿Cuándo una persona adulto mayor requiere de algún tratamiento de rehabilitación física acude solo o acompañado?

Por lo general acuden acompañados pero encontramos pacientes que son muy funcionales, muy independientes que van solos, es de acuerdo a la edad. Entre los 60 y los 80 años pude ser que vayan solos pero cuando ya pasan los 80 siempre van a ir acompañados pero a recomendación de nosotros pedimos que vengan acompañados, porque es un poco complicado para que se suba o baje de la camilla; por eso pedimos la ayuda del familiar para que lo ayude a vestirse, bajar de la camilla una vez terminada la terapia y así nosotros ya nos evitamos problemas de caídas.

10. En su experiencia ¿Cuál es la relación que tienen los adultos mayores con sus hijos y con los fisioterapeutas?

En realidad el adulto mayor cuando llega a la consulta con el familiar muchos de ellos no hablan, el familiar es el que hable del problema que tiene sus papás. Nosotros tenemos que dejar que sea el paciente el que hable. Tenemos que saber cómo llegar al paciente para fomentar una mayor comunicación para poder ayudarlo, tal es así que la indicaciones se le debe dar al familiar y al adulto mayor, tenemos que trabajar entre los tres, de nada sirve que una haga el mejor tratamiento en consultorio si sé que en casa van a realizar responsabilidades que requieran actividades físicas como el cuidado de sus nietos. Nosotros tenemos que hacer un trabajo entre el adulto mayor y los hijos y siempre buscar que sean acompañados por familiares.

11. ¿Cuáles son los procedimientos administrativos y médicos por los que pasan los pacientes? El paciente llega por primera vez y se le pregunta cuál es su lesión o por qué acude al establecimiento de salud, en base a eso se le deriva a las diversas especialidades como traumatología, reumatología o neurología, luego de la evaluación se le deriva al área de medicina física o a un tecnólogo médico quien también lo evalúa para diagnosticar el tratamiento. Luego de los pagos de los tratamientos, estos se inician y en promedio se programan las sesiones que son entre 7 a 10 sesiones porque es el tiempo promedio en que un paciente se va a recuperar. Luego de concluir con las sesiones se pasa a una evaluación nuevamente con el tecnólogo médico o con el fisiatra, aquí se evalúa si el paciente sigue teniendo dolor; si el paciente tuvo limitación en un inicio lo que se quiere es evaluar si el paciente ha recuperado el movimiento o ya puede realizar actividades de la vida diaria. Si nosotros vemos que el paciente ya ha mejorado en más del $90 \%$ es muy probable que el paciente sea dado de alta. Pero si vemos que todavía falta mejorar se le manda un nuevo tratamiento dependiendo de la patología. Cuando hay una lesión neurológica esos pacientes 
si tienen que llevar varias series de sesiones de terapia entre 20 a 30 sesiones. Por lo general se manda ecografías y radiografías a los pacientes para saber si ha mejorado el tejido blando que son los músculos, tendones y ligamentos.

12. ¿Que contienen las historias clínicas de los pacientes?

En primer lugar, lo datos del paciente, nombre, edad, DNI, fecha de nacimiento, en el caso de ser adulto mayor se le pide la personas responsable, el teléfono de casa, la dirección y la ocupación del paciente, esto es dentro de los datos generales del paciente. Luego hay una parte de antecedentes, aquí se colocan las enfermedades que pueda tener el paciente como la presión arterial alta, diabetes, si sufre de alergias tanto farmacológicas como del ambiente, frutas, alimentos, al polvo; operaciones que ha tenido, y sobretodo antecedentes de cáncer $u$ otras. Luego viene la evaluación general donde se coloca todo lo que el paciente refiere, como caídas, males movimientos, si siente dolor, etc. Después viene la evaluación terapéutica donde trabajamos con escalas de intensidad de dolor, niveles de contracturas musculares, si hay limitación funcional que es cuando el paciente no logra levantar el brazo o la pierna, si hay inflación o edema, si hay deformación; todo eso se coloca en el ítem de evaluación terapéutica. El siguiente punto es el diagnóstico y al finalizar se le coloca el tratamiento, es decir todo los agentes que le vamos a poner como son las compresas, ultrasonido, magneto, si se van a realizar masajes y ejercicios. Se recomienda que las 3 primeras sesiones se hagan diarias y luego que sea interdiario hasta completar las 10 sesiones. Para ver una pronta mejoría se deben realizar las sesiones de 2 a 3 veces por semana, si el paciente va 1 sola vez por semana la mejoría la va a ver en un largo plazo. Hablando de periodos de terapia, por ejemplo un paciente con una lesión traumatología como máximo se tiene que realizar 20 sesiones, después de este lapso el paciente tiene que descansar de los quipos entre 7 a 10 días.

13. Con respecto a los precios, de toda la gama de hospitales, clínicas y centros, ¿cuáles son las diferencias de precios?

En cuanto a clínicas y hospitales si hay diferencias; la terapia en una clínica te puede llegar a costar entre 70 y 100 soles, en hospitales te cuesta entre 30 y 40 soles la sesión y en los hospitales municipales los precios radican entre 25 y 35 soles, ahora las clínicas especializadas cuestan entre 100 y 150 soles porque pasas por médicos especialistas y en cuanto a tratamiento se enfocan en que el tecnólogo médico tenga una especialidad. Ahora lo que hacen las clínicas es tener alianzas con seguros, por eso que las clínicas están abarrotadas de pacientes, uno se va a una clínica para recibir tratamiento de fisioterapia y te dan cita para después de 2 meses como si te fueras al seguro. Y te lo digo por experiencia propia, la clínica internacional es una de ellas, yo fui para una cita con el medico fisiatra y me dieron 2 meses y luego para la cita con el fisioterapeuta 2 meses más. Se ve últimamente que los pacientes tienen que esperar mucho tiempo por una consulta. Sobre el tema de los seguros es rentable para el paciente porque te va a disminuir el precio pero la clínica se llena de pacientes y tiene que esperar mucho tiempo por una consulta y la mayoría va a los centros municipales o prefiere pagar al terapista para que se acerque a su domicilio. El terapista te cuesta entre 50 y 80 soles pero si voy a apagar eso en un clínica mejor que vaya a mi casa pero no es lo mismo por los equipos pero igual van. Ahora existe una figura llamada el PADOMI que es un programa de ESSALUD de atención domiciliaria, el terapista va a la casa del paciente porque dicho paciente es discapacitado, no puede acercarse a ningún centro por su mismo estado. También hay terapistas a domicilio que cuestan un poco más hablando de clínicas y centros especializados, pero si tienes seguro ESSALUD si es un beneficio, es más económico.

14. ¿Cuál es su opinión acerca de la instalación de un centro de rehabilitación física basado en la ecoeficiencia de sus instalaciones que permite un ahorro de recursos y cuidado del medio ambiente?

Si bien es cierto el paciente no lo va a ver, pero en general nosotros lo que necesitamos es cuidar del medio ambiente, nos ayudamos mutuamente, ustedes están ayudando al paciente y si lo concientizan al cuidado del medio ambiente y ustedes también contribuyen en todo lo que son instalaciones, equipos y residuos. Antes no se tenía mucho cuidado pero ahora todos los hospitales están siendo muy capacitados en ese tema. Se ven los tachos de residuos y muchas más cosas. Pero la gran mayoría llega a tu consultoría por las recomendaciones que haya recibido, por el trato, atención, de la calidad del servicio, hay centros que no saben tratar a sus pacientes, se mecanizan y no hablan con el paciente, creo que van a ver más que todo por esto que por un tema ambiental, las personas asisten al centro por las recomendaciones que reciben de otros pacientes. 


\section{ANEXO 3: CÁLCULO DE LUMINARIAS}

\begin{tabular}{|l|c|c|}
\hline \multicolumn{3}{|c|}{ Cálculo de fuentes por Cubículo } \\
\hline Iluminancia & 750 & lux \\
\hline Área & 9 & $\mathrm{~m}^{2}$ \\
\hline Factor corrección & 0.7 & - \\
\hline Nro lámparas por fuente & 2 & und \\
\hline Lúmenes por lámpara & 95 & lum/watts \\
\hline Potencia lumínica & 20 & watts \\
\hline Nro Fuentes & 3 & und \\
\hline Nro Fluorescentes & 6 & und \\
\hline Nro Cubículos & 34 & und \\
\hline Nro Fluorescentes totales & 204 & und \\
\hline
\end{tabular}

\begin{tabular}{|l|c|c|}
\hline \multicolumn{3}{|c|}{ Cálculo de fuentes de Consultorio Médico } \\
\hline lluminancia & 750 & lux \\
\hline Área & 16 & $\mathrm{~m}^{2}$ \\
\hline Factor corrección & 0.7 & - \\
\hline Nro lámparas por fuente & 2 & und \\
\hline Lúmenes por lámpara & 95 & lum/watts \\
\hline Potencia lumínica & 20 & watts \\
\hline Nro Fuentes & 5 & und \\
\hline Nro Fluorescentes & 10 & und \\
\hline
\end{tabular}

\begin{tabular}{|l|c|c|}
\hline \multicolumn{3}{|c|}{ Cálculo de fuentes de otras áreas 1er Piso } \\
\hline Iluminancia & 500 & lux \\
\hline Área & 291 & $\mathrm{~m}^{2}$ \\
\hline Factor corrección & 0.7 & - \\
\hline Nro lámparas por fuente & 2 & und \\
\hline Lúmenes por lámpara & 95 & lum/watts \\
\hline Potencia lumínica & 20 & watts \\
\hline Nro Fuentes & 55 & und \\
\hline Nro Fluorescentes & 110 & und \\
\hline
\end{tabular}

\begin{tabular}{|l|c|c|}
\hline \multicolumn{3}{|c|}{ Cálculo de Fuentes en oficinas de $\mathbf{2 0} \mathbf{~ m}^{\mathbf{2}}$} \\
\hline Iluminancia & 500 & lux \\
\hline Área & 20 & $\mathrm{~m}^{2}$ \\
\hline Factor corrección & 0.7 & - \\
\hline Nro lámparas por fuente & 2 & und \\
\hline Lúmenes por lámpara & 95 & lum/watts \\
\hline Potencia lumínica & 20 & watts \\
\hline Nro Fuentes & 4 & und \\
\hline Nro Fluorescentes & 8 & und \\
\hline Nro Oficinas & 3 & und \\
\hline Nro Fluorescentes totales & 24 & und \\
\hline
\end{tabular}

\begin{tabular}{|l|c|c|}
\hline \multicolumn{3}{|c|}{ Cálculo de Fuentes en oficinas de $\mathbf{1 2} \mathbf{~ m}^{\mathbf{2}}$} \\
\hline lluminancia & 500 & lux \\
\hline Área & 12 & $\mathrm{~m}^{2}$ \\
\hline Factor corrección & 0.7 & - \\
\hline Nro lámparas por fuente & 2 & und \\
\hline Lúmenes por lámpara & 95 & lum/watts \\
\hline Potencia lumínica & 20 & watts \\
\hline Nro Fuentes & 3 & und \\
\hline Nro Fluorescentes & 6 & und \\
\hline Nro Oficinas & 6 & und \\
\hline Nro Fluorescentes totales & 36 & und \\
\hline
\end{tabular}

\begin{tabular}{|l|c|c|}
\hline \multicolumn{3}{|c|}{ Cálculo de fuentes del Sótano } \\
\hline Iluminancia & 75 & lux \\
\hline Área & 456 & $\mathrm{~m}^{2}$ \\
\hline Factor corrección & 0.7 & - \\
\hline Nro lámparas por fuente & 2 & und \\
\hline Lúmenes por lámpara & 95 & lum/watts \\
\hline Potencia lumínica & 20 & watts \\
\hline Nro Fuentes & 13 & und \\
\hline Nro Fluorescentes & 26 & und \\
\hline
\end{tabular}

\begin{tabular}{|l|c|c|}
\hline \multicolumn{3}{|c|}{ Cálculo de Fuentes en pasadizos y corredores 1er piso } \\
\hline Iluminancia & 200 & lux \\
\hline Área & 271 & $\mathrm{~m}^{2}$ \\
\hline Factor corrección & 0.7 & - \\
\hline Nro lámparas por fuente & 2 & und \\
\hline Lúmenes por lámpara & 95 & lum/watts \\
\hline Potencia lumínica & 20 & watts \\
\hline Nro Fuentes & 21 & und \\
\hline Nro Fluorescentes & 42 & und \\
\hline
\end{tabular}

Cálculo de fuentes de Oficina Coordinador Tecnólogo

\begin{tabular}{|l|c|c|}
\hline Iluminancia & 750 & lux \\
\hline Área & 12 & $\mathrm{~m}^{2}$ \\
\hline Factor corrección & 0.7 & - \\
\hline Nro lámparas por fuente & 2 & und \\
\hline Lúmenes por lámpara & 95 & lum/watts \\
\hline Potencia lumínica & 20 & watts \\
\hline Nro Fuentes & 4 & und \\
\hline Nro Fluorescentes & 8 & und \\
\hline
\end{tabular}

\begin{tabular}{|l|c|c|}
\hline \multicolumn{3}{|c|}{ Cálculo de Fuentes en Oficina Gerente General } \\
\hline Iluminancia & 500 & lux \\
\hline Área & 25 & $\mathrm{~m}^{2}$ \\
\hline Factor corrección & 0.7 & - \\
\hline Nro lámparas por fuente & 2 & und \\
\hline Lúmenes por lámpara & 95 & lum/watts \\
\hline Potencia lumínica & 20 & watts \\
\hline Nro Fuentes & 5 & und \\
\hline Nro Fluorescentes & 10 & und \\
\hline
\end{tabular}

\section{Cálculo de Fuentes en pasadizos y corredores 2 do piso}

\begin{tabular}{|l|c|c|}
\hline \multicolumn{3}{|c|}{ Calculo de Fuentes en pasadizos y corredores 2do piso } \\
\hline Iluminancia & 200 & lux \\
\hline Área & 139 & $\mathrm{~m}^{2}$ \\
\hline Factor corrección & 0.7 & - \\
\hline Nro lámparas por fuente & 2 & und \\
\hline Lúmenes por lámpara & 95 & lum/watts \\
\hline Potencia lumínica & 20 & watts \\
\hline Nro Fuentes & 11 & und \\
\hline Nro Fluorescentes & 22 & und \\
\hline
\end{tabular}

\begin{tabular}{|l|c|c|}
\hline \multicolumn{3}{|c|}{ Cálculo de fuentes de otras áreas 2do Piso } \\
\hline Iluminancia & 500 & lux \\
\hline Área & 58 & $\mathrm{~m}^{2}$ \\
\hline Factor corrección & 0.7 & - \\
\hline Nro lámparas por fuente & 2 & und \\
\hline Lúmenes por lámpara & 95 & lum/watts \\
\hline Potencia lumínica & 20 & watts \\
\hline Nro Fuentes & 11 & und \\
\hline Nro Fluorescentes & 22 & und \\
\hline
\end{tabular}

\begin{tabular}{|l|c|c|}
\hline \multicolumn{3}{|c|}{ Cálculo de Fuentes en Oficinas de $\mathbf{9} \mathbf{~ m}^{\mathbf{2}}$} \\
\hline Iluminancia & 500 & lux \\
\hline Área & 9 & $\mathrm{~m}^{2}$ \\
\hline Factor corrección & 0.7 & - \\
\hline Nro lámparas por fuente & 2 & und \\
\hline Lúmenes por lámpara & 95 & lum/watts \\
\hline Potencia lumínica & 20 & watts \\
\hline Nro Fuentes & 2 & und \\
\hline Nro Fluorescentes & 4 & und \\
\hline Nro Oficinas & 2 & und \\
\hline Nro Fluorescentes totales & 8 & und \\
\hline
\end{tabular}

\begin{tabular}{|l|l|}
\hline Total de fuentes del servicio & 222 \\
\hline Total fuentes de oficinas & 300 \\
\hline
\end{tabular} 


\section{ANEXO 4: CÁLCULO DEL NÚMERO DE EQUIPOS DE AIRE ACONDICIONADO}

\begin{tabular}{|l|r|r|}
\hline \multicolumn{1}{|c|}{ Cálculo del Nro de aire acondicionado para el servicio } & Valores & \multicolumn{1}{c|}{ BTU/h requerido } \\
\hline $\mathrm{m}^{2}$ del área a acondicionar & $800 \mathrm{~m}^{2}$ & 172,500 \\
\hline Nro personas & 53 & 36,000 \\
\hline Watts de los equipos & 4780 watts & 17,070 \\
\cline { 2 - 3 } & 225,570 \\
\hline
\end{tabular}

\begin{tabular}{|c|c|c|}
\hline Nro de $\mathbf{A} / \mathrm{C}$ para el servici & 3.7595 & 4 \\
\hline Cálculo del Nro de aire acondicionado para oficinas & Valores & BTU/h requerido \\
\hline $\mathrm{m}^{2}$ del área a acondicionar & $372 \mathrm{~m}^{2}$ & 82,500 \\
\hline Nro personas & 15 & 9,000 \\
\hline Watts de los equipos & 3980 watts & 13,656 \\
\hline
\end{tabular}

\begin{tabular}{l}
\hline Nro de A/C para oficinas $r \mid$ \\
\begin{tabular}{|l|r|}
\hline \multicolumn{2}{|c|}{ Potencia de A/C } \\
\hline Capacidad de A/C tipo split ducto (BTU) & $\mathbf{1 . 7 5 2 6}$ \\
\hline Factor conversion (Kw/BTU) & 60,000 \\
\hline Kw & 0.00013333 \\
\hline
\end{tabular}
\end{tabular}

\section{ANEXO 5: Tasas de interés COFIDE}

\begin{tabular}{|c|c|c|c|c|c|}
\hline \multirow{2}{*}{$\begin{array}{l}\text { PROGRAMAS I } \\
\text { LÍNEAS }\end{array}$} & \multicolumn{4}{|c|}{ TASAS DE INTERÉS } & \multirow{2}{*}{ COMISIONES } \\
\hline & \multicolumn{2}{|c|}{ Nuevos Soles (efectiva anual) } & \multicolumn{2}{|c|}{ Dólares Americanos (nominal anual) ${ }^{(1)}$} & \\
\hline PROBID & $\begin{array}{l}\text { Hasta } 3 \text { años: } \\
\text { Más de } 3 \text { años hasta } 5 \text { años: } \\
6,500 \% \\
\text { Más de } 5 \text { años hasta } 7 \text { años: } \\
7,000 \% \\
\text { Más de } 7 \text { años hasta } 10 \text { años: } \\
7,125 \%\end{array}$ & $\begin{array}{l}\text { VAC }+6,000 \% \\
\text { VAC }+ \\
V A C+ \\
V A C+\end{array}$ & $\begin{array}{l}\text { Hasta } 3 \text { años: } \\
\text { Más de } 3 \text { años hasta } 5 \text { años: } \\
\text { Más de } 5 \text { años hasta } 7 \text { años: } \\
\text { Más de } 7 \text { años: }\end{array}$ & $\begin{array}{l}\text { Libor }+1,500 \% \\
\text { Libor }+1,750 \% \\
\text { Libor }+2,000 \% \\
\text { Libor }+2,250 \%\end{array}$ & $\begin{array}{l}\text { De Inspección y Vigilancia: } 1,000 \% \text { flat } \\
\text { De Compromiso: } \quad 0,750 \% \\
\text { anual }\end{array}$ \\
\hline
\end{tabular}




\section{ANEXO 6: Tasas de libre riesgo y riesgo de mercado}

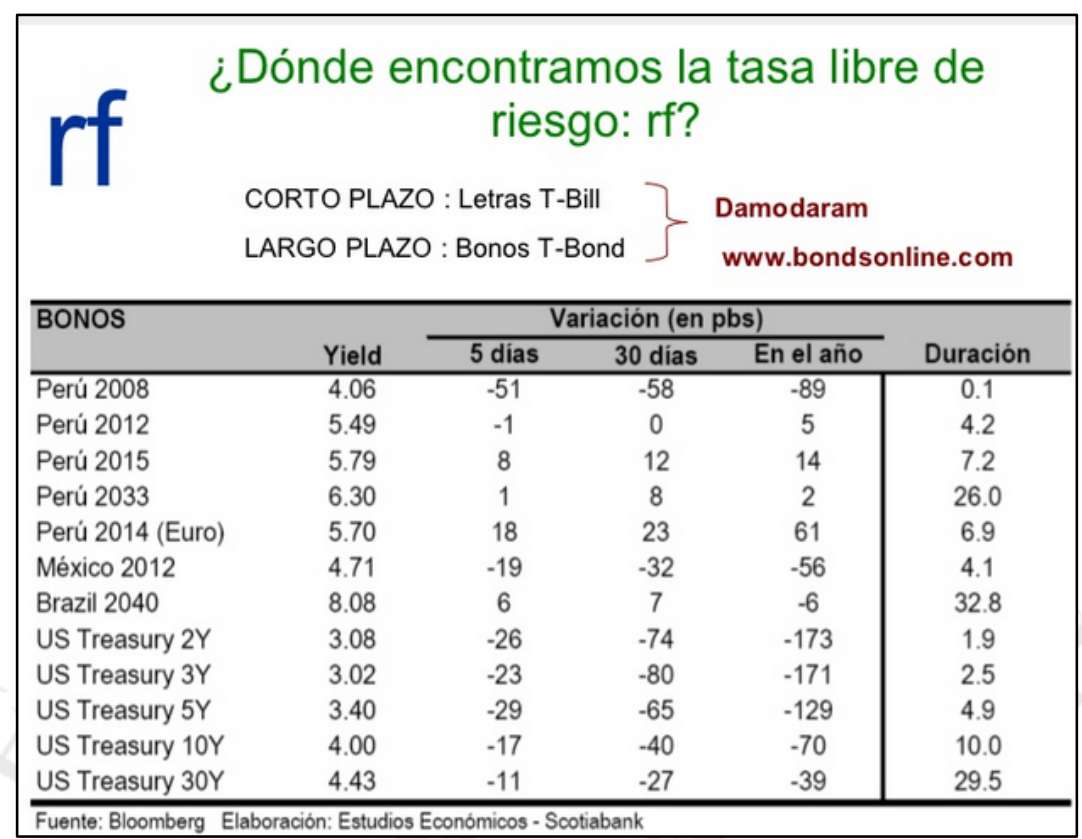

\section{¿Dónde encontramos la tasa de mercado : rm ?}

JWA market return Benchmark Results

\begin{tabular}{|l|c|c|c|c|}
\hline \multicolumn{1}{|c|}{ Benchmark } & $\mathbf{2 0 0 6}$ & $\begin{array}{c}\mathbf{2 0 0 7} \\
\text { YTD } \\
\mathbf{( 1 0 / 3 1 / / 2} \\
\text { 07) }\end{array}$ & $\begin{array}{c}\text { 3 Year } \\
\text { Annlzd. }\end{array}$ & $\begin{array}{c}\text { 5 Year } \\
\text { Annlzd. }\end{array}$ \\
\hline $\begin{array}{l}\text { Market Return } \\
\text { Benchmark }\end{array}$ & $20.90 \%$ & $12.92 \%$ & $19.26 \%$ & $21.81 \%$ \\
\hline S\&P 500 Index & $15.80 \%$ & $10.87 \%$ & $13.16 \%$ & $13.88 \%$ \\
\hline
\end{tabular}

http://www.marketreturnbenchmark.com/ 


\section{ANEXO 7: Ficha de inscripción}

virtual de establecimientos de salud

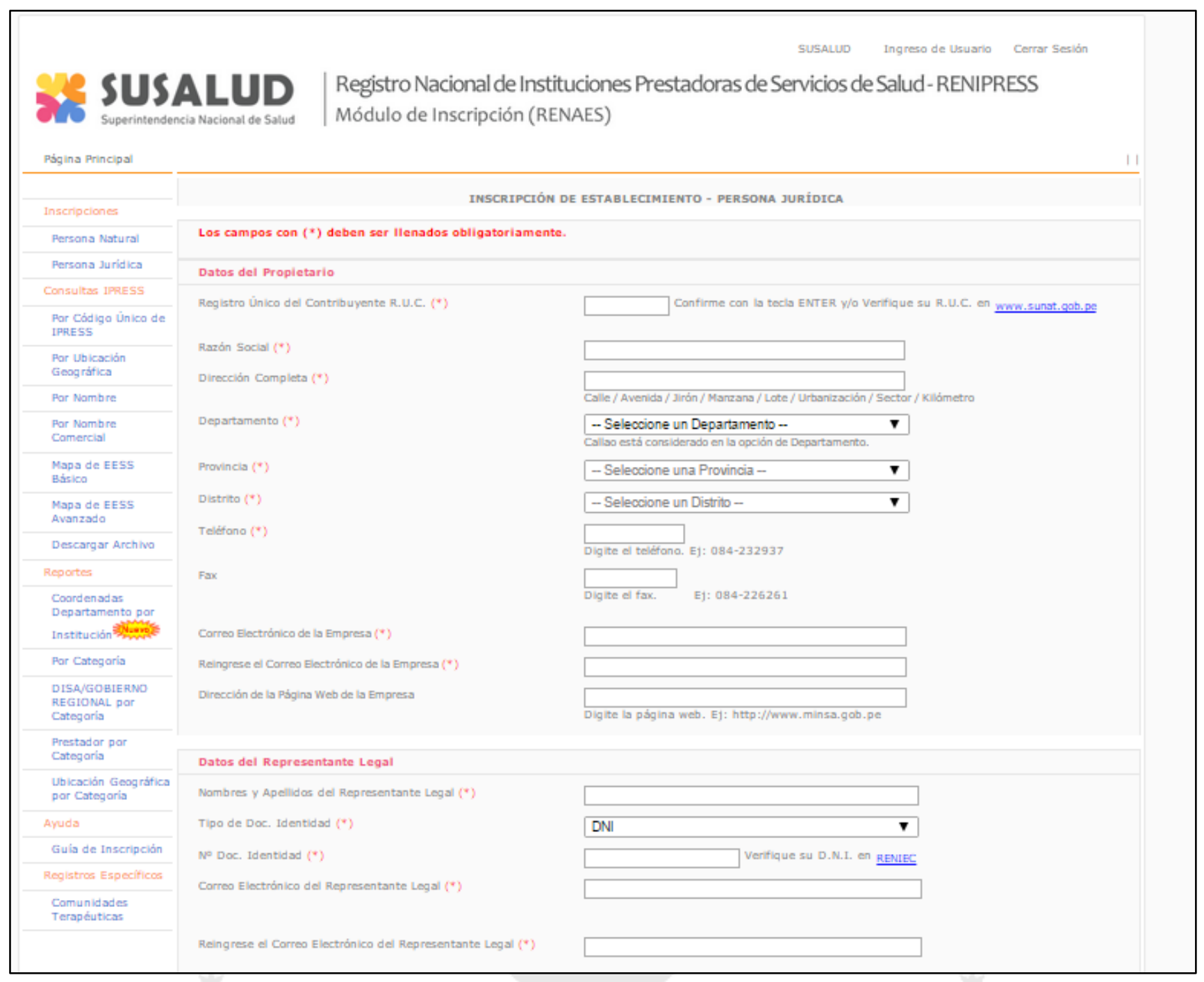

